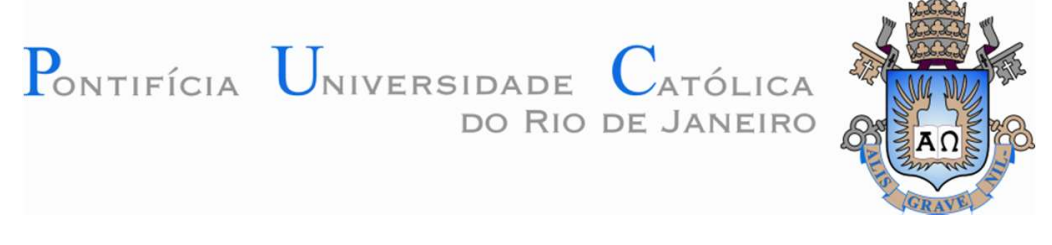

Talles Barsanti Meneguim

\title{
Integração Sísmica-Geomecânica no Pré-Sal Brasileiro, Bacia de Santos
}

\section{Dissertação de Mestrado}

Dissertação apresentada como requisito parcial para obtenção do grau de Mestre pelo Programa de Pós-graduação em Engenharia Civil do Departamento de Engenharia Civil e Ambiental da PUC-Rio.

Orientadora: Profa. Raquel Quadros Velloso 


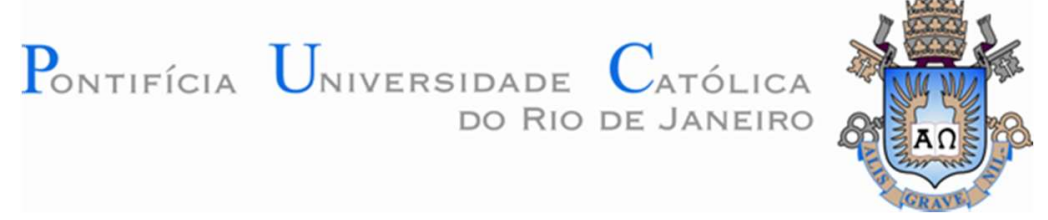

Talles Barsanti Meneguim

\title{
Integração Sísmica-Geomecânica no Pré-Sal Brasileiro, Bacia de Santos
}

Dissertação apresentada como requisito parcial para obtenção do grau de Mestre pelo Programa de Pós-Graduação em Engenharia Civil do Departamento de Engenharia Civil e Ambiental do Centro Técnico Científico da PUC-Rio. Aprovada pela Comissão Examinadora abaixo.

\author{
Profa. Raquel Quadros Velloso \\ Orientadora \\ Departamento de Engenharia Civil - PUC-Rio
}

Prof. Eurípedes do Amaral Vargas Júnior

Departamento de Engenharia Civil - PUC-Rio

Dr. Guilherme Vasquez

Cenpes / IRPS - Petróleo Brasileiro S.A.

Rio de Janeiro, 24 de Maio de 2019. 
Todos os direitos reservados. É proibida a reprodução total ou parcial do trabalho sem autorização da universidade, do autor e do orientador.

\section{Talles Barsanti Meneguim}

Graduou-se no Bacharelado em Física pela Universidade de São Paulo (USP), na cidade de São Paulo, em Dezembro de 2009. Trabalha na Petrobras - Petróleo Brasileiro S.A. - desde 2011. Em 2012 juntou-se ao grupo de geofísica de reservatórios do Polo Pré-Sal da Bacia de Santos (PPSBS), Brasil, e com foco no desenvolvimento da produção dos reservatórios carbonáticos do PPSBS, atua em: modelagem sísmica 3D/4D, inversão sísmica, processamento sísmico, modelagem geológica de velocidades, petrosísmica (integração rocha-perfil-sísmica), interpretação de atributos sísmicos e modelagem geomecânica.

Ficha Catalográfica

Meneguim, Talles Barsanti

Integração sísmica-geomecânica no pré-sal brasileiro, Bacia de Santos / Talles Barsanti Meneguim; orientadora: Raquel Quadros Velloso. - 2019.

200 f. : il. color. ; $30 \mathrm{~cm}$

Dissertação (mestrado) - Pontifícia Universidade Católica do Rio de Janeiro, Departamento de Engenharia Civil e Ambiental, 2019.

Inclui bibliografia

1. Engenharia Civil e Ambiental - Teses. 2. Pólo Pré-Sal da Bacia de Santos (PPSBS), Brasil. 3. Integração sísmica-geomecânica. 4. Conversão estático vs. dinâmico I. Velloso, Raquel Quadros. II. Pontifícia Universidade Católica do Rio de Janeiro. Departamento de Engenharia Civil e Ambiental. III. Título. 
À minha família: Márcia Regina, Sidnei, Bianca, Maria Aparecida, Primo, Mário e Renata.

Pelo encorajamento e apoio. 


\section{Agradecimentos}

Aos orientadores, pesquisadores da PUC-RJ, prof ${ }^{a}$ Raquel Velloso Quadros e prof Eurípedes Vargas pelos ensinamentos, solicitude e frutíferas conversas.

À Petróleo Brasileiro S.A., pelo fomento a pesquisa mediante dispensa parcial de horas, à Agência Nacional do Petróleo pela cessão de dados sísmicos e de poço empregados nesta dissertação e a Puc-Rio pela disponibilidade do bloco de travertino romano para os ensaios mecânicos realizados. Agradecimentos especiais aos gerentes da Petróleo Brasileiro S.A.: Walter Becker Maciel, Roberto Motta Gomes e Tiago da Rosa Homem pela oportunidade e incentivo durante o período do mestrado.

Aos colegas companheiros de mestrado, e com quem muito aprendi: Thiago Freitas Lopes Conceição, Guilherme da Silva Bispo Pereira, Richard Ney Guimarães Dantas, Franco Borges Quadros, Maria Alice Morgado Castanheira Cordeiro Fernandes, Pedro de Almeida Martins das Neves Miranda, Tatiana Alice Soares de Oliveira, Felipe Tajá Costa Pinto, Rodrigo dos Santos Maia Corrêa e Bruno Pinheiro Pires.

A Rita de Cassia e Luana da secretaria do Departamento de Engenharia Civil e Ambiental da PUC-RJ pela ajuda nas questões envolvendo a coordenação e certificação da Pós-Graduação.

Agradeço aos colegas de Petrobras que me apoiaram com discussões enriquecedoras e foram prestativos quando da minha necessária ausência do escritório durante a pesquisa: Erick Slis Raggio Santos, Flavia de Oliveira Lima Falcão, Leonardo Cabral Pereira, Daniel Escobar Steagall, José Fernando Rosalba, João Paulo Pereria Nunes, Antônio Maurício Nabuco Tartarini, Alexandre Maul, Thiago Martins Yamamoto, Luiz Eduardo Silva Queiroz, Leandro do Carmo Thompson, Marlos Lipski, Carlos Eduardo Lourenço Pereira, Mario Paes de Almeida Júnior e Rejhane Santos Cunha. 
Aos colegas do Laboratório de Física de Rochas do Cenpes/Petrobras: Guilherme Vasquez, Júlio Justen e Márcio Mörschbächer pelos valiosos ensinamentos teóricos e experimentais em física de rochas. Agradecimentos especias ao Guilherme Vasquez pela cuidadosa revisão e sugestões que fez a este texto o que muito contribuiu para sua consolidação.

À minha mãe Márcia Regina, ao meu pai Sidnei, à minha irmã Bianca, às minhas avós Maria Aparecida e Renata Carmela (in memoriam) e aos meus avôs Primo e Mário (in memoriam) pelo entusiasmo, paciência e dedicação em minha formação.

A CAPES e à PUC-RJ, pelos auxílios concedidos, sem os quais este trabalho não poderia ter sido realizado.

O presente trabalho foi realizado com apoio da Coordenação de Aperfeiçoamento de Pessoal de Nível Superior - Brasil (CAPES) - Código de Financiamento 001 


\section{Resumo}

Meneguim, Talles Barsanti; Velloso, Raquel Quadros. Integração SísmicaGeomecânica no Pré-Sal Brasileiro, Bacia de Santos. Rio de Janeiro, 2019, 200 p. Dissertação de Mestrado - Departamento de Engenharia Civil e Ambiental, Pontíficia Universidade Católica do Rio de Janeiro.

No Brasil, a partir de Março de 2006 com a constatação de indícios de gás e condensado de óleo na Locação Paraty (poço 1-RJS-617D do bloco BM-S-10) e poucos meses depois, em Agosto, com a descoberta da acumulação de óleo (poço 1-RJS-628A do bloco BM-S-11, pioneiro da área atualmente declarada como LULA) nos reservatórios carbonáticos de idade Aptiana e localizados na camada Sub-Sal da Bacia de Santos, estes reservatórios adquiriram importância estratégica para o desenvolvimento econômico e tecnológico do Brasil. A pesquisa realizada neste projeto visa desenvolver metodologia para estimativa de cenários $3 \mathrm{D}$ de propriedades mecânicas elásticas estáticas de deformabilidade: módulo de elasticidade e coeficiente de Poisson e do fator de acoplamento fluído-mecânico: coeficiente de Biot-Willis, integradas ao dado sísmico e que destinam-se a alimentar simulador mecânico, mitigando incertezas e riscos econômicos e de SMS ao longo da vida produtiva dos diversos campos do PPSBS. O pioneirismo do presente estudo encontra-se em: (I) realização de inversão sísmica determinística CSSI (constrained sparse spike) baseada em modelo inicial de Impedância-P ao longo de toda a sequência estratigráfica da Bacia de Santos: Pós-Sal, Sal e Pré-Sal considerando o efeito do soterramento em dado sísmico 0-offset cedido pela ANP (Agência Nacional do Petróleo), (II) desenvolvimento de Modelo de Física de Rochas (MFR) para toda a sessão estratigráfica da Bacia de Santos, com base em perfis de poços cedidos pela ANP e furos geotécnicos, para estimativa das propriedades mecânicas elásticas dinâmicas a partir da Impedância-P obtida na inversão sísmica e (III) realização de ensaios mecânicos simultâneos em análogo mecânico (bloco de travertino romano) da camada Pré-Sal da Bacia de Santos para determinação de relação de equivalência estático vs. dinâmico, como também emprego de mais duas relações de equivalência estático vs. dinâmico advindas de trabalhos científicos totalizando três cenários de propriedades mecânicas de deformabilidade estáticas e de coeficiente de Biot-Willis. Como resultado foi constatado que os três cenários 3D de propriedades mecânicas elásticas estáticas de 
deformabilidade e coeficiente de Biot-Willis, herdaram o nível de detalhamento da sísmica HD (High Definition) empregada, a saber: resolução vertical de aproximadamente $35 \mathrm{~m}$ e resolução horizontal de aproximadamente $600 \mathrm{~m}$. Ao comparar o mais rígido dos três cenários com o menos rígido deles, observou-se que o módulo de elasticidade estático chega a variar até $35 \%$, o coeficiente de poisson estático chega a variar até $22 \%$ e o coeficiente de acoplamento fluídomecânico de Biot-Willis chega a variar até $8 \%$, sendo que a maior variação está especialmente nos carbonatos do Pré-Sal de idade Aptiana, nos carbonatos do PósSal de idade Albiana e nos arenitos do Pós-Sal do Paleógeno e Cretáceo Superior.

\section{Palavras-chave}

Polo Pré-Sal da Bacia de Santos (PPSBS), Brasil; Modelagem Geomecânica; Integração Sísmica-Geomecânica; Inversão Sísmica; Estimativa de Propriedades Mecânicas; Ensaios Simultâneos; Equivalência Estático vs. Dinâmico 


\begin{abstract}
Meneguim, Talles Barsanti; Velloso, Raquel Quadros (Advisor). Seismic Geomechanical Integration in the Brazilian Pre-Salt, Santos Basin. Rio de Janeiro, 2019, 200 p. Dissertação de Mestrado - Departamento de Engenharia Civil e Ambiental, Pontíficia Universidade Católica do Rio de Janeiro.
\end{abstract}

In Brazil, in March 2006, with evidence of gas and oil condensate in the Paraty location (well 1-RJS-617D of block BM-S-10) and a few months later, in August, with the discovery of oil accumulation (well 1-RJS-628A of the block BMS-11, pioneer of the area currently declared as LULA) in the Aptian-age carbonate reservoirs and located in the Sub-Salt layer of the Santos Basin, these reservoirs have acquired relevance for the economic and technological development of Brazil. The research carried out in this project aims to develop methodology for estimating 3D scenarios of static elastic mechanical properties of deformability: modulus of elasticity and Poisson's coefficient and the fluid-mechanical coupling factor: BiotWillis coefficient, integrated to the seismic data and destined to feed mechanical simulator, mitigating uncertainties and economic and SMS risks throughout the productive life of the various PPSBS deposits. The pioneerism of the present study is: (I) performing deterministic CSSI (constrained sparse spike) seismic inversion based on the initial P-Impedance model throughout stratigraphic sequence of the Santos Basin: Post-Salt, Salt and Pre-Salt taking into account burial depth effect on the seismic trace, (II) development of Rock Physics Models (RFM) for the entire stratigraphic column of the Santos Basin, based on well logs and geotechnical holes, in order to estimate the dynamic elastic mechanical properties from the PImpedance obtained in the seismic inversion and (III) realization of simultaneous 
mechanical tests on mechanical analogue rock (Roman Travertine block) of Santos Basin Pre-Salt layer to determine static vs. dynamic relation, as well as using two static vs. dynamic relations from scientific studies to build three scenarios of static elastic mechanical properties of deformability and Biot-Willis coeficient. As a result, it was verified that the three $3 \mathrm{D}$ scenarios of static elastic mechanical properties of deformability, as well as, Biot-Willis coeficient inherited the level of detail of the HD (High Definition) used seismic, that is: vertical resolution of approximately $35 \mathrm{~m}$ and horizontal resolution of approximately $600 \mathrm{~m}$.

When comparing the most rigid of the three scenarios with the least rigid, it is observed that the static elasticity modulus vary up to 35\%, static poisson's ratio vary up to $22 \%$ and the Biot-Willis coefficient variy up to $15 \%$. The greater variation is especially in the carbonates of the Pre-Salt of Aptian age, in the carbonates of the Post-Salt of Albian age and in the sands of the Pos-Salt of Paleogeno and Upper Cretaceous.

\section{Keywords}

Pre-Salt Pole of Santos Basin (PPSBS), Brazil; Geomechanical Modeling; Seismic-Geomechanical Integration; Seismic Inversion; Mechanical Properties from Seismic; Simultaneous Assays; Relations Static vs. Dynamic. 


\section{Sumário}

1.Introdução 32

1.1 Objetivo 34

$\begin{array}{ll}1.2 \text { Organização do Trabalho } & 35\end{array}$

2. Revisão Bibliográfica 36

2.1 Comportamento Mecânico da Rocha 36

2.2 Geomecânica de Reservatórios 43

2.2.1 Hidrogeologia 50

2.2.2 Engenharia de Petróleo $\quad 51$

2.3 Casos Reais de Efeitos Geomecânicos em Reservatórios 51

2.3.1 Compactação e Subsidência 52

2.3.2 Injeção Acima da Pressão de Fratura 53

2.3.3 Reativação de Falhas $\quad 55$

2.3.4 Injeção de $\mathrm{CO}_{2} \quad 58$

2.3.5 Campo de Ekofisk 62

2.3.6 Campo de Wilmington $\quad 65$

2.3.7 Campo de South Belridge $\quad 66$

2.4 Modelos Constitutivos $\quad 67$

2.4.1 Equações Constitutivas na Ausência de Fluído 70

2.4.2 Equações Constitutivas com Acoplamento Hidromecânico 76

2.5 Teoria Elastoplástica 78

2.5.1 Função e Superfície de Escoamento Plástico 83

$\begin{array}{ll}2.6 \text { Inversão Sísmica } & 97\end{array}$

3. Material e Método 102

3.1 Material 102

3.2 Caracterização do Material 110

3.2.1 Descrição Macroscópica dos Corpos de Prova 110

3.2.2 Peso Específico e Porosidade 111

3.2.3 Análise do Sinal Sísmico 114

3.3 Caracterização Elástica dos Corpos de Prova 118 
3.3.1 Equivalência Estático-Dinâmico: Ensaios de Compressão Hidrostática Simultâneos

3.3.2 Equivalência Estático-Dinâmico: Ensaios Triaxiais

Simultâneos

3.3.3 Equivalência Estático-Dinâmico: Ensaios Edométricos

Simultâneos

132

3.4 Caracterização do Dado Sísmico Emplihado 136

3.4.1 Modelo a Priori para Inversão Sísmica 137

3.4.2 Pulso Sísmico Residual (Wavelets) 143

3.5 Equivalência entre Propriedades Mecânicas Drenadas e Não-Drenadas

4.Resultados

4.1 Estimativa de Propriedades Mecânicas Integradas ao Dado Sísmico

4.1.1 Seção Pós-Sal 157

4.1.2 Seção Salífera 160

4.1.3 Seção Sub-Sal 163

4.1.4 Modelo Litológico 166

$\begin{array}{ll}4.2 \text { Incertezas } & 167\end{array}$

4.2.1 Relações de Equivalência entre Propriedades Mecânicas Dinâmicas vs. Estáticas

4.2.2 Parâmetros Petrofísicos Empregados na Equação de Gassmann

4.2.3 Cenários de Propriedades Mecânicas Estáticas de

Deformabilidade

5 Conclusões 


\section{Lista de Figuras}

Figura 2.1 Convenção de Sinais de Tensões em Geotecnia

Figura 2.2 Modos de Falha típicos para Rocha Friccional

Figura 2.3 Deformação sob Compressão Hidrostática (Goodman 1989)

Figura 2.4 Deformação sob Compressão Triaxial: (a) Deformação Axial e Lateral ; (b) Dilatância (Goodman 1989)

Figura 2.5 Gráfico Deformação Volumétrica vs. Tração Regime Trativo

Figura 2.6 Experimento principal 1-D da teoria de Terzaghi do Adensamento

Figura 2.7 Subsidência do Leito Marinho e Compactação do Reservatório

Figura 2.8 Superfície de Escoamento do Modelo Constitutivo de Mohr-Coulomb

Figura 2.9 Ilustração de Fluxo de Fluídos no Wag

Figura 2.10 Redução de Espaço em Plataforma por Subsidência em Ekofisk

Figura 2.11 Subsidência em Wilmington Field, Long Beach

Figura 2.12 Infinitésimo de Solo com Eixos Orientados e Tensões 
Figura 2.13 Infinitésimo de Volume com Aplicação de Tensão Cisalhante

Figura 2.14 Ensaio de Compressão Simples em Corpo de Prova Cilíndrica

Figura 2.15 Representação Gráfica do Critério de Escoamento Plástico de Mohr-Coulomb no domínio $\sigma$ vs. $\tau$

Figura 2.16 Seção Transversal da Superfície de Escoamento Plástico de Mohr-Coulomb no espaço das tensões principais

Figura 2.17 Superfície de Escoamento Plástico de Mohr-Coulomb no espaço das Tensões Principais

Figura 2.18 Superfície de Escoamento Plástico Cam-Clay com "End-Cap" no espaço $\sigma_{3}$ vs. $\sigma_{1}$

Figura 2.19 Superfície de Escoamento Plástico Cam-Clay Modificado com "End-Cap" no espaço das tensões principais

Figura 2.20 Superfície de Escoamento Plástico por Tração, Cisalhamento e Compactação no espaço no espaço $\sigma_{3}$ vs. $\sigma_{1}$

Figura 2.21 Superfície de Escoamento de Tresca para um estado 2D de Tensões

Figura 2.22 Superfície de Escoamento de Tresca para um estado 3D de Tensões

Figura 2.23 Superfície de Escoamento de Von Mises, estado 3D de Tensões 
Figura 2.24 Superfície de Escoamento de Von Mises, estado 2D de Tensões

Figura 2.25 Superfície de Escoamento de Rankine, estado 2D de Tensões

Figura 2.26 Seção Transversal da Superfície de Escoamento Plástico de Drucker-Prager e Mohr-Coulomb no espaço das tensões principais 96

Figura 2.27 Superfície de Escoamento Plástico 3D do modelo de Drucker-Prager 97

Figura 2.28 Traço Sísmico (em preto) como contraste de propriedades mecânicas - impedância (colorido)

Figura 2.29 Conteúdo de Frequência do Perfis de Poços, do Modelo a Priori e do Dado de Amplitude Sísmica

Figura 3.1 Localização da Bacia de Santos

Figura 3.2 Carta Estratigráfica Bacia de Santos, Brasil, modificada de Pereira e Feijó 1990

Figura 3.3 Bloco de Travertino Romano

Figura 3.4 Bloco de Travertino Romano serrado com moto-serra diamantada

Figura 3.5 Sub-bloco A1 de Travertino Romano 107

Figura 3.6 Sub-bloco A1 Rotacionado com Furos de Barriletes Cilíndricos Extraídos 
Figura 3.7 Barriletes Cilíndricos de Rocha com diâmetro de 54mm, extraídos do Sub-bloco A1

Figura 3.8 Polígono do Dado Sísmico 3D (bloco BM-S-0282) com os Poços Fornecidos pela ANP

Figura 3.9 Coordenadas Geográficas (Datum Sirgas 2000) dos Vértices do Polígono do Dado Sísmico 3D 109

Figura 3.10 Lista com os Poços Fornecidos pela ANP

Figura 3.12 Balança Adventurer Pro (Ohaus)

Figura 3.13 Dessecador Empregado para Saturar os Corpos de Prova 112

Figura 3.14 Proveta Graduada Empregada para Determinar Volume Poroso da Superfície do Corpo de Prova

Figura 3.15 Sistema Balança e Rede empregados para medir o peso do corpo de prova quando submerso em água

Figura 3.16 Sessão de Amplitude Sísmica em Profundidade com Poços e Camadas para Análise da Dispersão do Pulso Sísmico

Figura 3.17 Espectro de frequência camada entre Topo Fm.

Marambaia e Topo Fm. Itajaí-Açú em preto com espectro empregado para o estudo em vermelho

Figura 3.18 Espectro de frequência camada entre Topo Fm. Itajai-Açú e Topo Fm. Itanhaém em preto com espectro empregado para o estudo em amarelo 
Figura 3.19 Espectro de frequência camada entre Topo Fm. Itanhaém e Topo Fm. Ariri em preto com espectro empregado para o estudo em azul

Figura 3.20 Espectro de frequência camada entre Topo Fm. Ariri e Topo Fm. Barra Velha em preto com espectro empregado para o estudo em lilás

Figura 3.21 Espectro de frequência camada entre Topo Fm. Barra Velha e Topo Fm. Piçarras em preto com espectro empregado para o estudo em verde

Figura 3.22 Célula triaxial cilíndrica axissimétrica RTR-1500 (rapid rock triaxial system) desenvolvida pela empresa GCTS. Extraída de Botao Lin, Yan Jin, Huiwen Pang Amy B. Cerato 2016

Figura 3.23 Esquema ilustrativo do sistema de medidas de velocidades elásticas em amostras de rochas. (Vasquez 2010)

Figura 3.24 Amostra ajustada ao cabeçote de medida preparada para ensaio mecânico

Figura 3.25 Corpo de Prova no Cabeçote de Medida com LVDT acoplados

Figura 3.26 Gel Acoplante Colocado no Topo e Base do Corpo de Prova

Figura 3.27 Formas de onda compressional (acima) e de cisalhamento (abaixo), mostrando a correlação do sinal do tempo de sistema (curva azul) e o sinal da amostra (curva vermelha) 
Figura 3.28 Onda P (esquerda) e Onda P (direita). Interpretação do Tempo da Primeira Quebra e Tempo do Sistema para onda P (pico ) e onda S (vale)

Figura 3.29 Tempo (s) vs. Confinamento (Mpa) no ensaio de compressão hidrostática realizado no CPTR-2

Figura 3.30 Deformação Volumétrica Total do CPTR-2 vs.

Confinamento (Mpa)

Figura 3.31 Confinamento (Mpa) vs. Módulo de Compressibilidade Volumétrica para valores de confinamento nos quais propagou-se pulso ultrassônico no CPTR-2

Figura 3.32 Filtro Passa-Banda [90-150] KHz aplicado à onda $\mathrm{P}$

Figura 3.33 Filtro Passa-Banda [70-160] KHz aplicado à onda S

Figura 3.34 Onda-P ultrassônica para o tempo $T=240$ s do ensaio de compressão hidrostática com tempo de chegada (linha vertical vermelha) interpretado

Figura 3.35 Onda-S ultrassônica para o tempo $T=240$ s do ensaio de compressão hidrostática com tempo de chegada (linha vertical vermelha) interpretado

Figura 3.36 Confinamento vs. Módulo de Compressibilidade Volumétrica Dinâmico (GPa) para o CPTR-2

Figura 3.37 Módulo de Compressibilidade Volumétrica Dinâmico vs. Estático (GPa) para o CPTR-2 
Figura 3.38 Sessão passando por todos os poços do cubo de VP advindo do processamento sísmico (tomografia de reflexão) transparência de $50 \%$, por cima do cubo de amplitude sísmica

Figura 3.39 Crossplot de VP (eixo-x) vs. IP (eixo-y), obtido dos perfis de poços disponíveis para a área no Pós-Sal

Figura 3.40 Modelo a Priori de Impedância-P para o Pós-Sal do PPSBS

Figura 3.41 Modelo a Priori de Impedância-P na Seção Salífera sem máscara baseada na amplitude sísmica

Figura 3.42 Modelo a Priori de Impedância-P na Seção Salífera com máscara baseada na amplitude sísmica

Figura 3.43 Modelo a Priori de Impedância-P no Pré-Sal do PPSBS

Figura 3.44 Sessão Sísmica com Horizontes Mapeados e Trajetória de Poços no domínio do tempo (s)

Figura 3.45 Wavelets Normalizadas ao Longo do Soterramento (x-tempo, y-amplitude da wavelet)

Figura 3.46 Espectro de Frequência Normalizado das Wavelets ao longo do soterramento

Figura 3.47 Algoritmo para Conversão dinâmico vs. estático entre propriedades mecânicas de deformabilidade seguindo o MFR (Modelo de Física de Rochas) de Gassmann

Figura 4.1 Fluxograma Básico, Integração Geomecânica - Sísmica para construção de propriedades mecânicas de deformabilidade 
Figura 4.2 Impedância-P invertida do dado sísmico no Sub-Sal em tempo (s)

Figura 4.3 Impedância-P vs. VP de perfis de poços no Sub-Sal 158

Figura 4.4 Impedância-P vs. VS de perfis de poços no Sub-Sal 158

Figura 4.5 Impedância-P vs. RHO de perfis de poços no Sub-Sal 159

Figura 4.6 Impedância-P Invertida do dado sísmico na Seção Salífera em tempo (s) 160

Figura 4.7 Impedância- P vs. VP de perfis de poços na Seção Salífera 161

Figura 4.8 Impedância-P vs. VS de perfis de poços na Seção Salífera 161 Figura 4.9 Impedância-P vs. RHO de perfis de poços na Seção Salífera 162

Figura 4.10 Impedância-P invertida do dado sísmico na Seção Pós-Sal em tempo (s) 163

Figura 4.11 Impedância-P vs. VP de perfis de poços na Seção Pós-Sal 164

Figura 4.12 Impedância-P vs. VS de perfis de poços na Seção Pós-Sal 164

Figura 4.13 Impedância-P vs. RHO de perfis de poços na Seção Pós-Sal 165

Figura 4.14 Litologias de amostra de calha ou interpretadas a partir de perfis de poços 166

Figura 4.15 Sessão em profundidade do modelo litológico 3D 167 
Figura 4.16 Relação de equivalência entre módulos estáticos e dinâmicos (Brotons 2016)

Figura 4.17 Diferentes funcionais para equivalência entre módulos estáticos e dinâmicos (Brotons 2016)

Figura 4.18 Comportamento Gráfico das diferentes relações de equivalência entre módulos estáticos e dinâmicos ( $\mathrm{x}$-módulo de elasticidade dinâmico, y-módulo de elasticidade estático) (Brotons 2016)

Figura 4.19 Impedância-P vs. Porosidade Efetiva de perfis dos poços no carbonato Sub-Sal

Figura 4.20 Módulo de elasticidade estático não-drenado em profundidade-cenário 2 (Tabela 4.2)

Figura 4.21 Coeficiente de poisson estático não-drenado em profundidade cenário 2 (Tabela 4.2)

Figura 4.22 Sessão Sísmica em Profundidade passando pelo poço 8-SPH23-SPS

Figura 4.23 Módulo de elasticidade estático não-drenado. Preto (Dinâmico-Sísmica), Azul (Estático-Cenário 1), Verde (Estático-Cenário 2) e Vermelho (Estático-Cenário 3)

Figura 4.24 Coeficiente de Poisson estático não-drenado. Preto (Dinâmico-Sísmica), Azul (Estático-Cenário 1), Verde (Estático-Cenário 2) e Vermelho (Estático-Cenário 3)

Figura 4.25 Módulo de Compressibilidade Volumétrico Estático nãodrenado. Preto (Dinâmico-Sísmica), Azul (Estático-Cenário 1), Verde (Estático-Cenário 2) e Vermelho (Estático-Cenário 3) 
Figura 4.26 Módulo de Cisalhamento Estático não-drenado.

Preto (Dinâmico-Sísmica), Azul (Estático-Cenário 1), Verde (Estático-Cenário 2) e Vermelho (Estático-Cenário 3)

Figura 4.27 Coeficiente de Biot. Preto (Dinâmico-Sísmica), Azul (Estático-Cenário 1), Verde (Estático-Cenário 2) e Vermelho (Estático-Cenário 3)

Figura 4.28 Módulo de Elasticidade estático não-drenado ( $\mathrm{x}$ - cenário 2 vs. $\mathrm{y}$ - cenário 1 )

Figura 4.29 Módulo de Elasticidade Estático não-drenado (x- cenário 3 vs. y-cenário 1)

Figura 4.30 Módulo de Elasticidade Estático não-drenado ( $\mathrm{x}$-cenário 3 vs. $\mathrm{y}$-cenário 2 ) 


\section{Lista de Equações}

Equação 2.1 Equação da Teoria de Adensamento 1D de Terzaghi 47

Equação 2.2 Equação do Principio das Tensões Efetivas de Terzaghi

Equação 2.3 Equação do Acoplamento Hidro-Mecânico de Biot-Willis

Equação 2.4 Equação do Parâmetro de acoplamento fluídomecânico de Biot-Willis

Equação 2.5 Equação envolvendo variação das tensões totais, efetivas e poropressão 57

Equação 2.6 Expressão do Módulo de Elasticidade 71

Equação 2.7 Expressão do Coeficiente de Poisson 71

Equação 2.8 Expressão do Módulo de Compressibilidade Volumétrica

Equação 2.9 Expressão do Módulo de Deformação Cisalhante

Equação 2.11 Lei de Hooke (Forma Matricial) para materiais ortotrópicos em termos de tensões totais

Equação 2.12 Lei de Hooke (Forma Matricial) para materiais transversalmente isotrópicos em termos de tensões totais 
Equação 2.13 Lei de Hooke (Forma Matricial) para materiais totalmente isotrópicos em termos de tensões totais

Equação 2.15 Relação entre módulo de elasticidade, coeficiente de poisson e módulo de compressibilidade volumétrica para comportamento elástico

Equação 2.16 Lei de Hooke (Forma Matricial) para materiais totalmente isotrópicos em termos de tensões efetivas

Equação 2.17 Deformação para materiais totalmente isotrópicos em termos de tensões efetivas

Equação 2.18 Deformação para materiais totalmente isotrópicos em termos de tensão total e parâmetro $\alpha_{B}$ de Biot-Willis

Equação 2.19 Critério de escoamento plástico de Mohr-Coulomb em função da tensão normal e cisalhante

Equação 2.20 Critério de escoamento plástico de Mohr-Coulomb em função da tensão principal e ângulo de atrito interno

Equação 2.21 Critério de escoamento plástico de Mohr-Coulomb em função da tensão principal e resistência a compressão simples

Equação 2.22 Função de escoamento plástico pelo critério de MohrCoulomb em termos de Tensões Efetivas principais e resistência a compressão simples 
Equação 2.23 Função de escoamento plástico pelo critério de MohrCoulomb para um estado 3D de tensões em termos dos invariantes de tensão

Equação 2.24 Superfície de Escoamento Plástico Cam-Clay em termos de tensões principais (Roscoe 1968)

Equação 2.25 Superfície de Escoamento Plástico Cam-Clay Modificado em termos das tensões principais

Equação 2.27 Superfície de escoamento plástico de Drucker e Prager no espaço 3D das tensões principais

Equação 3.1 Relação de Equivalência entre módulo de compressibilidade volumétrica dinâmico e estático para o CPTR-2

Equação 3.3 Relação entre velocidade-P e Impedância -P para construção de modelo a priori no Pós-Sal

Equação 3.4 Equação de Gassmann para módulo de compressibilidade volumétrica

Equação 3.6 Módulo de compressibilidade volumétrica e módulo de cisalhamento como função do módulo de elasticidade e coeficiente de poisson 
Equação 3.7 Módulo de elasticidade e coeficiente de poisson como função do módulo de compressibilidade volumétrica e módulo de cisalhamento

Equação 3.8 Inversa da equação de Gassmann

Equação 3.9 Expressão do coeficiente de acoplamento fluídomecânico de Biot-Willis

Equação 4.1 Módulo de elasticidade e coeficiente de poisson como função das velocidades compressional e cisalhante no regime elástico

Equação 4.2 Modelo de Física de Rochas no Sub-Sal que relaciona Impedância-P e Velocidade-P obtido a partir dos perfis de poços

Equação 4.3 Modelo de Física de Rochas no Sub-Sal que relaciona Impedância-P e Velocidade-S obtido a partir dos perfis de poços

Equação 4.4 Modelo de Física de Rochas no Sub-Sal que relaciona Impedância-P e Densidade obtido a partir dos perfis de poços

Equação 4.5 Módulo de compressibilidade volumétrica e módulo de cisalhamento como função das velocidades compressional e cisalhante no regime elástico

Equação 4.6 Modelo de Física de Rochas na Seção Salífera que relaciona Impedância-P e Velocidade-P obtido a partir dos perfis de poços

Equação 4.7 Modelo de Física de Rochas na Seção Salífera que relaciona Impedância-P e Velocidade-S obtido a partir dos perfis de poços 
Equação 4.8 Modelo de Física de Rochas na Seção Salífera que relaciona Impedância-P e Densidade obtido a partir dos perfis de poços

Equação 4.9 Modelo de Física de Rochas no Pós-Sal que relaciona Impedância-P e Velocidade-P obtido a partir dos perfis de poços

Equação 4.10 Modelo de Física de Rochas no Pós-Sal que relaciona Impedância-P e Velocidade-S obtido a partir dos perfis de poços

Equação 4.11 Modelo de Física de Rochas no Pós-Sal que relaciona Impedância-P e Densidade obtido a partir dos perfis de poços

Equação 4.12 Modelo de Física de Rochas que relaciona Porosidade Efetiva e Impedância-P para carbonatos do Sub-Sal

Equação 4.13 Modelo de Física de Rochas que relaciona Porosidade Efetiva e Impedância-P para carbonatos do Pós-Sal

Equação 4.14 Modelo de Física de Rochas que relaciona Porosidade Efetiva e Impedância-P para areias do Pós-Sal 


\section{Lista de Tabelas}

Tabela 2.1 Parâmetros de Modelo Analítico de Iniciação e Propagação de Fraturas

Tabela 2.2 Parâmetros para estimativa da pressão máxima de injeção $(\Delta P)$ para reativação de falhas

Tabela 3.1 Pesos, Porosidade efetiva e Pesos específicos dos corpos de prova de travertino romano (CPTR)

Tabela 3.2 Descritivo das Wavelets Empregadas para Inversão Sísmica

Tabela 4.1 Cenário 1- Relações de equivalência dinâmico vs estático (Pandula 2002)

Tabela 4.2 Cenário 2- Relações de equivalência dinâmico vs estático (Lacy 1996)

Tabela 4.3 Cenário 3- Relações de equivalência dinâmico vs estático (Lacy 1996), (Morales 1993) e (Borges 2010)

Tabela 4.4 Parâmetros Petrofísicos de Fluídos

Tabela 4.5 Módulo de compressibilidade volumétrica mineral para os carbonatos do Sub-Sal

Tabela 4.6 Módulo de compressibilidade volumétrica mineral para os carbonatos do Pós-Sal

Tabela 4.7 Módulo de compressibilidade volumétrica para as areias do Pós-Sal 


\section{Lista de Símbolos}

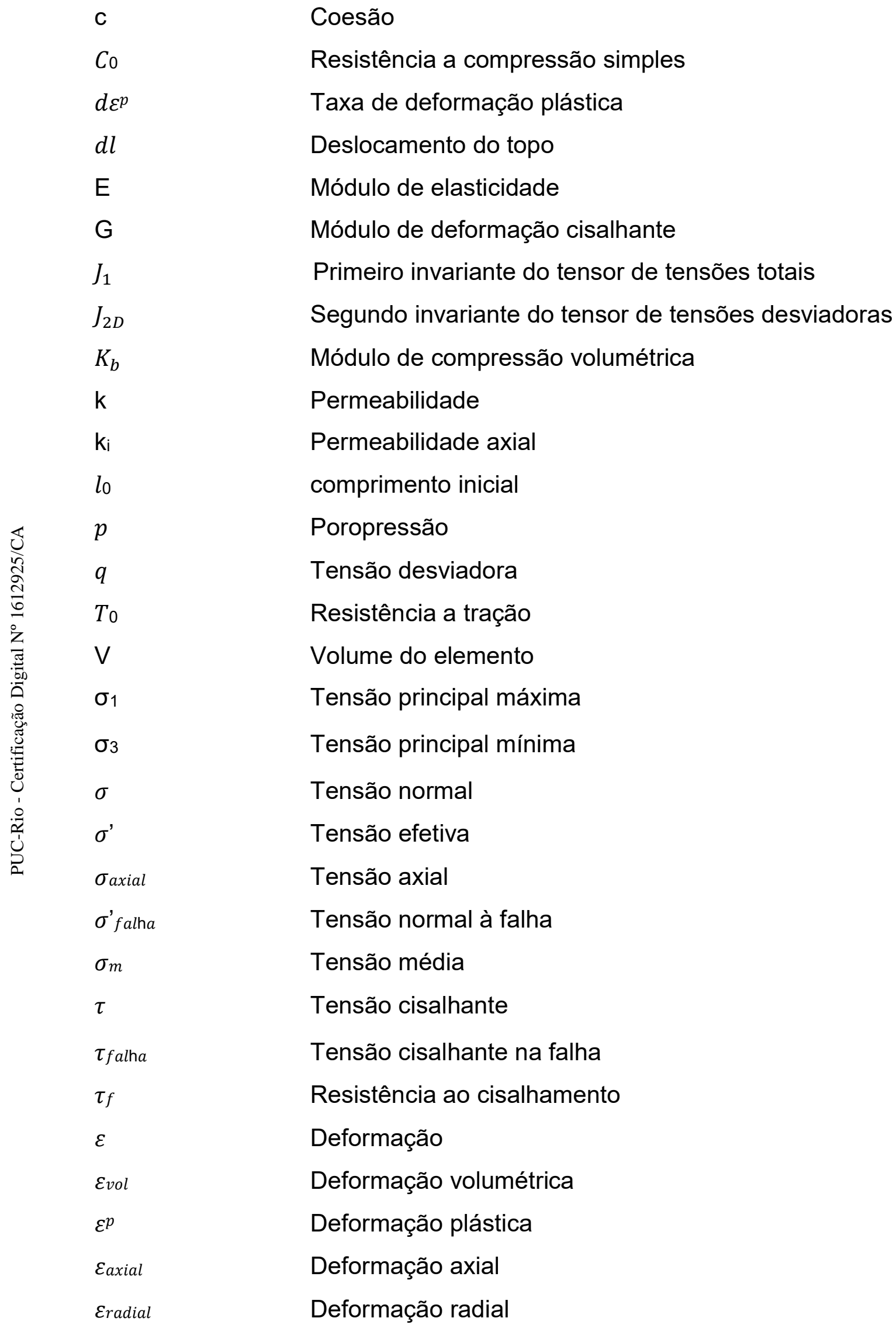




$\begin{array}{ll}\gamma & \text { Deformação cisalhante } \\ v & \text { Coeficiente de Poisson } \\ \phi & \text { Ângulo de atrito } \\ \psi & \text { Ângulo de dilatância } \\ \lambda & \text { Parâmetro de Lamé } \\ \alpha & \text { Inclinação do critério de escoamento no plano } \sigma^{\prime} 1 x \sigma^{\prime} 3 \\ \delta & \text { Multiplicador de Lagrange } \\ \emptyset_{e f f} & \text { Porosidade Efetiva da Rocha } \\ K_{\min } & \text { Módulo de Compressão Volumétrica Mineral } \\ K_{f} & \text { Módulo de Compressão Volumétrica do Fluído }\end{array}$


"Pouco conhecimento faz com que as pessoas se sintam orgulhosas. Muito conhecimento, que se sintam humildes. É assim que as espigas sem grãos erguem desdenhosamente a cabeça para o céu, enquanto que as cheias as baixam para a terra, sua mãe" Leonardo da Vinci

"O que vale na vida não é o ponto de partida e sim a caminhada. Caminhando e semeando, no fim terás o que colher" Cora Coralina 


\section{Introdução}

Estima-se que mais de $60 \%$ das reservas mundiais de óleo e $40 \%$ das reservas mundiais de gás estejam em reservatórios carbonáticos (Schlumberger Carbonate Reservoirs Market Analysis, 2007 and World Energy Outlook, 2006).

Desde 2006 até os dias atuais (2019), as maiores descobertas mundiais de jazidas de petróleo em reservatórios convencionais ocorreram nos carbonatos de idade Aptiana do Pólo Pré-Sal da Bacia de Santos (PPSBS), Brasil. Por tratarem-se de reservatórios profundos (aproximadamente $5000 \mathrm{~m}$ de profundidade), localizados em águas ultra-profundas (aproximadamente $2200 \mathrm{~m}$ de lâmina d'água) e distantes do continente (aproximadamente $300 \mathrm{Km}$ ao Leste da cidade do Rio de Janeiro), as atividades de exploração, desenvolvimento e gerenciamento da produção tornam-se onerosas e tecnicamente complexas, por serem susceptíveis ao comportamento fortemente heterogêneo da rocha em termos de: porosidade, permeabilidade e propriedades mecânicas de deformabilidade. Neste contexto, o dado sísmico HD (High Definition) - medida indireta e espacialmente densa - do contraste de propriedades mecânicas ao longo da coluna estratigráfica de rochas em subsuperfície, permite agregar valioso conteúdo à modelagem geomecânica, através do melhor entendimento da natureza heterogênea da rocha em termos de propriedades mecânicas de deformabilidade.

A pesquisa na integração do dado sísmico à modelagem geomecânica surge para minimizar incerteza na resposta a questões chave de concepção do modelo inicial de desenvolvimento de projeto, como:

\section{Viabilidade Econômica}

As pressões limite de injeção bem como as máximas depleções permitidas ao longo da vida produtiva do campo, impactam diretamente sua curva de produção tão logo sua viabilidade econômica. 


\section{SMS (Segurança, Meio Ambiente e Saúde)}

A ocorrência de eventos que ao longo da vida produtiva do campo possam vir a comprometer a Segurança, Meio Ambiente e Saúde nas Unidades de Produção: sudsidência do fundo marinho, reativação de falhas e fraturas, integridade da camada selante, fraturamento hidráulico da formação e vazamento de fluidos de subsuperfície.

\section{Perfuração de Poços}

Otimização da trajetória de poços visando evitar ocorrências durante a perfuração de poços, tais como: prisões da coluna de perfuração, arraste da broca, kick em areias sobre pressurizadas e perda dinâmica de fluidos, que levem ao aumento do tempo de perfuração e, por conseguinte, do custo do projeto, bem como comprometam premissas de SMS.

Essencial a integração do dado sísmico à modelagem geomecânica é também a adequada conversão de propriedades elásticas dinâmicas de deformabilidade advindas do dado sísmico (baixíssimas deformações de aproximadamente $10^{-9} \mathrm{com}$ ciclos de carga-descarga-recarga da ordem de dezenas de Hertz), para propriedades elásticas estáticas (ou de ciclo) de deformabilidade (elevadas deformações de aproximadamente $10^{-2} \mathrm{com}$ ciclos de carga-descarga-recarga da ordem de dezena de minutos) as quais são mais interessantes ao desenvolvimento e gerenciamento de reservatórios, imaginando um horizonte de dezenas de anos para a vida produtiva do campo.

Existe uma boa quantidade de referências para relações de equivalência entre propriedades elásticas de deformabilidade dinâmica vs. estáticas que resultam de ensaios laboratoriais para a Bacia de Santos, Brasil :

(Justen 2014) e (Santos 2010) e em bacias fora da América do Sul: (AlShayea 2004 ), (Brotons 2016), (Mockovčiaková 2003) e (Lacy 1996). 


\section{1}

\section{Objetivo}

A pesquisa realizada neste projeto visa desenvolver metodologia para estimativa de cenários 3D de propriedades mecânicas elásticas estáticas de deformabilidade: módulo de elasticidade e coeficiente de Poisson e do fator de acoplamento fluído-mecânico: coeficiente de Biot-Willis, integradas ao dado sísmico e que destinam-se a alimentar simulador mecânico.

Os materiais empregados são: amplitude sísmica 0-offset migrada, cubo de velocidade -P de migração sísmica e perfis de dez poços concedidos pela ANP (do bloco BMS-282 do PPSBS), bem como bloco de travertino romano empregado como análogo mecânico dos carbonatos Sub-Sal do PPSBS.

Baseado no uso integrado de dado sísmico, de perfis de poços e de rocha (travertino romano), o presente trabalho pretende passar pelas seguintes etapas:

I. Realização de inversão sísmica determinística CSSI (constrained sparse spike) baseada em modelo inicial de Impedância-P ao longo de toda a sequência estratigráfica da Bacia de Santos: Pós-Sal, Sal e Pré-Sal considerando o efeito do soterramento em dado sísmico 0-offset cedido pela ANP (Agência Nacional do Petróleo).

II. Desenvolvimento de Modelo de Física de Rochas (MFR) para toda a sessão estratigráfica da Bacia de Santos, com base em perfis de poços cedidos pela ANP e furos geotécnicos, para estimativa das propriedades mecânicas elásticas dinâmicas a partir da ImpedânciaP obtida na inversão sísmica.

III. Realização de ensaios mecânicos simultâneos em corpos de prova retirados de análogo mecânico (bloco de travertino romano) da camada Pré-Sal da Bacia de Santos para determinação de relação de equivalência estático vs. dinâmico, como também emprego de duas relações de equivalência estático vs. dinâmico advindas de 
trabalhos científicos totalizando três cenários de propriedades mecânicas de deformabilidade estáticas e de coeficiente de BiotWillis.

\section{2}

\section{Organização do trabalho}

A dissertação está dividida em seis capítulos:

O Capítulo 1 situa o leitor sobre os objetivos da pesquisa em integração sísmica-geomecânica.

No Capítulo 2 apresenta-se uma revisão bibliográfica sobre os temas: Comportamento Mecânico da Rocha, Casos Reais de Efeitos Geomecânicos em Reservatórios, Modelos Constitutivos e Inversão Sísmica.

No Capítulo 3 é introduzida a carta estratigráfica da Bacia de Santos e apresentados os dados cedidos pela ANP, materiais, equipamentos e metodologia de uso do dado sísmico, perfis de poços e ensaios laboratoriais simultâneos de equivalência dinâmico vs. estático para estimativa de propriedades mecânicas estáticas de deformabilidade.

É apresentada a relação de equivalência dinâmico vs. estático para o corpo de prova de travertino romano ensaiado.

No Capítulo 4 o dado sísmico é integrado à modelagem geomecânica através de inversão sísmica determinística baseada em modelo inicial de Impedância-P, são construídos os modelos de física de rochas (MFR) advindos de perfis de poços para toda a coluna estratigráfica da Bacia de Santos bem como calculados os três cenários de propriedades mecânicas estáticas de deformabilidade obtidos com a equivalência dinâmico vs. estático obtida no Capítulo 3 e mais duas equivalências advindas de jornais científicos.

No Capítulo 5 são feitas as conclusões gerais do trabalho.

No Capítulo 6 é exibida a lista completa das referências bibliográficas utilizadas. 


\section{Revisão Bibliográfica}

Para o melhor entendimento dos resultados obtidos e descritos nos capítulos finais, é interessante contextualizar a pesquisa.

Este capítulo encaixa-se como uma curta revisão bibliográfica de tópicos estratégicos e abrange de forma geral os aspectos indispensáveis de: Comportamento Mecânico da Rocha, Casos de Domínio Público de Efeitos Geomecânicos em Reservatórios, Modelos Constitutivos e Inversão Sísmica.

\section{1}

\section{Comportamento Mecânico}

Nesta seção são abordados os conceitos base do comportamento mecânico de solos e rochas: tensões, deformações e modos de falha. A convenção de sinais empregada para tensão e deformação é a de mecânica dos solos, na qual tensões normais compressivas são positivas, estão associadas a deformações positivas e há diminuição de volume. As tensões cisalhantes são positivas quando o binário de forças faz um elemento de volume do corpo rodar no sentido anti-horário

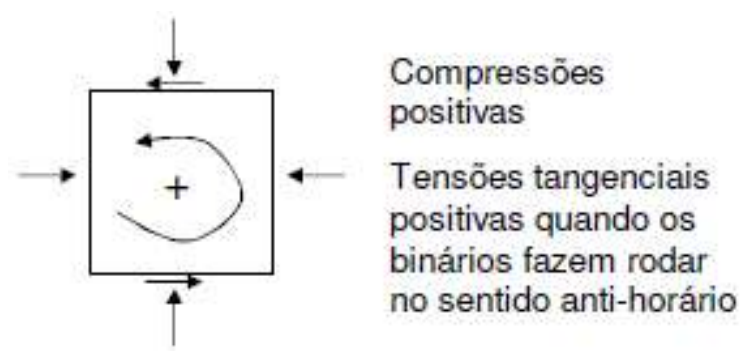

Figura 2.1: Convenção de Sinais de Tensão em Geotecnia

Tensões normais trativas são negativas e estão associadas a deformações negativas, havendo incremento do volume.

Nas Bacias Sedimentares Brasileiras, as rochas sedimentares típicas de granulometria argila (aproximadamente $\mu \mathrm{m}$ ) até seixo (aproximadamente $\mathrm{cm}$ ) e que podem ou não apresentar cimento coesivo exibem resistência mecânica variável como função do grau de confinamento, propriedade 
esta conhecida como friccionalidade. É comum observar friccionalidade em rochas brandas ou pouco consolidadas, solos e até mesmo concreto. Pode-se particionar a estrutura interna de uma rocha em pelo menos duas fases:

- Arcabouço sólido ou Matriz (para Geologia de Engenharia): formado pela matriz, grãos (estrutura) e cimento (se presente).

- Fluido dos poros: fluído que preenche o esqueleto poroso (poros da rocha). Neste trabalho considera-se apenas a porosidade intersticial da matriz e um único fluido saturante.

Simplificadamente, pode-se entender o aumento do confinamento como um maior intertravamento da estrutura interna das rochas friccionais, contribuindo com o aumento da coesão e, logo, da resistência ao cisalhamento.

Num material friccional, os três principais modos de falha são ilustrados a seguir:

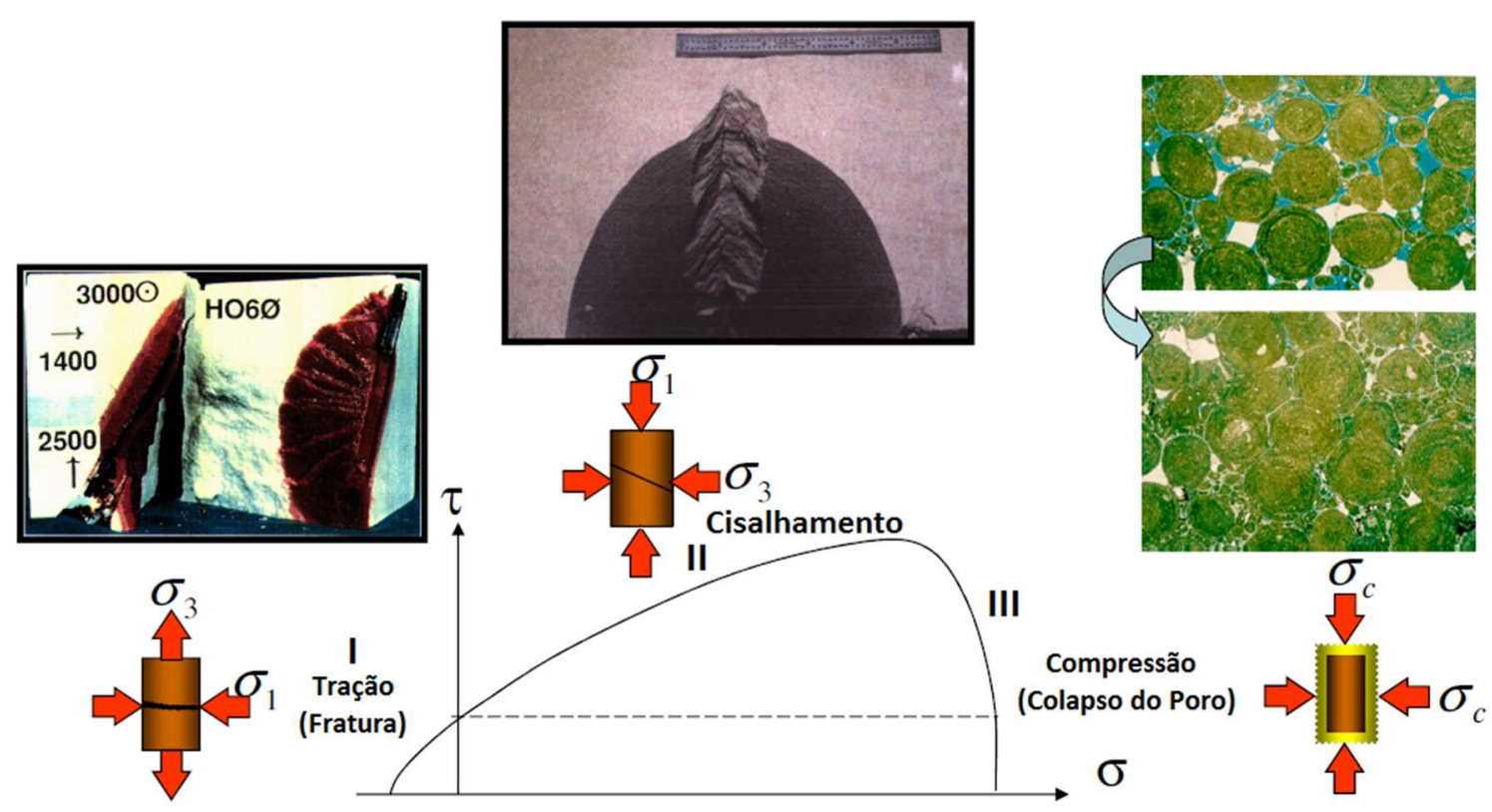

Figura 2.2: Modos de Falha Típicos para Rocha Friccional

- Região I - Tração Direta

A resistência à tração dos materiais friccionais é bem inferior à resistência a compressão, um valor usado em aplicações práticas é 1:10. Em maciços rochosos a ruptura por tração surge em casos de 
flexão de camadas de rocha, em tração direta associada ao cisalhamento de descontinuidades não persistentes ou bordas de fraturas e em operações de fraturamento hidráulico. Na Figura 2.2 este modo de falha é ilustrado por um ensaio de fraturamento hidráulico realizado em corpo de prova de gesso

- Região II - Cisalhamento

Há formação ou reativação de uma superfície de ruptura devido a esforços de cisalhamento. Em geral há aumento de volume do material, fenômeno denominado dilatância, e que se deve ao rearranjo do material trabalhado no plano de falha no caso de rochas brandas e às rugosidades das superfícies de ruptura em deslocamento no caso de rochas competentes. Na Figura 2.2 este modo de falha é ilustrado por uma falha de cisalhamento devido à concentração de esforços decorrente da escavação de uma cavidade circular.

- Região III - Colapso da Estrutura Porosa Compressão que provoca redução do volume e micro fragmentação da rocha bem como rotação de grãos e colapso da estrutura porosa. $\mathrm{Na}$ Figura 2.2 este modo de falha é ilustrado por duas análises de lâmina no microscópio: uma da rocha intacta e a outra da mesma rocha após ensaio laboratorial de compactação na qual foi observada redução no volume poroso, fragmentação de cimento e bordas de grãos, compactação da estrutura porosa e geração de material particulado fino que tende a obstruir a garganta dos poros remanescentes (diminuição da permo-porosidade).

As rochas apresentam fissuras naturais antes mesmo de qualquer carregamento ser aplicado, o que influencia diretamente seu comportamento tensão-deformação. Quando tensão hidrostática é aplicada à rocha, um decréscimo de volume é gerado e eventualmente ocorrem mudanças na estrutura interna tais como colapso da estrutura porosa e esmagamento de grãos para níveis de tensão suficientemente altos. A 
Figura 2.3 representa um exemplo de comportamento tensão-deformação para um ensaio de compressão hidrostática no qual se observam quatro regiões bem definidas

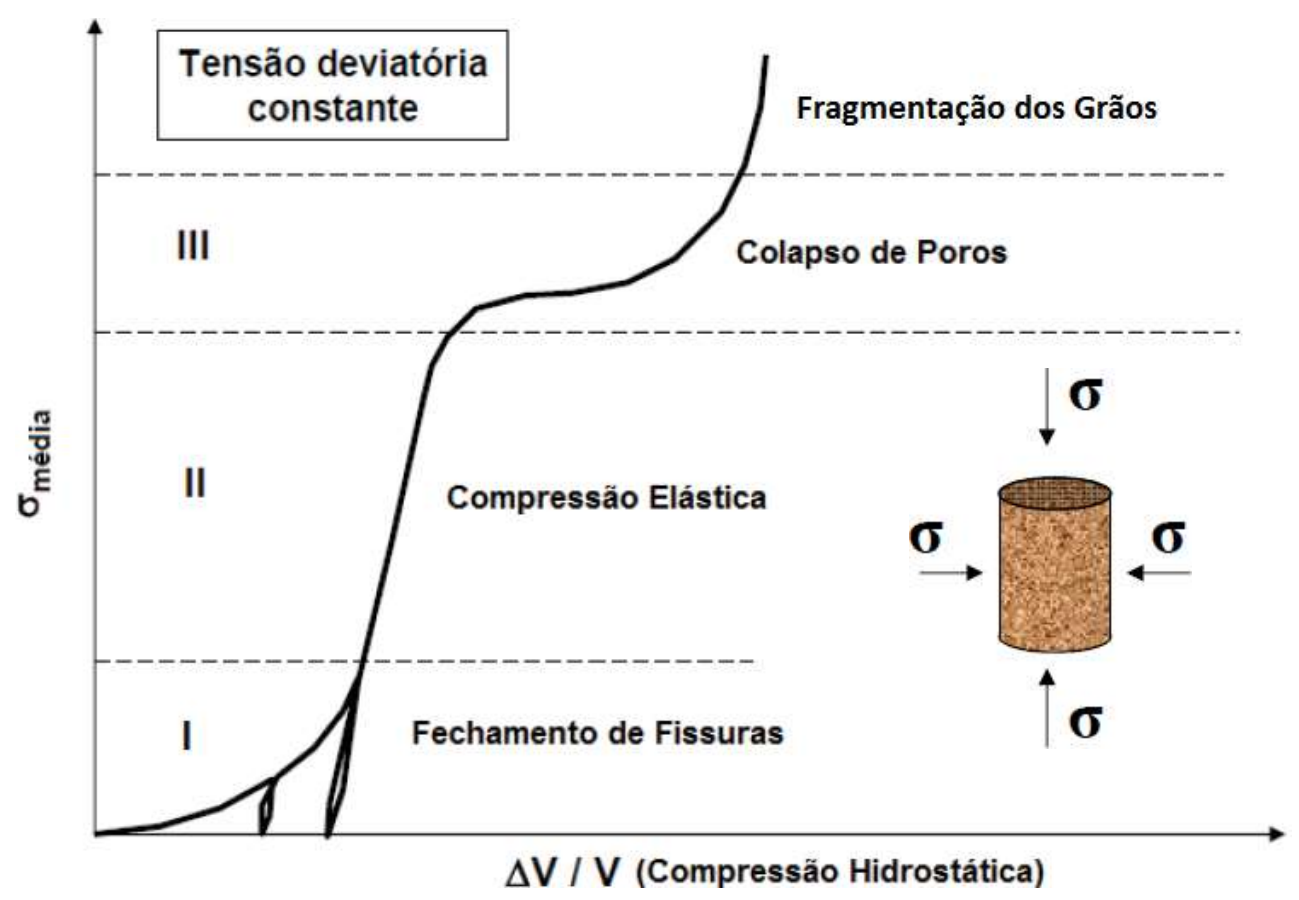

Figura 2.3: Deformação Volumétrica sob Compressão Hidrostática

(Goodman 1989)

- Região I - Fechamento de fissuras pré-existentes na rocha Nesta primeira fase do carregamento, caracterizada pelo desenvolvimento de grandes deformações com baixo grau de confinamento, as fissuras preexistentes são fechadas e os grãos são levemente comprimidos. As deformações não recuperáveis observadas nos descarregamentos se devem às fissuras que permanecem fechadas após o descarregamento

- Região II - Carregamento Puramente Elástico da Rocha Prosseguindo com a aplicação do carregamento, a rocha continua a diminuir de volume, mas agora, pela deformação dos poros e compressão dos grãos numa taxa aproximadamente linear como mostra a Figura 2.3. A inclinação da reta nesta região representa o módulo de compressão volumétrica da rocha $\left(K_{b}\right)$ e as deformações 
são reversíveis. A depender do grau de consolidação (rocha pouco consolidada, friável ou inconsolidada) esta região pode não ocorrer.

- Região III - Colapso da Estrutura Porosa da Rocha: Nesta etapa ocorre o colapso dos poros envolvendo grandes deformações irrecuperáveis, elevada dissipação de energia devido a quebra do cimento (quando presente), fragmentação e rotação de grãos. Observa-se aumento progressivo no valor da resistência e rigidez da rocha (Goodman, 1989).

- Região IV - Travamento da Estrutura Após o colapso, na etapa anterior, da estrutura porosa e do cimento (se presente), apenas os grãos permanecem como elementos deformáveis. O meio se torna mais denso e intertravado, aumenta a área de contato ente os grãos proporcionando um melhor desenvolvimento de cadeias de tensões intergranulares. A resistência e rigidez do material aparentam crescer indefinidamente. 
$\mathrm{Na}$ presença de tensão desviadora, as rochas comportam-se de maneira mais complexa, conforme a Figura 2.4 de ensaio triaxial:

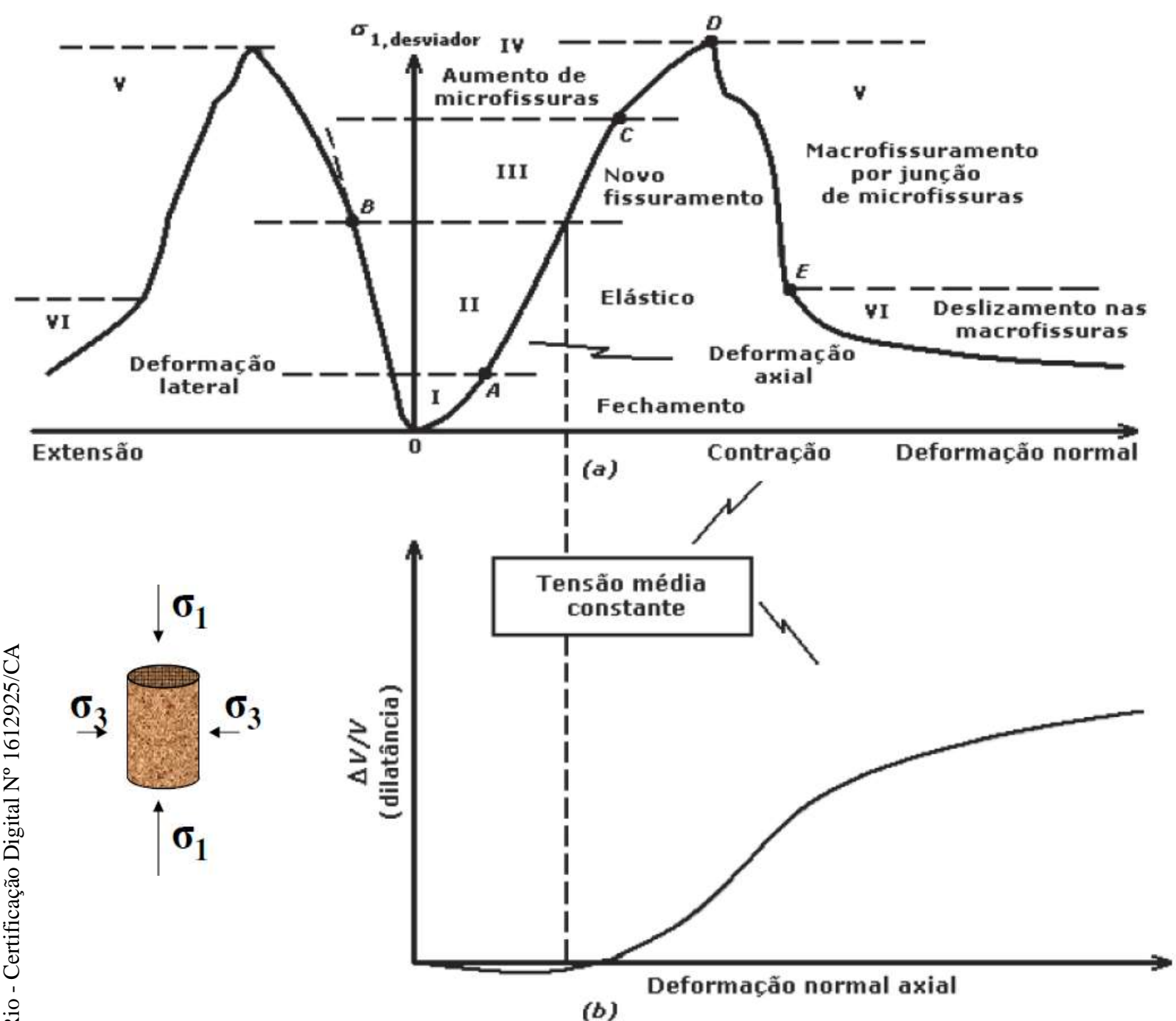

Figura 2.4: Deformação sob Compressão Triaxial: (a) Deformação Axial e Lateral ; (b) Dilatância (Goodman, 1989)

- Região I-Fechamento de Fissuras De início, com a aplicação do carregamento desviador, tem-se um comportamento inelástico. A rocha decresce de volume em virtude do fechamento das fissuras preexistentes e de alguns poros.

As deformações não recuperáveis observadas nos descarregamentos se devem às fissuras que permanecem fechadas após o descarregamento, assim como na compressão hidrostática (Figura 2.3 - Região I). 
- Região II - Comportamento Elástico

Em seguida, na maioria das rochas, segue-se uma fase de comportamento linear entre as tensões e deformações.

Observa-se que na região elástica a rocha continua a decrescer de volume com o aumento da tensão desviadora e as deformações são reversíveis.

- Região III - Criação de Novas Fissuras Nesta fase que inicia-se com o regime pós-elástico, a rocha apresenta incremento volumétrica (dilatância) devido ao surgimento de novas fissuras. O crescimento das fissuras é estável, ou seja, elas crescem até um comprimento definido.

- Região IV - Aumento na Densidade de Microfissuração O aumento da tensão desviadora é responsável pelo surgimento e propagação instável de microfissuras, que eventualmente coalescem. Há incremento do volume da rocha em decorrência do aumento das tensões desviadoras a que dá-se o nome de dilatância.

- Região V - Fraturamento Macroscópico pela Coalescência das Microfissuras Inicialmente há ruptura macroscópica da rocha devido a criação e coalescência de novas fissuras nas etapas anteriores (III e IV). A rocha continua a apresentar incremento volumétrico devido as tensões desviadoras (dilatância).

- Região VI - Deslizamento nos Planos de Macrofissuras (Falhas) Sob a ação de tensão cisalhante, as superfícies de macrofissuras (produzidas na etapa anterior $\mathrm{V}$ ) deslizam umas sobre as outras. Ocorre um afastamento relativo, que provoca a abertura da macrofissura. Macroscopicamente, a abertura destas macrofissuras gera incremento de volume da rocha (dilatância).

No regime trativo, o comportamento (Deformação vs. Tração) idealizado dos materiais friccionais consiste numa porção elástica 
linear que uma vez ultrapassada admite-se que o material tenha falhado por tração (Figura 2.5) . A resistência a tração muitas vezes empregada relaciona-se a resistência a compressão simples pelo fator 1:10.

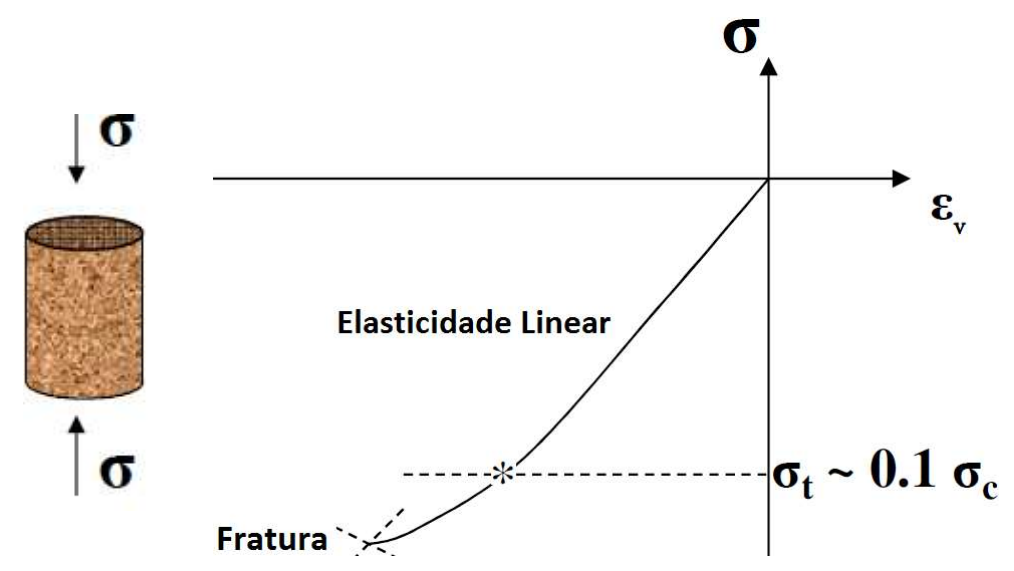

Figura 2.5: Gráfico Deformação Volumétrica vs. Tração, Regime Trativo

\section{2}

\section{Geomecânica de Reservatórios}

$\mathrm{Na}$ subseção anterior a rocha foi tratada ignorando-se o fluido que satura o seu volume poroso, o que é adequado para rochas secas ou saturadas em condições drenadas. Na maior parte das situações práticas, no entanto, o fluido presente nos poros interfere na resposta mecânica do reservatório. À disciplina que formula um meio contínuo equivalente e acopla o comportamento de rocha e fluido em meio poroso dá-se o nome poromecânica que, na prática, é também empregada como uma generalização de todos conceitos mecânicos em rochas saturadas como: poroelasticidade, poroelastoplasticidade e até mesmo poroviscoelasticidade. Segundo (Wang, 2000) os conceitos de poromecânica se desenvolveram independentemente nas disciplinas de geotecnia, engenharia de petróleo e hidrogeologia. No princípio, nas aplicações de engenharia, a rocha era tratada como material de engenharia focando na sua capacidade de: suportar superestruturas, estabilidade em taludes, obras de superfície em geral e no que se referia a estabilidade de escavações. Com o passar do tempo e a ocorrência de grandes desastres a partir da metade do século XIX (alguns casos interessantes de domínio 
público são abordados na seção 2.3), percebeu-se a necessidade de melhor compreender o acoplamento entre rocha e fluido dos poros, matéria esta que é tratada em Geotecnia nos seus moldes atuais.

Já nas historicamente mais recentes disciplinas de engenharia de petróleo e hidrogeologia, acredita-se que os conceitos, mesmo que primordiais, de poromecânica sempre estiveram presentes, uma vez que a rocha é tratada como portadora de fluídos cuja percolação ou exploração são de interesse ao ser humano.

Podemos colocar o trabalho de Karl Terzaghi (1883-1963), como um dos marcos que fundamentam o acoplamento entre rocha e fluído.

Terzaghi procurou entender o comportamento do solo como material de fundação e a teoria de adensamento, fruto de seu trabalho entre 1916 e 1925, relaciona de que maneira os esforços aplicados no solo ou em um material permoporoso são distribuídos entre o arcabouço sólido e o fluído que satura os poros. Ao incremento de pressão de fluido devido ao carregamento do solo deu-se o nome de excesso de poropressão.

O excesso de poropressão representa a energia disponível para o transporte do fluido no meio poroso e é dado pela diferença entre a pressão atuante no fluido e a pressão devida à hidrostática da coluna de fluido.

O desenvolvimento de excesso de poropressão no fluído decorre de uma mobilidade limitada do mesmo no meio poroso (condição parcialmente drenada ou não-drenada). A transferência de tensão entre arcabouço sólido e fluido varia para cada região do solo e dá-se a taxas limitadas das zonas de maior para menor excesso de poropressão, o que imprime um comportamento temporal ao sistema.

Terzaghi, em 1923, propôs a primeira teoria para quantificar a evolução do adensamento em solo de argilas saturadas.

A dedução dessa teoria está baseada em seis hipóteses (DAS,2007)

\section{- O sistema argila-água é homogêneo}

Isso indica que a distribuição dos vazios no solo é uniforme e que o fluxo acontece sob as mesmas condições. 
- O solo está totalmente saturado

Essa hipótese admite que toda a água que se encontra na mesma linha de referência deverá percorrer a mesma distância para sair do solo e que o aumento de poropressão ocorre em todos os pontos do solo.

- A compressibilidade da água é desprezível

Quando o carregamento é aplicado o fluido presente no solo deverá fluir para zonas de baixas pressões e não haverá redução do volume das moléculas de água.

- A compressibilidade dos grãos do solo é desprezível Isso indica que não haverá deformação por redução do volume do arcabouço sólido do solo, mas sim por uma alteração no arranjo estrutural entre os grãos devido à saída da água.

- O escoamento é unidimensional O meio é considerado como semi-infinito na direção longitudinal e simétrico ao longo da direção transversal de modo que o fluxo pode ser idealizado em apenas uma direção.

\section{- A lei de Darcy governa o fluxo}

A velocidade de escoamento é governada pela lei de Darcy e a carga hidráulica é representada pelo acréscimo de pressão.

Para um pequeno elemento de solo argiloso saturado e sujeito a um carregamento constante na direção $z$, analisa-se o balanço de água que entra e sai do solo:

$$
\begin{gathered}
\left(v_{z}+\frac{\partial v_{z}}{\partial z} \cdot \Delta z\right) \cdot \Delta x \cdot \Delta y-v_{z} \cdot \Delta x \cdot \Delta y=\frac{\partial V_{f}}{\partial t} \rightarrow \\
\frac{\partial v_{z}}{\partial z} \cdot \Delta z \cdot \Delta x \cdot \Delta y=\frac{\partial V_{f}}{\partial t}
\end{gathered}
$$


em que $V_{f}$ representa o volume de fluído, $v_{z}$ a velocidade na respectiva direção e $t$ o tempo. Supondo válida a Lei de Darcy pode-se calcular a velocidade de escoamento do fluído no esqueleto poroso:

$$
\begin{aligned}
& v_{z}=k_{d} \cdot i=-k_{d} \cdot \frac{\partial h}{\partial z}=-k_{d} \cdot \frac{\partial\left(h_{e}+h_{p}\right)}{\partial z}=-k_{d} \cdot\left[1+\frac{\partial h_{p}}{\partial z}\right] \rightarrow \\
& \frac{\partial v_{z}}{\partial z}=-k_{d} \cdot \frac{\partial^{2} h_{p}}{\partial z^{2}}=\frac{1}{\gamma_{w}} \cdot-k_{d} \cdot \frac{\partial^{2}\left(\gamma_{w} \cdot h_{p}\right)}{\partial z^{2}}=-\mathrm{k} \cdot \frac{\partial^{2} p}{\partial z^{2}}
\end{aligned}
$$

Sendo $k_{d}$ é a permeabilidade de Darcy, seja $\mathrm{K}:=\frac{k_{d}}{\gamma_{w}}$ e $\mathrm{p}$ a poropressão do fluído, (b) e (a) fornecem :

$$
-\mathrm{k} \cdot \frac{\partial^{2} p}{\partial z^{2}}=\frac{1}{\Delta z \cdot \Delta x \cdot \Delta y} \cdot \frac{\partial V_{f}}{\partial t}
$$

Seja $V_{p}$ o volume poroso ( esqueleto poroso),$V_{s}$ o volume de sólido (esqueleto sólido) e o índice de vazios e $=\frac{V_{p}}{V_{S}}$.

Tem-se para um solo saturado, i.e, $V_{f}=V_{p}$ :

$$
\begin{gathered}
\frac{\partial V_{f}}{\partial t}=\frac{\partial V_{p}}{\partial t}=\frac{\partial\left(e \cdot V_{s}\right)}{\partial t} \rightarrow \\
\frac{\partial V_{f}}{\partial t}=V_{s} \cdot \frac{\partial e}{\partial t}+\text { e. } \frac{\partial V_{S}}{\partial t}
\end{gathered}
$$

Supondo o solo incompressível, i.e, $\frac{\partial V_{S}}{\partial t}=0$, (d) torna-se :

$$
\frac{\partial V_{f}}{\partial t}=V_{s} \cdot \frac{\partial e}{\partial t}=\frac{\Delta z \cdot \Delta x \cdot \Delta y}{(1+e)} \cdot \frac{\partial e}{\partial t}
$$

(e) e ( c ) fornecem:

$$
-\mathrm{k} \cdot \frac{\partial^{2} p}{\partial z^{2}}=\frac{1}{(1+e)} \cdot \frac{\partial e}{\partial t}
$$

Considera-se que a variação do índice de vazios e esteja relacionada com a variação da poropressão $p$ :

$$
\frac{\partial \mathrm{e}}{\partial \mathrm{t}}=\frac{\partial \mathrm{e}}{\partial \mathrm{p}} \cdot \frac{\partial \mathrm{p}}{\partial \mathrm{t}}=-\mathrm{a}_{\mathrm{v}} \cdot \frac{\partial \mathrm{p}}{\partial \mathrm{t}}
$$


em que admitiu-se que $\frac{\partial \mathrm{e}}{\partial \mathrm{p}}$ é igual $\mathrm{a}-\left(\mathrm{a}_{\mathrm{v}}\right)$ denominado coeficiente de compressibilidade e que pode ser considerado constante para uma faixa pequena de variação da tensão (DAS 2007):

$$
\frac{\partial \mathrm{e}}{\partial\left(\Delta \sigma^{\prime}\right)}=-\frac{\partial \mathrm{e}}{\partial \mathrm{p}}=\mathrm{a}_{\mathrm{v}}
$$

(f) e (g) fornecem:

$$
\mathrm{k} \cdot \frac{\partial^{2} p}{\partial z^{2}}=\frac{a_{v}}{(1+e)} \cdot \frac{\partial \mathrm{p}}{\partial \mathrm{t}}
$$

Sejam $m_{v}:=\frac{a_{v}}{(1+e)}$ o coeficiente de compressibilidade volumétrica e $c_{v}:=\frac{k}{m_{v}}$ o coeficiente de adensamento do solo, obtém-se de (h) a expressão principal da teoria de adensamento 1D de Terzaghi que consiste numa equação diferencial para expressar a variação de pressão de fluído no solo ao longo do tempo e profundidade :

$$
\frac{\partial p}{\partial t}=c_{v} \cdot \frac{\partial^{2} p}{\partial z^{2}}, c_{v}:=\frac{k_{d}}{\gamma_{w} m_{v}}, m_{v}:=\frac{a_{v}}{(1+e)}(\text { Eq 2.1) }
$$

Historicamente na indústria do petróleo, a grandeza permeabilidade corresponde não a permeabilidade de Darcy $\left(k_{d}\right)$ mas sim a permeabilidade intrínseca $\left(\mathrm{k}_{\mathrm{i}}=\frac{\mathrm{k}_{\mathrm{d}} \cdot \mu_{\mathrm{f}}}{\gamma_{\mathrm{f}}}\right), \mu_{\mathrm{f}}$ é a viscosidade cinemática do fluido, de modo que o conceito de permeabilidade torna-se unicamente propriedade do meio e reduz-se a um fator geométrico que define a área de fluxo efetiva na escala dos poros.

É comum em textos relacionados a engenharia de petróleo encontrar a Equação 2.1 porém com o coeficiente $c_{v}=\frac{k_{i}}{\mu_{f} \cdot S_{1 D}}$ no qual $S_{1 D}=\frac{1}{V} \cdot \frac{\partial V_{f}}{\partial p}$ é o coeficiente de armazenamento unidimensional que representa num solo de volume total $\mathrm{V}$, a taxa de variação do volume de fluído $V_{f}$ no sistema com a variação de pressão do fluído $(p)$ para condição de contorno de uma compressão unidimensional. 
O experimento principal da teoria do adensamento de Terzaghi é representado na Figura 2.6, em que há um vaso de seção transversal $A$ com um medidor de pressão (nível de fluido) à esquerda e fechado por um êmbolo na sua porção superior. Dentro do vaso há uma mola e um líquido que preenche $o$ volume restante do mesmo. No instante inicial $t=0$ (Figura2.6a) a pressão do fluído é a hidrostática e no instante $t=0^{+}$(Figura 2.6 b) é aplicada uma tensão vertical orientada para baixo no êmbolo, desenvolvendo instantaneamente o excesso de pressão W/A no fluido. Com a abertura da válvula no êmbolo, permitindo a saída de fluído a uma taxa limitada, há a transferência de tensão do fluído para a mola, até o momento em que o excesso de pressão do fluído seja nulo e toda a força é suportada pela mola.
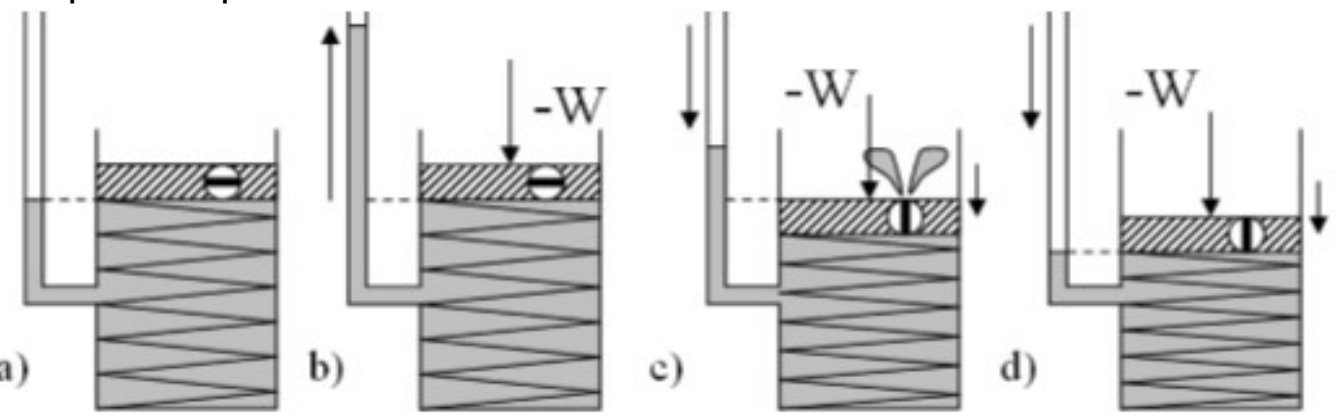

Figura 2.6: Experimento principal 1-D da Teoria de Terzaghi do

Adensamento

O experimento descrito acima elucida um importante conceito da poromecânica, conhecido como princípio das tensões efetivas e enunciado por Terzaghi na forma apresentada a seguir :

$$
\sigma_{i j}=\sigma_{i j}^{\prime}-p . \delta_{i j}
$$

em que $\delta_{i j}$ é o delta de Kronecker e a convenção de sinais é a de mecânica de solos. Segundo Terzaghi, a tensão total atuante em um solo $\left(\sigma_{i j}\right)$ é composta de duas parcelas: a tensão $\left(\sigma_{i j}^{\prime}\right)$ efetivamente atuante no arcabouço sólido - mola na Figura 2.6 e a pressão atuante no fluído que satura o meio poroso $(p)$. Terzaghi também assume que todos os efeitos mensuráveis resultantes de variações de tensões em solos, como compressão, distorção e resistência ao cisalhamento, são devidos a variações de tensões efetivas (Pinto, 2006), ou seja, somente variações 
nas tensões efetivas são capazes de provocar deformações no arcabouço sólido do solo.

Adotou-se a convenção de sinais da mecânica de solos em que pressão de fluído acima da pressão atmosférica é positiva.

Decorre da equação 2.2 , de Terzaghi, a linearidade do acoplamento hidromecânico, entre as tensões atuantes no arcabouço sólido e a pressão no fluído, bem como a atuação da pressão do fluído apenas na componente hidrostática $\left(\sigma_{m}\right)$ do tensor de tensões, mantendo inalteradas as tensões de cisalhamento. Skempton observou em laboratório que o cisalhamento também é afetado pela pressão do fluído e propôs nova expressão que diferente da Equação 2.2, relaciona a pressão do fluído com as tensões normal média $\left(\sigma_{m}\right)$ e cisalhante. Nos casos 1D e 2D o trabalho de Skempton conduz a teoria linear. Contudo a generalização para o caso 3D implica em acoplamento hidro-mecânico não-linear e foge do escopo deste trabalho.

A Teoria de Biot generaliza a teoria de adensamento de Terzaghi para o caso 3D e a partir da inclusão do fator poroelástico $\alpha_{B}$ (Biot e Willis, 1957) apresenta acoplamento hidromecânico linear entre tensões e pressão de fluído:

$$
\sigma_{i j}=\sigma_{i j}^{\prime}+\alpha_{B} \cdot p \cdot \delta_{i j}(\mathrm{Eq} 2.3)
$$

O parâmetro $\alpha_{B}$ representa a razão entre as deformações volumétricas do esqueleto poroso e total e pode ser obtido a partir da rigidez volumétrica drenada (módulo de compressibilidade volumétrica drenado $K_{B}$ ) do solo/rocha e da rigidez do arcabouço sólido $\left(K_{\min }\right)$ :

$$
\alpha_{B}=1-\frac{K_{B}}{K_{\min }} ; \emptyset_{e f f} \leq \alpha_{B} \leq 1
$$

em que $\emptyset_{\text {eff }}$ é a porosidade efetiva da rocha ou solo.

Nota-se que a Equação 2.2 proposta por Terzaghi é o caso particular da Equação 2.4 proposta por Biot e Willis para o qual $\alpha_{B}=1$, ou seja, arcabouço sólido incompressível. 
Embora a teoria de Terzaghi tenha sido amplamente empregada em Mecânica dos Solos e no estudo das tensões em solos saturados, é importante ter em mente as limitações que apresenta:

- Consideração do fluxo em apenas uma dimensão;

- Solo considerado totalmente saturado;

- Desacoplamento entre as deformações e poropressão;

- Consideração da tensão total constante durante o adensamento;

- Variação linear entre as tensões e índice de vazios;

- Comportamento elástico do solo.

\subsection{1}

\section{Hidrogeologia}

Há observações históricas de campo, de domínio público, referentes ao desenvolvimento da poromecânica em aquíferos. Estas vão desde a percepção de variação do nível d'água em poços, durante a passagem de trens carregados, próximos de linhas férreas até inexplicáveis volumes de água esgotados de poços sem que houvesse redução apreciável no nível d'água destes. Segundo (Wang 2000), três pesquisadores tiveram bastante influência no desenvolvimento da poromecânica na hidrogeologia:

- O. E. Meinzer, que em seu artigo "Compressibility and Elasticity of Artesian Aquifers" de 1928 atribuiu à deformabilidade do arenito Dakota a fonte de energia do aquífero responsável pelo volume de água bombeada para irrigação. Somente a recarga do aquífero por águas superficiais e compressibilidade da água sozinhas não conseguiam explicar os volumes produzidos. No artigo de Meinzer há menção explicita ao princípio das tensões efetivas de Terzaghi;

- Theis e o matemático Clarence Lubin desenvolveram a solução de Fluxo Transiente em Meio Poroso devido ao bombeio de água em poços através de analogias entre a teoria da poroelasticidade e da termoelasticidade; 
- Arnold Verruijt que em 1969 mostrou que a descrição mais geral do comportamento de aquíferos decorre da teoria de Biot-Willis

\subsection{2}

\section{Engenharia de Petróleo}

Segundo (Wang 2000), os seguintes trabalhos tiveram contribuição histórica no desenvolvimento da poromecânica em engenharia de petróleo:

- Muskat, empregado da Gulf Oil, desenvolveu soluções para a equação da difusividade durante a década de 1930. A equação da difusividade é resultado da combinação da equação da continuidade (conservação de massa) com uma lei de fluxo. Suas soluções analíticas consideravam a rocha como incompressível, hipótese aceita na época, e atribuía a energia do reservatório à compressibilidade do fluido, liberação de gás de dissolução e recarga por aquíferos;

- Jacob sugeriu em 1940 que a alta produtividade de alguns reservatórios seria devido à compressibilidade das rochas reservatório;

- Geertsma, empregado da Shell, que em 1969 relacionou as subsidências constatadas em jornais científicos de reservatórios com suas altas produtividades. Geertsma foi o primeiro a empregar o termo poroelasticidade para denominar o estudo de meios porosos saturados por fluídos.

\section{3}

\section{Casos Reais de Efeitos Geomecânicos em Reservatórios}

Nesta seção são discutidos tópicos da geomecânica de reservatórios mais relacionados à engenharia de petróleo e hidrogeologia. Além de introduzir 
os efeitos geomecânicos mais comumente observados na produção de reservatórios são também discutidos casos de domínio público e de ocorrência histórica com o intuito de melhor dimensionar a importância destes efeitos

\subsection{1}

\section{Compactação e Subsidência}

Denomina-se compactação ao deslocamento vertical que ocorre no reservatório e subsidência à manifestação deste deslocamento na superfície (fundo marinho, no caso de áreas offshore), como observa-se na (Figura 2.7). Esse deslocamento vertical pode estar associado, por exemplo, à remoção de hidrocarbonetos, à produção de água subterrânea ou a atividades de mineração.

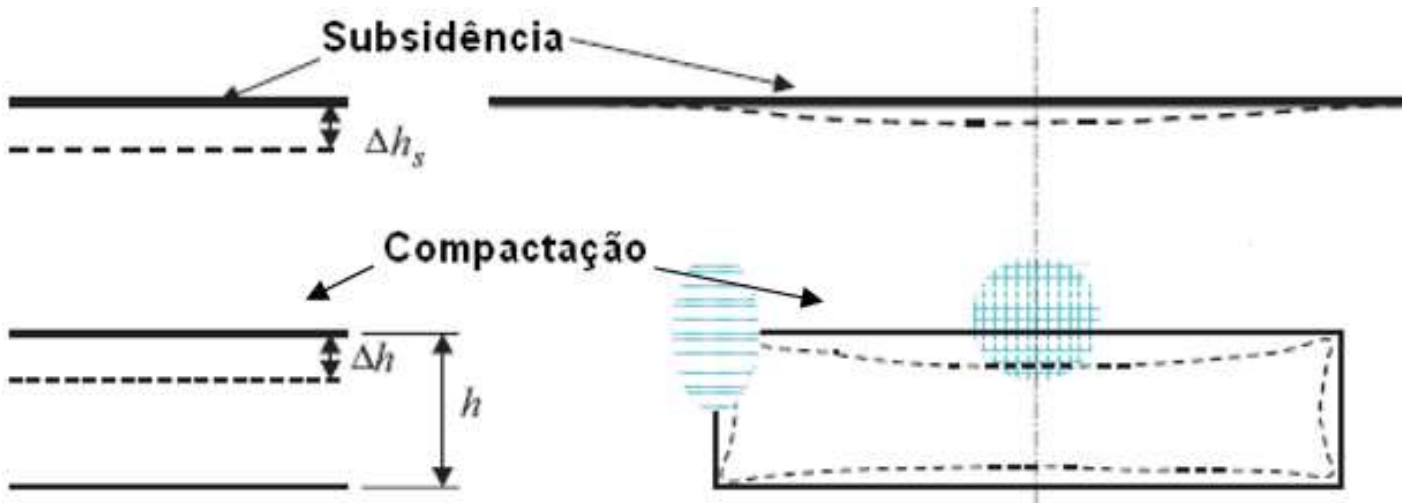

Figura 2.7: Subsidência do Leito Marinho e Compactação do Reservatório

Espera-se maior ocorrência de compactação e subsidência em rochas moles, de alta compressibilidade, pouco consolidadas, fraturadas, reservatórios carbonáticos tipo chalk e reservatórios naturalmente sobrepressurizados ou que serão severamente depletados.

Impactos associados com a subsidência do fundo do mar podem surgir nas linhas de produção. As linhas de escoamento, dispostas no leito marinho, podem atravessar zonas de excessiva tração e compressão gerando alta deformação ou mesmo ruptura dos dutos, requerendo a substituição ou manutenção das linhas de produção e escoamento. 
Impactos associados à compactação do reservatório podem se manifestar diretamente nos esforços para a produção de hidrocarboneto, como por exemplo: na estabilidade de poços e na deformação/rompimento de revestimentos em profundidade bem como diminuição da permoporosidade. É importante ter em mente que a compactação, vista como um grande desafio para a engenharia, pode contribuir com um acréscimo da energia de recuperação do reservatório.

No campo de Valhall, por exemplo, a compactação representou cerca de $50 \%$ da energia total do reservatório e no campo de Ekofisk, a estimativa inicial do impacto da compactação indicou um adicional de 243 milhões (BOE) até o fim do período de concessão em 2011. Uma última estimativa em 1998, com o impacto do enfraquecimento da rocha pela água indicou um adicional de 280 milhões (BOE), propiciando um adicional de energia até 2029 (Nagel, 2001).

O desenvolvimento de reservatórios com compactação é sempre mais complexo e requer melhor monitoramento. Estimativas imprecisas dos efeitos da compactação podem levar a uma sobre ou subestimativa de volume recuperável.

\subsection{2}

\section{Injeção Acima da Pressão de Fratura}

Após a produção primária, a injeção de água é um dos métodos mais utilizados, ainda nos estágios iniciais da vida produtiva, para manter a produção de reservatórios de petróleo.

É frequente, com o decorrer do processo de injeção de água, ocorrer queda do índice de injeção (II) devido a: propriedades mecânicas e de fluxo das rochas/fluídos, disposição da malha de drenagem dos poços injetores e produtores, precipitação de sais e presença de partículas sólidas na água de injeção. Uma medida largamente usada para evitar a perda de injetividade é a injeção controlada acima da pressão de fratura (De Souza 2005). 
A aplicação da técnica de injeção controlada acima da pressão de fratura, teoricamente, necessita de uma gama de parâmetros que controlam o processo de iniciação e propagação da fratura com o tempo.

Parâmetros empregados em modelos analíticos são exibidos na Tabela 2.1, que acoplam o fluxo de água e a fratura mecânica, amplamente divulgados desde 1985 até os dias atuais como os (De Souza 2005) e (Perkins 1985).

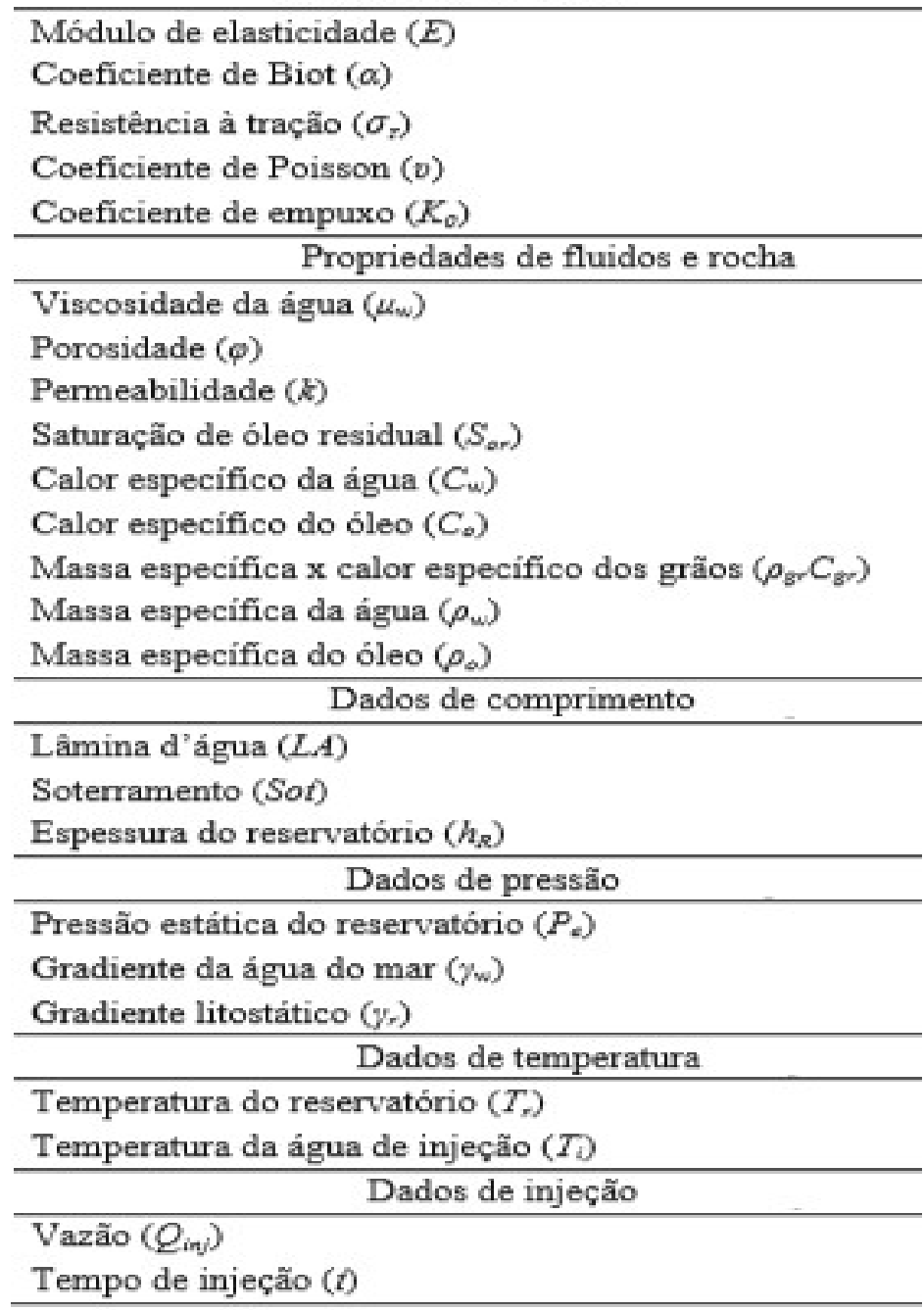

Tabela 2.1: Parâmetros de Modelo Analítico de Iniciação e Propagação de Fraturas

Dos parâmetros necessários na Tabela 1, constata-se que o conhecimento das propriedades mecânicas, térmicas e permo-porosas das rochas 
reservatório e capeadora, bem como do estado de tensões in-situ ( $\sigma_{1}$, $\sigma_{2}$ e $\sigma_{3}$ ) são de suma importância para o estudo do início e propagação de fraturas na formação. O papel do estado de tensões in-situ é ilustrado por um rápido argumento físico (Hubbert 1972):

- Fraturas hidráulicas em subsuperfície irão sempre se propagar perpendicularmente à direção da menor tensão principal porque o trabalho realizado para abertura da fratura é proporcional ao produto entre valor da tensão atuante perpendicular ao plano de fratura e o tamanho da abertura da fratura. As fraturas hidráulicas irão sempre se propagar perpendicular à direção da tensão principal mínima, pois esta é a direção que define a menor configuração de energia.

É preciso ter em mente que a técnica de injeção controlada acima da pressão de fratura além de contribuir para o aumento da transmissibilidade e produção pode provocar: chegada prematura da água por fraturas que sofreram modificações em sua transmissibilidade e o vazamento decorrente do fraturamento acidental do selo. O desenvolvimento de reservatórios que farão uso desta técnica é sempre mais complexo e requer mais monitoramento. Estimativas imprecisas durante a operação podem incorrer em perdas expressivas de volume recuperável além de risco ambiental.

\subsection{3}

\section{Reativação de Falhas}

O aumento da produção por injeção, dada a possibilidade de se obter expressivos aumentos da transmissividade e volume recuperado, faz parte do planejamento arrojado e representa uma atividade central em torno de estratégias de desenvolvimento da produção de muitos reservatórios. Nesta subseção trata-se da questão de reativação de falhas devido à injeção de fluidos a alta pressão, como complemento a questão da iniciação e propagação de fraturas na rocha intacta (subseção anterior - 2.3.2). 
Para as falhas geológicas selantes, ou seja, que comportam-se como selos naturais, impedem a migração ascendente de hidrocarbonetos e garantem o acúmulo destes na rocha, é crucial a correta compreensão dos limites hidráulicos do reservatório.

Planejamentos robustos de produção não devem permitir a reativação destas falhas, pois a perda da capacidade selante deve ser encarada como a perda descontrolada de fluidos com potenciais impactos nos custos de produção e ambiental.

Há também a possibilidade de comunicação entre diferentes blocos do reservatório, induzida pela ruptura do selo quando da reativação de falhas e, no pior cenário, comunicação do reservatório com a superfície.

Um grande desafio para a equipe de competências técnicas de reservatórios é, portanto, a estimativa da máxima pressão de injeção admissível visando o não comprometimento da capacidade selante de falhas e, ao mesmo tempo, elevar o fator de recuperação do campo.

O estudo do processo de reativação de falhas por meio de soluções analíticas e numéricas tem sido amplamente discutido na literatura Destaca-se o trabalho de (Teatini 2014) no qual foi simulado através de modelo de elementos finitos 3D: o deslocamento na superfície (subsidência), a reativação de falhas, bem como a possibilidade de ruptura mecânica e um possível colapso de poros tanto do reservatório quanto da capeadora para o caso de um reservatório off-shore profundo $(2000 \mathrm{~m}$ de profundidade), multi compartimentado, localizado na Bacia do Adriático e sujeito a injeção de $\mathrm{CO}_{2}$ por 10 anos. A partir deste trabalho concluiu-se que a avaliação do critério de Mohr-Coulomb e as propriedades geomecânicas das falhas geológicas são fatores muito importantes para uma correta previsão do comportamento mecânico de um reservatório pressurizado. Em soluções semi-analíticas do problema de reativação de falhas, foi mostrado que o potencial de reativação de falhas é dependente da geometria do reservatório e do ângulo de mergulho (dip) da falha geológica analisada (Soltanzadeh 2008).

Assim como na subseção anterior (2.3.1) uma dificuldade inerente ao problema de reativação de falhas é o enorme intervalo de variação dos parâmetros associados à zona de falha, tipicamente heterogênea. Além 
disso, é comum a completa ausência de dados experimentais confiáveis para caracterização dos materiais da zona de falha.

Uma boa estimativa do incremento de pressão de poros visando prevenir a reativação de falhas depende do estado de tensões in-situ e do fluxo de fluidos no meio poroso. A racional para estimar a máxima pressão de injeção no contexto da reativação de falhas geológicas envolve avaliar a variação da tensão efetiva, decorrente da produção ou injeção de líquido em um reservatório:

$$
\Delta \sigma_{i j}=\Delta \sigma_{i j}^{\prime}-\alpha_{B} \cdot \Delta p \cdot \delta_{i j}(\mathrm{Eq} 2.5)
$$

,ou seja, a variação da tensão total atuante na rocha $\left(\sigma_{i j}\right)$ é composta de duas parcelas: a variação da tensão efetivamente atuante no arcabouço sólido $\left(\sigma_{i j}^{\prime}\right)$ e a variação da pressão atuante no fluído que satura o meio poroso (p) ponderada pelo parâmetro de Biot-Willis $\left(\alpha_{B}\right)$.

O modelo constitutivo mecânico tipicamente empregado é o de MohrCoulomb, no qual a superfície de escoamento plástico pode ser expressa como:

$$
F_{\gamma}=\left(\sigma_{1}^{\prime}-\sigma_{3}^{\prime}\right)-\left(\sigma_{1}^{\prime}+\sigma_{3}^{\prime}\right) \cdot \sin \left(\Phi^{\prime}\right)-2 c^{\prime} \cdot \cos \left(\Phi^{\prime}\right)=0
$$

em que c' e $\Phi$ ' são, respectivamente, a coesão e ângulo de atrito efetivos referentes a falha.

O aumento da pressão do fluído $(\Delta p<0)$ induz um movimento progressivo do círculo de Mohr para a esquerda, podendo provocar ao escoamento plástico do material quando o círculo toca a superfície de escoamento (Figura 2.8), o que leva a reativação de falhas pré-existentes. 


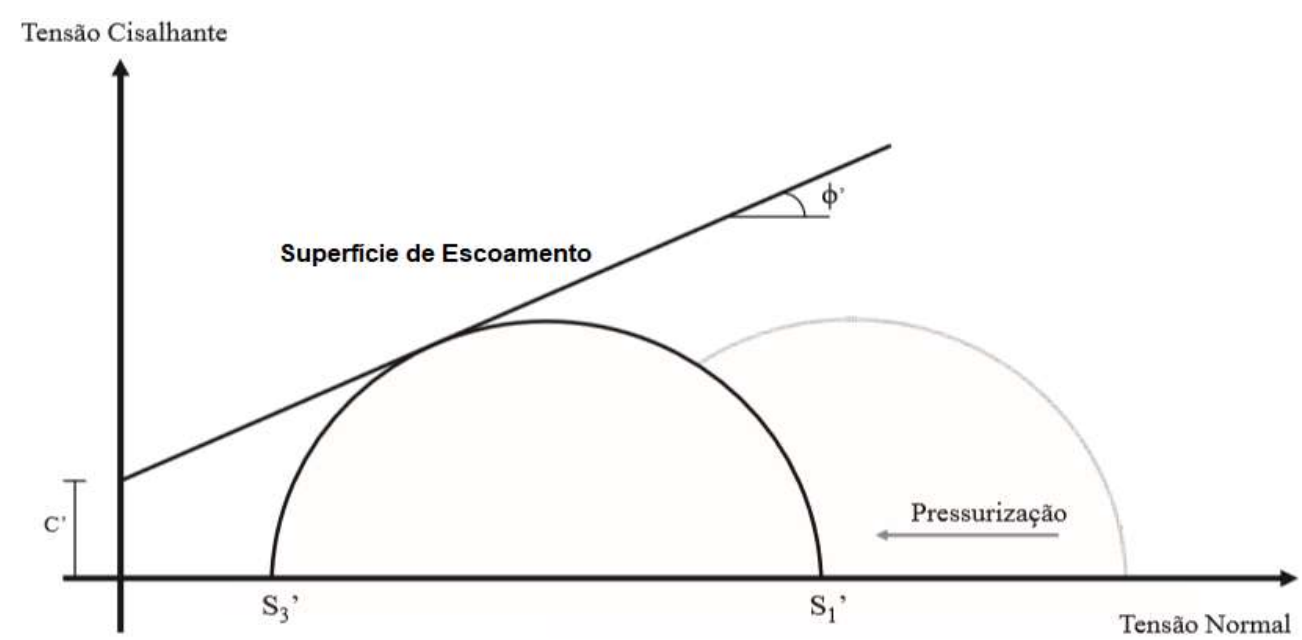

Figura 2.8: Superfície de Escoamento Plástico do Modelo Constitutivo de Mohr-Coulomb

Os parâmetros necessários para estimativa da pressão máxima de injeção para reativação de falhas $(\Delta p)$ considerando valores únicos para as propriedades de resistência e deformabilidade da falha são exibidos na Tabela 2.2

\begin{tabular}{l}
$\frac{\text { Dados Geomecânicos }}{\text { Coesão }\left(c^{\prime}\right)}$ \\
Coeficiente de Biot $(\alpha)$ \\
Ângulo de Atrito $\left(\varphi^{\prime}\right)$ \\
Tensão Total Principal Máxima $\left(S_{l}\right)$ \\
Tensão Total Principal Minima $\left(S_{3}\right)$ \\
\hline
\end{tabular}

Tabela 2.2: Parâmetros para Estimativa de $\Delta p$ Máxima de Reativação de Falhas

\subsection{4}

Injeção de $\mathrm{CO}_{2}$

A injeção $\mathrm{CO}_{2}$ em reservatórios de petróleo é um dos métodos normalmente usados para a recuperação secundária de óleo em reservatórios depletados pela produção primária e, possivelmente, onde a injeção de água não tem sido efetiva (Holm 1974). 
No processo WAG (Water Alternating Gas), a água é injetada no reservatório até que se recupere a pressão de fluído original e, em seguida $\mathrm{CO}_{2}$, é injetado no reservatório pelos mesmos poços injetores. No caso da injeção miscível de $\mathrm{CO}_{2}$ à medida em que o $\mathrm{CO}_{2}$ flui no reservatório uma zona de $\mathrm{CO}_{2}$ e hidrocarbonetos leves miscíveis formam uma frente de saturação solúvel ao óleo, tornando o óleo menos viscoso e, consequentemente, aumentando sua mobilidade em direção aos poços produtores. A produção é proveniente de uma frente de saturação solúvel ao óleo que propaga-se a partir dos poços injetores (Minssieux 1994)

Dependendo das propriedades dos fluidos no reservatório e da injeção de $\mathrm{CO}_{2}$, o deslocamento do óleo pode ser miscível ou imiscível.

$\mathrm{Na}$ injeção de $\mathrm{CO}_{2}$ imiscível há vantagens -- pressão requerida de injeção é menor, solventes mais baratos e, ainda assim, consegue-se aumentar o fator de recuperação do óleo.

$\mathrm{Na}$ injeção de $\mathrm{CO}_{2}$ miscível é necessário que, ao chegar no reservatório, a pressão do $\mathrm{CO}_{2}$ seja superior à pressão mínima de miscibilidade (PMM) dependente da temperatura e pressão do reservatório, bem como da pureza do solvente e do peso molecular dos componentes do óleo bruto. Nas condições de injeção miscível, o $\mathrm{CO}_{2}$ injetado atinge estado supercrítico e apesar de ter uma densidade equivalente a de líquido, sua viscosidade é como a de um gás em condições de reservatório e, por isso, é um solvente bastante eficiente (Holm 1974). A Figura 2.9 é uma representação do processo WAG. 

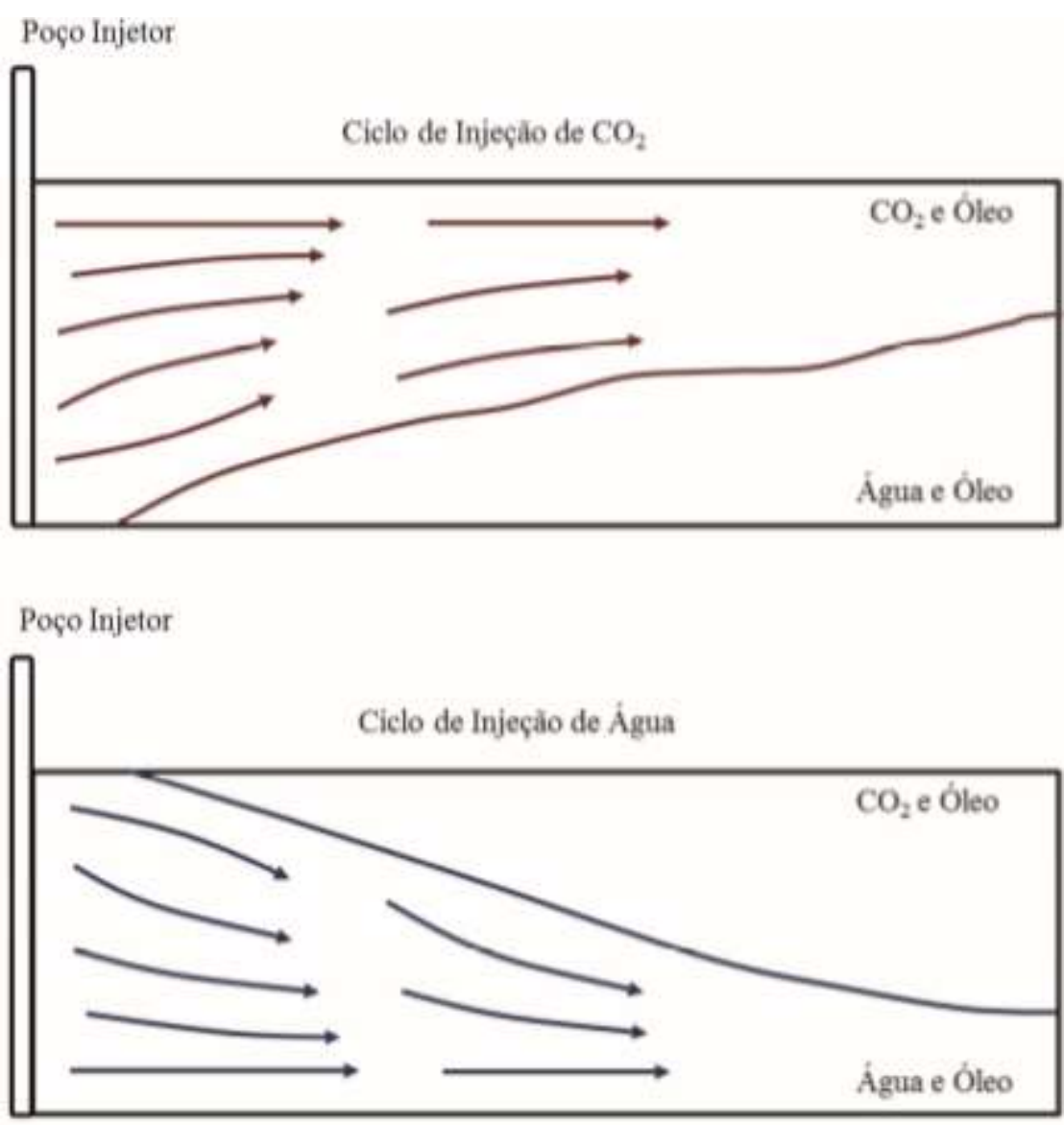

Figura 2.9: Ilustração de Fluxo de Fluídos no WAG

O método WAG de recuperação de petróleo apresenta interessantes características físico-químicas (Holm 1974), (Minssieux 1994), (Pegoraro 2012) :

- Deslocamento miscível. O solvente extrai componentes leves miscíveis do óleo até formar uma frente de fluído solúvel a este - o óleo agora menos viscoso terá mobilidade aumentada em direção aos poços produtores. Essa frente de saturação solúvel ao óleo pode inclusive ocorrer com o óleo residual, que se torna móvel.

- Inchamento da fase oleosa devido à solubilização do gás, que pode inclusive retardar a chegada (breakthrough) de gás. Este mecanismo ocorre mais em óleos subsaturados de gás. 
- Efeito de extração (stripping) de componentes leves mísciveis do óleo pelo solvente injetado. A importância do mecanismo de stripping pode ser avaliada experimentalmente através de análises cromatográficas do gás eluído.

- Redução da viscosidade do óleo, ajudando a aproximar as mobilidades do gás e do óleo.

- Alteração da permeabilidade absoluta e da resistência da rocha por efeitos de dissolução. Especificamente, no caso do $\mathrm{CO}_{2}$ em contato com água e injetado em rochas reativas (como por exemplo, rochas carbonáticas), existe um mecanismo adicional que é a alteração da permeabilidade da rocha. $\mathrm{O} \mathrm{CO}_{2}$ dissolvido na água gera ácido carbônico $\left(\mathrm{H}_{2} \mathrm{CO}_{3}\right)$, capaz de atacar os componentes presentes na rocha carbonática (calcita e dolomita). A partir de dados experimentais em escala de laboratório, foram encontrados aumentos de permeabilidade de até três vezes o valor inicial após o escoamento de cerca de oito volumes porosos de água carbonatada (Holm 1974). No campo, este aumento de permeabilidade seria mais notado nas proximidades dos poços injetores, pelo menos no início da injeção e caso nenhuma medida que impedisse o contato do $\mathrm{CO}_{2}$ com a água do ciclo anterior fosse tomada. Reduções da resistência de rochas carbonáticas por efeitos da dissolução (water weakening) foram discutidos por (Sylte 1999).

É necessário introduzir o conceito de modelagem acoplada hidromecânica e química em meios porosos para considerar o impacto da dissolução nas propriedades mecânicas (parâmetros de deformabilidade e resistência) que tendem a diminuir de valor - e de fluxo (porosidade e permeabilidade) que tendem a ter seus valores aumentados na quantificação dos efeitos da frente de saturação quando da injeção de $\mathrm{CO}_{2}$. Modelagens numéricas 
possuem um maior grau de refinamento para tratar tais efeitos e estão fora do escopo deste trabalho. É sugerido um cálculo simplificado e analítico (Nordbotten 2005), no qual se calcula a elevação do topo do reservatório em função do acréscimo de pressão exercido pela injeção de $\mathrm{CO}_{2}$ considerando o processo de dissolução. Tal exemplo reproduz o efeito do acoplamento hidromecânico e químico de forma simplificada, através de lei linear de aumento da porosidade em função do tempo de injeção e módulo de compressibilidade unidimensional (Young) sensível ao dano químico. A produção de petróleo tem implicado na compactação e subsidência de muitos campos no Mar do Norte, Venezuela e costa dos EUA. Desses casos de domínio público na indústria de petróleo, serão analisados os campos de Ekofisk, de Wilmington e de South Belridge.

\subsection{5}

\section{Campo de Ekofisk}

O campo de Ekofisk descrito em (Nagel 2001) é um reservatório carbonático tipo chalk localizado no setor Norueguês do Mar do Norte, naturalmente fraturado e sobrepressurizado. Possui área de 49 quilômetros quadrados, coluna de hidrocarboneto totaliza $305 \mathrm{~m}$ em algumas regiões, porosidade de aproximadamente 30 a $40 \%$, saturação inicial de água de aproximadamente $10 \%$, permeabilidade da matriz de aproximadamente 1 a $2 \mathrm{mD}$ e permeabilidade da fratura em torno de $50 \mathrm{mD}$.

A produção teve início em julho de 1971 com quatro poços produtores produzindo pelo mecanismo de gás em solução. A subsidência foi primeiramente observada em 1984, nessa época o leito marinho havia afundado aproximadamente três metros, em decorrência da compactação do reservatório devido à combinação de fatores como -- alta porosidade da rocha, grande área do campo, larga espessura do intervalo produtivo e declínio da pressão de fluídos do reservatório (Nagel 2001).

Com o objetivo de reestabelecer a pressão de fluídos original do reservatório e assim dimimuir a taxa de subsidência, em 1987 houve o início da injeção de água, porém em escala limitada. Nesta época o governo norueguês pressionou a Phillips Petroleum Company- já no final 
do período de concessão da área - a agir, e a empresa francesa Technip foi contratada para encontrar uma solução à subsidência que já alcançava aproximadamente seis metros e tornava as plataformas não seguras.

Foi então iniciado um megaprojeto de engenharia que consistiu em levantar seis metros verticalmente para cima e ao mesmo tempo as 5 plataformas interligadas do complexo.

A operação consistiu em estender as pernas tubulares de aço das plataformas. Grandes flanges foram soldados a essas pernas e uma vez que todos os flanges estivessem soldados e a parte inferior das pernas cortadas, as 5 plataformas foram içadas simultaneamente. Em seguida tubos de extensão foram conectados aos flanges finalizando a operação e deixando as plataformas seguras novamente.

A arriscada operação de levantamento durou quatro dias e foi concluída em 17 de Agosto de 1987 às 11:30 p.m. Foram usados cerca de 108 cilindros hidráulicos sincronizados e gastos cerca de U\$ 1 bilhão. A capacidade total de levantamento de todos esses cilindros hidráulicos era de aproximadamente 40.000 tons e a operação foi publicada no Guinness World Records como o maior levantamento da história.

No início de 1994, após a implementação de um rígido programa de gerenciamento de reservatórios, a injeção de água aumentou o suficiente para estabilizar a pressão do reservatório, no entanto, não foi observada redução na taxa de subsidência - o fundo do mar continuava a rebaixar. Observações de campo e laboratório, levaram a conclusão de que a água estava enfraquecendo quimicamente o reservatório chalk. Com a chegada da água injetada - que reestabelece ou até mesmo aumenta a pressão de fluídos no reservatório - e leva a diminuição da tensão efetiva e subsidência, dá-se também o enfraquecimento químico do chalk e logo, aumento da subsidência.

Pesquisas e experimentos de laboratório, permitiram concluir que a injeção de água em certos tipos de reservatório pode diminuir os módulos de compressibilidade da rocha devido à interação entre a água e a calcita, modificando a relação grão a grão, facilitando a rotação e a translação entre eles, reduzindo a resistência mecânica da rocha a compactação bem como sua rigidez. 
A contínua subsidência após o início de 1994, em combinação com dados do campo e de laboratório, indicou que o fenômeno de enfraquecimento da rocha pela água se tornará o principal mecanismo de compactação do campo, sendo este fenômeno conhecido por compactação química.

Não é incomun encontrar-se hoje o entendimento de que em Ekofisk, a subsidência foi dominada pelo efeito do decréscimo da pressão de fluídos do reservatório chalk até o início dos anos 1990 e depois disso pela compactação química em decorrência da água injetada.

Assim, a taxa de subsidência de Ekofisk aumentou do início de 1990 de 25 $\mathrm{cm} /$ ano para um pico de $42 \mathrm{~cm} / \mathrm{ano} \mathrm{em} \mathrm{1993}$. Com o reestabelecimento da pressão de fluídos no reservatório a partir do início de 1994, a subsidência diminuiu para $35 \mathrm{~cm} / a n o$, mas ao invés da taxa continuar declinando, esta teve um aumento estabilizando em $38 \mathrm{~cm} /$ ano em 1998, acumulando um total de aproximadamente $7,8 \mathrm{~m}$ de subsidência até 1999, conforme apresentado em (Nagel 2001).

Ekofisk é suposto produzir pelo menos até 2050 e a questão da compactação e subsidência do reservatório é ainda um problema em função do tipo de reservatório (chalk) e uma das questões mais complexas a ser tratada pelo programa de gerenciamento de reservatórios da área.

A Figura 2.10 mostra uma fotografia com zoom em uma das plataformas fixas de Ekofisk em meados de 1973 e 1986. Claramente pode-se observar que o número de buracos na parede de proteção ao redor da plataforma diminuiu. A perda de espaço livre decorrente da subsidência do fundo marinho, levou à redução da segurança das operações na plataforma sendo necessários intervenção governamental e megaprojeto de engenharia - com altos riscos e custos - para o reestabelecimento da segurança. 


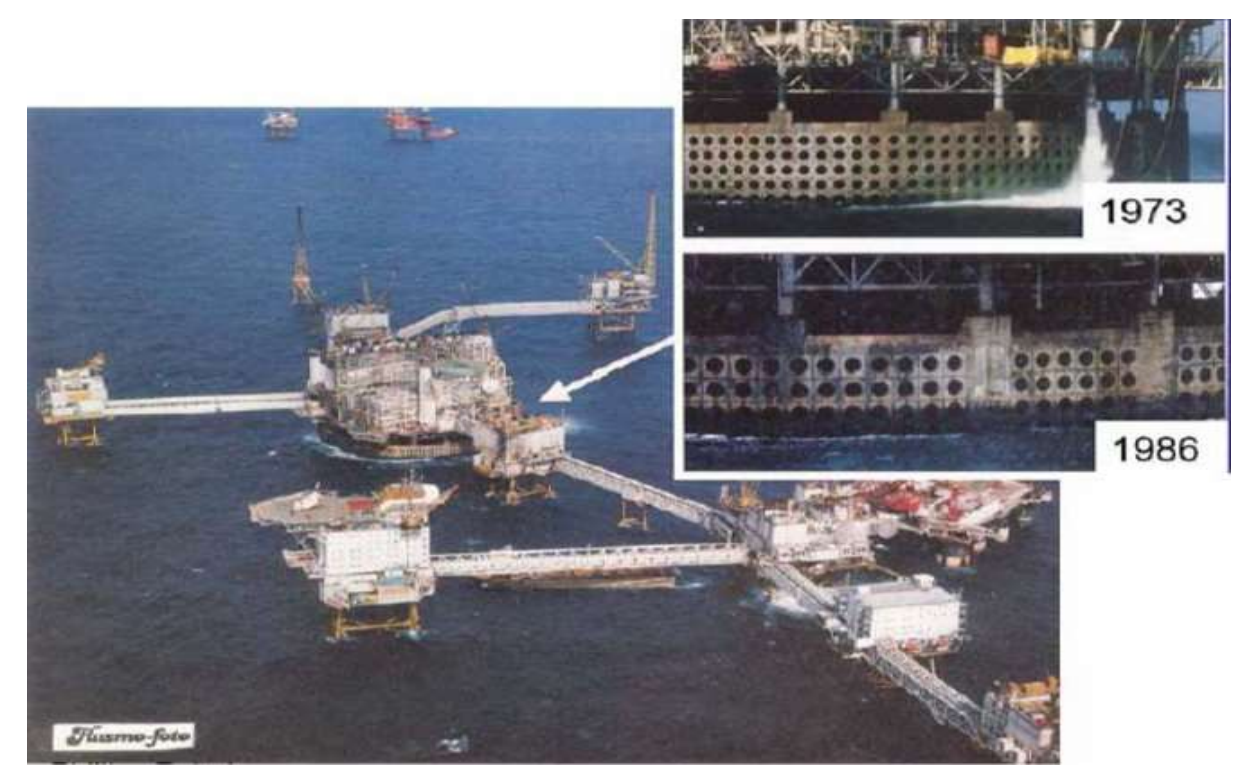

Figura 2.10: Redução de espaço em plataforma por subsidência em

Ekofisk

\subsection{6}

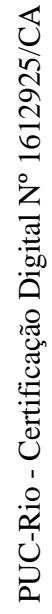

\section{Campo de Wilmington}

Campo descoberto em 1932, localizado no Estado da Califórnia, EUA, perto de Los Angeles. O reservatório é composto por arenitos do Plioceno e Mioceno de elevada porosidade aproximadamente 33-37 \% em profundidades de $800 \mathrm{~m}$ a $1900 \mathrm{~m}$. A produção iniciou-se em 1936, e a

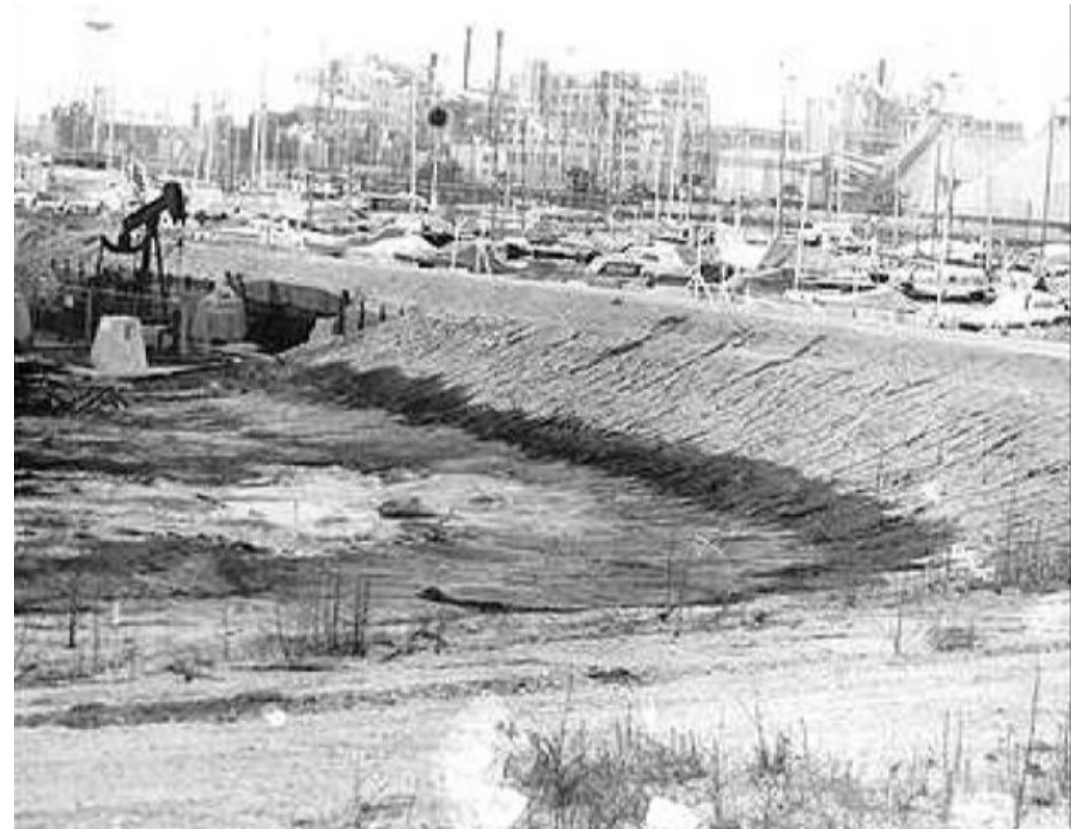

Figura 2.11: Subsidência em Wilmington Field, Long Beach 
subsidência foi detectada em 1940 dentro do perímetro da praia Long Beach Naval, causando sérios danos ao estaleiro próximo e nas regiões ao redor da cidade (Figura 2.11). Como resultado da subsidência, estritas regulamentações na operação do campo foram decretadas. A companhia THUMS, a qual opera a parte sul do campo, foi obrigada a assinar um contrato com a cidade de Long Beach do Estado da Califórnia comprometendo-se a manter a injeção de água em $105 \%$ da produção para prevenir a subsidência. A injeção de água no campo de Wilmington teve início em 1958 quando a taxa de subsidência estava em aproximadamente $38 \mathrm{~cm} /$ ano, chegando a aproximadamente $9.5 \mathrm{~m}$ metros em 1968. Com a injeção de água, em 1996 a taxa de subsidência já estava aproximadamente zero. Entretanto, os custos decorrentes, excediam em 100 Milhões de dólares, em 1970 (Nagel 2001).

Foram detectados também 5 terremotos rasos de grande intensidade no campo, provavelmente associados a: reativação de falhas, fraturamento da formação e compactação antes que sismos naturais e que provocaram mais de 500 casos de danos mecânicos nos revestimentos dos poços e deslocamento de cisalhamento horizontal de até $22 \mathrm{~cm}$.

\subsection{7}

\section{Campo de South Belridge}

Localizado na Califórnia, é um reservatório arenito inconsolidado, com espessura variando de 122 a $183 \mathrm{~m}$, possuindo formações subjacentes de 305 m de espessura e altamente compressíveis. Em meados de 1980, operadores detectaram danos em revestimento e rupturas em poços. Em 1987, após uma forte tempestade, foi observado fissuras na superfície ao norte do campo, onde tais fissuras estavam orientadas aproximadamente paralelas à orientação da tensão horizontal máxima. Suspeitou-se que tais danos e fissuras eram resultantes da compactação do reservatório e da subsidência do leito marinho (Hansen 1993).

Além do impacto na superfície do fundo do mar, a compactação e a subsidência podem afetar diretamente os esforços para a produção de 
hidrocarboneto. Como exemplo pode-se citar a deformação e ou ruptura dos revestimentos de poços, a qual pode ser inicialmente detectada quando as ferramentas de operação a cabo não conseguem ser descidas ao longo do interior do poço. Necessitando em alguns casos da perfuração de poços de desvio (sidetrack). No campo de Belridge, a deformação de revestimentos tornou-se um problema tão severo que em meados de 1980, $15 \%$ a $20 \%$ dos revestimentos estavam sofrendo ruptura por ano.

Com isso, apesar dos grandes esforços para reduzir a taxa de compactação, esforços também vem sendo desenvolvidos para evitar a deformação de revestimentos. Assim como a utilização de juntas telescópicas para reduzir deformações axiais. Ou até a utilização de linhas e revestimentos pesados, visando estender a vida útil do poço, mas de sucesso limitado.

\section{4}

\section{Modelos Constitutivos}

Modelos Constitutivos são um conjunto de relações - denominadas equações constitutivas - entre as variáveis que caracterizam um sistema físico por exemplo: pressão, volume, tensão, deformação, temperatura, densidade e entropia, em seus mais variados estados.

Tais relações não são deriváveis de nenhuma lei física de conservação ou príncipio mais fundamental e são historicamente obtidas a partir de direta observação experimental do fenômeno, donde fica evidente seu caráter fenomenológico (dados experimentais aliados a um modelo mental não refutado) e empírico (dados experimentais aliados a ajuste estatístico).

Para o uso em geotecnia e de maneira mais ampla em engenharia civil, os modelos constitutivos compõem-se de equações que relacionam o campo de tensões e deformações.

Para um material que esteja em regime elástico e linear, regime este por vezes interessante em termos de aplicações práticas, as equações constitutivas para pequenas deformações ( menores que 3\%) tomam a forma da Lei de Hooke. As quatro variáveis básicas da poroelasticidade podem ser agrupadas em: 
- Tensões $(\boldsymbol{\sigma})$ e Deformações $(\boldsymbol{\varepsilon})$

- Poropressão (p) e Variação da quantidade de água (ろ)

Tensões e deformações são grandezas tensoriais e em função de suas simetrias, decorrentes do princípio de conservação de energia, cada um destes tensores num espaço 3D pode ser definido por seis componentes. Poropressão e variação na quantidade de água são grandezas escalares. As variáveis $\boldsymbol{\varepsilon}$ e $\zeta$ são as duas variáveis cinemáticas da teoria da poroelasticidade e, portanto, estão associadas a geometria e movimento. Os componentes do tensor de deformação no regime de pequenas deformações são derivadas espaciais dos deslocamentos $(u, v, w)$ respectivamente nas direções $(x, y, z)$ - e $\zeta$ está associada ao fluxo do fluído. As variáveis $\boldsymbol{\sigma}$ e $\boldsymbol{p}$ são as duas variáveis dinâmicas da teoria da poroelasticidade e representam as forças que causam o movimento.

Essas quatro variáveis podem ser combinadas gerando diferentes estratégias de formulação baseadas em combinar variáveis do problema mecânico $(\boldsymbol{\sigma}$ e $\boldsymbol{\varepsilon})$ com uma das variáveis do problema de fluxo ( $p$ e $\zeta$ ) e, em seguida, fazer a combinação da variável de fluxo restante com uma das variáveis do problema mecânico.

A formulação aqui adotada remete a técnica de permutação entre estas 4 variáveis denominada Mixed Stiffness (Wang, 2000) e baseia-se em tratar as tensões e a quantidade de água como variáveis dependentes e exprimilas em termos de deformações e poropressão tratadas como variáveis independentes. Para facilitar o entendimento, antes de desenvolver as equações constitutivas gerais baseadas na poroelasticidade linear, seguiremos inicialmente com as equações constitutivas apenas da parte mecânica do problema i.e, na ausência de fluído (rocha seca ou drenada). Para tanto, considera-se inicialmente um elemento cúbico de solo/rocha seca (Figura 2.12) cujos lados são paralelos aos eixos coordenados e suficientemente pequenos se comparados à dimensão macroscópica do problema, podendo ser assumido em termos matemáticos como um elemento infinitesimal, porém cujas dimensões são suficientemente grandes quando comparadas aos poros existentes, de forma que o 
solo/rocha pode ser considerado um material homogêneo no interior do elemento cúbico.

A Figura 2.12 ilustra as tensões totais $\left(\sigma_{\mathbf{i j}}\right)$ atuantes neste elemento de solo em que $\boldsymbol{\sigma}_{\mathbf{i j}}$ representa a tensão total atuante na face i segundo a direção j sendo o mesmo válido para as deformações $\boldsymbol{\varepsilon}_{\mathbf{i j}}$.

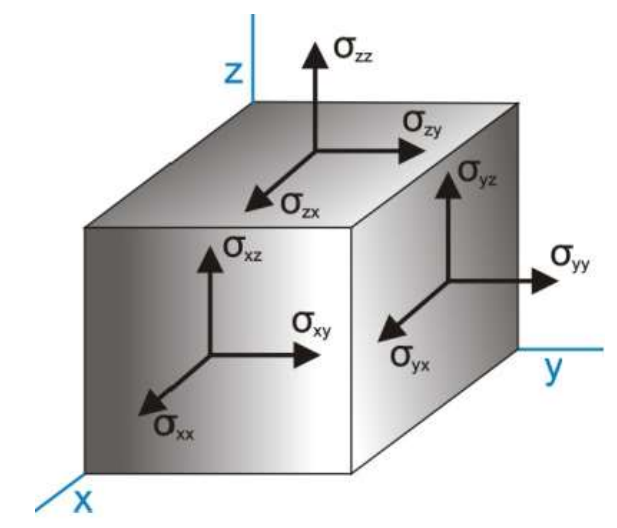

Figura 2.12: Infinitésimo de Volume com Eixos Orientados e Tensões

O estado de tensões e deformações totais em um ponto no interior do elemento é dado por:

$$
\sigma=\left[\begin{array}{lll}
\sigma_{x x} & \tau_{x y} & \tau_{x z} \\
\tau_{y x} & \sigma_{y y} & \tau_{y z} \\
\tau_{z x} & \tau_{z y} & \sigma_{z z}
\end{array}\right] \quad \varepsilon=\left[\begin{array}{lll}
\varepsilon_{x x} & \varepsilon_{x y} & \varepsilon_{x z} \\
\varepsilon_{y x} & \varepsilon_{y y} & \varepsilon_{y z} \\
\varepsilon_{z x} & \varepsilon_{z y} & \varepsilon_{z z}
\end{array}\right]
$$

Ambos os tensores são simétricos, possuem 6 componentes independentes cada, e segundo a hipótese de pequenos deslocamentos, pode-se expressar:

$$
\begin{array}{ll}
\varepsilon_{x x}=\frac{\partial u}{\partial x} & \varepsilon_{x y}=\frac{1}{2}\left(\frac{\partial u}{\partial y}+\frac{\partial v}{\partial x}\right) \\
\varepsilon_{y y}=\frac{\partial v}{\partial y} & \varepsilon_{x z}=\frac{1}{2}\left(\frac{\partial u}{\partial z}+\frac{\partial w}{\partial x}\right) \\
\varepsilon_{z z}=\frac{\partial w}{\partial z} & \varepsilon_{y z}=\frac{1}{2}\left(\frac{\partial v}{\partial w}+\frac{\partial z}{\partial y}\right)
\end{array}
$$

Em que $\vec{L}=(\mathrm{u}, \mathrm{v}, \mathrm{w})$ são os respectivos deslocamentos nas direções $(\mathrm{x}, \mathrm{y}, \mathrm{z})$. $\sigma_{i i}$ e $\varepsilon_{i i}$ são as tensões e deformações normais (ao longo das direções cartesianas) . 
$\tau_{i j}$ e $\varepsilon_{i j}(\mathbf{i} \neq j)$ são as tensões e deformações cisalhantes e relacionamse às distorções angulares $\boldsymbol{\gamma}$ do elemento.

Pode-se escrever de maneira mais compacta:

$$
\varepsilon_{i j}=\frac{1}{2}\left(\partial_{j} L_{i}+\partial_{i} L_{j}\right)
$$

define-se também a distorção angular $\boldsymbol{\gamma}$ :

$$
\gamma_{i, j}=\left(\partial_{j} L_{i}+\partial_{i} L_{j}\right)=2 \cdot \varepsilon_{i j},(i \neq j)
$$

A tensão de cisalhamento relaciona-se com a força aplicada paralelamente a uma superfície, com o objetivo de causar o deslizamento de planos paralelos uns em relação aos outros Figura 2.13.

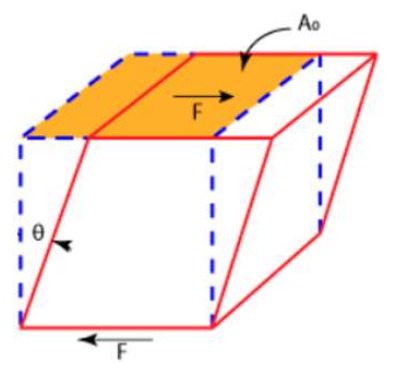

Figura 2.13: Infinitésimo de Volume com Aplicação de Tensão Cisalhante

No caso, a distorção angular, será a tangente do ângulo $\theta$ na Figura 2.13

\subsection{1}

\section{Equações Constitutivas na Ausência de Fluído}

Muitos materias de uso prático tem a capacidade de voltar a seu estado anterior mediante deformações produzidas por uma força menor que um dado valor (limite de escoamento elástico) - tal capacidade é chamada elasticidade (Fjaer 2008).

A teoria da elasticidade foi iniciada por Robert Hooke, no ano de 1660, quando este postulou uma relação linear entre a tensão aplicada sobre uma mola e a elongação gerada (Selvadurai 2000).

$\mathrm{Na}$ elasticidade linear, é importante definir-se alguns parâmetros a serem utilizados: 
- Módulo de Elasticidade (E) ou Módulo de Young: Num dado plano é definido como a razão entre a tensão axial aplicada e a deformação axial produzida neste plano, em condição de carregamento uniaxial com confinamento atmosférico

$$
\mathrm{E}:=\frac{\sigma_{\text {axial }}}{\varepsilon_{\text {axial }}}
$$

- Coeficiente de Poisson (v): Num dado plano é definido como a razão entre a deformação radial e a deformação axial neste plano, em condição de carregamento uniaxial com confinamento atmosférico. É posto o sinal negativo para tornar $\mathbf{v}$ não-negativo uma vez que na quase totalidade dos materiais estas deformações terão sinais opostos.

$$
\mathbf{v}:=-\frac{\varepsilon_{\text {radial }}}{\varepsilon_{\text {axial }}}
$$

- Módulo de Compressão Volumétrica ou Módulo Bulk $\left(\mathbf{K}_{\mathbf{B}}\right)$ : É definido como a razão entre a tensão média $\left(\sigma_{m}\right)$ e a deformação volumétrica $\left(\boldsymbol{\varepsilon}_{\mathrm{v}}\right)$.

$$
K_{B}:=\left(\frac{\sigma_{\mathrm{m}}}{\varepsilon_{\mathrm{v}}}\right)=\left(\frac{\sigma_{\mathrm{xx}}+\sigma_{\mathrm{yy}}+\sigma_{\mathrm{zz}}}{3 .\left(\varepsilon_{\mathrm{xx}}+\varepsilon_{\mathrm{yy}}+\varepsilon_{\mathrm{zz}}\right)}\right)
$$

- Módulo de deformação cisalhante (G): Num plano i, é definido como a razão entre a tensão cisalhante e a decorrente deformação cisalhante na mesma direção.

$$
G_{i j}:=\frac{1}{2}\left(\frac{\tau_{i j}}{\varepsilon_{i j}}\right)=\left(\frac{\tau_{i j}}{\gamma_{i j}}\right)(i \neq j)
$$

As equações constitutivas 3D da elasticidade linear que relacionam tensões e deformações, para solos/rochas secas, devem ter a seguinte forma da Lei de Hooke:

$$
\{\varepsilon\}_{6 \times 1}=\{D\}_{6 \times 6} \cdot\{\sigma\}_{6 \times 1}
$$

Por relacionar dois tensores de $2^{\circ}$ ordem $\left(\boldsymbol{\sigma}\right.$ e $\varepsilon$ ), o operador $\mathbf{D}$ é de $4^{\circ}$ ordem, tem 36 componentes e é chamado matriz de elasticidade.

Será considerado também que tensões normais relacionam-se apenas com deformações normais e tensões cisalhantes relacionam-se apenas com 
distorções angulares, de modo que $\mathrm{D}$ possuirá apenas 12 componentes e tem a forma (Eq 2.11) (Goodman 1989):

$$
\left\{\begin{array}{l}
\varepsilon_{x x} \\
\varepsilon_{y y} \\
\varepsilon_{z z} \\
\gamma_{x y} \\
\gamma_{y z} \\
\gamma_{z x}
\end{array}\right\}=\left[\begin{array}{cccccc}
\frac{1}{E_{x}} & -\frac{v_{y x}}{E_{y}} & -\frac{v_{z x}}{E_{z}} & 0 & 0 & 0 \\
-\frac{v_{x y}}{E_{x}} & \frac{1}{E_{y}} & -\frac{v_{z y}}{E_{z}} & 0 & 0 & 0 \\
-\frac{v_{x z}}{E_{x}} & -\frac{v_{y z}}{E_{y}} & \frac{1}{E_{z}} & 0 & 0 & 0 \\
0 & 0 & 0 & \frac{1}{G_{x y}} & 0 & 0 \\
0 & 0 & 0 & 0 & \frac{1}{G_{y z}} & 0 \\
0 & 0 & 0 & 0 & 0 & \frac{1}{G_{z x}}
\end{array}\right\}\left\{\begin{array}{c}
\sigma_{x x} \\
\sigma_{y y} \\
\sigma_{z z} \\
\tau_{x y} \\
\tau_{y z} \\
\tau_{z x}
\end{array}\right\}
$$

A matriz $\mathbf{D}$ da Equação 2.11 pelo príncipio de conservação de energia, é simétrica i.e, $\left(\frac{v_{i j}}{E_{i}}=\frac{v_{j i}}{E_{j}}\right)$, e o número de componentes reduz-se para 9 .

Em muitas aplicações práticas, os materiais possuem graus de simetria adicionais o que permite a redução do número de componentes de $\mathbf{D}$.

Materiais importantes do ponto de vista prático e com graus de simetria são os: ortotrópicos, transversalmente isotrópicos e totalmente isotrópicos.

Materiais ortotrópicos são aqueles cujas propriedades mecânicas são únicas e dependem das direções em que são observadas. São necessários 9 componentes para caracterizá-los (matriz D da Eq 2.11).

Materiais transversalmente isotrópicos é o caso especial de materiais ortotrópicos que apresentam as mesmas propriedades num plano de isotropia, as quais variam em uma direção normal a este plano Para um eixo-j de simetria, i.e plano-j de isotropia do material, é válido:

$$
G_{i j}=\frac{1}{2}\left(\frac{E_{i i}}{1+v_{i j}}\right)(\mathbf{i} \neq j)
$$

como complemento à Eq 2.11 e o número de componentes de $\mathbf{D}$ é ainda menor : 5 .

Admitindo o eixo vertical $z$ de simetria, i.e o plano $z$ é um plano de isotropia, a matriz $\mathbf{D}$ (Eq 2.11) assume a seguinte forma para um material transversalmente isotrópico: 


$$
\left\{\begin{array}{l}
\varepsilon_{x x} \\
\varepsilon_{y y} \\
\varepsilon_{z z} \\
\gamma_{x y} \\
\gamma_{y z} \\
\gamma_{z x}
\end{array}\right\}=\left[\begin{array}{cccccc}
\frac{1}{E_{x}} & -\frac{v_{y x}}{E_{y}} & -\frac{v_{z x}}{E_{z}} & 0 & 0 & 0 \\
-\frac{v_{y x}}{E_{y}} & \frac{1}{E_{y}} & -\frac{v_{z y}}{E_{z}} & 0 & 0 & 0 \\
-\frac{v_{z x}}{E_{z}} & -\frac{v_{z y}}{E_{z}} & \frac{1}{E_{z}} & 0 & 0 & 0 \\
0 & 0 & 0 & \frac{1}{G_{x y}} & 0 & 0 \\
0 & 0 & 0 & 0 & 2\left(\frac{1+v_{y z}}{E_{y}}\right) & 0 \\
0 & 0 & 0 & 0 & 0 & \frac{1}{G_{z x}}
\end{array}\right]\left\{\begin{array}{l}
\sigma_{x x} \\
\sigma_{y y} \\
\sigma_{z z} \\
\tau_{x y} \\
\tau_{y z} \\
\tau_{z x}
\end{array}\right\}
$$

E as variáveis necessárias para montar a matriz $\mathbf{D}$ (Eq 2.12) são 5 :

$$
\begin{gathered}
\boldsymbol{E}_{\|}=E_{z} \quad ; \quad \boldsymbol{E}_{=}=E_{x}=E_{y} \\
\boldsymbol{v}_{\|}=v_{y z}=v_{x z} ; \quad \boldsymbol{v}_{=}=v_{y x}=v_{z x}=v_{z y}=v_{x y} \\
\boldsymbol{G}_{=}=G_{x y}=G_{z x}
\end{gathered}
$$

Os componentes ( $\|$ ) atuam na direção do eixo transverso de simetria e os $(=)$ atuam nas direções ortogonais ao eixo de simetria.

Adicionando um eixo a mais de simetria, constituindo portanto 2 eixos de simetria (2 planos de isotropia), o número de variáveis necessárias para montar a matriz D reduz-se ainda mais: 2. A matriz D (Eq 2.13) neste caso é idêntica a de materiais totalmente isotrópicos mecanicamente, aqueles cujas propriedades mecânicas independem se tomadas ao longo de qualquer das 3 direções coordenadas (x, y e z).

$$
\left\{\begin{array}{l}
\varepsilon_{x x} \\
\varepsilon_{y y} \\
\varepsilon_{z z} \\
\gamma_{x y} \\
\gamma_{y z} \\
\gamma_{z x}
\end{array}\right\}=\left[\begin{array}{cccccc}
\frac{1}{E} & -\frac{v}{E} & -\frac{v}{E} & 0 & 0 & 0 \\
-\frac{v}{E} & \frac{1}{E} & -\frac{v}{E} & 0 & 0 & 0 \\
-\frac{v}{E} & -\frac{v}{E} & \frac{1}{E} & 0 & 0 & 0 \\
0 & 0 & 0 & 2\left(\frac{1+v}{E}\right) & 0 & 0 \\
0 & 0 & 0 & 0 & 2\left(\frac{1+v}{E}\right) & 0 \\
0 & 0 & 0 & 0 & 0 & 2\left(\frac{1+v}{E}\right)
\end{array}\right]\left\{\begin{array}{l}
\sigma_{x x} \\
\sigma_{y y} \\
\sigma_{z z} \\
\tau_{x y} \\
\tau_{y z} \\
\tau_{z x}
\end{array}\right\}
$$

Seja disponível no laboratório, um bloco ou testemunho de sondagem de um maciço rochoso seco. Munidos de equipamentos de usinagem como: furadeiras, serradeiras e lixadeiras pode-se fazer a retífica de corpos de prova o mais cilíndricos e simétricos possível - cada uma deles considerados homogêneos e isotrópicos por simplicidade. 
Será escolhido um destes corpos de prova para fazer um ensaio uniaxial de compressão simples (Figura 2.14). Os ensaios mecânicos devem obedecer um conjunto de normativos, como exemplo destacam-se as normas da ISRM (International Society for Rock Mechanics).

A padronização dos experimentos nas suas diversas etapas, como a questão das dimensões da amostra e da aplicação da carga possibilitam, em princípio, a troca de informação pelos grupos de pesquisa em nível global e a compreensão do conteúdo produzido por toda a comunidade científica.

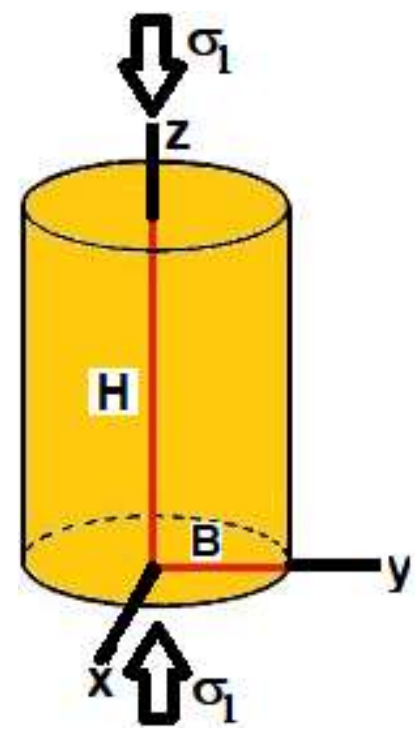

Figura 2.14: Ensaio de Compressão Simples em Corpo de Prova Cilíndrica

É indicado pela ISRM que as dimensões da amostra (Figura 2.14) devem satisfazer:

$$
2 \leq \frac{H}{B} \leq 3
$$

Mais comumente usa-se: $\mathrm{H}$ de aproximadamente 4 polegadas e $\mathrm{B}$ de aproximadamente 1,5 polegadas.

As prensas que aplicam o carregamento à amostra devem ser de material altamente rígido, em geral emprega-se o aço.

O aço e a amostra submetidos a mesma tensão ( $\sigma_{1}$ na Figura 2.14), por apresentarem diferentes coeficientes de poisson, tenderão a se deformar lateralmente em quantidades distintas o que faz surgir - uma vez que 
estamos interessados apenas na compressão simples - tensões cisalhantes indesejadas nas bordas da amostra.

Considera-se que o meio da amostra que satisfaz a (Eq 2.14) esteja consideravelmente a salvo de efeitos indesejáveis nas bordas, o que justifica o uso nessa porção do corpo de prova dos equipamentos de medidas extensiométricas (strain gauge e clip gauge) durante a realização do ensaio. Neste sentido vê-se a importância da Eq 2.14 -- amostras muito curtas i.e, $\frac{H}{B}<2$, podem ser demasiado contaminadas por efeitos de borda, enquanto que amostras muito longas, i.e $\frac{H}{B}>3$, podem vir apresentar efeitos de flambagem/encurvadura o que também não é desejável num ensaio que visa a compressão simples.

A aplicação do carregamento é também muito importante para a realização do ensaio e há um normativo de recomendações. A depender da rapidez com que o carregamento é aplicado tratar-se-á de uma variedade de tipos de ensaio: dinâmico, estático e quase-estático.

Os ensaios dinâmicos podem ser realizados através de ciclos de recarregamento e descarregamento de dezenas, centenas e até mesmo milhares de $\mathrm{Hz}$. Os ensaios estáticos podem ser realizados através de ciclos mais lentos que os dinâmicos de modo a permitir toda amostra acomodar-se sob o novo estado de tensões imposto. As deformações envolvidas neste caso são maiores, se comparadas aos ensaios dinâmicos, e por vezes cada incremento/decremento de carga/descarga é aplicado comumente de 1 a $5 \mathrm{~min}$. Os ensaios quase-estáticos situam-se na ampla interface entre os ensaios dinâmicos e estáticos tanto em relação ao tempo de aplicação da carga/descarga quanto as deformações envolvidas.

Dependendo do tipo de material ensaiado, adaptações devem ser feitas. Ao ensaiar materiais que apresentam viscosidade elevada, como exemplo, sais de: halita, taquidrita e carnalita pode-se constatar pelos parâmetros medidos (módulo de Young, coeficiente de Poisson e módulo Bulk) que o regime não é o elástico (Eq 2.15 a seguir não são satisfeitas), e sim com grande contribuição de parcelas viscosas e até mesmo plásticas (deformações permanentes). Em tais casos pode ser mais adequado 
aplicar a cada intervalo de tempo fixo, uma deformação fixa à amostra de modo a amenizar outros efeitos que não os puramente elásticos.

Há uma importante relação para materiais homogêneos e isotrópicos sob regime elástico de pequenas deformações, i.e quando vale a Eq 2.13.

Seja um ensaio de compressão simples axissimétrico (Figura 2.14), têm-se que:

$$
\begin{gathered}
\sigma_{\mathrm{m}}=\mathrm{K}_{\mathrm{B}} \cdot \varepsilon_{\mathrm{v}} \\
\frac{\sigma_{1}}{3}=\mathrm{K}_{\mathrm{B}} \cdot\left[\varepsilon_{z z}+\varepsilon_{x x}+\varepsilon_{y y}\right]=\mathrm{K}_{\mathrm{B}} \cdot\left[\varepsilon_{z z}+2 \cdot \varepsilon_{x x}\right] \\
\frac{\sigma_{1}}{3}=\mathrm{K}_{\mathrm{B}} \cdot \varepsilon_{z z}[1-2 . v] \\
K_{B}=\frac{1}{3} \cdot \frac{\sigma_{1}}{\varepsilon_{z z}} \cdot\left(\frac{1}{1-2 . v}\right) \\
K_{B}=\frac{E}{3(1-2 . v)}, 0<v<0.5 \quad(\text { Eq } 2.15)
\end{gathered}
$$

\subsection{2}

\section{Equações Constitutivas com Acoplamento Hidromecânico}

Considerando ainda o caso de pequenos deslocamentos, num meio elástico, linear, homogêneo e isotrópico porém agora na presença de fluído nos poros, a lei de Hooke oferece as seguintes (Eqs 2.16) que muito se assemelham as (Eqs 2.13) sendo a principal diferença entre elas que as (Eqs 2.16) são escritas em termos das tensões efetivas, enquanto que no caso puramente mecânico (Eqs 2.13) estas se igualavam as tensões totais pela ausência do fluído.

$$
\begin{array}{ll}
\varepsilon_{x x}=\frac{\sigma_{x x}^{\prime}}{E}-\frac{v}{E}\left(\sigma_{y y}^{\prime}+\sigma_{z z}^{\prime}\right) & \varepsilon_{x y}=\sigma_{x y}^{\prime} \cdot \frac{(1+v)}{E} \\
\varepsilon_{y y}=\frac{\sigma_{y y}^{\prime}}{E}-\frac{v}{E}\left(\sigma_{z z}^{\prime}+\sigma_{x x}^{\prime}\right) & \varepsilon_{y z}=\sigma_{y z}^{\prime} \cdot \frac{(1+v)}{E} \\
\varepsilon_{z z}=\frac{\sigma_{z z}^{\prime}}{E}-\frac{v}{E}\left(\sigma_{x x}^{\prime}+\sigma_{y y}^{\prime}\right) & \varepsilon_{z x}=\sigma_{z x}^{\prime} \cdot \frac{(1+v)}{E}
\end{array}
$$

O conjunto de (Eqs 2.16) pode ser expresso em notação indicial por : 


$$
\varepsilon_{i j}=\frac{(1+v)}{E} \cdot \sigma_{i j}^{\prime}-\frac{v}{E} \cdot \sigma_{k k}^{\prime} \cdot \delta_{i j}
$$

Introduzindo na (Eq 28) a (Eq 16) apresentada no artigo de Biot e Willis de 1957 e que envolve o parâmetro $\boldsymbol{\alpha}_{B}$, têm-se a expressão do modelo constitutivo elástico e linear para o caso de um meio homogêneo e isotrópico:

$$
\varepsilon_{i j}=\frac{\left[(1+v) \cdot \sigma_{i j}-v \cdot \sigma_{k k} \cdot \delta_{i j}+\alpha_{B} \cdot \mathrm{p} \cdot \delta_{i j}\right]}{E}
$$

em que índices repetidos significam soma sobre todos os índices, ou seja, $\left(\sigma_{k k}=\sigma_{x x}+\sigma_{y y}+\sigma_{z z}\right)$.

Os fenômenos que ocorrem na natureza são complexos e vale lembrar que, a depender da escala de interesse, esses fenômenos podem ser modelados considerando pequenas ou grandes simplificações de modo que as Eq 2.13 e Eq 2.15 não os representem bem.

$\mathrm{Na}$ análise de um reservatório submetido a depleção, por exemplo, podese admitir um comportamento elástico linear quando pequenas variações da pressão de fluído forem aplicados. Contudo, admitindo-se elevadas variações que ocasionam grandes deslocamentos, a consideração de deformações irreversíveis e permanentes é mais apropriada. O exemplo descrito acima deixa evidente que o modelo constitutivo mais apropriado é função do fenômeno analisado e da escala na qual se deseja obter uma resposta. Uma classificação mais geral divide esses modelos em elástico, plástico e viscoso, podendo ainda ser linear e não linear. O termo "elástico" está associado à ausência de deformações permanentes com o reestabelecimento do estado de tensões anterior, indicando que a estrutura consegue recuperar sua forma inicial. A designação "plástica" está associada às deformações irrecuperáveis, irreversíveis no material (Selvadurai 2000). E por fim, o termo "viscoso" associa uma dependência das deformações em relação ao tempo de aplicação do carregamento. Os termos linear e não linear estão associados ao grau de complexidade da relação entre a tensão e deformação da estrutura. 


\section{5}

\section{Teoria Elastoplástica}

A teoria elastoplástica está associada à presença de deformações recuperáveis (elástica) e irrecuperáveis (plástica) após um nível específico de tensões. O comportamento dos solos ou rochas é um tema que vem sendo estudado amplamente desde a antiguidade. Grandes e importantes construções têm sido afetadas pela falta ou imprecisão dos estudos nesta área do conhecimento. Um claro exemplo é a famosa Torre de Pisa, que não deixa dúvidas disto. Como em muitas outras disciplinas, o estudo do comportamento dos solos ou rochas teve início com a simples prática da observação e ensaios, até que ganhasse corpo, status e pudesse se converter nas disciplinas de geotecnia. Há muitos anos as bases do comportamento dos solos/rochas estão assentadas em teorias e fórmulas analíticas, aliadas a grandes fatores de segurança a fim de incluir as incertezas inerentes às variações nas propriedades de material, assim como a própria não exatidão das teorias disponíveis.

Se quisermos obter uma maior quantidade e melhor qualidade de informação do comportamento dos solos/rochas, seja para corroborar as teorias vigentes e/ou por sua vez melhorar ou refinar as análises, devemos recorrer a modelos constitutivos complexos do tipo não-linear (com plasticidade), que sejam capazes de representar um comportamento similar ao do material solo/rocha. Um modelo constitutivo como vimos anteriormente permite relacionar as tensões com as deformações produzidas no interior do material em função de um número determinado de parâmetros que dependem das propriedades mecânicas do solo ou rocha. Para que o modelo seja realmente útil, deve ser completo (determinar o comportamento do material para todo tipo de carregamento), deve possuir parâmetros identificáveis (mediante um número reduzido de ensaios simples) e deve ser capaz de interpretar físicamente a resposta do material (frente a qualquer mudança de tensões ou deformações).

É importante passar por alguns conceitos básicos da teoria da elastoplasticidade, que definem cada modelo constitutivo usado para simular o comportamento de um dado material. 
Para caracterizar um modelo constitutivo de comportamento elastoplástico, é necessário ter claro três conceitos básicos: "critério de escoamento", "regra de fluxo" e "regra de endurecimento".

O primeiro deles, critério de escoamento (Yield Criterion-Y), consiste em definir uma função das tensões que nos permita saber se o material está no estado plástico ou elástico. No simples caso de um material sujeito a compressão uniaxial, isto corresponde simplesmente à condição $\sigma_{1}<Y$ (um único ponto). Quando o material está sujeito a um estado triaxial de tensões, para avaliar se o material está em estado elástico ou plástico, devemos analisar uma combinação dessas tensões e compararmos com algum valor que defina o limite elástico, ou critério de escoamento, que no caso 3D corresponde a uma superfície $O$ segundo conceito, denominado regra de fluxo (flow rule), corresponde à função que define as deformações, quando o material já está em estado de comportamento plástico. Muitas vezes a "flow rule" é idêntica ao "yield criterion", denominando-se do tipo associativa e no caso em que sejam diferentes, corresponde ao tipo não associativa. As deformações plásticas podem ou não depender da velocidade de aplicação da carga. Nos casos em que sejam dependentes da velocidade, denominam-se "plasticidade dependente da taxa de carregamento", ou "viscoplasticidade". Este comportamento é dito fluência (creep) e exemplos de materiais com esta propriedade são sais: halita, carnalita e taquidrita. No caso da independência da velocidade de carregamento, estes materiais possuem "plasticidade independente da taxa de carregamento", caracterizam-se por produzir deformações plásticas imediatas, em termos práticos, e irreversíveis. O terceiro conceito é a regra de endurecimento/amolecimento (hardening/softening rule), que representa a mudança da superfície de escoamento de acordo com o incremento das deformações plásticas.

Existem dois tipos de endurecimento/amolecimento,o isotrópico (isotropic work hardening/softening) e o cinemático (kinematic hardening/softening) Materiais em que a superfície de escoamento permanece constante são ditos: elastoplásticos ideais.

Segundo (Souza Neto 2008), a origem da teoria da plasticidade data da metade do século XIX e segue com contínuo desenvolvimento matemático. 
Na primeira metade do século XX essa teoria se estabeleceu com forte embasamento matemático e pode ser considerada como um dos maiores sucessos de modelos constitutivos fenomenológicos. Alguns associam seu surgimento com os trabalhos desenvolvidos por Coulomb em 1773, quando ele estudou a definição de um critério de ruptura para solos. Contudo, Tresca é considerado um dos primeiros a apresentar um estudo científico da plasticidade através do seu critério de ruptura de metais. Uma análise elastoplástica, por representar 2 estados diferentes do corpo é necessariamente não linear na relação tensão-deformação e por isso a análise deve ser feita em termos incrementais. Inicialmente, dado um incremento de deformação, verifica-se o estado de tensão do corpo em estudo. Em seguida, após definido um critério de plastificação, verifica-se se esse estado conduz a uma deformação plástica. Em caso afirmativo, o modelo constitutivo deve fornecer a regra de fluxo imposta ao material para descrever as deformações nas condições plásticas. Antes de avançar para os modelos elastoplásticos clássicos, serão definidos os conceitos de estado de tensões principais, desviador e hidrostático.

Um tensor de tensões genérico $\left[\sigma_{i j}\right]$, pode ser dividido em dois tensores: hidrostático $[p]$ e desviador $\left[s_{i j}\right]$

$$
\sigma_{i j}=p . \delta_{i j}+s_{i j}, \text { no qual } \mathrm{p}=\frac{\left(\sigma_{x x}+\sigma_{y y}+\sigma_{z z}\right)}{3}
$$

Sendo o tensor de tensões $\left[\sigma_{i j}\right]$, simétrico e a valores reais, o sistema de referências pode ser convenientemente rotacionado de modo a um observador fixo em tal sistema medir apenas tensões longitudinais.

Este novo e especial sistema de referência denomina-se : sistema de eixos principais $\left\{\underset{n_{1}}{\rightarrow}, \underset{n_{2}}{,}, \underset{n_{3}}{\rightarrow}\right\}$ e tensões principais $\left(\sigma_{1}, \sigma_{2}, \sigma_{3}\right)$.

Basta resolver as seguintes equações para obtê-los:

$$
\left(\sigma_{i j}-\boldsymbol{\sigma}_{k} \delta_{i j}\right) \boldsymbol{n}_{k, j}=0 \text { com } \boldsymbol{n}_{k} \neq \mathbf{0}
$$

Em 3 dimensões tratam-se de 9 equações que resolve-se 3 a 3 para cada um dos k. Como quer-se soluções diferentes da trivial, i.e $\boldsymbol{n}_{k} \neq \mathbf{0}$, é necessário e suficiente que

$$
\operatorname{det}\left(\left[\sigma_{i j}\right]-\sigma . I\right)=0
$$




$$
\sigma^{3}-\mathrm{I}_{1} \cdot \sigma^{2}+\mathrm{I}_{2} \cdot \sigma-\mathrm{I}_{3}=0
$$

Esta equação do terceiro grau denomina-se equação característica do tensor de tensões, possui 3 raízes que são as tensões principais $\left(\sigma_{1}, \sigma_{2}, \sigma_{3}\right)$. As quantidades especiais $\left(\mathrm{I}_{1}, \mathrm{I}_{2}, \mathrm{I}_{3}\right)$, que se mantém inalteradas independente da rotação que sofra o sistema de referência, denominam-se invariantes do tensor de tensão e possuem as seguintes expressões:

$$
\begin{gathered}
I_{1}=\operatorname{tr}\left[\sigma_{i j}\right]=\sigma_{x x}+\sigma_{y y}+\sigma_{z z} \\
I_{2}=\operatorname{det}\left[\begin{array}{ll}
\sigma_{x x} & \tau_{x y} \\
\tau_{x y} & \sigma_{y y}
\end{array}\right]+\operatorname{det}\left[\begin{array}{ll}
\sigma_{x x} & \tau_{x z} \\
\tau_{x z} & \sigma_{z z}
\end{array}\right]+\operatorname{det}\left[\begin{array}{ll}
\sigma_{y y} & \tau_{y z} \\
\tau_{y z} & \sigma_{z z}
\end{array}\right] \\
I_{2}=\sigma_{x x} \cdot \sigma_{y y}+\sigma_{y y} \cdot \sigma_{z z}+\sigma_{x x} \cdot \sigma_{z z}-\tau_{x y}^{2}-\tau_{y z}^{2}-\tau_{x z}^{2} \\
I_{3}=\operatorname{det}\left[\begin{array}{ccc}
\sigma_{x x} & \tau_{x y} & \tau_{x z} \\
\tau_{x y} & \sigma_{y y} & \tau_{y z} \\
\tau_{x z} & \tau_{y z} & \sigma_{z z}
\end{array}\right] \\
I_{3}=\sigma_{x x} \cdot \sigma_{y y} \cdot \sigma_{z z}-\tau_{x y}^{2} \cdot \sigma_{z z}-\tau_{y z}^{2} \cdot \sigma_{x x}-\tau_{x z}^{2} \cdot \sigma_{y y}+2 \cdot \tau_{x y} \cdot \tau_{y z} \cdot \tau_{x z}
\end{gathered}
$$

São também de muito valor as tensões principais e os invariantes do tensor de tensão desviadora

$$
\left[s_{i j}\right]=\left[\sigma_{i j}\right]-\mathrm{p} .\left[\delta_{i j}\right], \text { no qual } \mathrm{p}=\frac{\left(\sigma_{x x}+\sigma_{y y}+\sigma_{z z}\right)}{3}
$$

Este problema é resolvido matematicamente da mesma forma que no caso anterior do tensor da tensão.

Basta substituir na Equação característica (I) os $\left[\sigma_{i j}\right]$ pelos $\left[s_{i j}\right]$.

Indica-se os invariantes do tensor desviador por $\left(J_{1}, J_{2}\right.$ e $\left.J_{3}\right)$, e são dados por:

$$
\begin{gathered}
J_{1}=\operatorname{tr}\left[s_{i j}\right]=s_{x x}+s_{y y}+s_{z z}=0 \\
J_{2}=\frac{1}{6} \cdot\left[\left(\sigma_{1}-\sigma_{2}\right)^{2}+\left(\sigma_{2}-\sigma_{3}\right)^{2}+\left(\sigma_{3}-\sigma_{1}\right)^{2}\right] \\
J_{3}=\frac{2}{27} \cdot\left(\sigma_{1}+\sigma_{2}+\sigma_{3}\right)^{3}-\frac{1}{9} \cdot\left[\sigma_{1}^{2}\left(\sigma_{2}+\sigma_{3}\right)+\sigma_{2}^{2}\left(\sigma_{1}+\sigma_{3}\right)+\right. \\
\left.\sigma_{3}^{2}\left(\sigma_{1}+\sigma_{2}\right)\right]+\frac{4}{9} \cdot \sigma_{1} \cdot \sigma_{2} \cdot \sigma_{3}
\end{gathered}
$$

É também muito empregado o "Lode Angle " $(\theta)$ definido por: 


$$
\theta=\frac{1}{3} \cdot \sin ^{-1}\left(\frac{-3 \sqrt{3}}{2} \cdot \frac{J_{3}}{J_{2}^{3 / 2}}\right)
$$

Há 4 postulados básicos comumente empregados na teoria elastoplástica clássica :

- Existe uma função denominada função de escoamento plástico, $\Phi(\sigma)$, tal que

a) Material em regime elástico se:

$$
\Phi(\sigma)<0 \text { ou } \Phi(\sigma)=0 \text { e } \partial_{\varepsilon} \Phi(\sigma)<0
$$

b) Material em regime plástico se:

$$
\Phi(\sigma)=0 \text { e } \partial_{\varepsilon} \Phi(\sigma)>0
$$

- Sendo o material isótropo, a função de escoamento plástico independe das direções e não muda com a permutação dos eixos, ou seja, $\Phi(\sigma)$ é simétrica com relação às tensões principais e pode ser expressa em função dos invariantes $\left(\mathrm{I}_{1}, \mathrm{I}_{2}, \mathrm{I}_{3}\right)$ do tensor tensão.

- Tensões hidrostáticas não provocam escoamento i.e,

$$
\Phi\left(\mathrm{I}_{1}, \mathrm{I}_{2}, \mathrm{I}_{3}\right)=\Phi\left(\mathrm{J}_{2}, \mathrm{~J}_{3}\right)
$$

em que $\left(\mathrm{J}_{2}, \mathrm{~J}_{3}\right)$ são os segundo e terceiro invariantes do tensor tensão desviadora.

- Os comportamentos à tração e à compressão são idênticos.

A função de escoamento plástico não muda quando o sinal de todas as componentes de tensão são trocados i.e,

$$
\Phi(\sigma)=\Phi(-\sigma)
$$

Veremos na próxima seção que os postulados 3 e 4 em muitas aplicações práticas na indústria do petróleo foram enfraquecidos a fim de melhor modelar fenômenos como o "end cap" da compactação e ruptura por tração. 


\subsection{1}

\section{Função e Superfície de Escoamento Plástico}

O estado de tensões que define $\mathrm{o}$ início do comportamento plástico descrito por um material denomina-se ponto de escoamento plástico e o conjunto destes vários pontos formam a chamada superfície de escoamento plástico, i.e, os estados de tensão em que se verifica $\Phi(\sigma)=$ 0. Nesta seção trataremos dos critérios de escoamento plástico, i.e, as condições matemáticas para ocorrer o escoamento plástico (Selvadurai, 2002). Os modelos de Tresca e Von Mises têm por objetivo a previsão do escoamento plástico em materiais dúcteis enquanto o de Rankine, MohrCoulomb e Ducker-Prager prestam-se aos materiais frágeis.

Os materiais frágeis são aqueles em que, na iminência da ruptura, observase a ausência de deformações irreversíveis (plásticas) e baixos níveis de deformação reversíveis (elásticas). A ruptura desses materiais quase sempre ocorre de forma brusca, ou seja, após um determinado nível de tensão (tensão de pico é muito próxima à tensão de escoamento plástico), ocorre a ruptura do corpo e pode-se continuar a deformar o material plasticamente aplicando tensão muito inferior a de pico, ou seja, após a ruptura a resistência do material diminui consideravelmente. Materiais como vidros, ferro fundido, fibras e rochas duras (metamórficas) são bons exemplos de materiais frágeis. Nos materiais dúcteis, a ruptura é frequentemente observada muito após a estrutura ter entrado em regime de escoamento plástico. Ao atingir a tensão de escoamento plástico ocorre o deslizamento dos cristais constituintes do material, os quais são ordenados aleatoriamente, ao longo de seus planos de contato. Esse deslizamento é provocado pelas tensões de cisalhamento atuantes no corpo, e gera deformação permanente decorrente da acomodação dos cristais em sua nova posição. A ruptura desses materiais quase sempre ocorre de forma continua, ou seja, após um determinado nível de tensão de pico muito maior que a tensão de escoamento plástico, ocorre a ruptura do corpo e pode-se continuar a deformar o material aplicando tensão que pouco difere da tensão de pico, ou seja, após a ruptura a resistência do 
material pouco se altera. Materiais como aço, alumínio, cobre e as rochas salíferas (halita, carnalita e taquidrita) são bons exemplos de materiais dúcteis.

Uma descrição do escoamento plástico apropriado para análise de solos/rochas, por exemplo, requer a introdução da dependência de tensões média (pressões hidrostáticas), como não acontece nos critérios de Tresca, Von-Mises e Rankine mas sim nos de Ducker-Prager e Mohr-Coulomb que se aborda a seguir.

\section{Critério de Escoamento de Mohr-Coulomb}

O critério de escoamento plástico de Mohr-Coulomb (1773) considera que o fenômeno do escoamento plástico é resultado do atrito devido ao deslizamento entre as partículas que constituem o material e assume que o escoamento plástico inicia quando, em um plano do corpo, a tensão cisalhante $(\boldsymbol{\tau} \neq \mathbf{0})$ e a tensão normal $\boldsymbol{\sigma}_{\boldsymbol{n}}$ atingem uma combinação crítica, definida pela equação

$$
\boldsymbol{\tau}=\mathbf{c}-\boldsymbol{\sigma}_{\boldsymbol{n}} \cdot \tan (\Phi) \quad(\text { Eq 2.19) }
$$

onde c é a coesão e $\Phi$ é o ângulo de atrito interno (ângulo de atrito). A superfície de escoamento plástico por esse critério é definida por todas as combinações que atendem a (Eq 2.19). Essa superfície pode ser mais facilmente visualizada na representação do estado de tensão através do círculo de Mohr, conforme a Figura 2.15. No mesmo plano cartesiano onde estão desenhados os círculos, projeta-se a reta referente a (Eq 2.19). 


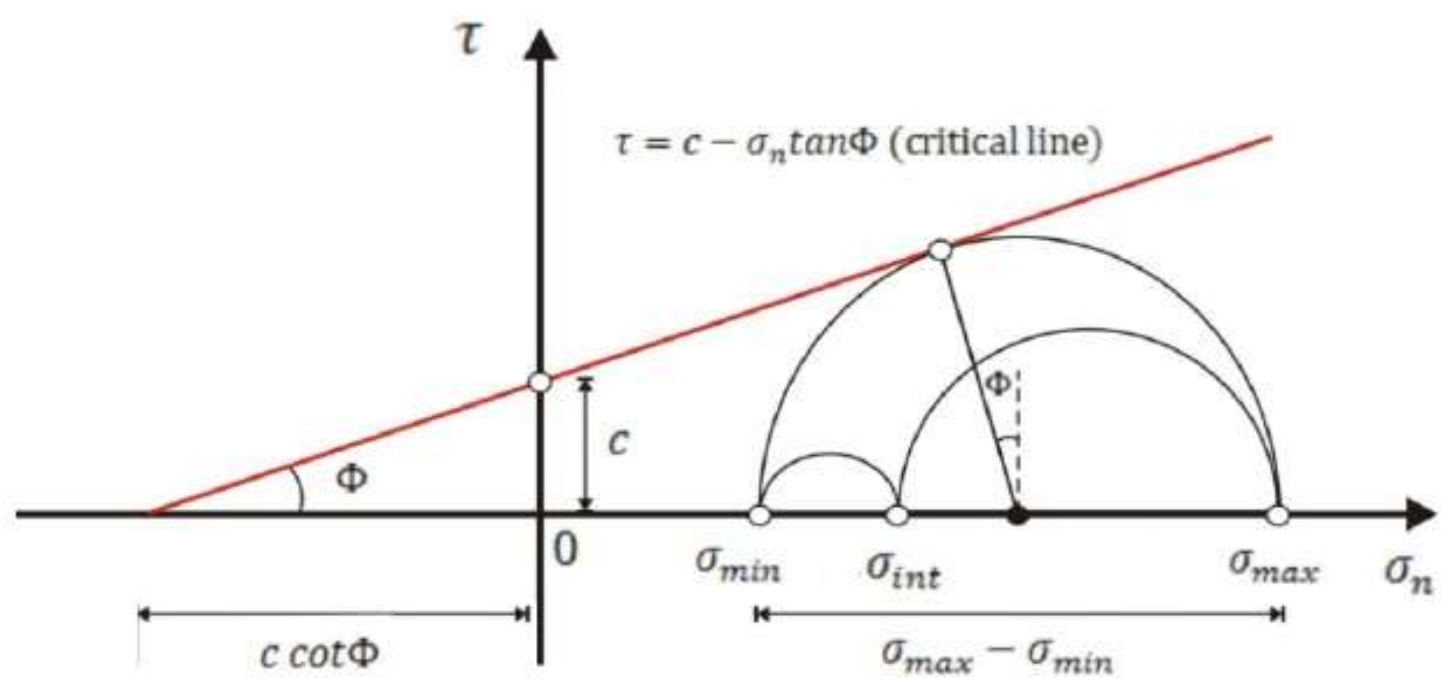

Figura 2.15: Representação Gráfica do Critério de Escoamento Plástico de Mohr-Coulomb (Reta Vermelha), domínio $\sigma$ vs. $\tau$

A (Eq 2.19) pode ser descrita em função das tensões principais :

$$
\begin{gathered}
\left(\frac{\sigma_{1}-\sigma_{3}}{2}\right) \cdot \cos (\Phi)=\mathrm{c}+\left[\left(\frac{\sigma_{1}+\sigma_{3}}{2}\right)-\left(\frac{\sigma_{1}-\sigma_{3}}{2}\right) \cdot \sin (\Phi)\right] \tan (\Phi) \\
\left(\frac{\sigma_{1}-\sigma_{3}}{2}\right)-\left(\frac{\sigma_{1}+\sigma_{3}}{2}\right) \cdot \sin (\Phi)=\mathrm{c} \cdot \cos (\Phi) \quad(\mathrm{Eq} 2 \cdot 20) \\
\sigma_{1} \cdot[1-\sin (\Phi)]-\sigma_{3} \cdot[1+\sin (\Phi)]=2 \cdot \operatorname{c} \cdot \cos (\Phi) \\
\sigma_{1}=\left[\frac{2 \cdot \operatorname{cc} \cos (\Phi)}{1-\sin (\Phi)}\right]+\left[\frac{2 \cdot \operatorname{cc} \cos (\Phi)}{1-\sin (\Phi)}\right] \cdot \sigma_{3}, \text { fazendo } \\
C_{0}=\left[\frac{2 \cdot \operatorname{coc} \cos (\Phi)}{1-\sin (\Phi)}\right] \text { e } \tan (\Psi)=\left[\frac{2 \cdot \operatorname{cc} \cdot \cos (\Phi)}{1-\sin (\Phi)}\right], \text { tem-se } \\
\sigma_{1}=C_{0}+\sigma_{3} \cdot \tan (\Psi) \quad(\text { Eq 2.21) }
\end{gathered}
$$

Portanto, a função de escoamento plástico pelo critério de Mohr-Coulomb em termos de tensões efetivas é definida por :

$$
\Phi\left(\sigma_{1}^{\prime}, \sigma_{3}^{\prime}\right)=\sigma_{1}^{\prime}-C_{0}-\sigma_{3}^{\prime} \cdot \tan (\Psi) \quad(\text { Eq 2.22) }
$$

Em que $C_{0}$ é a resistência a compressão simples, e $\Psi$ é a inclinação do critério de escoamento plástico de Mohr-Coulomb no plano $\sigma_{3}^{\prime}$ vs. $\sigma_{1}^{\prime}$ Para $\Phi<0$ tem-se o regime elástico, caso contrário diz-se que o material plastificou e as deformações devem ser obtidas a partir de uma regra para o fluxo plástico. 
A função de escoamento plástico do critério de Mohr-Coulomb (Eq 2.22) pode ainda ser generalizada para um estado 3D de tensões que não os estados (2D) mais simplificados: estado plano de tensões, estado plano de deformações ou estado axissimétrico.

Para isto usa-se os invariantes de tensão $\left(I_{1}, J_{2}\right.$ e $\left.J_{3}\right)$, que podem ser melhor identificados na (Eq 2.20), e obtêm-se:

$$
\begin{gathered}
\Phi(\sigma)=\left[\cos (\theta)-\frac{1}{\sqrt{3}} \cdot \sin (\theta) \cdot \sin (\Phi)\right] \cdot \sqrt{J_{2}}+\mathrm{p} \cdot \sin (\Phi)-\mathrm{c} \cdot \cos (\Phi)(\mathrm{Eq} 2 \cdot 23) \\
\mathrm{p}=\frac{I_{1}}{3}=\sigma_{m}
\end{gathered}
$$

e $\theta\left(J_{2}, J_{3}\right)$ é o " Lode angle "definido na seção anterior.

No espaço tridimensional das tensões principais, a superfície de escoamento plástico de Mohr-Coulomb (Eq $2.23 \mathrm{com} \Phi=0$ ) possui seção transversal hexagonal (Figura 2.16).

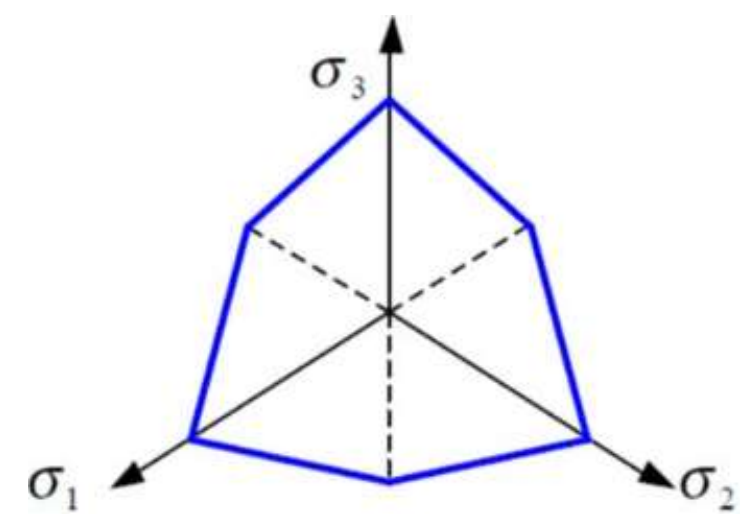

Figura 2.16: Seção Transversal da Superfície de Escoamento Plástico de Mohr-Coulomb no espaço das tensões principais.

e forma uma pirâmide hexagonal ao longo do eixo hidrostático com vértice aberto em $\mathrm{p}=\mathrm{c} \cdot \cot (\Phi)$ uma vez que neste eixo há ausência de tensão desviadora e logo de cisalhamento de modo que o critério perde seu significado físico (Figura 2.17). Sua forma piramidal, oposta à forma prismática do critério de Tresca, é uma consequência da dependência de pressões hidrostáticas ( $p$ na Eq 2.23). Posteriormente veremos, que esses 2 critérios coincidem quando o ângulo de atrito é nulo. 


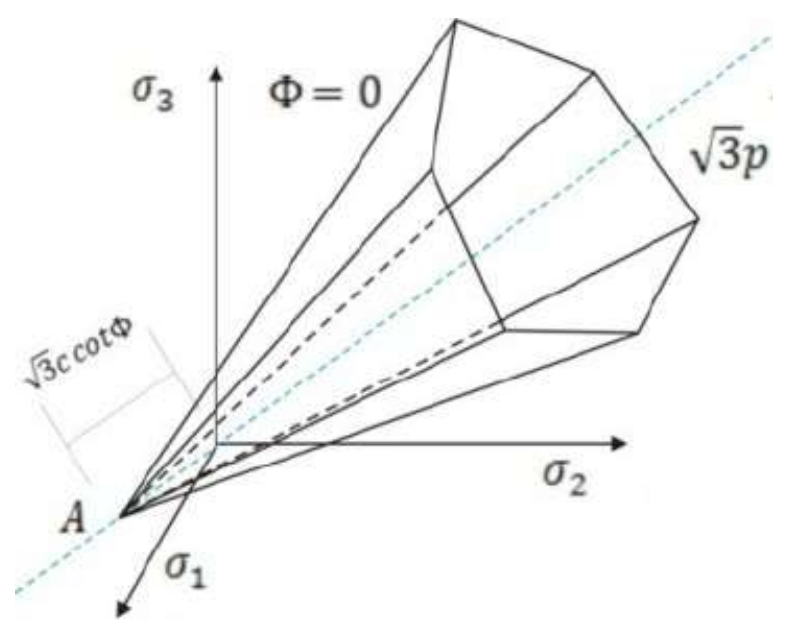

Figura 2.17: Superfície de Escoamento Plástico de Mohr-Coulomb no espaço das Tensões Principais

Como não é permitido nenhum estado de tensão associado a escoamento plástico fora da superfície de escoamento, o vértice da pirâmide seria uma extrapolação do critério de escoamento de Mohr Coulomb para tensão média. O critério de Mohr-Coulomb melhor se aplica em materiais como o concreto, rocha e solos. É importante observar que o critério de MohrCoulomb somente prevê escoamento plástico quando há tensão desviadora e, consequentemente, tensão cisalhante. De modo que, um grupo de pesquisadores da Universidade de Cambridge (Roscoe 1958, 1963), desenvolveram um critério de escoamento que também levasse em conta as deformações causadas pelo aumento da tensão média, também chamado de escoamento plástico por compactação ou colapso de poros. No espaço das tensões principais, este tipo de escoamento plástico é representado pelo chamado "end cap" (Figura 2.18), que fecha a superfície de escoamento em tensões médias muito altas.

O grande interesse nos modelos de ruptura por compactação foi o de conseguir modelar o comportamento plástico de solos em situação hidrostática, no qual somente a tensão média aumenta e mesmo assim observa-se deformações inelásticas devido ao empacotamento e esmagamento dos grãos.

A formulação apresentada abaixo para a superfície de escoamento plástico do modelo Cam-Clay em termos de tensões principais (Roscoe 1958) : 


$$
\Phi(\sigma)=q^{2}-M^{2} \cdot \sigma_{m} \cdot\left(2 p_{c}-\sigma_{m}\right) \quad(\text { Eq 2.24) }
$$

em que $\mathrm{q}=\sigma_{1}-\sigma_{3}$ é a tensão desviadora, $\sigma_{m}$ é a tensão média, $\mathrm{M}$ e $p_{c}$ são parâmetros do material.

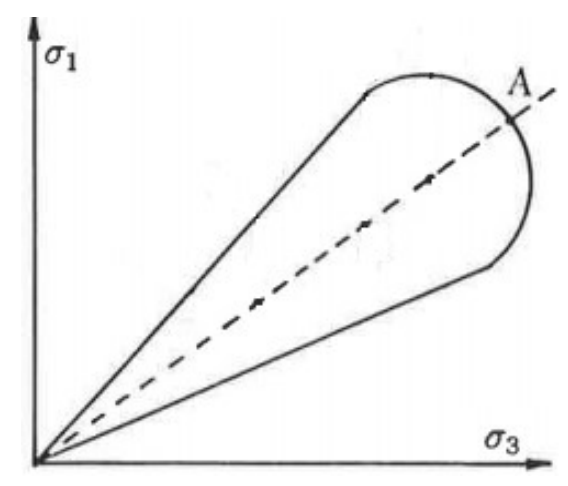

Figura 2.18: Superfície de Escoamento Plástico do modelo Cam-Clay com “ EndCap" no espaço $\sigma_{3}, \sigma_{1}$

Desenvolvimentos posteriores (Schofield 1968) e (Burland 1968), baseados no trabalho de (Roscoe 1958, 1963), levaram ao modelo de CamClay Modificado. A principal diferença entre o modelo Cam-Clay e o CamClay Modificado está na descrição da superfície de escoamento plástico. No primeiro caso esta superfície tem a forma de uma gota de água semiplana (Figura 2.18) enquanto no Cam-Clay Modificado ela tem a forma de uma elipsoide (Figura 2.19)

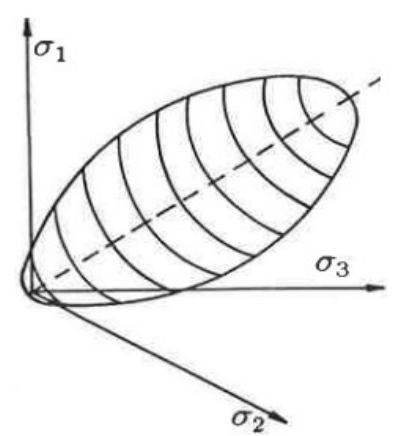

Figura 2.19: Superfície de Escoamento Plástico do modelo Cam-Clay Modificado com "End-Cap" no espaço das tensões principais.

A superfície de escoamento plástico do modelo de Cam-Clay Modificado em termos das tensões principais é dada por: 


$$
\Phi(\sigma)=\left[\frac{\left(9+M^{2}\right) \cdot\left(\sigma_{1}^{2}+\sigma_{2}^{2}+\sigma_{3}^{2}\right)+\left(2 M^{2}-9\right) \cdot\left(\sigma_{1} \sigma_{2}+\sigma_{2} \sigma_{3}+\sigma_{3} \sigma_{1}\right)}{3 \cdot M^{2} \cdot\left(\sigma_{1}+\sigma_{2}+\sigma_{3}\right)}\right]-p_{0} \quad(\text { Eq 2.25) }
$$

em que $p_{0}$ é um parâmetro de endurecimento isotrópico do material.

Por último, é necessário estabelecer um critério de ruptura para condições de tração. Um critério simplista e comumente usado, leva em conta a resistência à tração da rocha que pode ser obtida por meio de ensaios brasileiros.

$$
\sigma^{\prime}=T_{0}<0
$$

onde $\sigma^{\prime}$ é a tensão efetiva e $\mathrm{T}_{0}$ é a resistência à tração.

A junção de critérios de plastificação por cisalhamento (Mohr-Coulomb), tração e compactação (Cam-Clay ou Cam-Clay Modificado) formam as chamadas superfícies de escoamento plástico "capped" (Figura 2.20), que definem os pontos onde materiais geológicos plastificam.

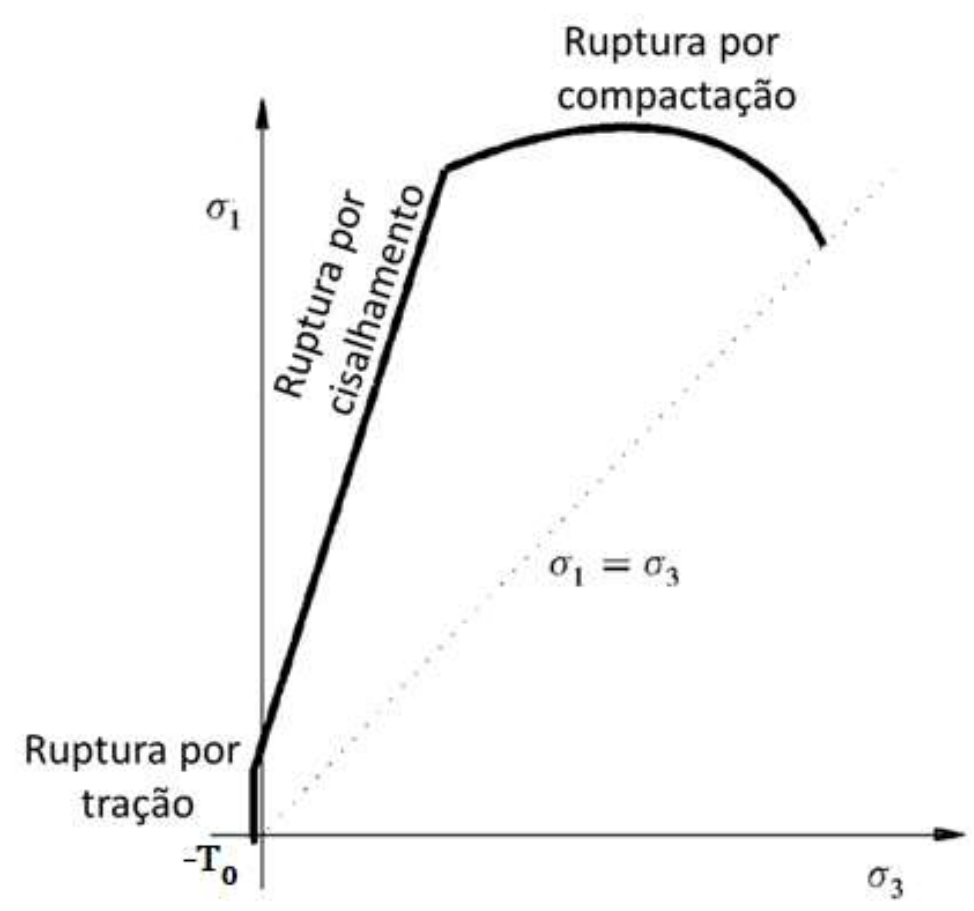

Figura 2.20: Superfície de Escoamento Plástico por Tração, Cisalhamento e Compactação no espaço $\sigma_{3}, \sigma_{1}$

Os modelos de Tresca e von Mises apresentam a característica de independência das tensões hidrostáticas, são baseados exclusivamente no tensor desviador. Na análise de solos e rochas, a dependência hidrostática 
é um importante fator e por isso os modelos de Mohr-Coulomb e DruckerPrager são mais utilizados. Outra propriedade importante presente em todos esses 5 modelos clássicos é a isotropia, isso significa que o tensor de tensões pode ser rotacionado e os limites de escoamento plástico não serão alterados. Por isso é frequente a representação das superfícies de plastificação no espaço das tensões principais.

\section{Critério de Escoamento de Tresca ou Teoria da Tensão de Cisalhamento Máxima}

Este critério foi proposto por Henri Édouard Tresca (1868) para descrever o escoamento plástico em metais. O critério de escoamento de Tresca assume que o escoamento plástico inicia quando a máxima tensão de cisalhamento atinge um valor crítico. A máxima tensão de cisalhamento pode ser encontrada em função das tensões principais máxima e mínima:

$$
\tau_{\text {max }}=\frac{1}{2} .\left(\sigma_{1}-\sigma_{3}\right)
$$

Isso pode ser facilmente observado no círculo de Mohr - a tensão cisalhante máxima representa o raio do círculo. A definição de Tresca para o limite elástico do material para um estado $2 \mathrm{D}$ de tensões é, portanto:

$$
\frac{Y}{2}=\frac{1}{2} \cdot\left(\sigma_{1}-\sigma_{3}\right)
$$

na qual $\frac{Y}{2}$ é uma constante e representa a máxima tensão de cisalhamento a que o metal resiste na iminência do escoamento plástico.

A função de escoamento plástico $(\Phi)$ pelo critério de Tresca para um estado 2D de tensões é dada por:

$$
\Phi(\sigma)=\left(\sigma_{1}-\sigma_{3}\right)-Y
$$

A generalização do critério de Tresca para um estado 3D de tensões é:

$$
\Phi\left(J_{2}, J_{3}\right)=2 \cdot \sqrt{J_{2}} \cdot \cos (\theta)-Y
$$

Em um modelo unidimensional o critério de Tresca é representado no espaço por um ponto (limite de escoamento do material). 
No caso bidimensional de tensões, o limite de escoamento é definido por um conjunto de retas em um plano definidas por $\Phi(\sigma)=0$ e representadas na Figura 2.21

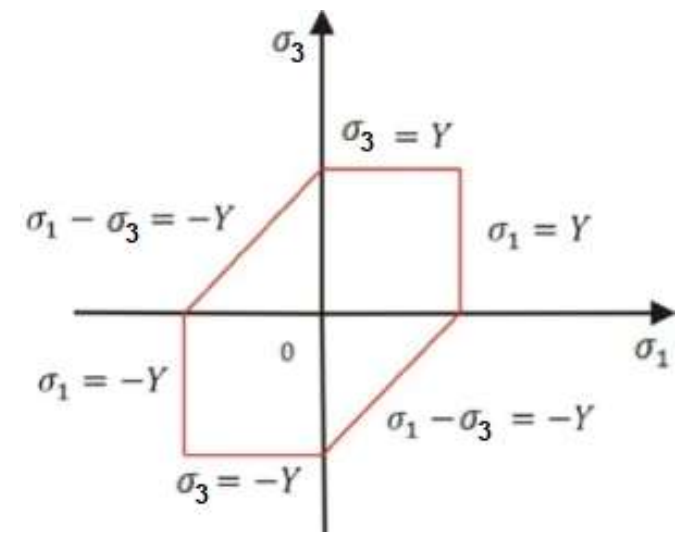

Figura 2.21: Superfície de Escoamento de Tresca para um estado 2D de Tensões

Por fim, no espaço tridimensional, o critério de Tresca pode ser definido por $\Phi\left(J_{2}, J_{3}\right)=0$ e sua representação gráfica é dada na Figura 2.22

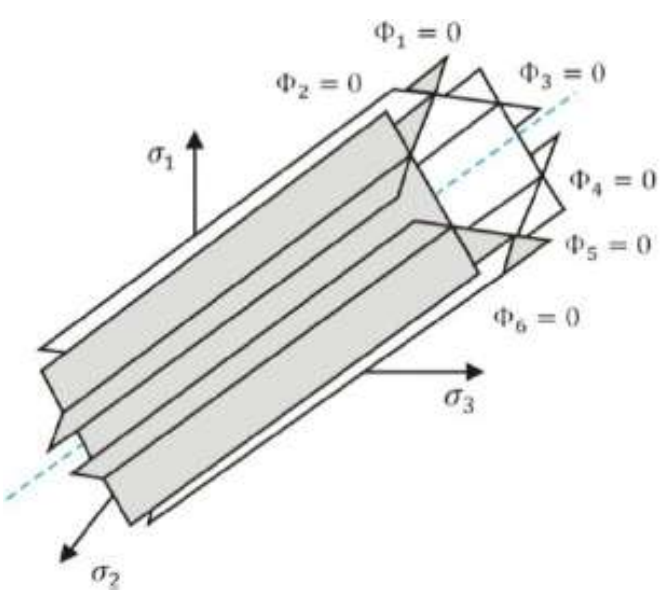

Figura 2.22: Superfície de Escoamento de Tresca para um estado 3D de Tensões

É interessante notar que a função de escoamento plástico do critério de Tresca coincide com a função de escoamento plástico do critério de Mohr-Coulomb (Eq 2.19) quando o ângulo de atrito é tomado igual a 0. 


\section{Critério de Escoamento de Von Mises ou Teoria da Energia de Distorção Máxima}

Este critério proposto por Richard Edler von Mises em 1913, baseia-se na máxima energia de distorção armazenada em um estado genérico de tensões e é mais apropriado para descrever o escoamento plástico em metais e materiais de comportamento plástico dúctil.

A energia elástica específica armazenada num material para um dado estado de tensões é composta de duas parcelas: energia de distorção ligada as tensões desviadoras (mudança de forma do corpo) e energia volumétrica ligada a tensão hidrostática (mudança de volume do corpo).

A parcela hidrostática do tensor de tensões é responsável pela deformação volumétrica do material porém não causa distorções angulares.

A parcela desviadora do tensor de tensões, por sua vez, não causa deformação volumétrica, mas é responsável pelas distorções angulares no material. Seja a energia elástica específica em termos de tensões e deformações principais:

$$
u=\frac{1}{2} \cdot\left(\sigma_{1} \varepsilon_{1}+\sigma_{2} \varepsilon_{2}+\sigma_{3} \varepsilon_{3}\right)
$$

Esta pode ser dividida como a soma de duas parcelas: hidrostática $\left(u_{\mathrm{v}}\right)$ e desviadora $\left(u_{D}\right)$.

$$
\begin{gathered}
u_{\mathrm{v}}=\frac{1}{2} \cdot\left(\sigma_{1} \varepsilon_{v}+\sigma_{2} \varepsilon_{v}+\sigma_{3} \varepsilon_{v}\right) \\
\text { no qual } \varepsilon_{v}=\frac{\left(\sigma_{1}+\sigma_{2}+\sigma_{3}\right)}{3 \cdot \mathrm{K}_{B}}=\frac{(1-2 v)\left(\sigma_{1}+\sigma_{2}+\sigma_{3}\right)}{\mathrm{E}}, \mathrm{e} \\
u_{\mathrm{D}}=\frac{1}{2} \cdot\left[\sigma_{1}\left(\varepsilon_{1}-\varepsilon_{v}\right)+\sigma_{2}\left(\varepsilon_{2}-\varepsilon_{v}\right)+\sigma_{3}\left(\varepsilon_{3}-\varepsilon_{v}\right)\right] \\
\text { no qual } \varepsilon_{i}=\frac{\sigma_{i}-v \cdot\left(\sigma_{j}+\sigma_{k}\right)}{E}, \mathrm{i} \neq \mathbf{j} \neq \mathrm{k}=1,2,3
\end{gathered}
$$

O critério de Von Mises estabelece um valor crítico para a máxima energia de distorção específica:

$$
u_{\mathrm{D}}=\frac{(1+v)}{6 E} \cdot\left[\left(\sigma_{1}-\sigma_{2}\right)^{2}+\left(\sigma_{2}-\sigma_{3}\right)^{2}+\left(\sigma_{3}-\sigma_{1}\right)^{2}\right]
$$


Pode-se observar que a energia de distorção independe das tensões hidrostáticas e o escoamento deve ocorrer quando essa energia atinge um valor crítico. Esse valor pode ser obtido em um ensaio experimental de uma barra tracionada que começa a escoar plasticamente com $\sigma_{1}=\mathrm{Y}, \sigma_{2}=$ $\sigma_{3}=0$

$$
\frac{(1+v)}{6 \mathrm{E}} \cdot\left[\left(\sigma_{1}-\sigma_{2}\right)^{2}+\left(\sigma_{2}-\sigma_{3}\right)^{2}+\left(\sigma_{3}-\sigma_{1}\right)^{2}\right]=\frac{(1+v)}{3 \mathrm{E}} \cdot \mathrm{Y}^{2}
$$

Podemos expressar o critério de Von Mises identificando $J_{2}$ :

$$
\sqrt{3 \mathrm{~J}_{2}}=\mathrm{Y}
$$

E a respectiva função de escoamento plástico do critério:

$$
\Phi\left(J_{2}\right)=\sqrt{3 \cdot J_{2}}-Y
$$

O critério também pode ser expresso na seguinte forma:

$$
\left(\sigma_{1}-\sigma_{2}\right)^{2}+\left(\sigma_{2}-\sigma_{3}\right)^{2}+\left(\sigma_{3}-\sigma_{1}\right)^{2}=2 . Y^{2}
$$

De modo que a superfície de escoamento plástico no espaço das tensões principais 3D é um prisma regular (Figura 2.23) cuja seção 2D é uma elipse (Figura 2.24) que é bem visualizada fazendo, por exemplo $\sigma_{3}=0$.

$$
\sigma_{1}{ }^{2}-\sigma_{1} \cdot \sigma_{2}+\sigma_{2}^{2}=Y^{2}
$$

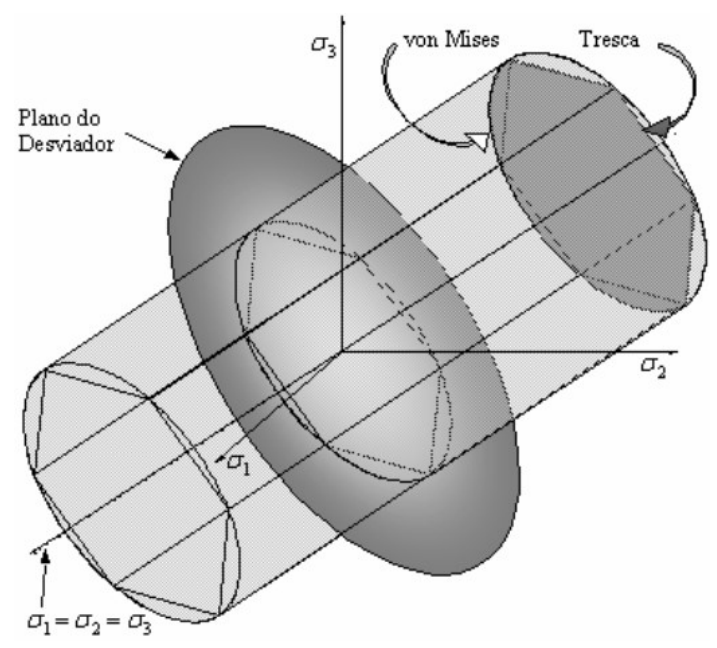

Figura 2.23: Superfície de Escoamento de Von Mises, estado 3D de Tensões 


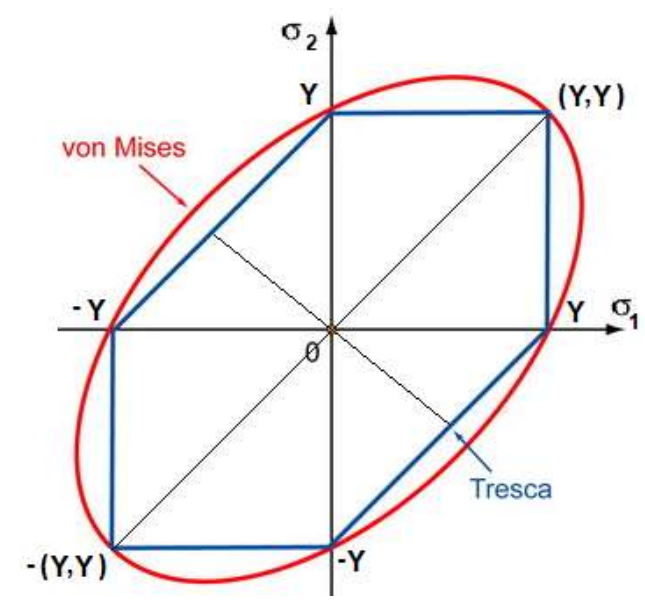

Figura 2.24: Superfície de Escoamento de Von Mises, estado 2D de Tensões

\section{Critério de Rankine ou Teoria da Tensão Normal Máxima}

Este critério proposto em 1880 para materiais frágeis (tendem a falhar subitamente sem escoamento plástico).

Em um teste de tração, a fratura ocorre quando a tensão normal atinge o limite de resistência. Esta teoria estabelece nada mais que um material frágil falha quando a tensão principal máxima atinge um valor limite igual ao limite de resistência que o material suporta quando submetido a tração simples e vale para materiais frágeis cujos diagramas tensão-deformação sejam similares tanto sob tração quanto sobre compressão (Ex: ferro fundido). Podemos expressar o critério de Rankine da seguinte maneira (Figura 2.25)

$$
\left|\sigma_{1}\right|=\sigma_{r} \text { e }\left|\sigma_{3}\right|=\sigma_{r}
$$

em que $\sigma_{r}$ é o valor da resistência a tração simples. 


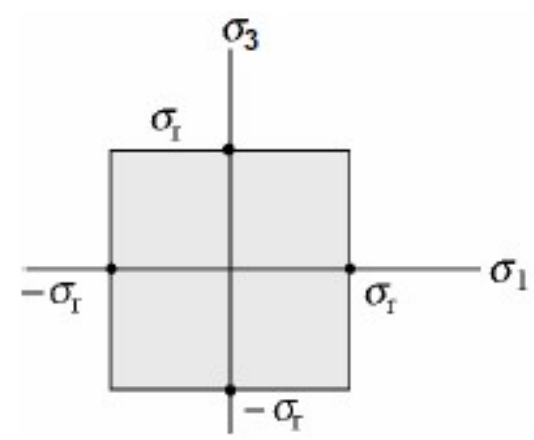

Figura 2.25: Superfície de Escoamento de Rankine, estado 2D de Tensões

\section{Critério de Escoamento de Drucker-Prager}

O modelo constitutivo de Drucker-Prager (DP) de 1952, e sua versão extendida (EDP) consistem basicamente de modelos de comportamento elasto-plástico, onde o escoamento é controlado por uma combinação entre a tensão hidrostática e a tensão desviadora. Ambos os modelos são uma extensão e aperfeiçoamento do conhecido critério de Mohr-Coulomb (1773) No modelo de Mohr-Coulomb observam-se cantos pontudos quando se traça a função no espaço das tensões principais (Figura 2.16). Esses cantos pontudos implicam em singularidades no cálculo da deformação plástica quando do uso da expressão do critério de Mohr-Coulomb como regra de fluxo plástico de modo a comprometer o compto de um parâmetro muito importante no comportamento dos solos e rochas: a dilatância, que corresponde à mudança de volume do material devido as tensões aplicadas. Essas singularidades, no entanto, podem ser tratadas, adotando uma superfície suave e que envolva a superfície de escoamento de Mohr Coulomb como apresentado na (Figura 2.26). 


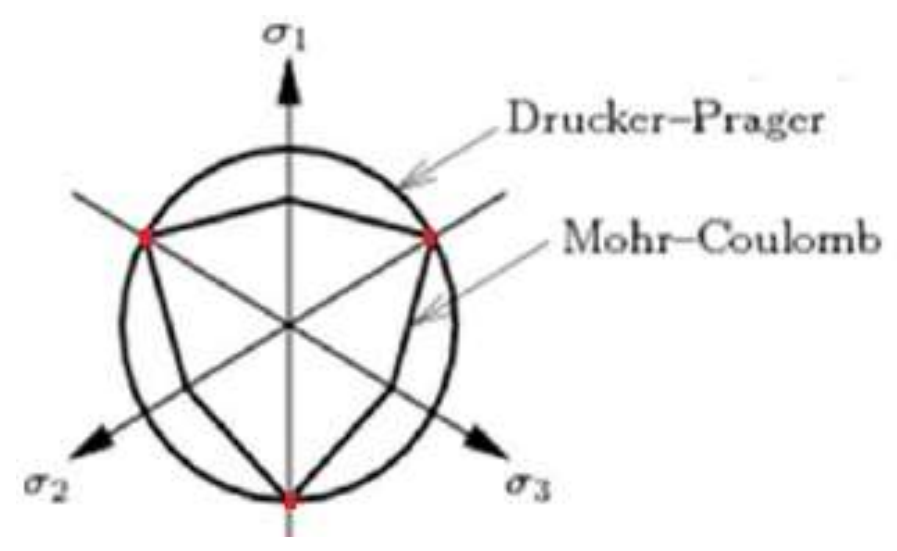

Figura 2.26: Seção Transversal da Superfície de Escoamento Plástico de Drucker-Prager e Mohr-Coulomb no espaço das tensões principais.

Como pode-se perceber, a superfície de escoamento de Drucker-Prager é uma versão suavizada da superfície de escoamento de Mohr-Coulomb Drucker e Prager propuseram a seguinte superfície de escoamento (Figura 2.27) no espaço 3D das tensões principais (Eq 2.27).

$$
\left[\left(\sigma_{1}-\sigma_{2}\right)^{2}+\left(\sigma_{2}-\sigma_{3}\right)^{2}+\left(\sigma_{3}-\sigma_{1}\right)^{2}\right]-A-B .\left(\sigma_{1}+\sigma_{2}+\sigma_{3}\right)=0
$$

(Eq 2.27)

Em que A e B são funções da coesão e do ângulo de atrito:

$$
A=\frac{6 . c \cdot \cos \Phi}{\sqrt{3}(3+\sin \Phi)} \text { e } \mathrm{B}=\frac{2 \sin \Phi}{\sqrt{3}(3+\sin \Phi)}
$$

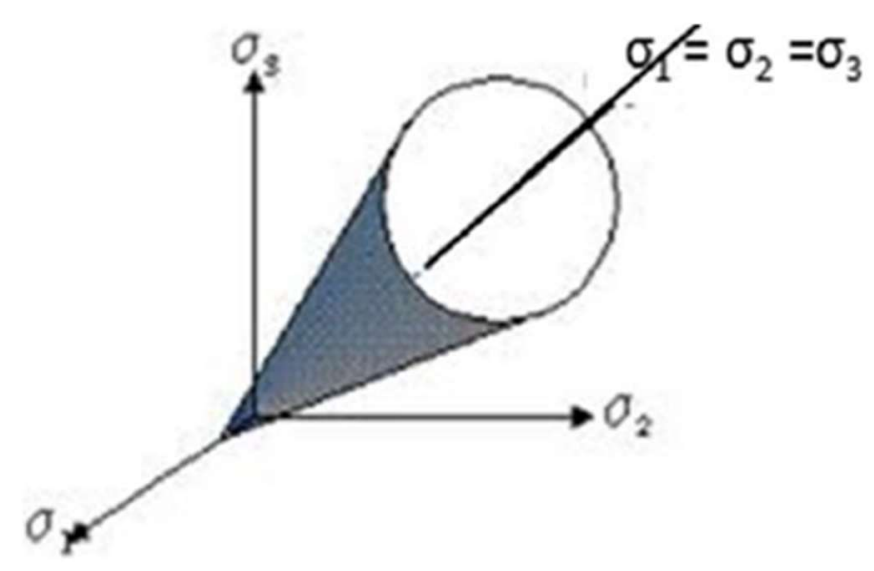

Figura 2.27: Superfície de Escoamento Plástico 3D do modelo de Drucker-Prager. 
No espaço 2D (problemas em estado plano de tensão, deformação ou axissimétrico) os parâmetros A e B são dados pelas equações:

$$
A=\frac{\tan \Phi}{\sqrt{9+12 \cdot(\tan \Phi)^{2}}} \text { e } B=\frac{3 . c}{\sqrt{9+12 \cdot(\tan \Phi)^{2}}}
$$

As deformações plásticas associadas aos modelos de (DP) e (EDP) são independentes da taxa de carregamento, portanto, estes modelos não são apropriados para modelar materiais que apresentam fluência.

No caso dos modelos de DP e EDP, pode-se calcular as deformações plásticas empregando como regra de fluxo "flow rule", as próprias expressões dos modelos (caso associativo) ou empregar outras expressões (caso não associativo). O comportamento elasto-plástico ideal corresponde a um endurecimento/amolecimento nulo, e é o que oferece o modelo de DP. No entanto, o modelo EDP oferece ainda diferentes modelos de endurecimento/amolecimento, como: linear, hiperbólico e lei de potência, todos considerando endurecimento/amolecimento do tipo isotrópico. O DP e EDP apresentam muitas variantes, que permitem a estes modelos serem aplicados com bons resultados em: rochas, concreto, polímeros.

\section{6}

\section{Inversão Sísmica}

O ponto chave para a integração entre geomecânica e sísmica é o entendimento de que no dado sísmico condicionado, os eventos (picos e cavas) associam-se ao contraste de propriedades mecânicas entre as rochas encaixantes como ilustrado (Figura 2.28).

Em geociências, o processo de inversão sísmica destina-se a estimar propriedades petrofísicas, mecânicas e de fluxo: porosidade, litologia, fácies, saturação de fluído, densidade, módulo de Young, coeficiente de Poisson e unidades de fluxo-FZI (Flow Zone indicator) da rocha em subsuperfície através dos dados sísmicos de reflexão. 


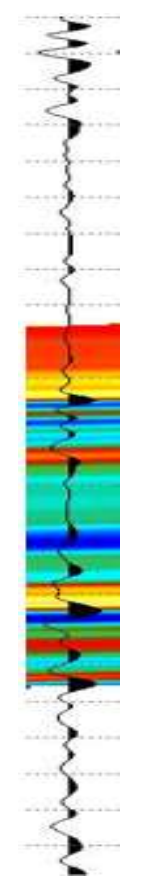

Figura 2.28: Traço Sísmico (em preto) como contraste de propriedades mecânicas - impedância (colorido)

A operação computacionalmente mais rápida, mais amplamente usada na indústria e que fornece bons resultados para a grande maioria das aplicações é o modelo convolucional :

$$
\mathbf{T}=\mathbf{w}^{*} \mathbf{r} \quad \text { (Eq 2.28) }
$$

Ou seja, o traço sísmico (T) é modelado como a convolução do pulso sísmico residual ou wavelet $(\mathbf{w})$ com a refletividade $(\mathbf{r})$ :

- w : representa o pulso sísmico que chega em subsuperfície e que interage com o meio geológico.

- $\mathbf{r}$ : representa a série dos coeficientes de reflexão das camadas geológicas em subsuperfície. É o elemento que fornece as propriedades do meio e a informação que se deseja obter.

A inversão sísmica, simplificadamente, baseia-se na convolução de um modelo de refletividade com uma wavelet (forma de onda) estimada, comparação do dado sísmico modelado com o de entrada e então 
atualização, condicionada pelo algoritmo usado, da refletividade para minimizar a diferença entre os traços sísmicos modelado e de entrada.

O principal produto obtido será o volume de impedância acústica (IP) das rochas, que é dado pelo produto entre sua densidade e velocidade compressional. No algoritmo de inversão SSI (sparse spike inversion), a refletividade estimada e que representa o dado sísmico de entrada, é composta por picos com afastamento máximo e de grande amplitude (Dossal) e (Fuchs 2002, 2005).

A série de coeficientes de reflexão geológicos recuperada do dado sísmico, por ter número mínimo de picos e grande amplitude, representa de maneira simples e clara a geologia em subsuperfície a partir do dado sísmico. Nesse tipo de algoritmo (1973), os picos da refletividade relacionam-se aos grandes eventos sísmicos (supostos verdadeiros eventos geológicos). Os eventos sísmicos de muito baixa: amplitude e afastamento vertical são atribuídos a artefatos como: lobos - laterais, tuning e dimming do pulso sísmico residual (wavelet) e também a ruído, sendo, portanto, desejável que não contaminem a refletividade e introduzam falsos eventos nas propriedades acústicas ou elásticas invertidas. A solução do problema inverso, contudo, não é única. Existem muitas séries de coeficientes de reflexão que se convolvidas com a wavelet reproduzem o dado sísmico de entrada com uma dada precisão. Em muitas aplicações práticas é desejável reduzir a não unicidade do problema inverso a uma única solução (inversão determinística) mais alinhada à geologia da área, o que é conseguido através de restrições adicionais com significância geofísica e geológica, impostas no processo de inversão.

O uso de modelo a priori na inversão sísmica (model based seismic inversion) se dá tipicamente através do gradiente vertical e lateral da impedância acústica obtido a partir de dados de poços e ferramentas geoestatísticas, sendo por vezes usado também modelo de Velocidade-P advindo do processamento sísmico e obtido por técnicas como: tomografia de reflexão e FWI (Full Waveform inversion)

O cômputo da refletividade concomitante à aplicação das restrições do modelo a priori é realizado num processo iterativo onde se deseja minimizar uma função objetivo que integra todos os vínculos do problema inverso. 
A inversão sísmica aqui empregada CSSI (constrained sparse spike inversion) é determinística, baseada em modelo a priori e possui em sua função objetivo os importantes termos a serem atribuídos pesos: grau de suavidade lateral e vertical em respeito ao modelo a priori, grau de incorporação do dado sísmico de entrada e um termo de norma L-1 da refletividade para controlar o grau de Sparse-Spike.

O modelo a priori, além de restringir o processo de inversão a uma única solução alinhada à informação geológica conhecida, possibilita também o aumento da banda de frequência nas baixas frequências (menores que, região do espectro em que o dado sísmico é muito atenuado ou mesmo ausente por efeitos de interferência destrutiva (ghost da fonte e receptor) como ilustra a (Figura 2.29). Em geral usa-se ferramentas geoestatísticas aplicadas à baixa frequência dos perfis de impedância dos poços para gerar o modelo a priori 3D que entrará no processo iterativo de inversão junto ao dado sísmico, como foi o caso da Seção Reservatório (Sub-Sal) e Salífera do PPSBS.

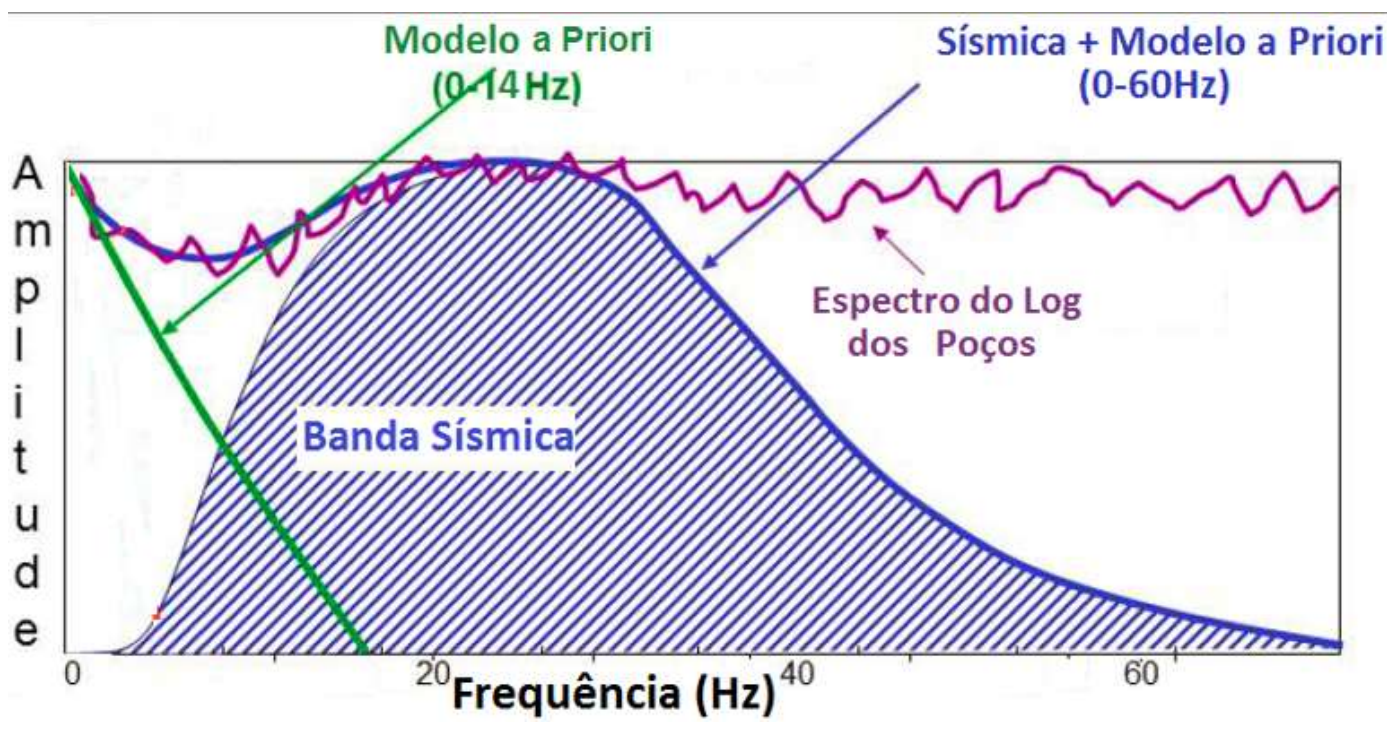

Figura 2.29: Conteúdo de Frequência do Log de Poços, do Modelo a Priori e do Dado de Amplitude Sísmica

$\mathrm{Na}$ ausência ou baixa amostragem de perfis de poços, como é o caso da Seção Pós-Sal, pode-se empregar o modelo de velocidades acústicas do processamento sísmico. 
Para uso quantitativo das propriedades acústicas ou elásticas resultantes da inversão sísmica CSSI é fundamental ter-se um bom modelo a priori que ao menos alinhe-se ao modelo geológico conceitual da área.

Quanto mais incorreto o modelo a priori, mais incorretas serão as propriedades resultantes do meio as quais a inversão conduzirá, podendose observar em casos extremos artefatos de : lobos-laterais acima e abaixo da camada invertida bem como tuning e dimming na camada.

Neste sentido, é interessante ter a disposição um bom repertório de técnicas que permitam refinar o modelo a priori. 


\section{3}

\section{Material e Método}

Este capítulo aborda os materiais e métodos utilizados na pesquisa. Apresenta os corpos de prova para os ensaios mecânicos simultâneos e o dado sísmico e de poço utilizado, bem como, o método de caracterização elástica dos corpos de prova e do dado sísmico.

\subsection{Material}

O material empregado constitui-se de:

- Análogo mecânico dos reservatórios carbonáticos Sub-Sal (bloco de travertino romano).

- Dado sísmico migrado, empilhado e cubo de velocidade-P intervalar de uma área de 100 quilômetros quadrados do bloco BM-S-0282 do PPSBS, cedidos pela ANP.

- Perfis de 10 poços do bloco BM-S-0282 do PPSBS, cedidos pela ANP

A Bacia de Santos possui uma pequena parte onshore e sua quase totalidade offshore. Está localizada na margem sudeste brasileira e é limitada pela: Bacia de Campos a Norte, Bacia de Pelotas a Sul, Serra do Mar a Oeste e Plateau de São Paulo a Leste (Figura 3.1) 


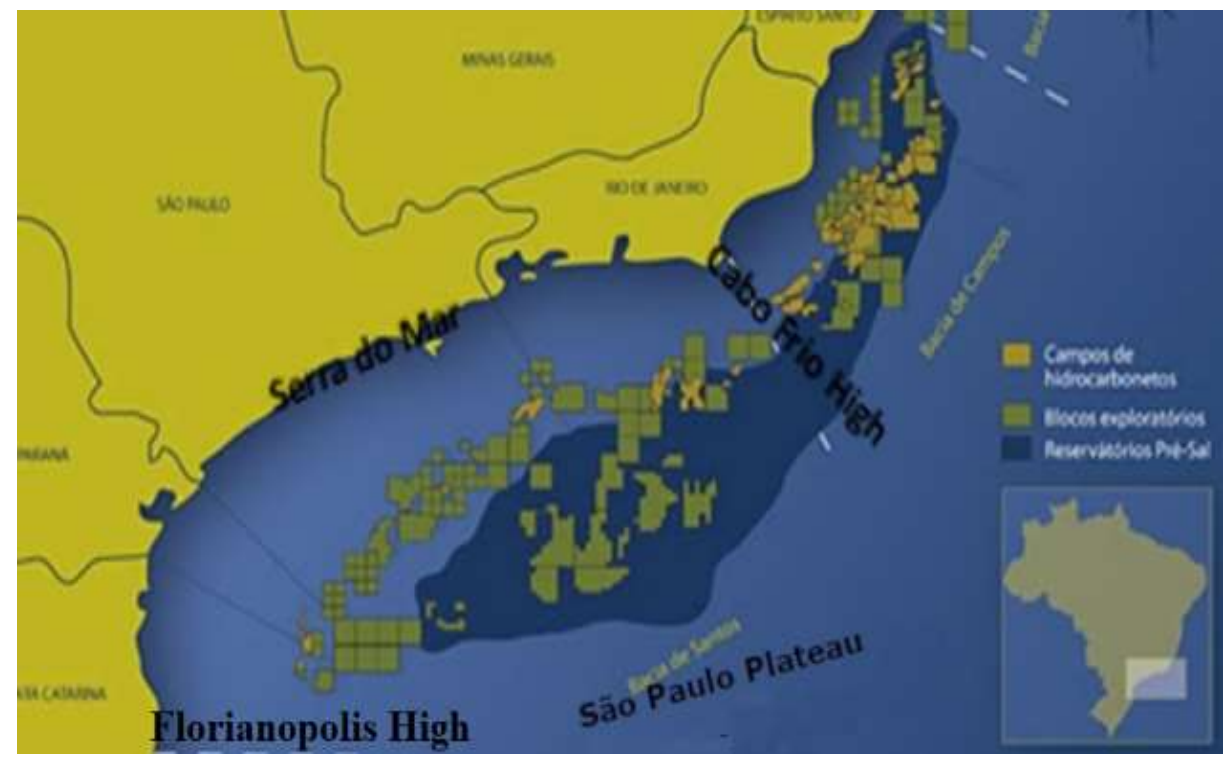

Figura 3.1: Localização da Bacia de Santos

O PPSBS dista em torno de $300 \mathrm{Km}$ a Leste da cidade do Rio de Janeiro, localiza-se em águas ultra profundas (aproximadamente 2200 m de lâmina d'água) e os reservatórios carbonáticos pré-sal possuem profundidade em torno de $5000 \mathrm{~m}$.

A Bacia de Santos foi formada durante a abertura do supercontinente Gondwana e seu preenchimento será disposto a seguir com base na carta estratigráfica da Bacia de Santos (Figura 3.2) 


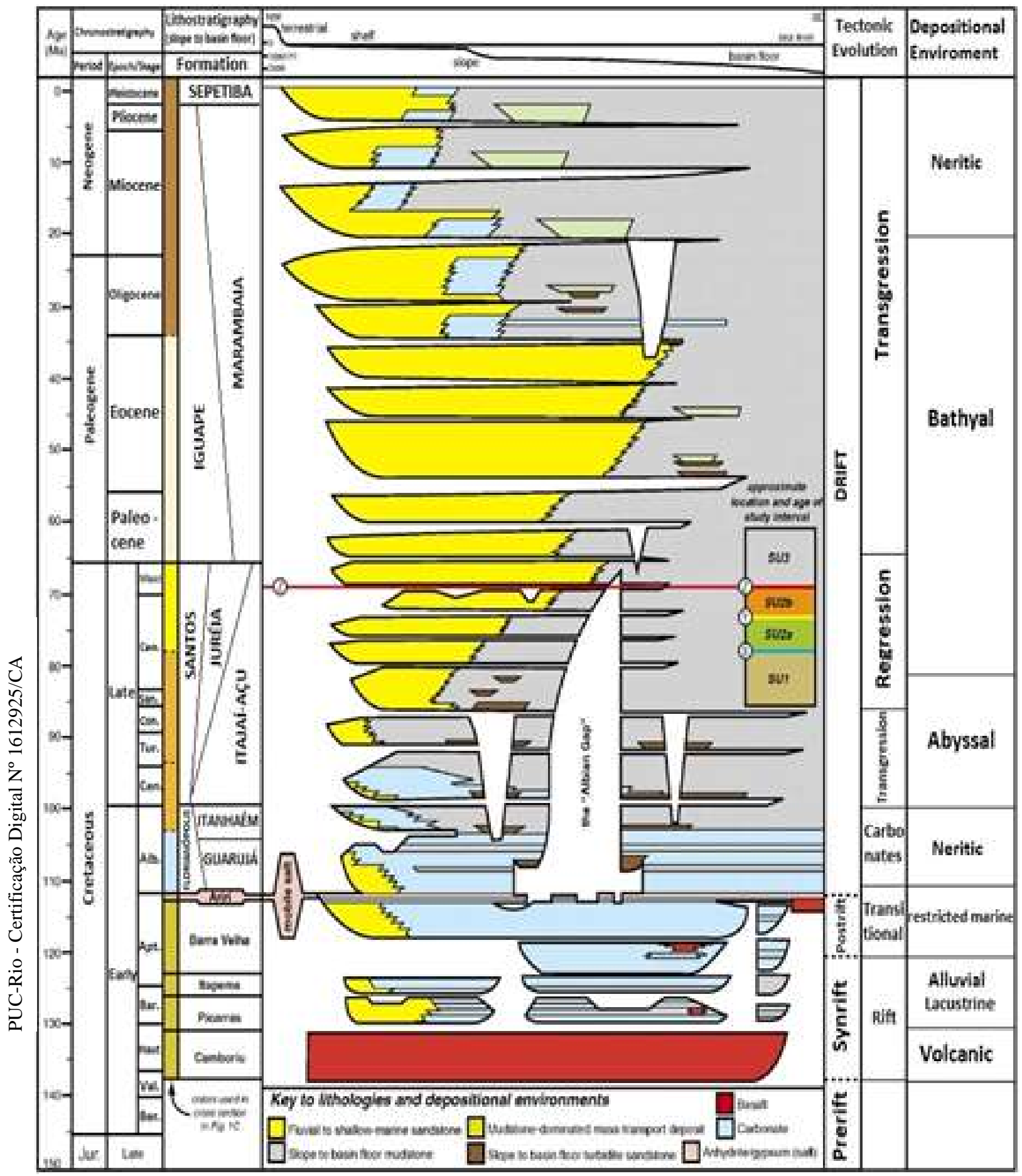

Figura 3.2: Carta Estratigráfica Bacia de Santos, Brasil, modificada de

Pereira e Feijó 1990

De idade Neocomiana, situada na base da carta, há a fase rift na qual se iniciou a abertura do supercontinente Gondwana e se encontram as Formações Camboriú, Piçarras, Itapema e Barra Velha 300.

A Formação Camboriú constitui-se em grande parte de rochas basálticas num ambiente vulcânico. 
A Formação Piçarras inclui conglomerados num ambiente aluvial e folhelhos de composição estivensita num ambiente lacustre.

A Formação Itapema forma-se basicamente de conchas de bivalves num ambiente lacustre que em alguns casos constitui-se em excelente reservatório.

Em seguida de idade aptiana há a fase transicional SAG na qual se encontram as Formações Barra Velha 200, 100 e a Formação Ariri.

A Formação Barra Velha inclui microbialitos e argila magnesiana nos flancos e baixos estruturais num ambiente transicional continental.

Com poucas exceções, a Formação Barra Velha é o melhor reservatório da seção pré-sal em termos de permoporosidade, grau API e espessura da coluna de óleo.

A Formação Ariri é formada por uma grande variedade de sais: halita, anidrita, carnalita, taquidrita e silvita que atuam como o selo do reservatório pré-sal num ambiente transicional continental e marinho raso. $O$ sal de maior predominância, tipicamente $80 \%$ da Formação, Ariri é a halita.

Em seguida inicia-se a fase drift de margem passiva (formação de mar).

De idade Albiana são as Formação Itanhaém e Formação Guarujá, que se constituem basicamente de folhelhos carbonatados e margas.

Do final do Cretáceo tendo havido uma fase transgressiva e uma grande fase regressiva são as Formação Itajaí, Formação Santos e Formação Juréia que se constituem basicamente de folhelhos e arenitos.

Finalmente do Paleoceno até o Recente são as Formação Marambaia e Formação Iguapé que constituem-se basicamente de argilitos e siltitos numa grande fase transgressiva.

Para a realização dos ensaios laboratoriais mecânicos simultâneos que resultam na equivalência estático-dinâmico usada na modelagem das propriedades mecânicas de deformabilidade integradas ao dado sísmico do reservatório carbonático Sub-Sal, foram usadas amostras provenientes de um bloco de travertino romano como análogo mecânico da Formação Barra Velha 100 do PPSBS. 


\section{Dados de Rocha}

Uma fotografia do bloco de travertino romano empregado é exibida na Figura 3.3. Do bloco de travertino romano (Figura 3.3) foi serrado com uso de motosserra diamantada (Figura 3.4) o sub-bloco A1 (Figura 3.5).

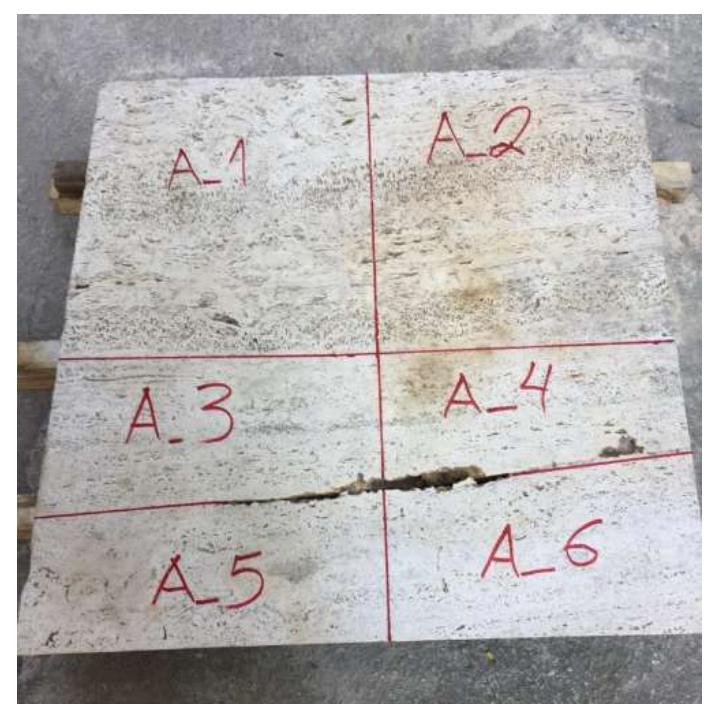

Figura 3.3: Bloco de Travertino Romano

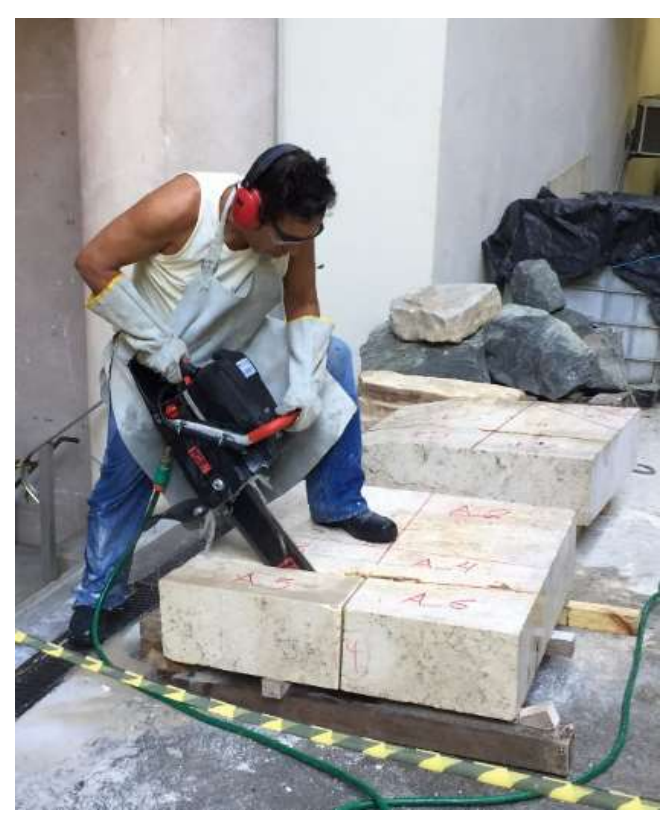

Figura 3.4: Bloco de Travertino Romano Serrado com Motosserra Diamantada 
Do Sub-Bloco A1 de travertino romano, rotacionado de 90 graus (Figura 3.6), foram extraídos barriletes cilíndricos de rocha (Figura 3.7) de $54 \mathrm{~mm}$ de diâmetro com uso de uma perfuratriz rotativa.

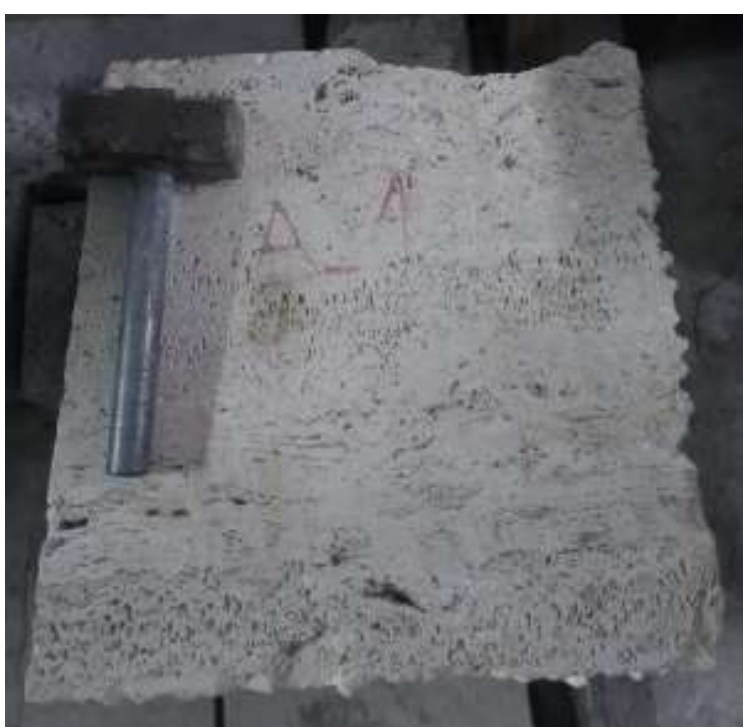

Figura 3.5: Sub-bloco A1 de Travertino Romano

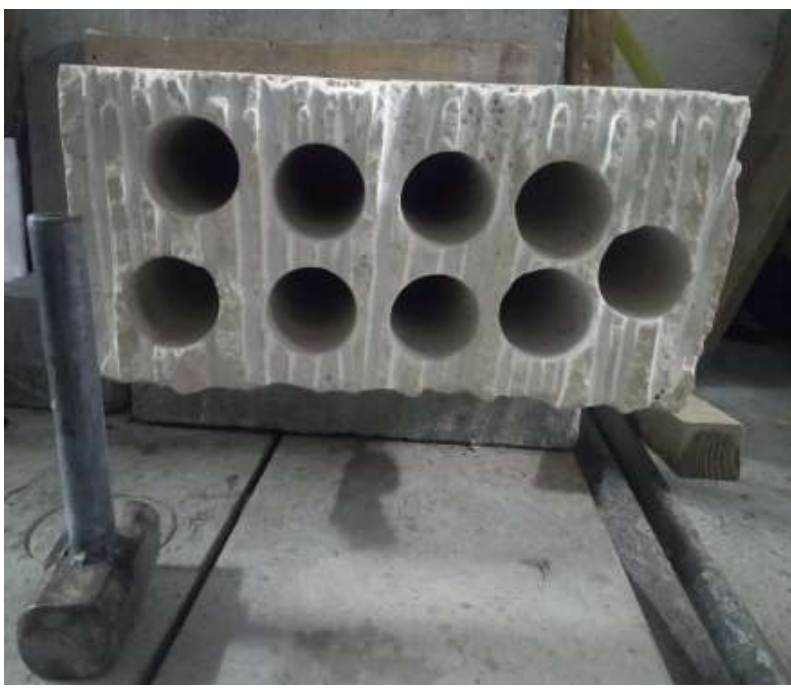

Figura 3.6: Sub-bloco A1 Rotacionado de 90 graus com Furos de Barriletes Cilíndricos Extraídos 


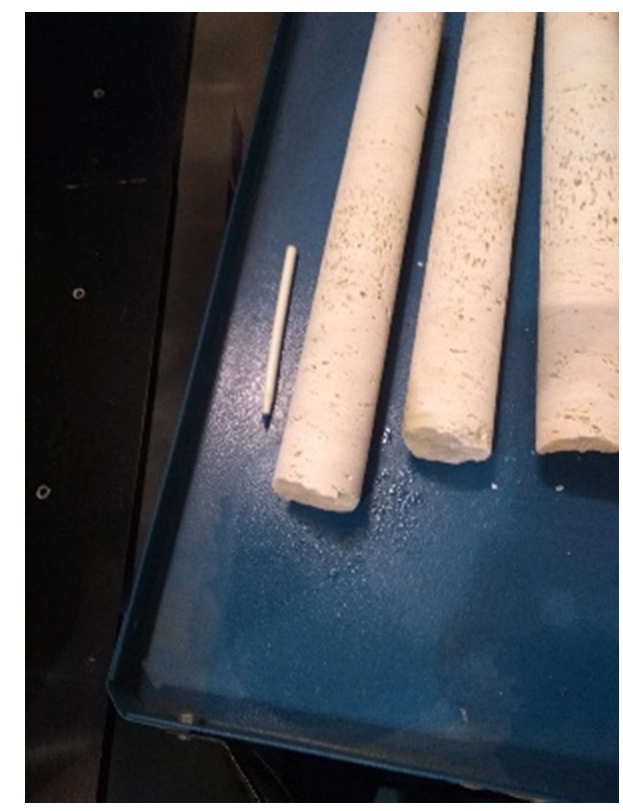

Figura 3.7: Barriletes Cilíndricos de Rocha com diâmetro de 54mm, extraídos do Sub-bloco A1

Os barriletes cilíndricos foram ainda retificados com rebolo para atingir as dimensões finais de diâmetro: $54 \mathrm{~mm}$ e comprimento: $108 \mathrm{~mm}$. Foram seguidas as instruções da norma ASTM D4543-08 para preparação dos corpos de prova resguardando material suficiente para manter a relação sugerida na norma 2:1 entre o comprimento e o diâmetro da base do corpo de prova.

\section{Dado Sísmico e de Poço}

O dado sísmico empregado foi concedido pela ANP e limita-se arealmente ao polígono (Figura 3.8) cujos vértices em coordenadas geográficas referenciadas ao datum SIRGAS 2000 (Figura 3.9) são exibidos a seguir. 


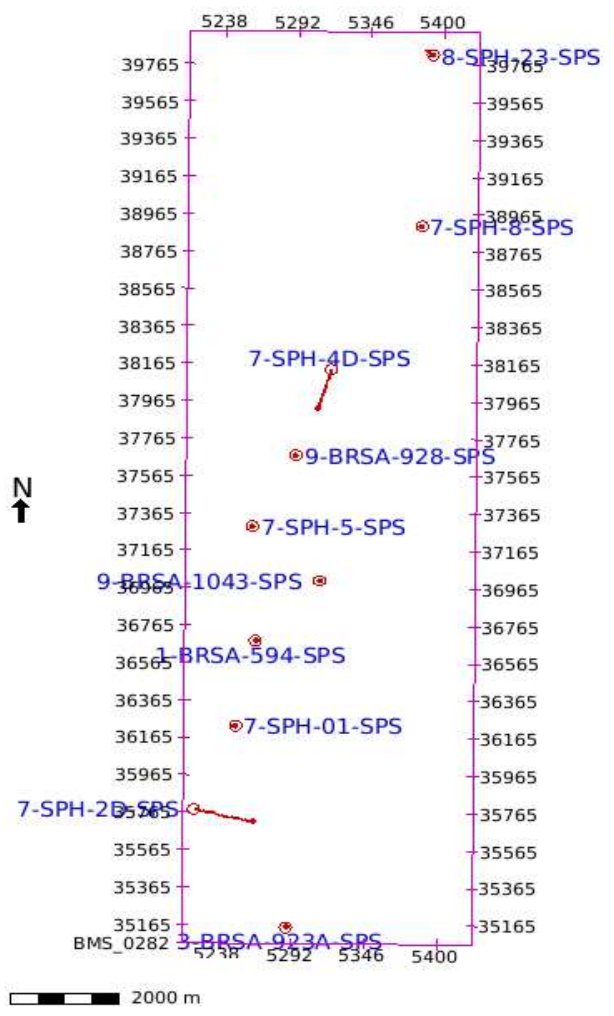

Figura 3.8: Polígono do Dado Sísmico 3D (0282 BMS Fase2) com os Poços Fornecidos pela ANP

\begin{tabular}{ll|l|}
\multicolumn{2}{c}{ LATITUDE } & \multicolumn{2}{c}{ LONGITUDE } \\
\cline { 2 - 3 } 1 & $25^{\circ} 51^{\prime} 51,421^{\prime \prime} \mathrm{S}$ & $43^{\circ} 14^{\prime} 21,589^{\prime \prime} \mathrm{W}$ \\
\hline 2 & $25^{\circ} 51^{\prime} 51,421^{\prime \prime} \mathrm{S}$ & $43^{\circ} 08^{\prime} 44,476^{\prime \prime} \mathrm{W}$ \\
\hline 3 & $25^{\circ} 40^{\prime} 58,565^{\prime \prime} \mathrm{S}$ & $43^{\circ} 14^{\prime} 21,589^{\prime \prime} \mathrm{W}$ \\
\hline & $25^{\circ} 40^{\prime} 58,565^{\prime \prime} \mathrm{S}$ & $43^{\circ} 08^{\prime} 44,476^{\prime \prime} \mathrm{W}$ \\
\hline
\end{tabular}

Figura 3.9: Coordenadas Geográficas (Datum SRIGAS 2000) dos Vértices do Polígono da Figura 3.8

Os dados de poços empregados foram concedidos pela ANP e tratam-se dos perfis de Sônico-P, Sônico-S, Densidade, Raios Gama e Litologia dos poços exibidos (Figura 3.10). 


\begin{tabular}{r|c}
\multicolumn{1}{c|}{} & nome do poço \\
\cline { 2 - 2 } $\mathbf{1}$ & 1-BRSA-594-SPS \\
\cline { 2 - 2 } $\mathbf{2}$ & 9-BRSA-928-SPS \\
\cline { 2 - 2 } $\mathbf{3}$ & 3-BRSA-923A-SPS \\
\cline { 2 - 2 } $\mathbf{4}$ & 9-BRSA-1043-SPS \\
$\mathbf{5}$ & 7-SPH-02D-SPS \\
$\mathbf{6}$ & 7-SPH-04D-SPS \\
$\mathbf{7}$ & 7-SPH-08-SPS \\
\cline { 2 - 2 } $\mathbf{8}$ & 7-SPH-01-SPS \\
\cline { 2 - 2 } $\mathbf{9}$ & 7-SPH-05-SPS \\
\hline $\mathbf{1 0}$ & 8-SPH-23-SPS
\end{tabular}

Figura 3.10: Lista com os Poços Fornecidos pela ANP

O dado de amplitude sísmica migrada e empilhada e de velocidade-P intervalar cedidos pela ANP foram obtidos respectivamente por migração kirchoff em profundidade e inversão tomográfica por traçado de raios. $\mathrm{O}$ dado de amplitude sísmica foi empilhado dentro da faixa de ângulos de reflexão $\left(05^{\circ}-32^{\circ}\right)$.

\subsection{Caracterização do Material}

\subsubsection{Descrição Macroscópica das Amostras de Rocha}

Os corpos de prova de travertino romano (CPTR) possuem diâmetro e comprimento, nominal de retifica, de respectivamente: $54 \mathrm{~mm}$ e $108 \mathrm{~mm}$. Os 5 CPTR produzidos apresentam porosidade efetiva elevada de aproximadamente $15 \%$ tanto no que refere à porosidade intergranular (de matriz) como a superficial. Evitou-se de produzir os CPTR com regiões visivelmente muito karstificadas, o que reduz o confinamento e tensão desviadora que se pode atingir nos ensaíos.

É exibido na Figura 3.11 o CPTR de número 2 de um total de 5 CPTRs empregados para os ensaios mecânicos simultâneos. 


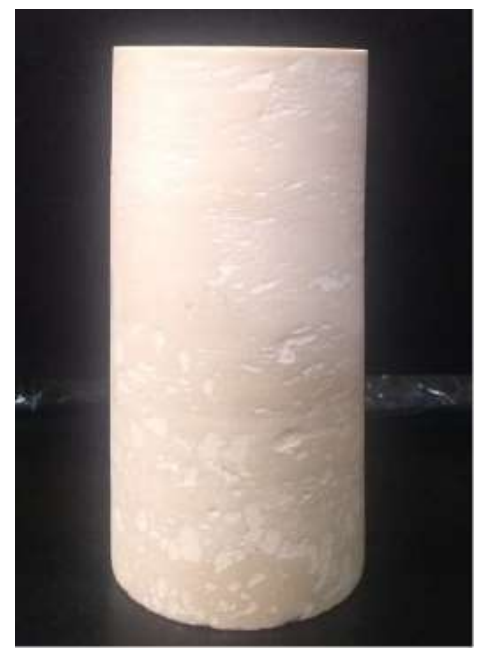

Figura 3.11: Corpo de Prova Tipo de Travertino (CPTR-2)

\subsection{2}

\section{Peso Específico e Porosidade}

Para a determinação dos índices físicos da rocha: peso específico e porosidade efetiva, foi empregado o padrão (ISRM 1977) Suggested Methods for Determining Water Content, Porosity, Density, Absorption and Related Properties and Swelling and Slake-Durability Index Properties. Inicialmente os corpos de prova são deixados secar em estufa por um período de $24 \mathrm{~h}$ e temperatura de $100^{\circ} \mathrm{C}$.

Uma vez seco, o corpo é pesado na balança da Figura 3.12

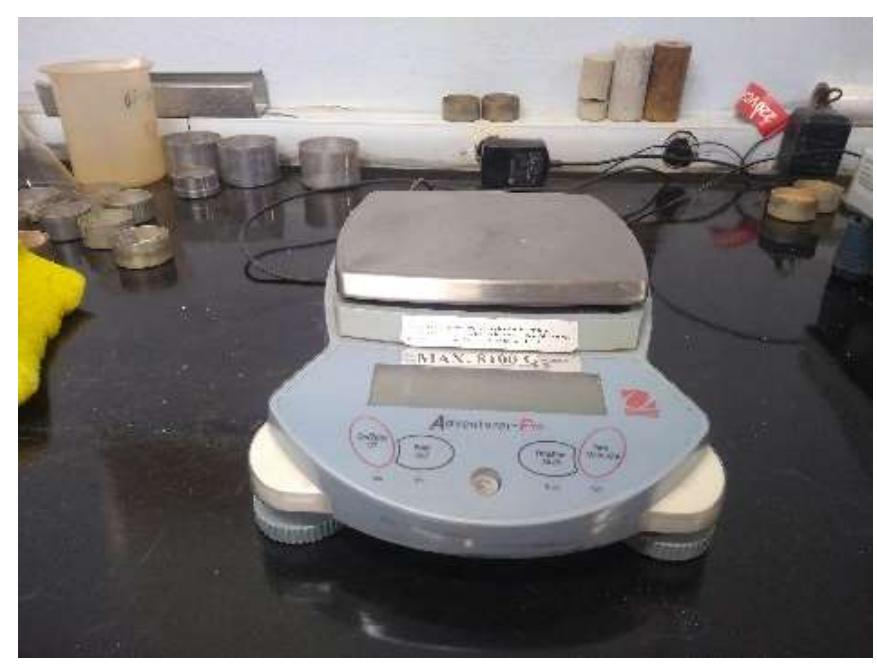

Figura 3.12: Balança Adventurer Pro (Ohaus) 
Obtendo-se deste modo o peso do corpo seco $W_{\text {seco }}$. Em seguida o corpo de prova é saturado com água sendo inicialmente posto imerso em água por $24 \mathrm{~h} \mathrm{e}$, em seguida, posto em dessecador contendo água (Figura 3.13), e com aplicação de contrapressão produzido por bomba a vácuo, deixado saturar por mais $1 \mathrm{~h}$.

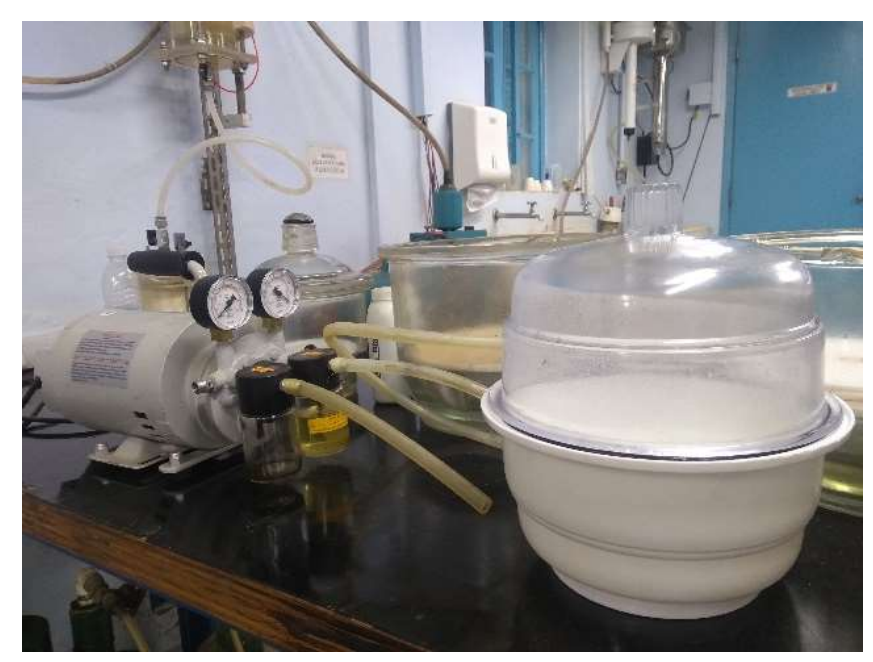

Figura 3.13: Dessecador Empregado para Saturar os Corpos de Prova

O corpo deste modo saturado é então pesado na balança da Figura 3.12. Para obter o peso saturado do corpo, é adicionado ao peso do corpo de prova saturado no dessecador da Figura 3.13, o peso do volume de água alojado nos poros superficiais da amostra. Este peso é determinado colocando a amostra saturada na proveta graduada cheia de água e observando a diminuição do volume de água da proveta (em decorrência da água que se alojou nos poros superficiais da amostra) quando da retirada rápida do corpo de prova da proveta (Figura 3.14). 


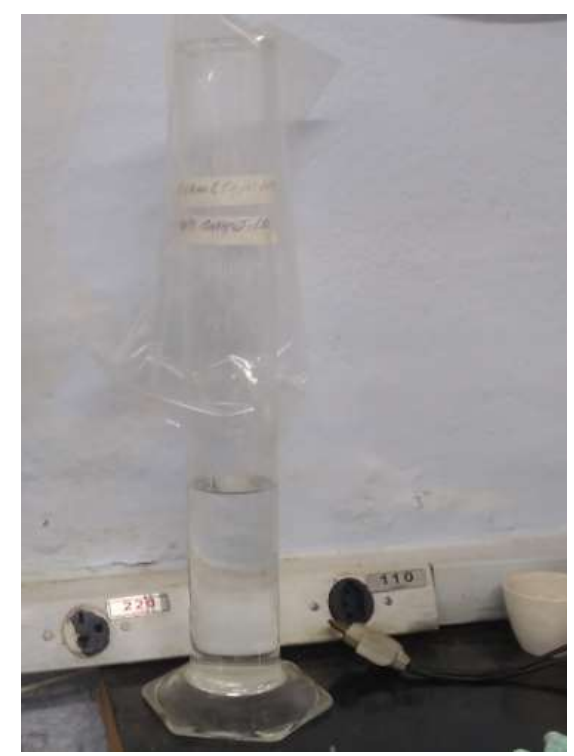

Figura 3.14: Proveta Graduada Empregada para Determinar Volume Poroso da Superfície do Corpo de Prova

Tendo-se deste modo $W_{\text {sat }}$ para o corpo de prova, pode-se determinar seu volume poroso $V_{p}$ através de:

$$
W_{\text {sat }}=W_{\text {seco }}+\gamma_{w} \cdot V_{p}
$$

Em seguida com o sistema rede (presa num gancho situado na base da balança) e balança (Figura 3.15), mede-se o peso submerso $W_{\text {sub }}$ do corpo de prova

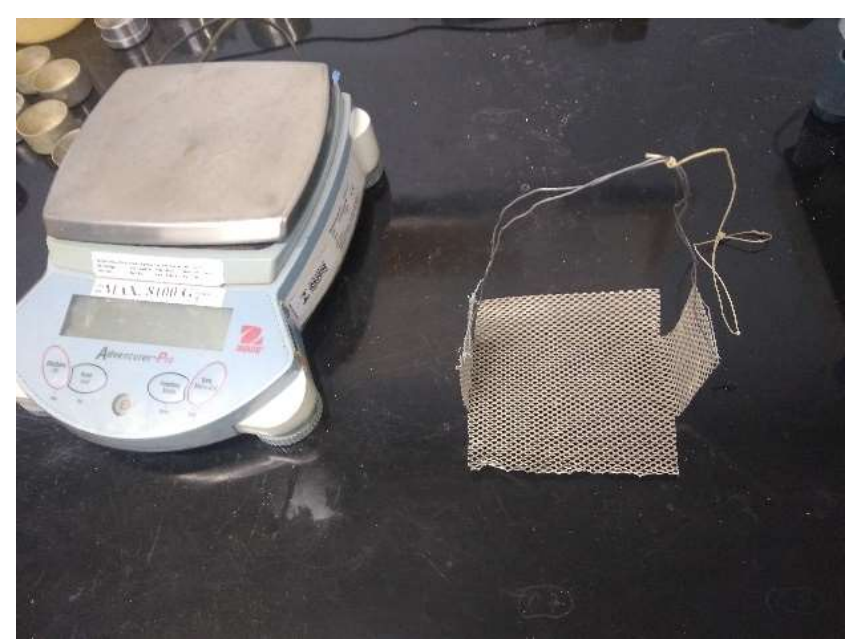

Figura 3.15: Sistema Balança e Rede empregados para medir o peso do corpo de prova quando submerso em água 
Tendo-se deste modo $W_{\text {sub }}$ para o corpo de prova, pode-se determinar seu volume total $\mathrm{V}$ através de:

$$
W_{\text {sub }}=W_{\text {sat }}-\gamma_{w} . V
$$

Pode-se deste modo estimar a porosidade da amostra $\emptyset_{\text {eff }}=V_{p} / \mathrm{V}$, o peso específico do grão $\gamma_{s}=W_{\text {seco }} /\left(\bigvee-V_{p}\right)$, o peso específico seco $\gamma_{\text {seco }}=W_{\text {seco }} / \mathrm{V}$ e o peso específico saturado $\gamma_{\text {sat }}=W_{\text {sat }} / \mathrm{V}$.

São exibidos na Tabela 3.1 para os cinco corpos de prova de travertino romano (CPTR), os pesos $W_{\text {seco }}, W_{\text {sat }}, W_{\text {seco }}$ em $(\mathrm{N})$, a porosidade efetiva $\emptyset_{\text {eff }}$ e os pesos específicos $\gamma_{\text {seco }}, \gamma_{s}, \gamma_{\text {sat }}$ em KN/m ${ }^{3}$

\begin{tabular}{|c|c|c|c|c|c|c|c|}
\hline & $W_{\text {seco }}$ & $W_{\text {sat }}$ & $W_{\text {sub }}$ & $\emptyset_{e f f}$ & $\gamma_{\text {seco }}$ & $\gamma_{s}$ & $\gamma_{\text {sat }}$ \\
\hline CPTR-1 & 5,18 & 5,46 & 3,09 & 0,12 & 21,4 & 24,3 & 22,6 \\
\hline CPTR-2 & 4,67 & 5,01 & 2,73 & 0,15 & 20,1 & 23,7 & 21,6 \\
\hline CPTR-3 & 4,95 & 5,25 & 2,93 & 0,13 & 20,9 & 24,0 & 22,2 \\
\hline CPTR-4 & 5,13 & 5,39 & 3,03 & 0,11 & 21,3 & 23,9 & 22,4 \\
\hline $\begin{array}{l}\text { CPTR-5 } \\
\end{array}$ & 5,39 & 5,60 & 3,21 & 0,09 & 22,1 & 24,3 & 23,0 \\
\hline
\end{tabular}

Tabela 3.1: Pesos, Porosidade Efetiva e Pesos Específicos dos cinco corpos de prova de travertino romano (CPTR)

\subsection{3}

\section{Análise do Sinal Sísmico}

Foi analisado o espectro de frequência do dado sísmico em cinco diferentes camadas com objetivo de se modelar a mudança na forma do pulso sísmico com o soterramento. Nas camadas delimitadas pelos horizontes mapeados na sessão sísmica ilustrada na Figura $3.16 \mathrm{em}$ ordem de profundidade: Topo Fm. Marambaia, Topo Fm. Itajaí-Açú, Topo Fm. Itanhaém, Topo Fm. Ariri, Topo Fm. Barra Velha e Topo da Fm. Piçarras foram extraídos cindo espectros de frequência do dado de amplitude sísmica. 


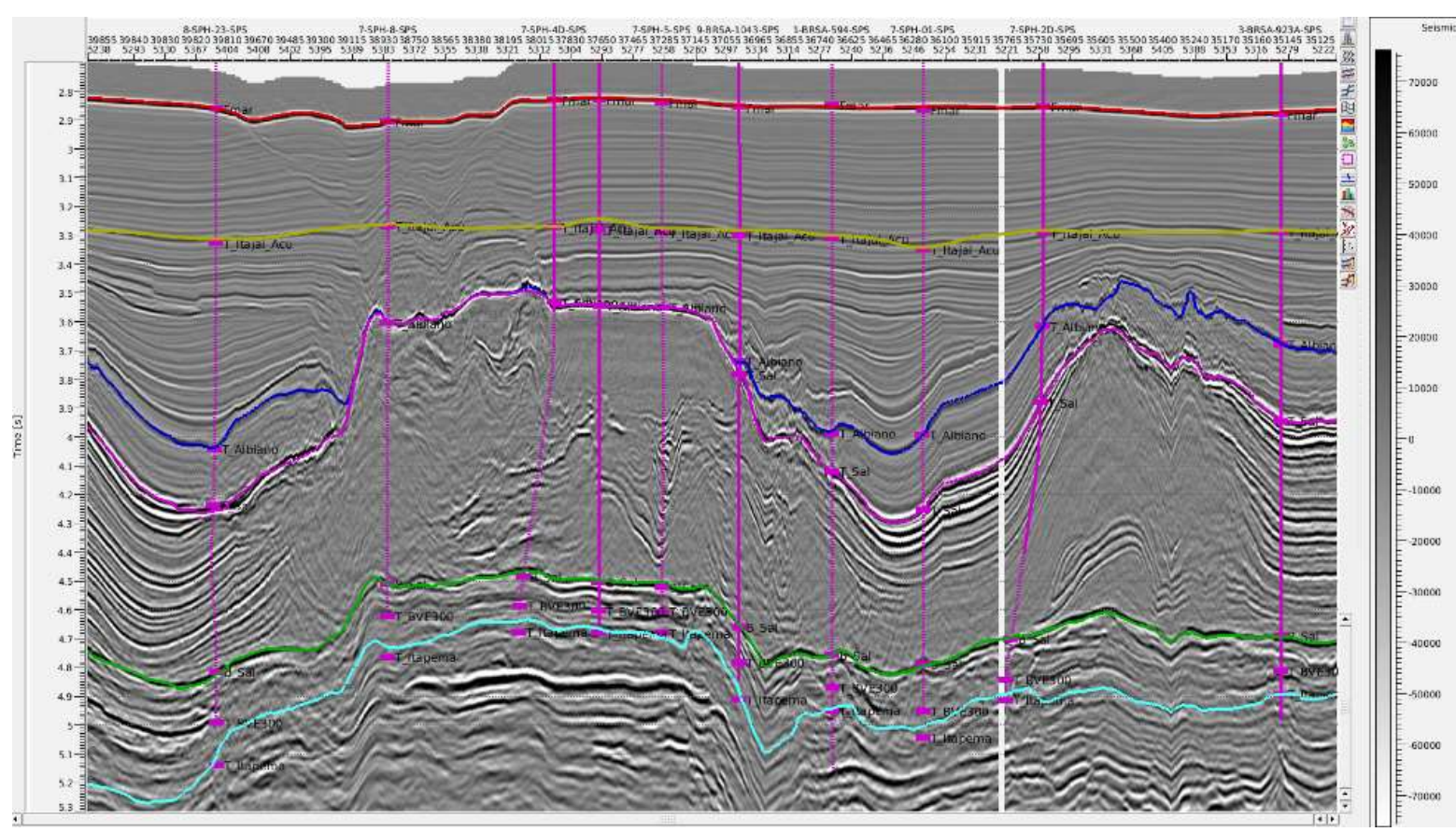

Figura 3.16: Sessão de Amplitude Sísmica em Profundidade com Poços e Camadas para Análise da Dispersão do Pulso Sísmico

A Figura 3.17 ilustra em preto o espectro de frequência extraído do dado sísmico na primeira camada que é delimitada pelos horizontes: Topo da Fm. Marambaia e Topo da Fm. Itajaí-Açú na Figura 3.16 junto do espectro de frequência do pulso empregada no estudo (em vermelho).

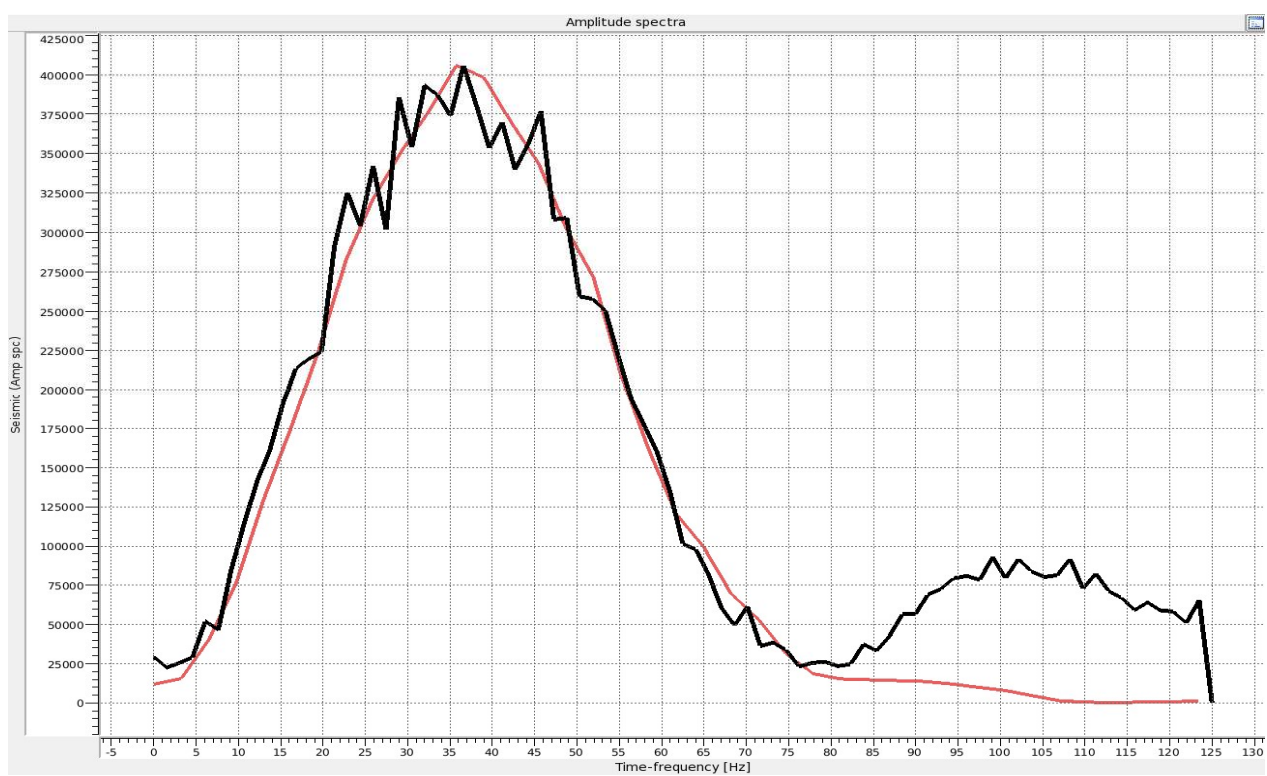

Figura 3.17: Espectro de frequência extraído do dado sísmico na camada entre Topo Fm. Marambaia e Topo Fm. Itajaí-Açú (preto) e espectro de frequência empregado no estudo para essa camada (vermelho) 
A Figura 3.18 ilustra em preto o espectro de frequência extraído do dado sísmico na segunda camada que é delimitada pelos horizontes: Topo da Fm. Itajaí-Açú e Topo da Fm. Itanhaém na Figura 3.16 junto do espectro de frequência do pulso empregada no estudo (em amarelo).

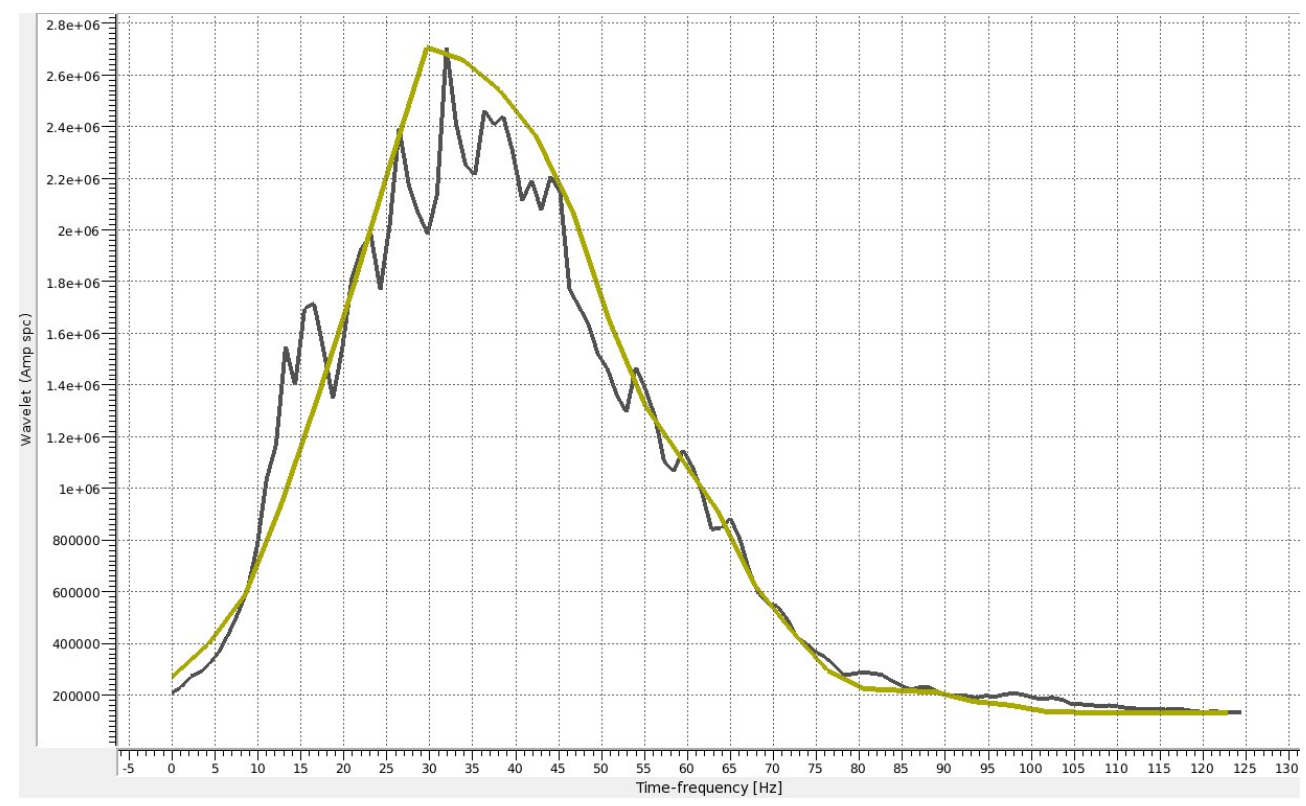

Figura 3.18: Espectro de frequência extraído do dado sísmico na camada entre Topo Fm. Itajaí-Açú e Topo Fm. Itanhaém (preto) e espectro de frequência empregado no estudo para essa camada (amarelo)

A Figura 3.19 ilustra em preto o espectro de frequência extraído do dado sísmico na terceira camada que é delimitada pelos horizontes: Topo da Fm. Itanhaém e Topo da Fm. Ariri na Figura 3.16 junto do espectro de frequência do pulso empregada no estudo (em azul). 


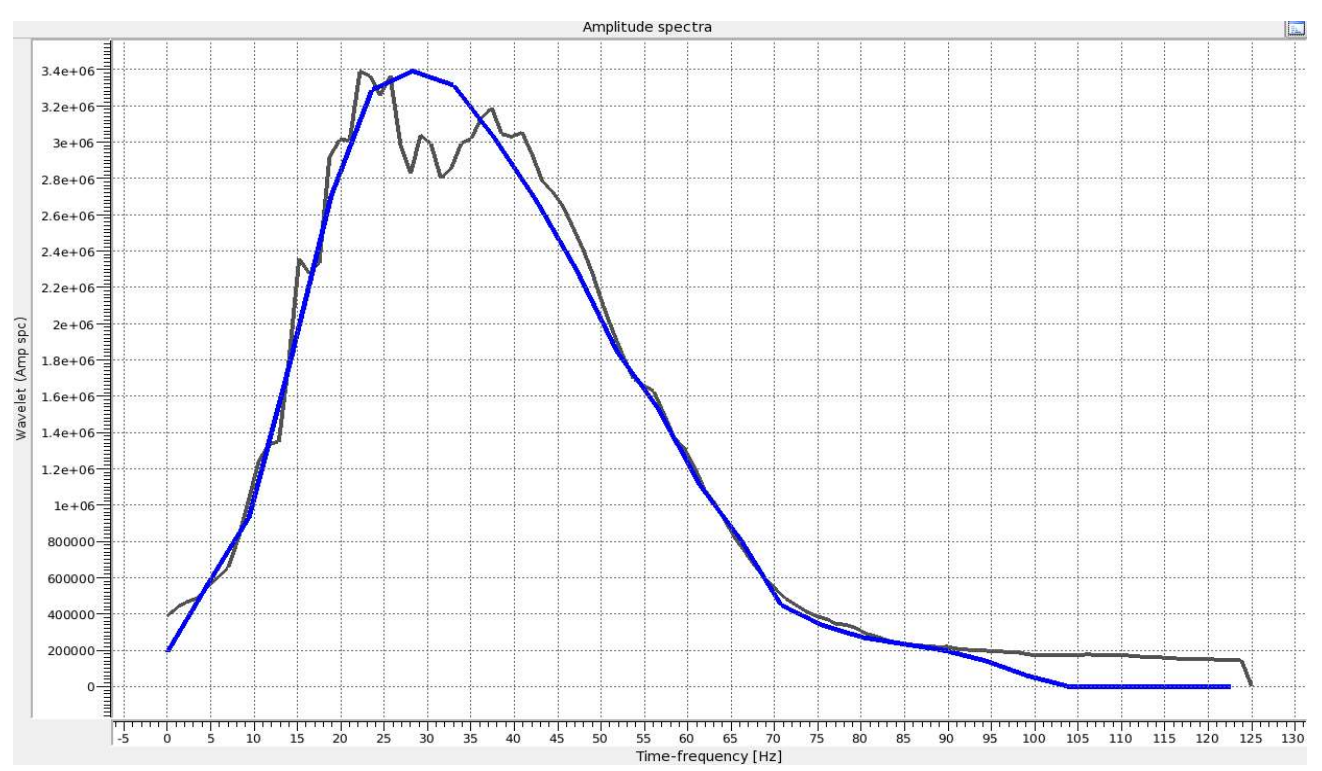

Figura 3.19: Espectro de frequência extraído do dado sísmico na camada entre Topo Fm. Itanhaém e Topo da Fm. Ariri (preto) e espectro de frequência empregado no estudo para essa camada (azul)

A Figura 3.20 ilustra em preto o espectro de frequência extraído do dado sísmico na quarta camada que é delimitada pelos horizontes: Topo da Fm. Ariri e Topo da Fm. Barra Velha na Figura 3.16 junto do espectro de frequência do pulso empregada no estudo (em vermelho).

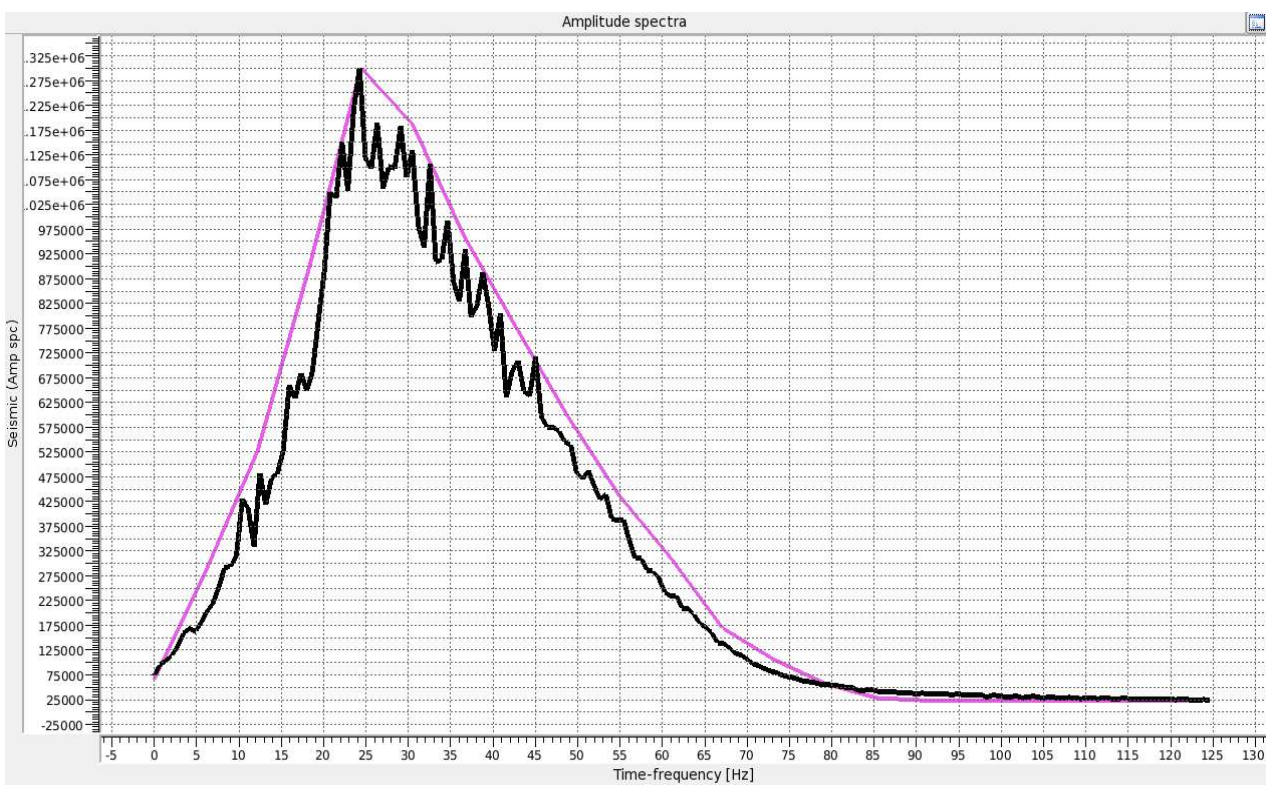

Figura 3.20: Espectro de frequência extraído do dado sísmico na camada entre Topo da Fm. Ariri e Topo da Fm. Barra Velha (preto) e espectro de frequência empregado no estudo para essa camada (vermelho) 
A Figura 3.21 ilustra em preto o espectro de frequência extraído do dado sísmico na quinta camada que é delimitada pelos horizontes: Topo da Fm. Barra Velha e Topo da Fm. Itapema na Figura 3.16 junto do espectro de frequência do pulso empregada no estudo (em verde)

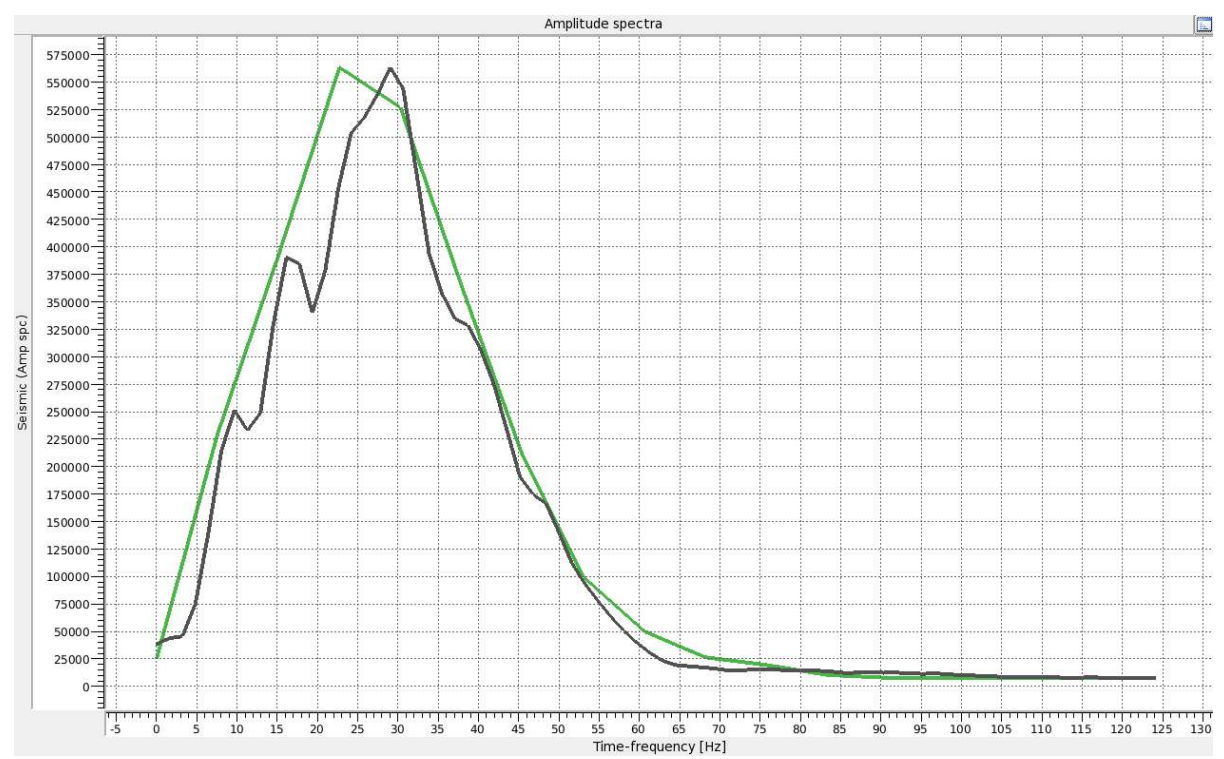

Figura 3.21: Espectro de frequência extraído do dado sísmico na camada entre Topo da Fm. Barra Velha e Topo da Fm. Itapema (preto) e espectro de frequência empregado no estudo para essa camada (verde)

A simples inspeção das Figuras 3.17, 3.18, 3.19, 3.20 e 3.21 evidência a mudança de forma do pulso sísmico com a profundidade (dispersão) e perda do conteúdo das altas frequências.

\section{3}

\section{Caracterização Elástica dos Corpos de Prova}

O equipamento empregado na medição dos parâmetros elásticos dos corpos de prova consiste, simplificadamente, de uma parte eletrônica com cristal piezoelétrico e de uma parte hidromecânica com prensa de aço e vaso hidráulico. Para um dado estado de tensão do corpo de prova, o uso simultâneo destas duas partes permite a aferição tanto das velocidades ultrassônicas compressional e cisalhante (usadas na estimativa dos parâmetros elásticos dinâmicos) quanto das deformações axial e radial 
sofrida pelo corpo de prova (usadas para obtenção dos parâmetros elásticos estáticos), sabendo-se a tensão aplicada ao corpo.

Para a caracterização dos parâmetros elásticos por ensaios simultâneos, seguiram-se os padrões estabelecidos na norma ASTM D2845-08, e foi utilizada uma célula triaxial cilíndrica axissimétrica, $\sigma 2=\sigma 3$, modelo RTR1500 desenvolvida pela empresa GCTS (Geotechnical Consulting \& Testing Systems), ilustrada na Figura 3.22. O aplicativo utilizado para o controle dos ensaios foi o CATS Triaxial Test Mode 1.85 For Rocks.

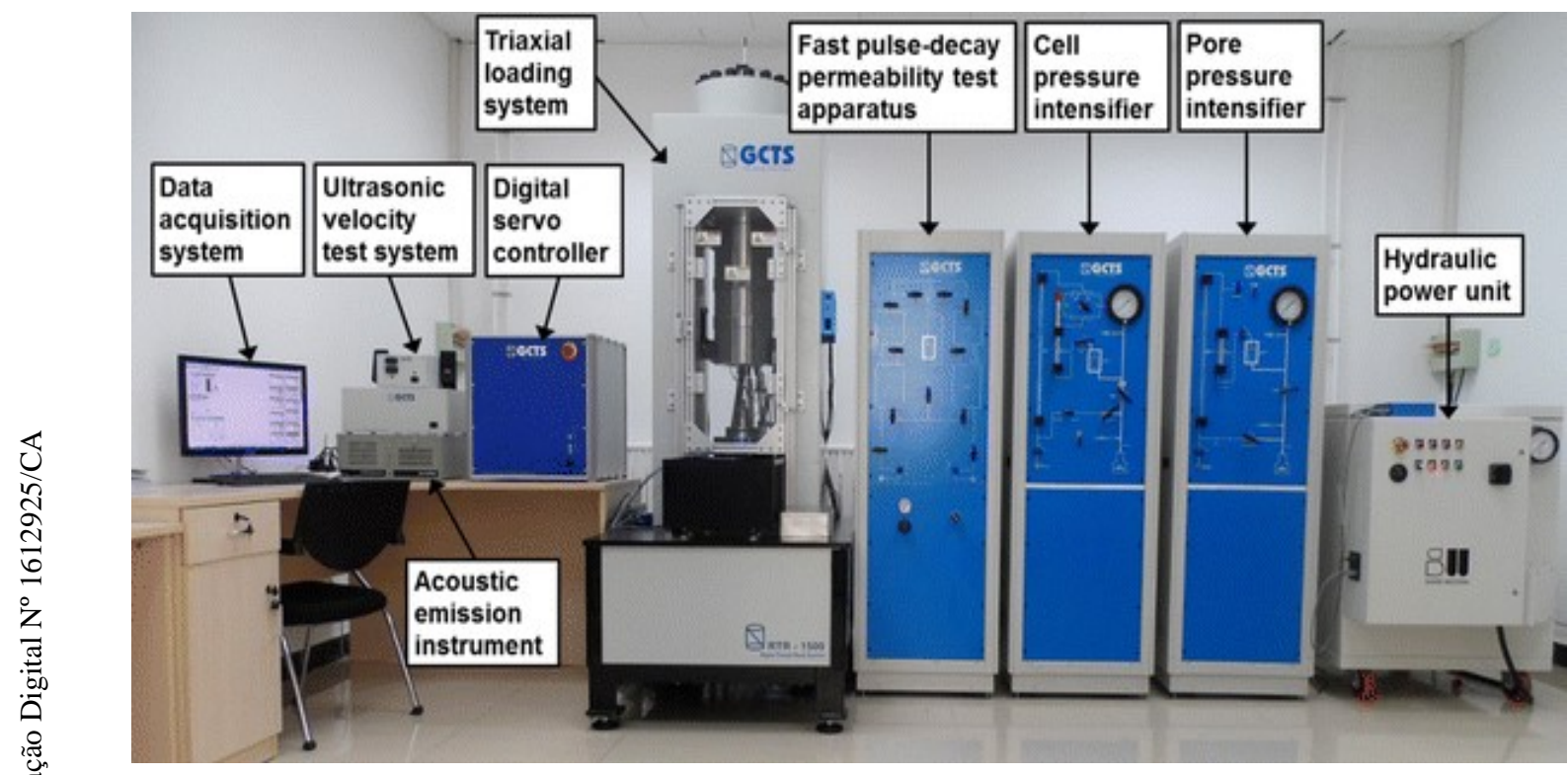

Figura 3.22 - Célula triaxial cilíndrica axissimétrica RTR-1500 (rapid rock triaxial system) desenvolvida pela empresa GCTS. Extraída de Botao Lin, Yan Jin, Huiwen Pang Amy B. Cerato 2016.

Para a medição das velocidades elásticas ultrassônicas nos corpos de rocha, o equipamento empregado conta com o seguinte arranjo simplificado exposto na (Figura 3.23): 


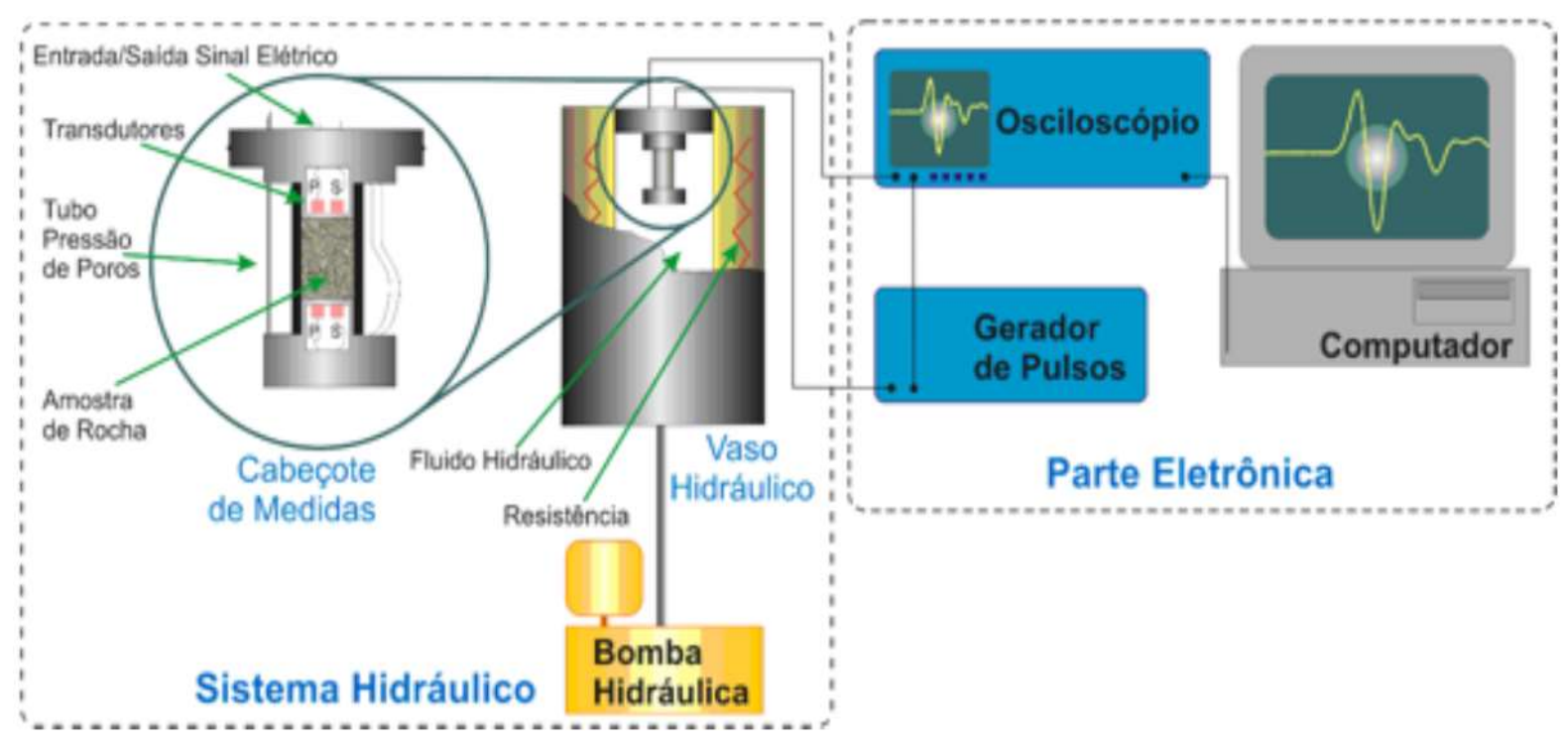

Figura 3.23 - Esquema ilustrativo do sistema de medidas de velocidades elásticas em amostras de rochas. (Vasquez 2010).

Na parte eletrônica tem-se um gerador de funções e um amplificador de potência que fornecem um sinal bem conhecido para um cabeçote metálico que contém em seu interior: dois transdutores piezoelétricos idênticos de material cerâmico localizados um no topo e outro na base e o corpo de prova localizado entre esses, no meio do cabeçote.

O cabeçote metálico de medida é posto no interior do vaso hidráulico por intermédio de um flange de modo a isolar hidráulica e eletricamente os componentes internos ao cabeçote: transdutores emissor, receptor e corpo de prova (isolado do fluido confinante por uma camisa de material termoretrátil ou borracha nitrílica). $O$ vaso hidráulico geralmente preenchido com água ou glicerina conta com válvulas para imposição de pressão de poros e pressão de confinamento, com uma resistência elétrica que permite o aquecimento da amostra para realização de ensaios a temperaturas controladas e sob o efeito de uma haste de aço de carregamento vertical para imposição de tensão (desviadora) à amostra. $\mathrm{O}$ transdutor do topo do cabeçote tem a função de transformar o sinal elétrico vindo do gerador de funções em uma vibração mecânica, compressional ou cisalhante, conforme o caso. Após percorrer o corpo de prova sujeito ao campo de tensões imposto no vaso, a vibração mecânica é recebida pelo transdutor na base, que a converte em sinal elétrico. Este sinal elétrico é então 
analisado em um osciloscópio após passar, caso necessário, por um amplificador e as formas de onda são armazenadas em computador para análises posteriores. Os ensaios foram realizados em 5 corpos de prova secos e pressão de poros aberta à pressão atmosférica e com um cabeçote de $54 \mathrm{~mm}$ de diâmetro. A Figura 3.24 ilustra a configuração de montagem do corpo de prova no cabeçote de medida. A imagem à esquerda mostra o corpo de prova encaixado no cap (cabeçote) e envolto numa membrana fina e transparente feita de material termo retrátil (borracha nitrílica) para isolar o corpo do fluído confinante.

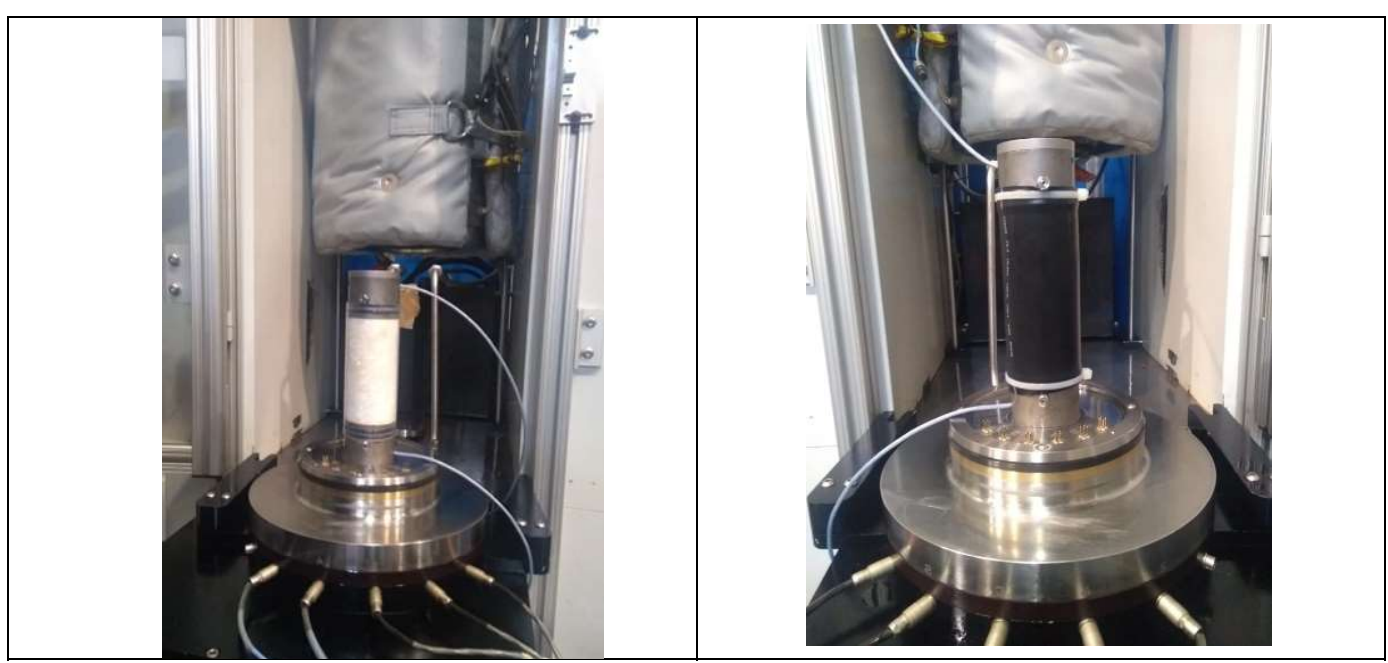

Figura 3.24 - Amostra ajustada ao cabeçote de medida preparada para ensaio mecânico.

A imagem à direita mostra uma segunda membrana, mais espessa e preta, para evitar rompimento do sistema de membranas e presa ao corpo de prova por braçadeira plástica (tairape/hellermann).

O travertino, por apresentar alta porosidade superficial necessita, adicionalmente a este sistema de duas membranas, do tamponamento de seus poros superficiais com material específico (pó do travertino misturado a gesso). A Figura 3.25 ilustra o arranjo empregado com os LVDT (Linear Variable Differential Transformer) axial e radial acoplados a um corpo de prova de Alumínio para a medida da deformação do corpo. 


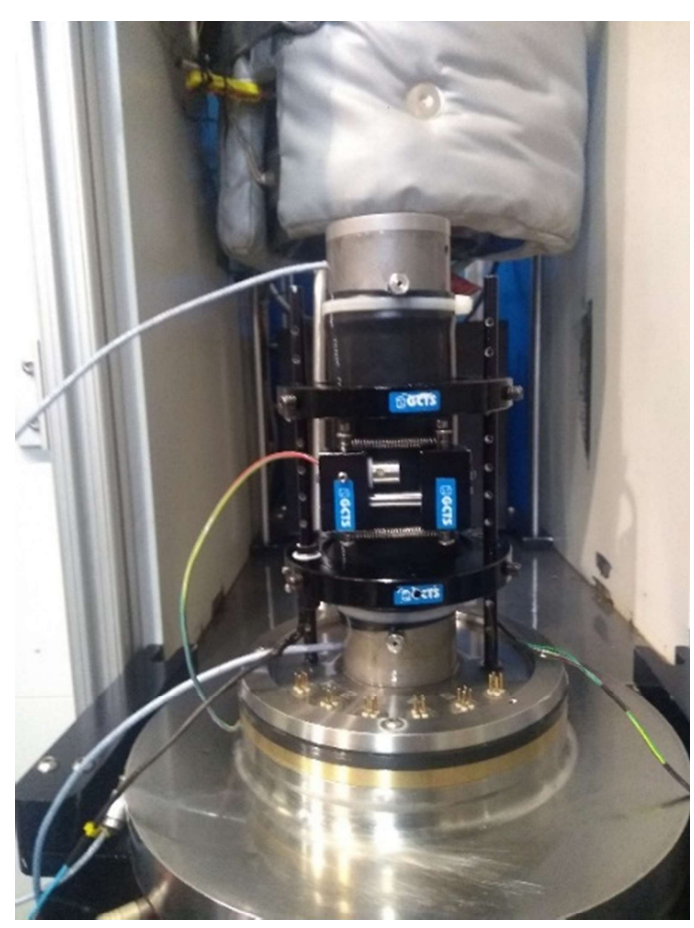

Figura 3.25: Corpo de Prova de Alumínio no Cabeçote de Medida com LVDT axiais e radiais acoplados.

A Figura 3.26 a seguir mostra o gel espalhado no topo e base do corpo de prova quando do encaixe ao cap para melhorar o acoplamento.

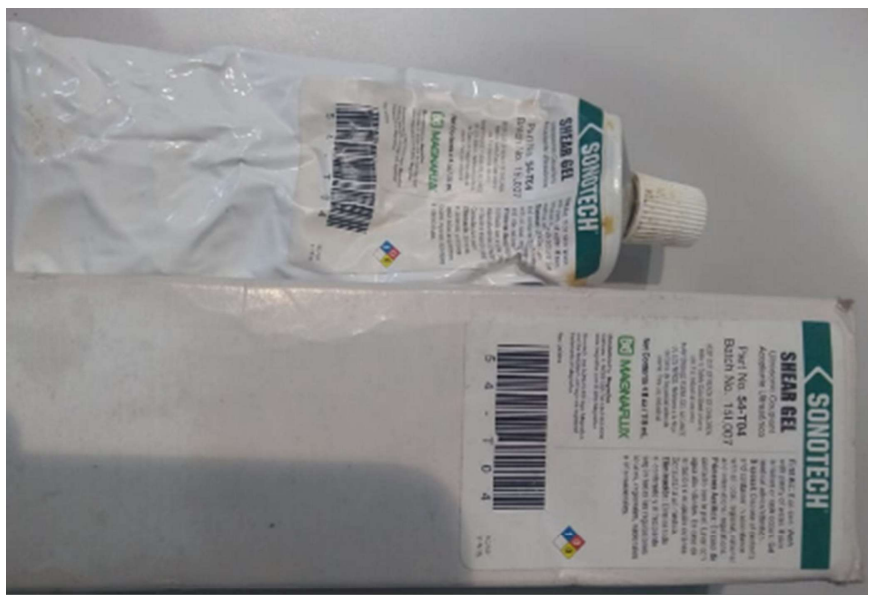

Figura 3.26: Gel Acoplante Colocado no Topo e Base do Corpo de Prova.

As velocidades de propagação das ondas elásticas nas rochas são calculadas dividindo-se o comprimento do corpo de prova, $\Delta \mathrm{x}$, pelo tempo de trânsito, $\Delta \mathrm{t}$, efetivamente gasto pelo pulso para percorrer o corpo de prova conforme ilustrado na Figura 3.27. O tempo de trânsito $\Delta$ t é dado pelo 
tempo observado no osciloscópio diminuído do tempo do sistema ou tempo de atraso $\Delta t_{0}$ (intrínseco ao sistema de medida), que é o tempo gasto pelo sinal na parte eletrônica e nos cabeçotes metálicos, sem nenhuma amostra inserida entre os mesmos.
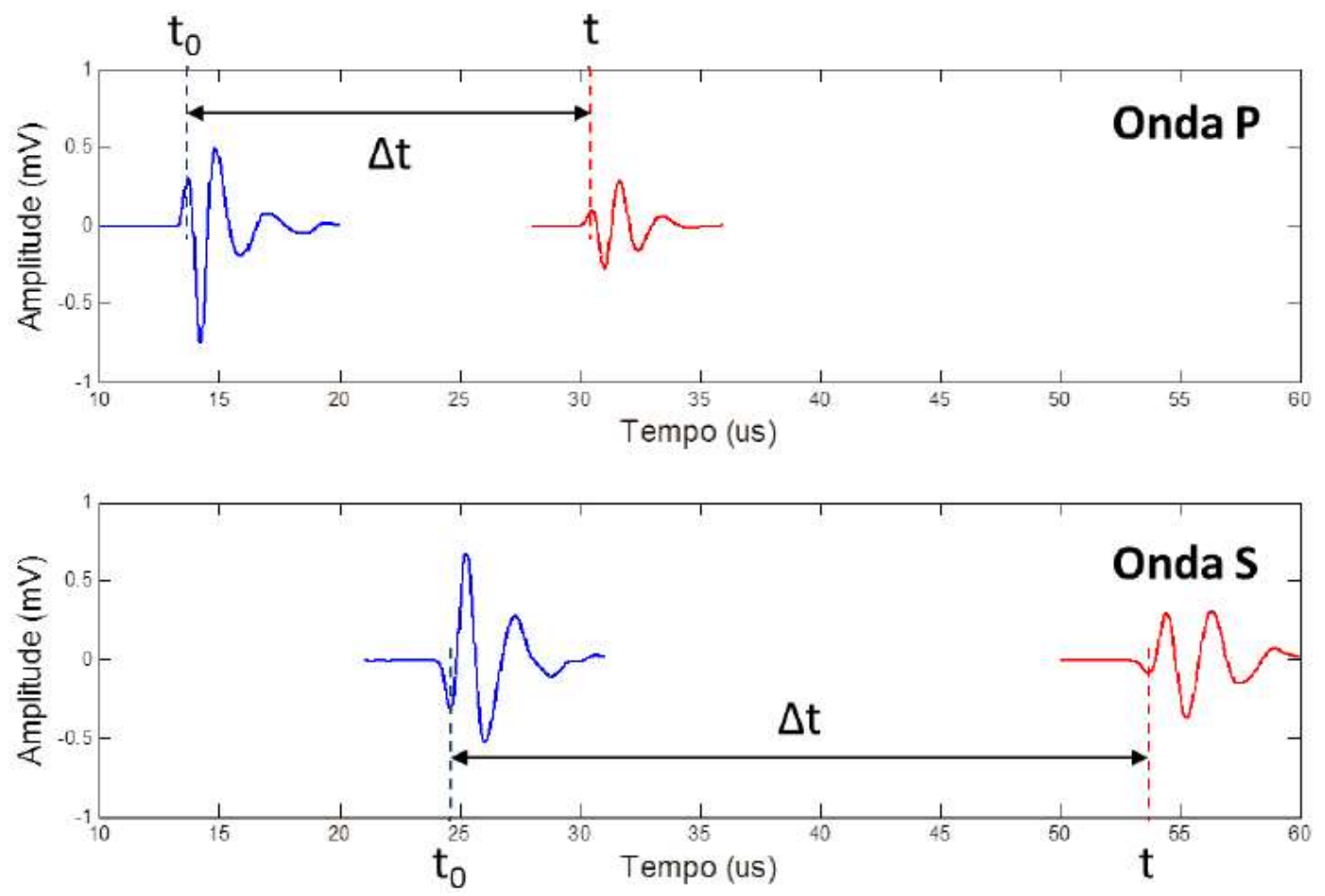

Figura 3.27 - Formas de onda compressional (acima) e de cisalhamento (abaixo), mostrando a correlação do sinal do tempo de sistema (curva azul) e o sinal da amostra (curva vermelha).

O tempo do sistema para o cabeçote(conhecido também por CAP de medida) empregado foi interpretado das ondas $\mathrm{P}$ e $\mathrm{S}$ ilustradas na Figura 3.28 e adquiridas na configuração em que não há material dentro do CAP, ou seja, o topo e a base do CAP se tocam .Foi assumido para o tempo de trânsito, o tempo do primeiro pico (ou vale) após a primeira quebra, de acordo com as recomendações de (Morschbacher 2010)

\section{Onda P :}

Primeira quebra $=0,0105 \mathrm{~ms}$ (ou 10,50 us)

Pico $=0,0141 \mathrm{~ms}$ (ou 14,10 us) (Tempo do Sistema Onda P) 


\section{Onda S :}

Primeira quebra $=0,0173 \mathrm{~ms}$ (ou 17,30 us)

Vale $=0,0191 \mathrm{~ms}$ (ou 19,10 us) (Tempo do Sistema Onda S)

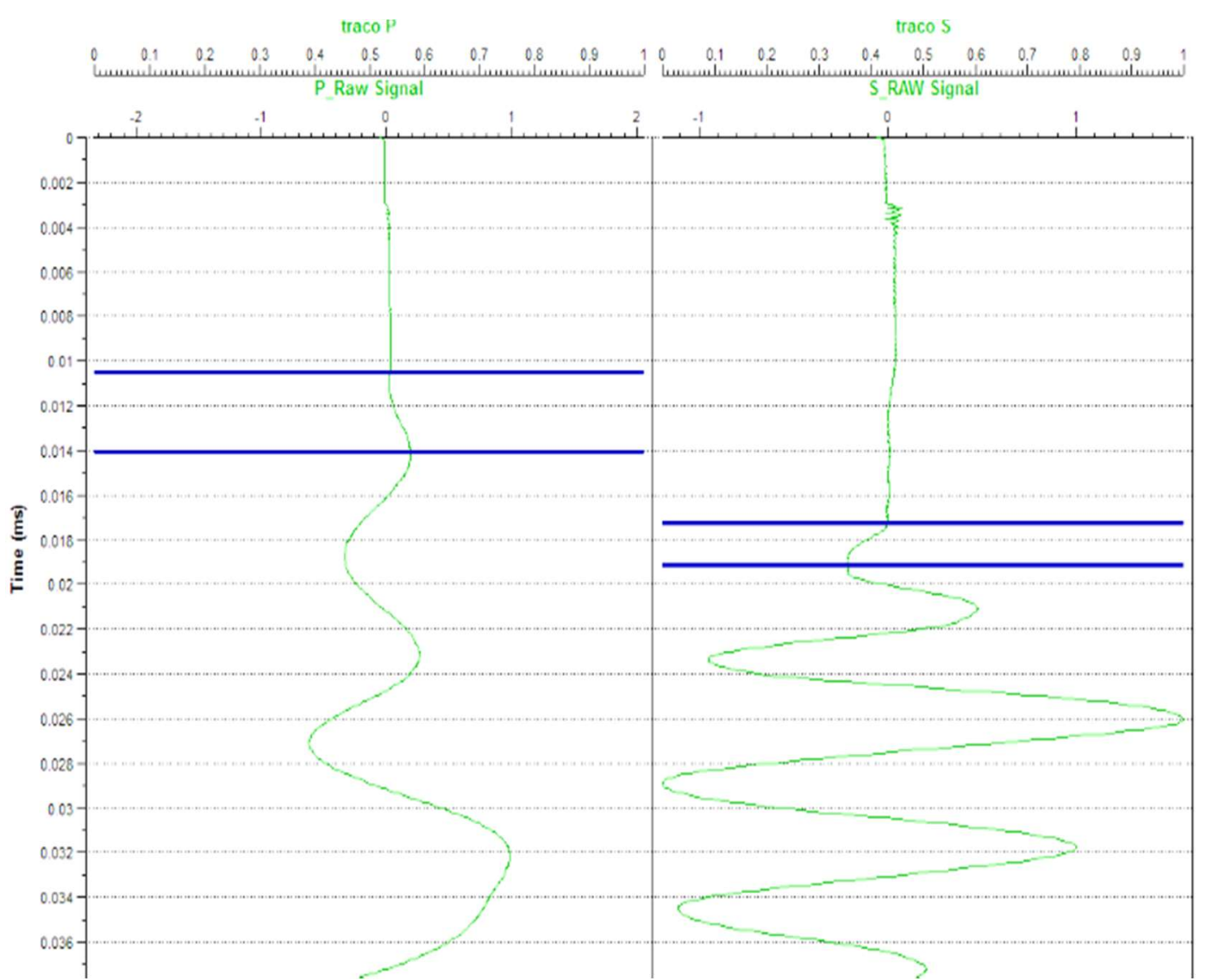

Figura 3.28: Onda P (esquerda) e Onda P (direita). Interpretação do Tempo da Primeira Quebra e Tempo do Sistema para onda P (pico) e onda $S$ (vale).

\subsection{1}

\section{Equivalência Estático-Dinâmico: Ensaios de Compressão}

\section{Hidrostática Simultâneos}

O ensaio de compressão hidrostática é um dos métodos disponíveis para a determinação do módulo de compressibilidade volumétrica da rocha (módulo bulk da rocha). O ensaio consiste em aplicar carregamento hidrostático no corpo de prova cilíndrico livre para este deformar. Neste tipo de ensaio analisa-se a deformação volumétrica do corpo de prova e, com o aumento do carregamento aplicado, pode-se observar o colapso dos poros da rocha ou até mesmo sua ruptura (por compactação). 
Durante a produção de poços de petróleo, uma depleção severa que conduz a um aumento do componente hidrostático das tensões poderia levar ao colapso da estrutura porosa ou até mesmo à ruptura .

Para os ensaios de compressão hidrostática nos corpos de prova de travertino romano foram seguidas as recomendações estabelecidas na norma ASTM 7012-14 $\varepsilon 1$, método $B$

No CPTR-2 foi realizado um ensaio hidrostático a uma taxa de carregamento de $0,5 \mathrm{Mpa} / \mathrm{min}$, no qual o aumento do confinamento ao longo do tempo de realização do ensaio é exibido na Figura 3.29. Destacase na flecha em azul o rompimento das membranas isolantes e contaminação do CPTR seco pelo fluido confinante.

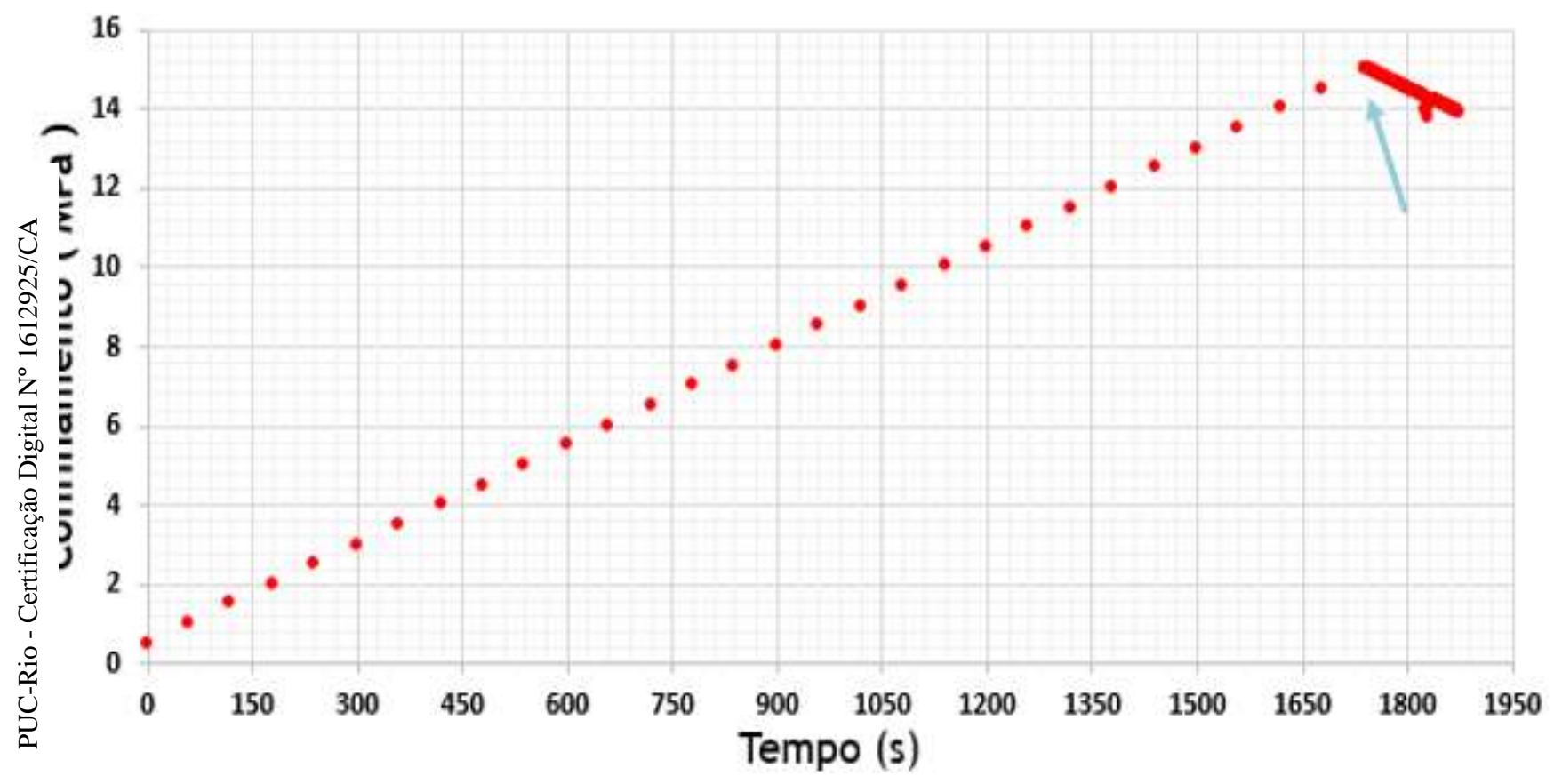

Figura 3.29: Tempo (s) vs. Confinamento (Mpa) para Ensaio de Compressão Hidrostática realizado no CPTR-2

Foi observado o comportamento exibido na Figura 3.30 da deformação volumétrica total do CPTR-2 como função do confinamento aplicado. 


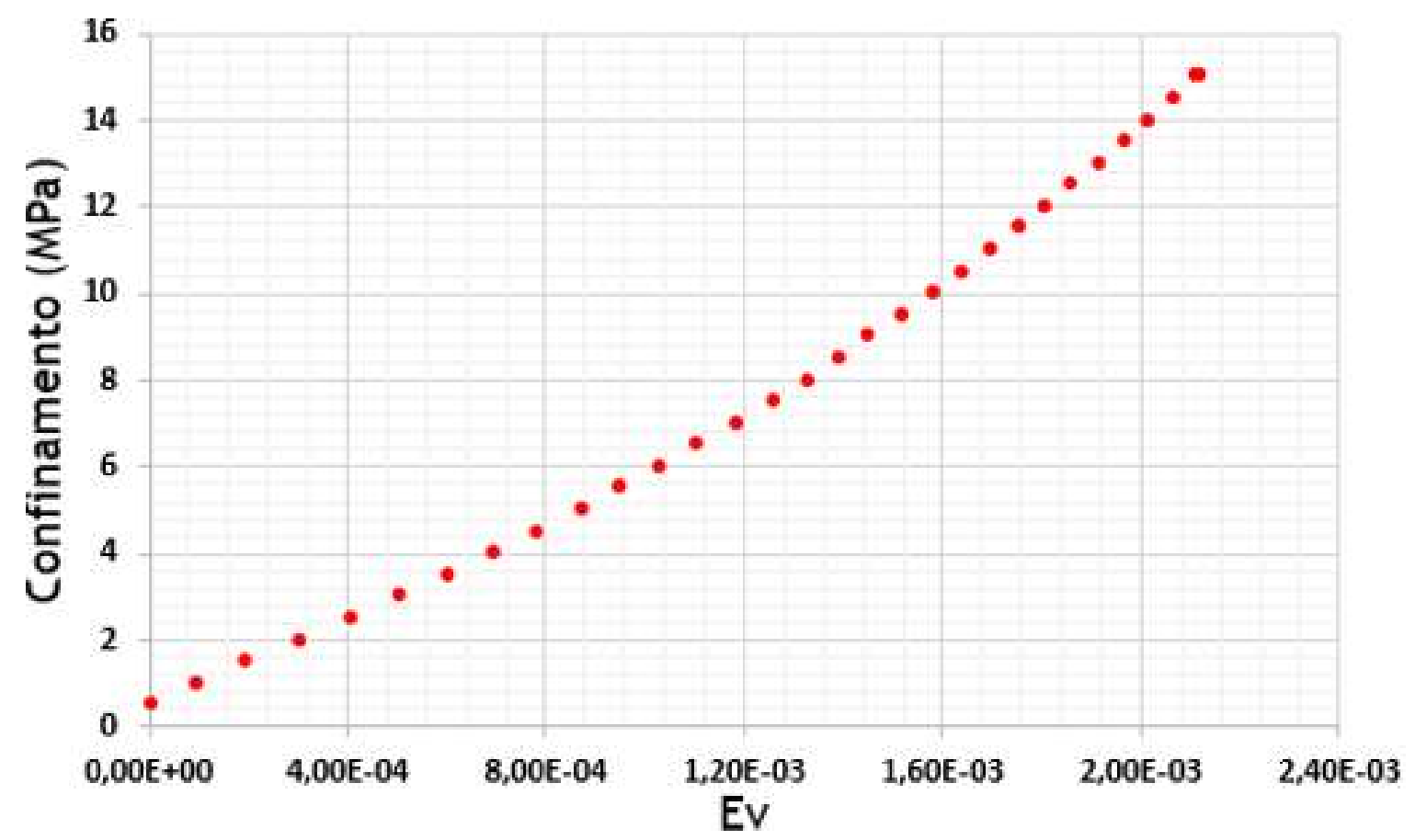

Figura 3.30: Deformação Volumétrica Total do CPTR-2 vs. Confinamento Aplicado (Mpa)

\begin{abstract}
Através dos dados da Figura 3.30 pode-se calcular o módulo de compressibilidade volumétrica estático que é a tangente à curva formada pelos dados para cada confinamento. Na Figura 3.31 é exibido o módulo de compressibilidade estático como função do confinamento aplicado para cada valor de confinamento no qual foi propagado pulso ultrassônico no CPTR-2. A cada 4 min fez-se propagar pulsos ultrassônicos de ondas $\mathrm{P}$ e $S$ no CPTR-2.
\end{abstract}




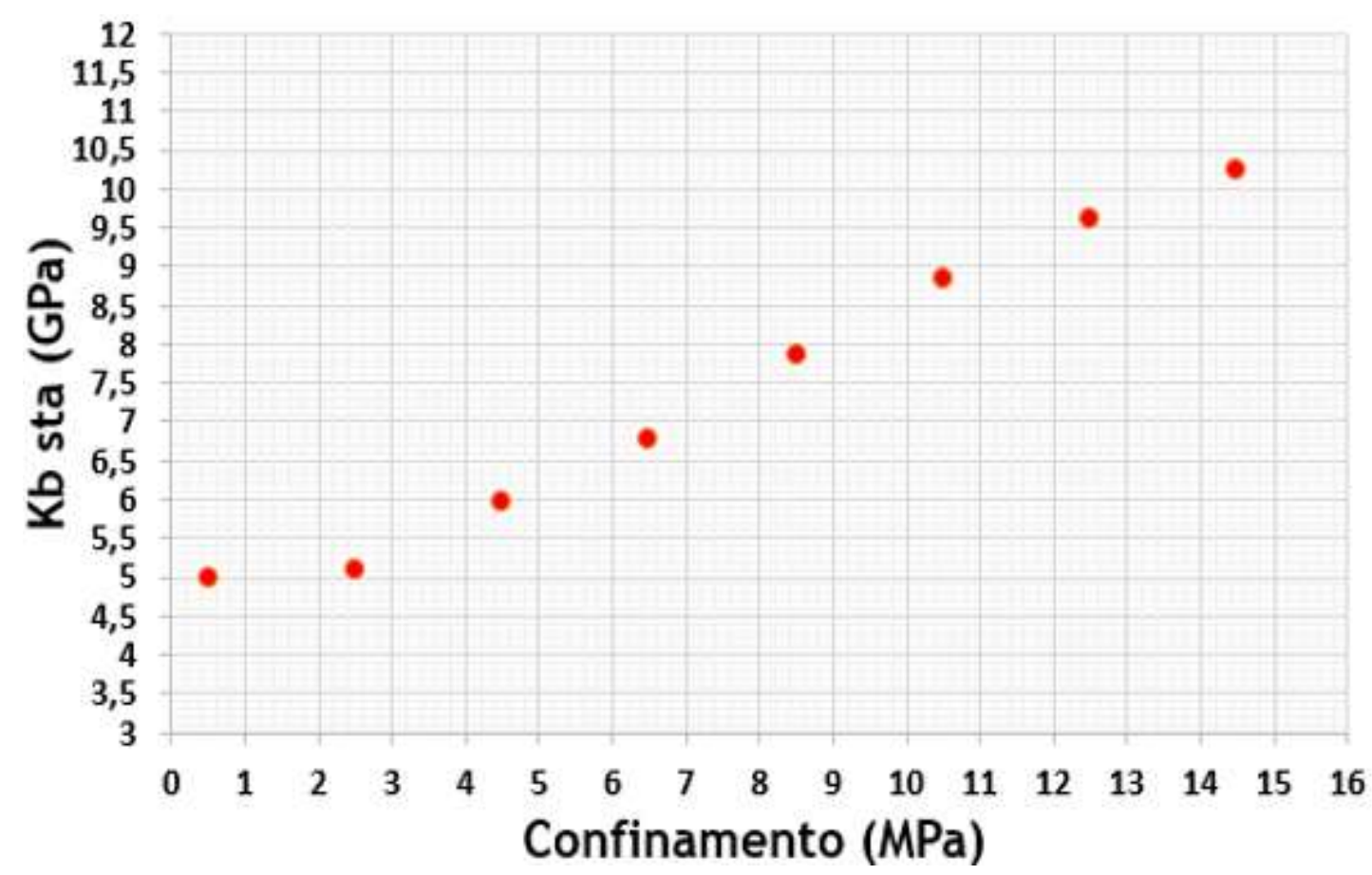

Figura 3.31: Confinamento (Mpa) vs. Módulo de Compressibilidade Volumétrica Estático para valores do confinamento nos quais forram propagados pulsos ultrassônicos no CPTR-2

A Figura 3.31 fornece a variação do módulo de compressibilidade volumétrica do CPTR-2 no ramo estático.

No ramo dinâmico para fazer a picagem do tempo de trânsito dos pulsos ultrassônicos aplicou-se, com o objetivo de atenuar frequências espúrias, um filtro passa-banda [ 90-150] $\mathrm{KHz}$ na onda P exibido na Figura 3.32 e um filtro passa-banda de [70-160] KHz na onda S exibido na Figura 3.33.

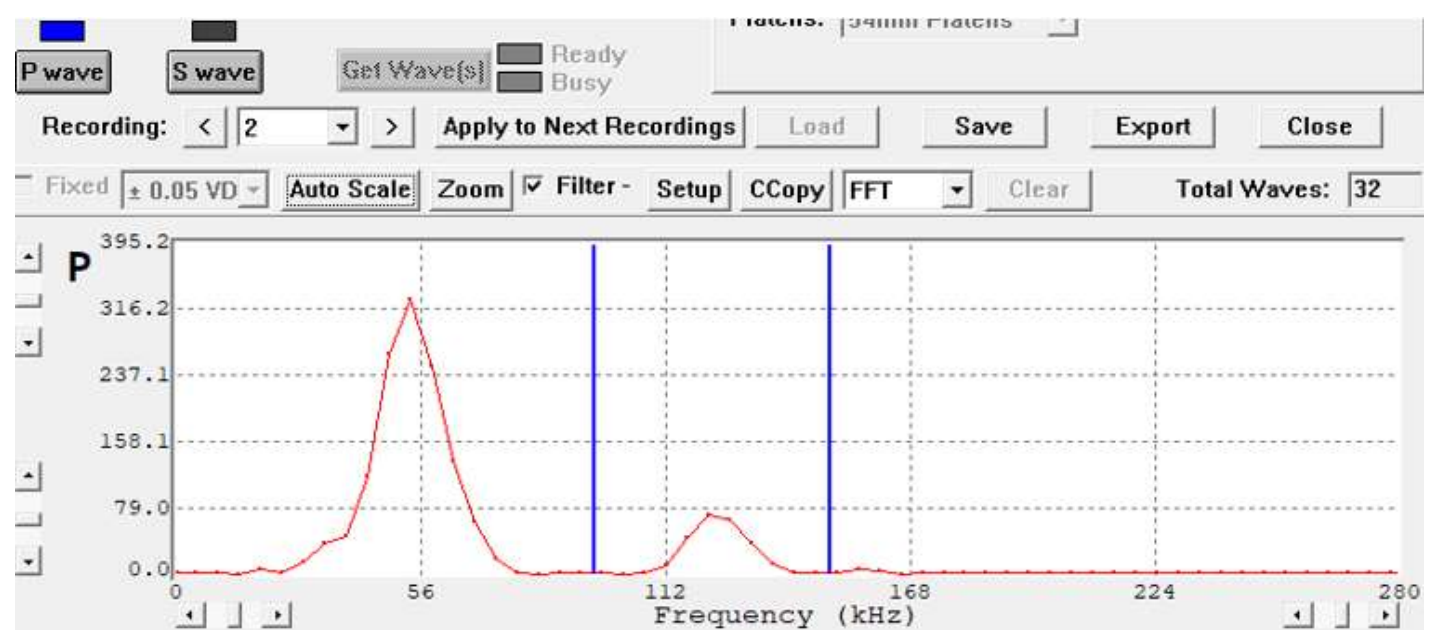

Figura 3.32: Filtro Passa-Banda [90-150] KHz aplicado à onda $\mathrm{P}$ 


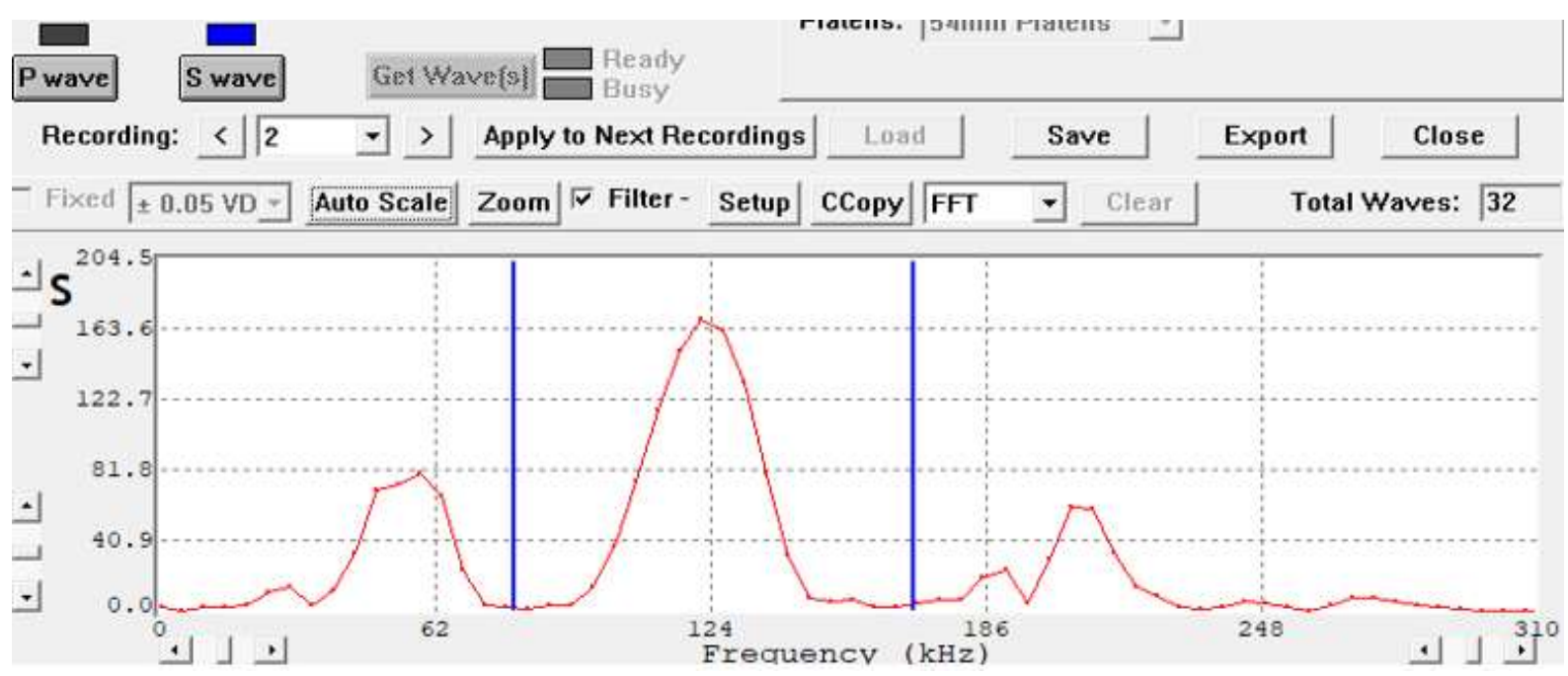

Figura 3.33: Filtro Passa-Banda [70-160] KHz aplicado à onda $\mathrm{S}$

Para o tempo $T=240 \mathrm{~s}$ do ensaio de compressão hidrostática do CPTR-2, a Figura 3.34 ilustra o formato da ondas $\mathrm{P}$ ultrassônica filtrada pelo passabanda da Figura 3.32 e a Figura 3.35 ilustra o formato da onda $S$ ultrassônica filtrada pelo passa-banda da Figura 3.33, bem como os tempos de chegada interpretados para estas duas ondas.

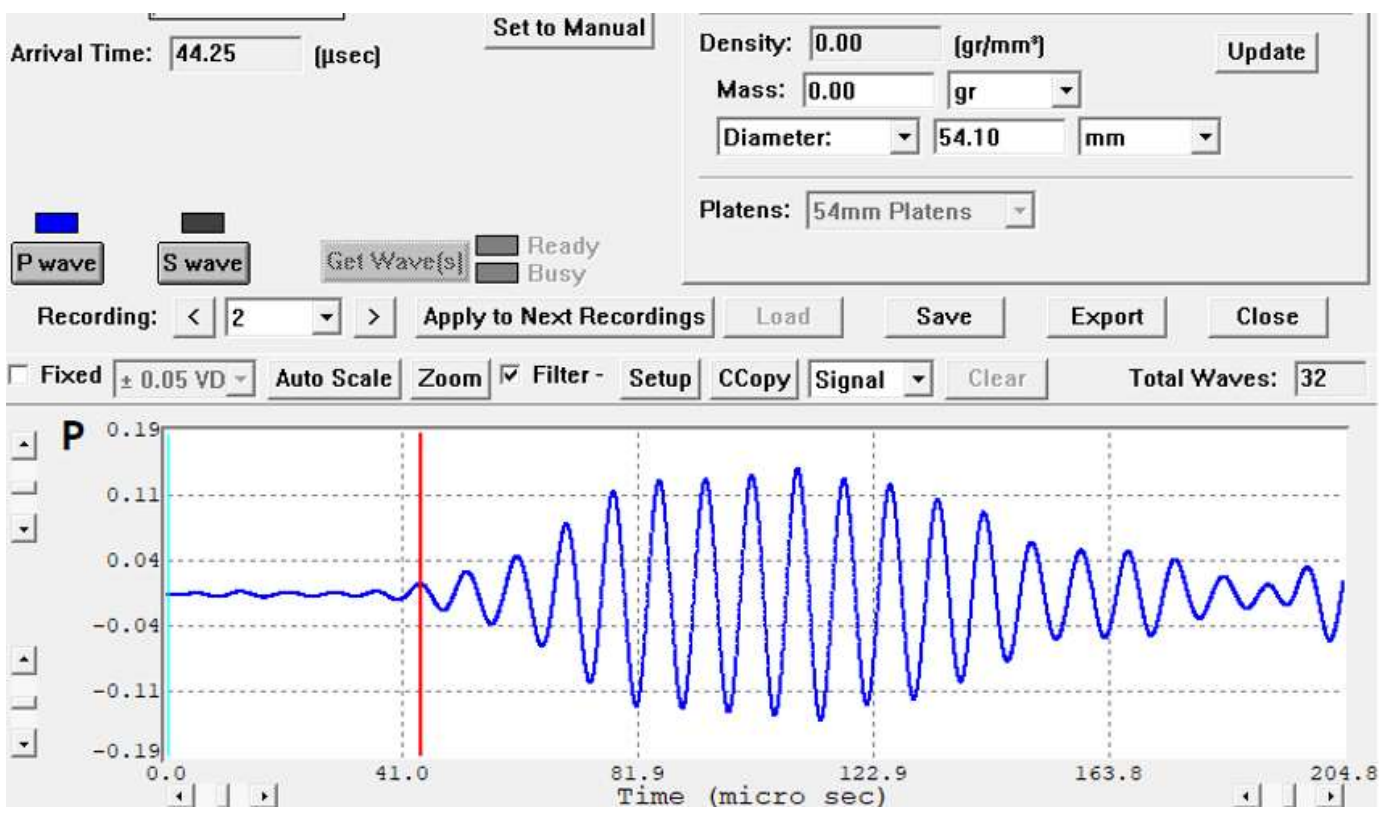

Figura 3.34: Onda - $P$ ultrassônica para o tempo $T=240 \mathrm{~s}$ do ensaio de compressão hidrostática com tempo de chegada (linha vertical vermelha) interpretado. 


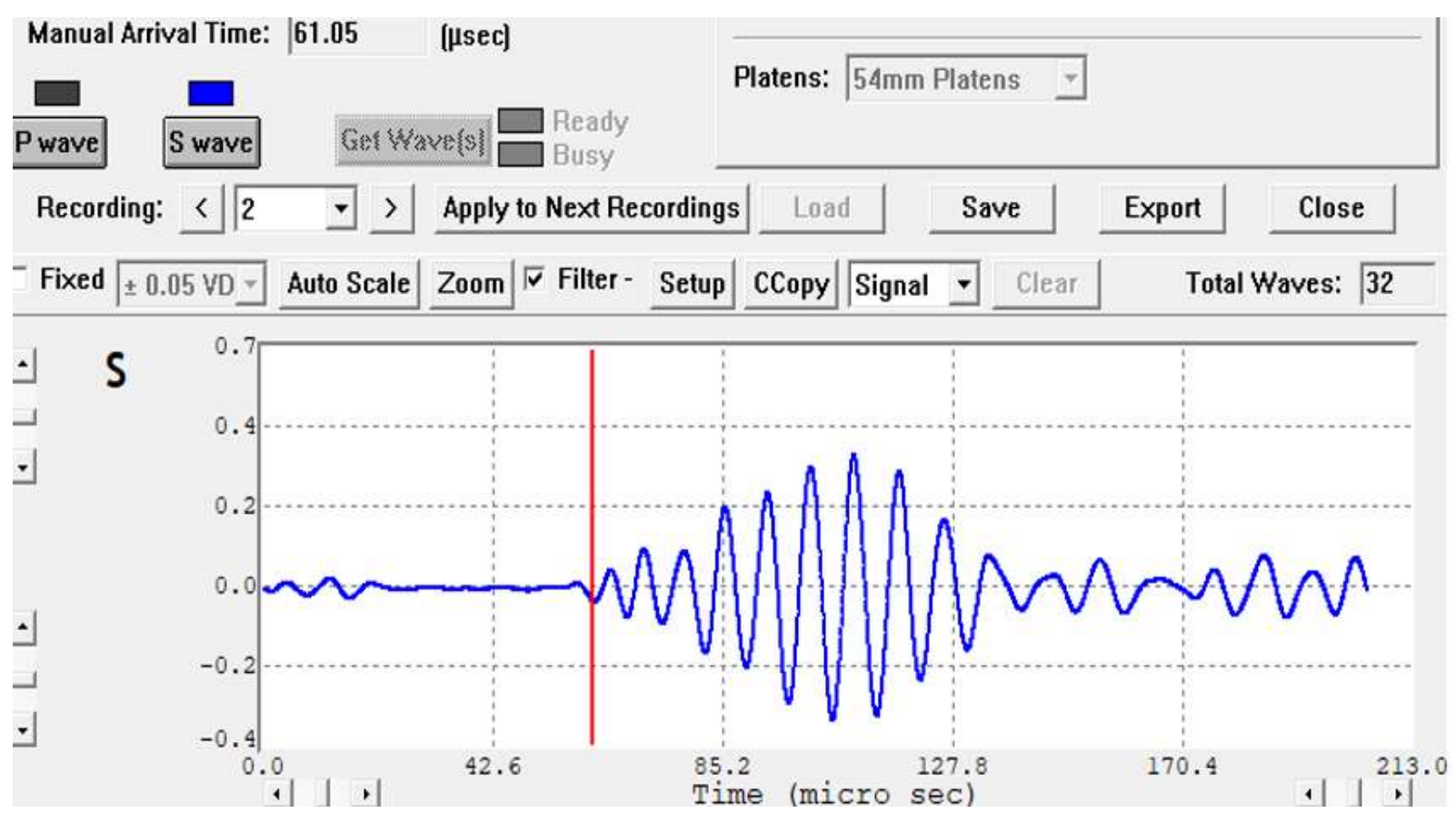

Figura 3.35: Onda - S ultrassônica para o tempo $\mathrm{T}=240 \mathrm{~s}$ do ensaio de compressão hidrostática com tempo de chegada (linha vertical vermelha) interpretado.

Tendo interpretado o tempo de chegada para as ondas ultrassônicas $\mathrm{P}$ e S a cada 4 min durante todo o tempo de duração do ensaio de compressão hidrostática, foi calculado o módulo de compressibilidade volumétrica dinâmico exibido na Figura 3.36 em função do confinamento aplicado. 


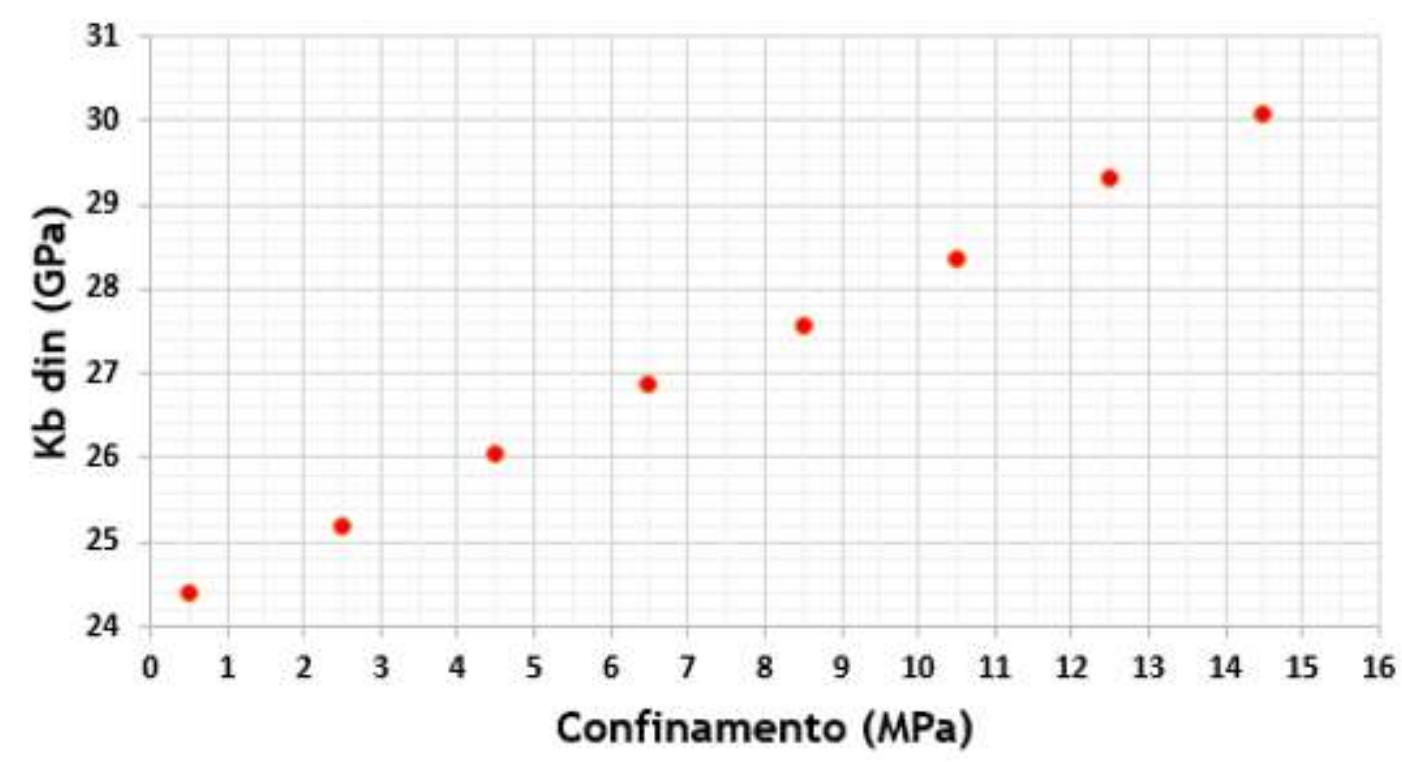

Figura 3.36: Confinamento vs. Módulo de Compressibilidade Volumétrica (GPa) Dinâmico

A partir dos dados dispostos na Figura 3.36 de módulo de compressibilidade volumétrica dinâmico vs. confinamento aplicado e dos dados dispostos da Figura 3.31 de módulo de compressibilidade volumétrica vs. confinamento aplicado, obteve-se a equivalência entre os módulos de compressibilidade volumétrica dinâmico e estático para o CPTR-2 exibida na Figura 3.37 e na Equação 3.1. 


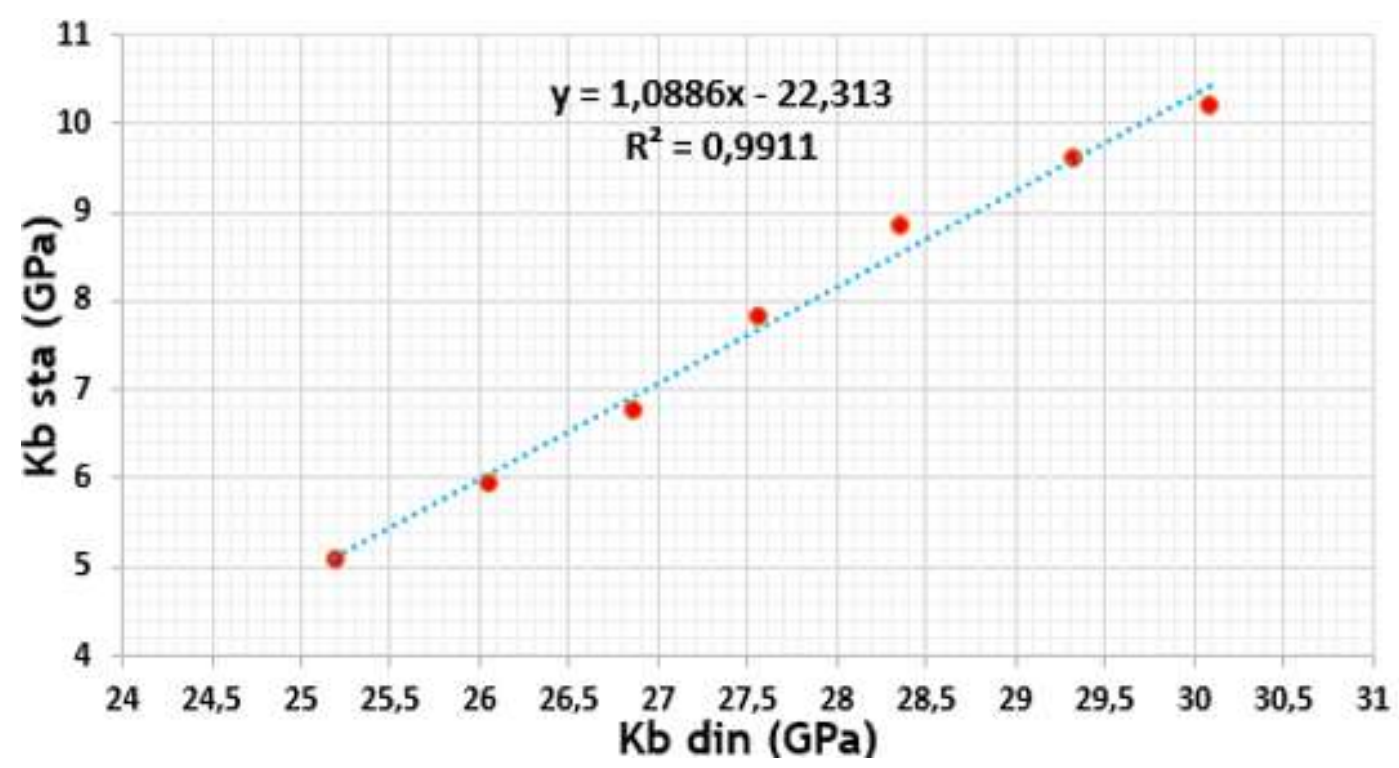

Figura 3.37: Módulo de Compressibilidade Volumétrica Dinâmico (GPa)

vs. Módulo de Compressibilidade Volumétrica Estático (GPa) para o CPTR-2

A reta que melhor ajusta os dados da Figura 3.37 é dado por:

$$
K_{B} \mathrm{sta}=1,089 K_{B} \text { din }-22,313(\mathrm{GPa}) \quad(\mathrm{Eq} 3.1)
$$

que é a relação de equivalência entre módulo de compressibilidade volumétrica dinâmica e estática para o CPTR-2 e que dará origem a um dos três cenários de propriedades mecânicas estáticas a serem computados na seção de resultados.

\subsection{2}

\section{Equivalência Estático-Dinâmico: Ensaios Triaxiais Simultâneos}

O ensaio de compressão triaxial axisimétrico é um dos mais confiáveis métodos disponíveis para a determinação de parâmetros elásticos (módulo de Young, coeficiente de Poisson e módulo de compressibilidade volumétrica) do corpo de prova. Consiste basicamente em aplicar carregamento vertical (desviador) num corpo de prova cilíndrico livre para se deformar radialmente e sob uma dada pressão de confinamento, 
situação que se assemelha a perfuração de poços na medida em que a rocha da formação na parede do poço encontra-se também livre para se deformar radialmente. Neste ensaio são usados sensores extensométricos do tipo LVDT para a direção axial e um sensor circunferencial para a direção radial. Para os ensaios de compressão triaxial são seguidas as recomendações estabelecidas na norma ASTM 7012-14 ع1.

Entretanto no caso de corpos de prova de rochas salíferas, apesar de não disponíveis neste trabalho para ensaios mas serem muito importantes por tratarem-se da rocha capeadora dos reservatórios Sub-Sal, dentro do próprio escopo da norma ASTM 7012-14 $\varepsilon 1$ (item 1.4) é feito um comentário sobre os problemas de deformação inelástica inerentes a este tipo de material que apresenta fluência. Como solução é sugerido que os parâmetros elásticos sejam obtidos em ciclos de descarregamentorecarregamento, método que não é discutido nesta norma técnica.

Pare este tipo de material, nos ciclos recomenda-se seguir as orientações de (Justen 2014) que realizou análises com controle de tensão e com controle de deformação axial, este último tendo mostrado melhores resultados frente ao fenômeno inelástico da fluência natural dos corpos de prova salíferos. Ainda em relação a (Justen 2014) foram também realizadas análises com diferentes taxas de deformação a fim de mitigar o efeito da fluência no ensaio de compressão triaxial. Foi constatado que taxas de deformação axial de $10^{-5} / s$ apresentaram resultados mais coerentes com o regime elástico, o que resultava em taxas de tensão da ordem de $0,5 \mathrm{MPa} / \mathrm{s}$ nos ciclos de descarregamento-carregamento.

\subsection{3}

\section{Equivalência Estático-Dinâmico: Ensaios Edométricos Simultâneos}

O ensaio edométrico axisimétrico consiste basicamente de um corpo de prova cilíndrico seco sujeito a escalões crescentes de carga e descargarecarga, porém sob condições edométricas i.e, com condições de contorno que impeça deformações laterais do corpo. 
É tipicamente utilizado para medir as propriedades mecânicas do material: módulo edométrico $M$ (que relaciona a tensão vertical e a deformação volumétrica do corpo sob condições edométricas).

Para os ensaios edométricos foram seguidas as recomendações estabelecidas na norma da ISRM Suggested Method for Uniaxial-Strain Compressibility Testing for Reservoir Geomechanics 2016.

$\mathrm{Na}$ determinação do estado de tensões in-situ para a etapa de DP (desenvolvimento da produção) de uma região, credita-se o estado atual às seguintes parcelas que tipicamente tem ordem decrescente de importância:

- Gravitacionais - devido ao peso das camadas de rocha que atuam sobre porções de rocha subjacentes. Esta parcela pode ser estimada com razoável precisão a partir da densidade das rochas e parâmetros de deformabilidade, parâmetros estes que determinarão como as tensões se desenvolverão na adjacência de cada ponto do maciço.

- Tectônica - devido a efeitos ativos ou remanescentes de esforços e movimentações do maciço que decorrem de atividades tectônicas.

- Residuais - são tensões que remontam do histórico da rocha e têm origem em processos diagenéticos, metamórficos, resfriamento de magma e variações de poropressão.

- Heterogeneidades e Anisotropia - diferenças locais de tensão devido aos diferentes minerais ou rochas em contato nas escalas micro e macroscópicas respectivamente.

- Terrestre - influência do campo gravitacional lunar, maré e variações sazonais de temperatura.

É interessante introduzir o conceito de bacia relaxada que, em termos funcionais, traduz que a bacia no recente não é mais ativa i.e, a contribuição para o estado de tensão in-situ de parcelas que não a gravitacional são de 
ordens superiores e, portanto, negligenciadas. Em tal caso, a componente gravitacional é dominante e sendo uma região geograficamente pouco acidentada da crosta terrestre, têm-se a direção vertical como uma das direções principais de tensão. Por ortogonalidade entre as direções principais de tensão, as outras duas direções de tensão principal recaem no plano horizontal. Em regiões realmente relaxadas e pouco acidentadas da crosta terrestre, as componentes horizontais da tensão principal podem em primeira ordem ser consideradas iguais entre si, fato este que sendo observadas com bom grau no corpo de prova as premissas de: uniformidade, isotropia, boa usinagem, elasticidade e empregabilidade da lei de Hooke generalizada, decorre também da condição de contorno de um ensaio edométrico. Assim, um ensaio no qual os movimentos horizontais são impedidos e o único deslocamento possível é o vertical, valendo

$$
\sigma_{h}=\sigma_{H}=\frac{v}{1-v} \cdot \sigma_{v}
$$

Justifica-se portanto, em primeira aproximação, o uso de ensaios edométricos para tratar os reservatórios carbonáticos do Pólo Pré-Sal da Bacia de Santos e por se tratarem de reservatórios antigos, profundos e situados em extensas porções de uma grande Bacia de margem passiva. É importante nunca esquecer que bacias totalmente relaxadas (sem componentes tectônicas ou residuais) são casos muito particulares.

O que costumeiramente é feito na indústria em termos de determinação mais acurada do estado de tensões in-situ para inicialização de uma simulação geomecânica é considerar que há tensões residuais atuantes na rocha mas que estas afetam principalmente o estado de tensões horizontal. Nestas condições a determinação do estado de tensões in -situ no reservatório é refinada do seguinte modo:

- $\sigma_{v}$ - magnitude da tensão vertical, continua a ser obtida pela integração do peso específico das camadas acima. 
- $\sigma_{h}$ - magnitude da tensão horizontal mínima, geralmente obtida pela Eq 2.29 e refinada por evidências de campo.

As evidências de campo decorrem de operações que envolvem fraturamento da formação ou abertura de fraturas naturais, como por exemplo os testes de absorção em poços e operações de microfraturamento, fraturamento hidráulico e Step Rate Test (SRT).

Destes testes os mais abundantes e mais imprecisos são os testes de absorção. No caso de existência de uma massa de dados abundantes destes testes é preferível calibrar o valor de $\sigma_{h}$ ao invés de se empregar a Eq 2.29.

- $\sigma_{H}$ - magnitude da tensão horizontal máxima, de difícil determinação. Geralmente é considerada como sendo a tensão horizontal mínima acrescida de uma componente tectônica.

Em engenharia de poço as únicas maneiras de se obter $\sigma_{H}$ são através da análise de magnitudes de deformação inelástica de ensaios de $A S R$ (Anelastic Strain Recovery) ou através de retroanálises de quantificação de zonas de cisalhamento em fenômenos de breakout e faturamento induzidos em poços. Como se tratam de análises muito sensíveis, o mais recomendado é que se considere um conjunto de cenários nos quais $\sigma_{H}$ assume valores considerados possíveis.

- $\theta_{h}$ - azimute de tensão horizontal mínima.

Este azimute é um dos valores que mais varia no campo e reflete a orientação dos fenômenos tectônicos e é bastante influenciado por eventos locais. Boas estimativas locais para este valor podem ser obtidas de análises de direção de breakout e fraturas induzidas em poços (sobretudo verticais), por meio de ensaios de $A S R$ ou pela análise do contexto tectônico e deposicional regional por geólogos estruturais ou geofísicos. 


\section{4}

\section{Caracterização do Dado Sísmico Empilhado}

O dado sísmico devidamente adquirido, processado e condicionado permite obter informação indireta e de valor de um meio inacessível - como é o caso dos reservatórios de hidrocarbonetos - diversificando as fontes de informação, restritas outrora aos métodos tradicionalmente diretos de observação, análise e testes de campo. A bem sucedida prática e o grande crescimento do emprego do dado sísmico na indústria de hidrocarbonetos deve-se a um elevado número de fatores dentre os quais pode-se destacar:

I. Riqueza de Informações: uma primeira análise de uma sessão sísmica imageada já permite dar luz a todo o arcabouço estrutural e estratigráfico em subsuperfície, nisto incluso por exemplo: feições geológicas, sismofácies, ambientes deposicionais e espessamento/acunhamento de camadas. Por muito tempo, as locações dos poços pioneiros de uma área eram suportadas por não mais que modelo geológico mental e dado de amplitude sísmica.

II. Alto Valor da Informação (VDI) associado: O dado sísmico é rico em informações, e o custo de uma nova aquisição sísmica para todo um projeto é muito inferior ao custo da perfuração de um novo poço. No PPSBS o custo de uma nova aquisição sísmica HD a cabo ou de superfície, a qual dará suporte a todos os poços perfurados na etapa de desenvolvimento da produção (DP) situa-se em aproximadamente U\$ 12 milhões, enquanto que o custo de perfuração de um novo poço em aproximadamente U $\$ 300$ milhões.

III. Boa Performance em Reservatórios Complexos: mesmo no contexto do PPSBS, de reservatórios profundos e em áreas complexas (halocinese severa), o dado sísmico oferece informação com conteúdo de frequência de algumas dezenas de $\mathrm{Hz}$ 
(aproximadamente $40 \mathrm{~Hz}$ ), resolução vertical de aproximadamente $40 \mathrm{~m}$ e horizontal de aproximadamente $700 \mathrm{~m}$. Neste contexto, outros métodos geofísicos como gravimétrico, elétrico e magnético apresentam resolução mais reduzida e se usados conjuntamente ao dado sísmico podem fornecer valiosas informações adicionais.

É importante salientar que o dado sísmico, a despeito de todas as suas vantagens, requer um tempo de espera para ser obtido. Atualmente o tempo de espera mínimo até a solicitação e a obtenção de um novo dado sísmico na estação de trabalho é de aproximadamente 1,5 anos.

O tempo consumido na etapa de licenciamento ambiental e aquisição sísmica é de aproximadamente 1 ano e o tempo consumido no processamento do dado sísmico adquirido é de aproximadamente 6 meses. O emprego da sísmica é essencial na indústria de hidrocarbonetos e requer, portanto, bom planejamento e coordenação para que se integre no tempo correto às etapas de desenvolvimento e gerenciamento da produção.

\subsection{1}

\section{Modelo a Priori para Inversão Sísmica}

O modelo a priori de Impedância acústica (IP) do Pós-Sal do PPSBS foi construído através de cubo de velocidade intervalar da onda P (VP) advindo de tomografia de reflexão sísmica exibido na Figura 3.38 e de relação obtida dos perfis de poços disponíveis no Pós-Sal, exibida na Figura 3.39, que relaciona a velocidade intervalar da onda $P(V P)$ vs. impedância acústica (IP). 


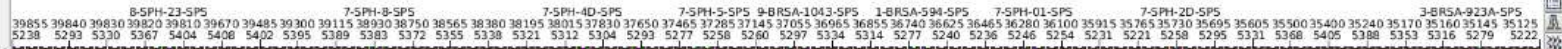
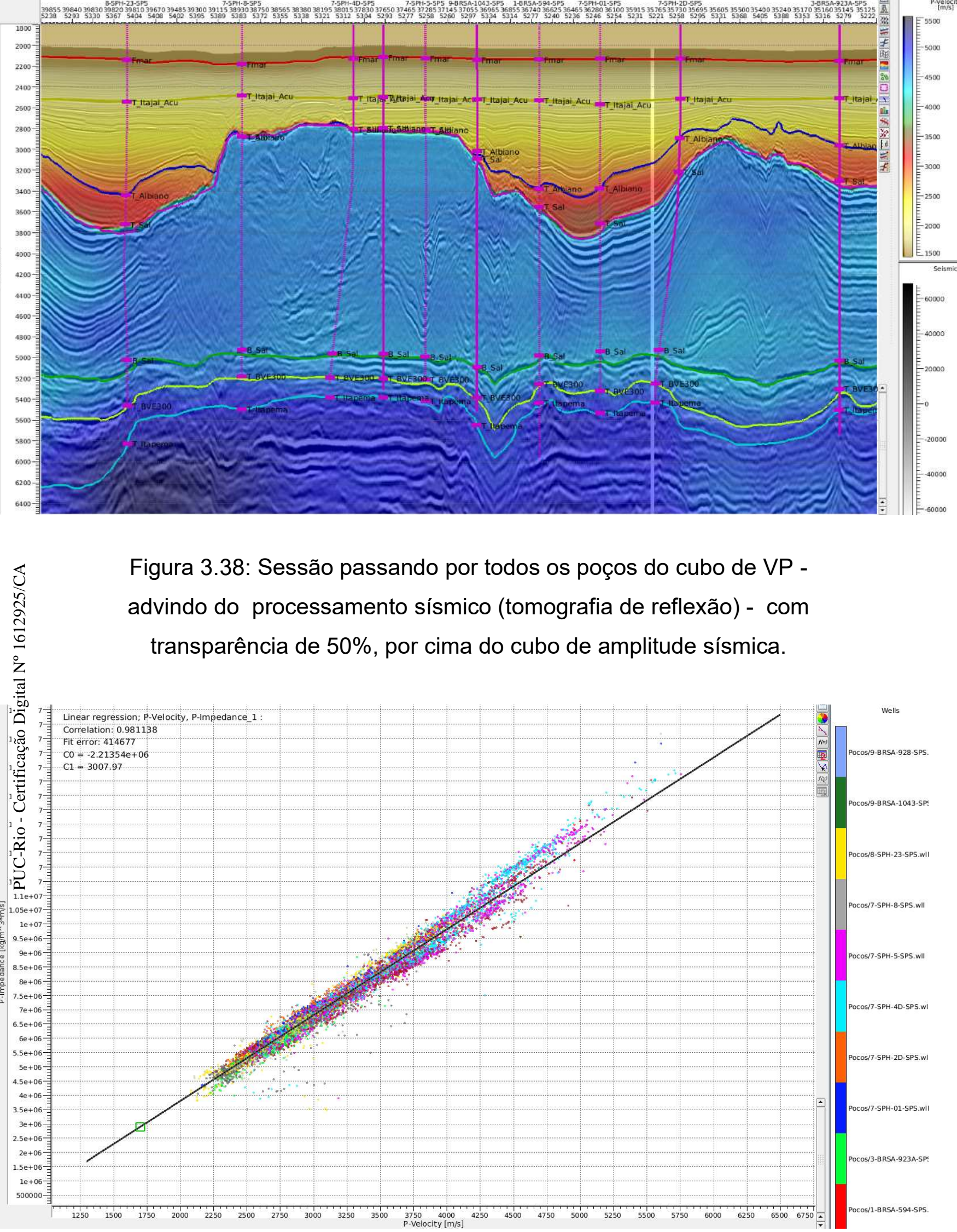

Figura 3.39: Crossplot de VP (eixo -x) vs. IP (eixo -y), obtido dos perfis de poços disponíveis para a área no Pós-Sal. 
Obtevê-se a seguinte relação linear que relaciona VP e IP para a nuvem de perfis de poços da Figura 3.39

$$
I P=-2213540+3008 . V P \quad(S I)
$$

A aplicação da (Eq 3.3) ao cubo de VP advindo da tomografia sísmica, encarado como propriedade de deriva, fornece o modelo a priori de IP no Pós-Sal exibido na Figura 3.40.

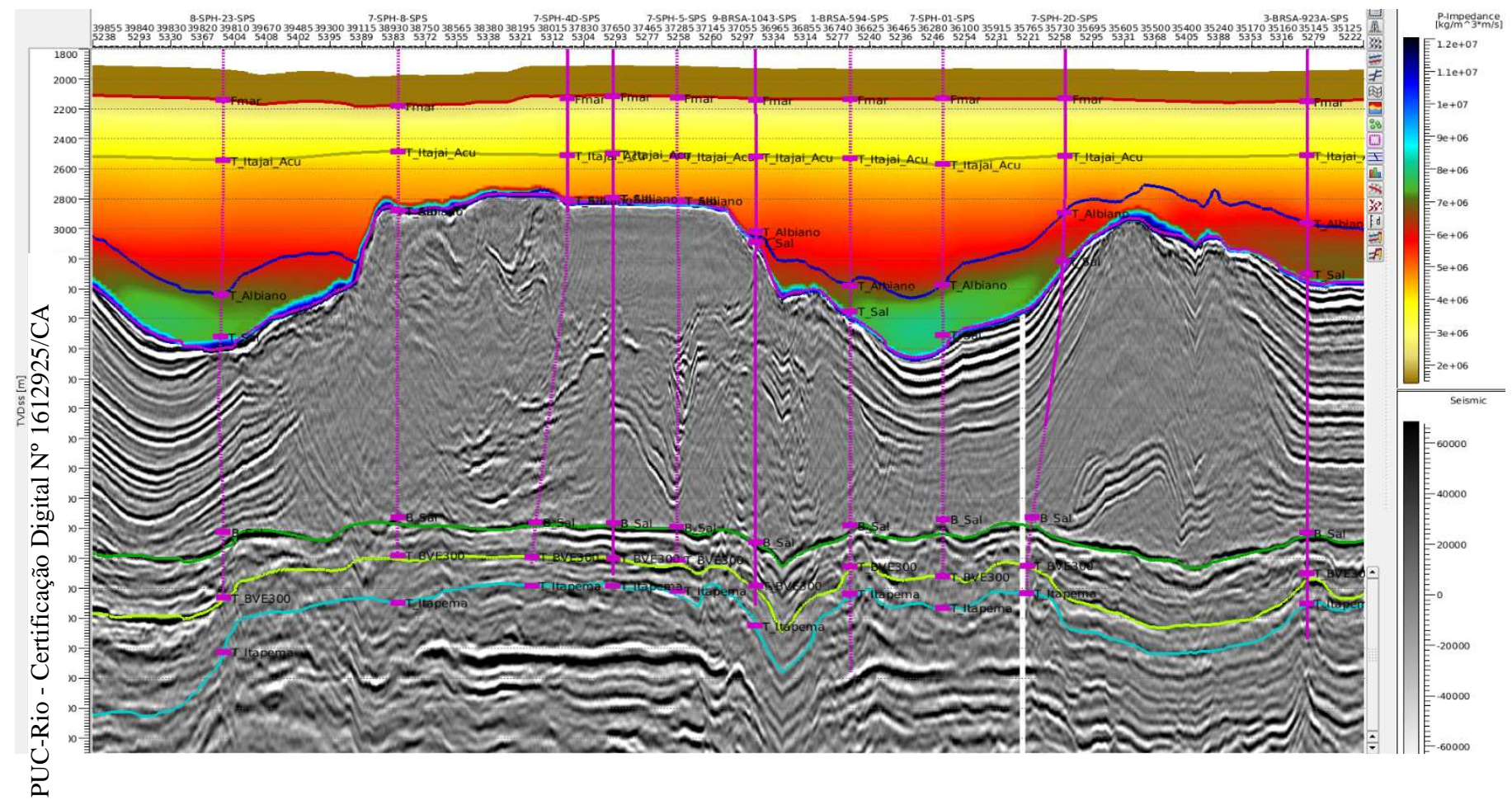

Figura 3.40: Modelo a Priori de Impedância-P para o Pós-Sal do PPSBS.

Para caracterização da Seção Salífera no contexto do PPSBS recomendase as referências (Meneguim 2015), (Yamamoto 2016), (Teixeira 2017), (Toribio 2017), (Falcão 2017) e (Maul 2018).

Em (Maul 2018) é apresentado um modelo conceitual de deposição e ciclicidade dos diferentes tipos de sais e, no contexto do PPSBS, é abordada a questão da importância da caracterização das estratificações salíferas em termos de modelagem de velocidades intervalares, estudos de iluminação, imageamento sísmico e segurança operacional na perfuração e produção de poços. 
Em (Meneguim 2015) as estratificações salíferas do PPSBS são caracterizadas através de classificação Bayesiana de fácies empregando a Impedância-P invertida na Seção Salífera com base em modelo a priori de perfil de poços e máscara de amplitude sísmica, além da modelagem 3D de 3 cenários de velocidades intervalares para calibração tempo $x$ profundidade e análise de incerteza quanto ao volume de rocha do reservatório Pré-Sal.

Em (Yamamoto 2016) é abordada a questão da estatística dos diversos tipos de sais constatados nos poços do PPSBS bem como o controle de qualidade e revisão destes litotipos empregando os demais perfis de poços, além da incorporação das estratificações salíferas no modelo de velocidades para processamento sísmico de uma jazida da Bacia de Santos.

Em (Teixeira 2017) é apresentado modelo de física de rochas, no contexto da seção salífera do PPSBS, que associe a observável geofísica Impedância-P à velocidade compressional dos sais, além da modelagem de velocidades 3D empregando o modelo de física de rochas desenvolvido e a Impedância-P invertida na Seção Salífera com base em modelo a priori e inversão em duas passadas.

Em (Toribio 2017) é desenvolvido modelo de física de rochas advindo de perfis de poços do PPSBS para estimativa 3D de propriedades de deformabilidade na Seção Salífera: módulo de elasticidade e coeficiente de poisson empregando a Impedância -P invertida na Seção Salífera com base em modelo a priori com pseudopoço para eliminação de estratificações salíferas espúrias.

Em (Falcão 2017) é estressado o impacto da caracterização dos sais na Seção Salífera do PPSBS em termos de processamento e imageamento sísmico.Diferentes algoritmos de migração sísmica são empregados: Kirchhoff e RTM ( Reverse Time Migration) e comparadas seções migradas e gathers quando da incorporação ou não das estratificações na Seção Salífera. 
Na Seção Salífera recomenda-se realizar inversão sísmica em 2 passadas para evitar a contaminação na impedância $-\mathrm{P}$ resultante da inversão sísmica de estratificações salíferas espúrias sem correspondência com o dado sísmico. São portanto necessários dois modelos a priori, sendo um para cada passada da inversão sísmica. Para o modelo a priori da primeira passada foi usada uma ferramenta geoestatística de interpolação, baseada no inverso da distância aos poços tendo como insumos os horizontes sísmicos mapeados (Topo e Base do Sal) e os perfis de Impedância -P dos poços filtrados até $6 \mathrm{~Hz}$ como exibido na Figura 3.41.

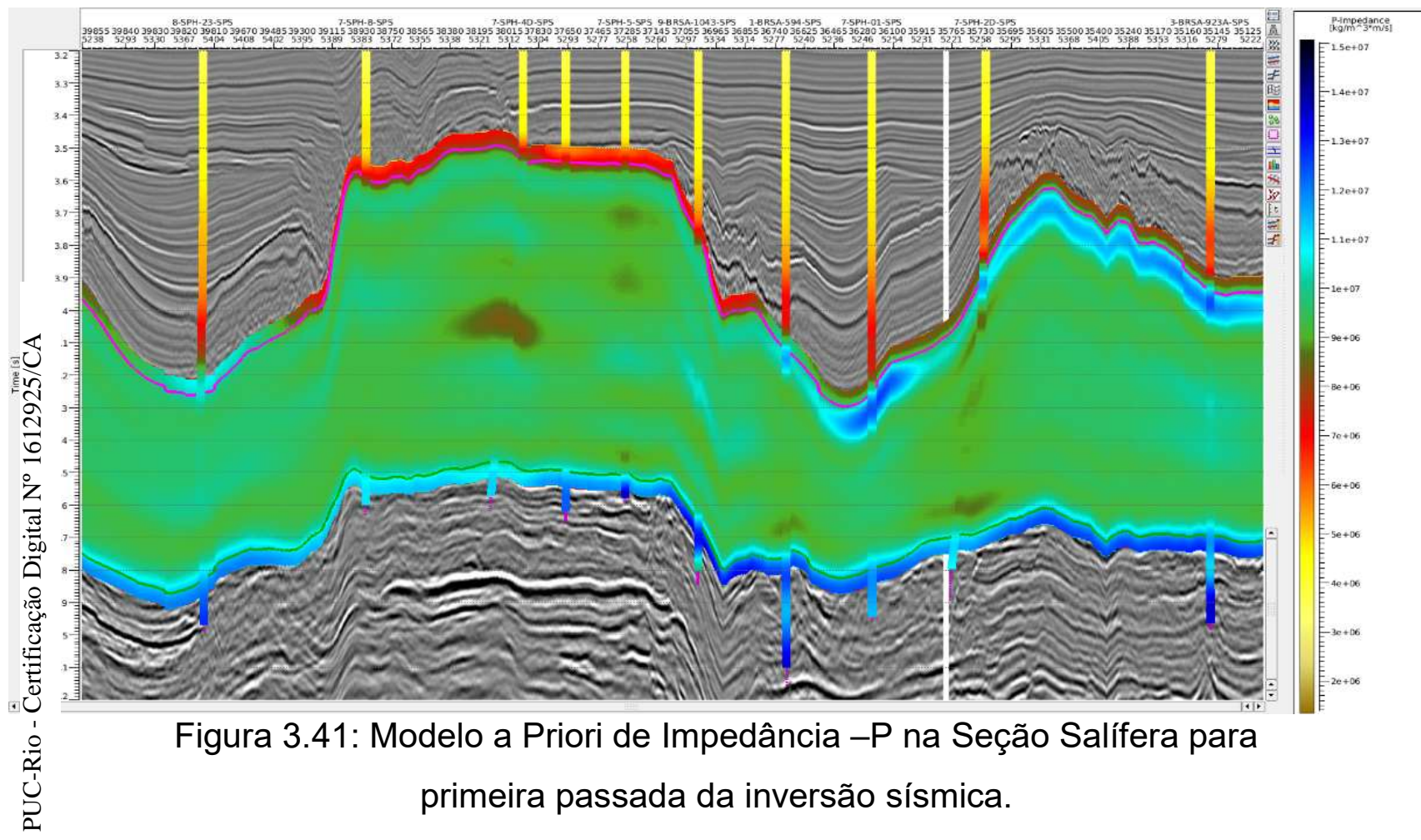

O modelo a priori de Impedância-P para a segunda passada usa a impedância -P obtida na primeira passada da inversão sísmica, porém condicionada à máscara baseada na amplitude sísmica com função de evitar o surgimento de estratificações salíferas espúrias criadas pela ferramenta geoestatística no modelo a priori da primeira passada e que não possuem correspondência sísmica. O modelo a priori para a segunda passada exibido na Figura 3.42, deste modo concebido, assume valores de Impedância -P da halita homogênea (sal mais frequente na Seção Salífera IP $=9,42 E+6(\mathrm{SI}))$ onde não houver refletores intensos na amplitude sísmica e, assume valores da Impedância -P iguais aos obtidos para 
impedância $-\mathrm{P}$ resultante na primeira passada da inversão sísmica $\mathrm{e}$ filtrada até $16 \mathrm{~Hz}$.

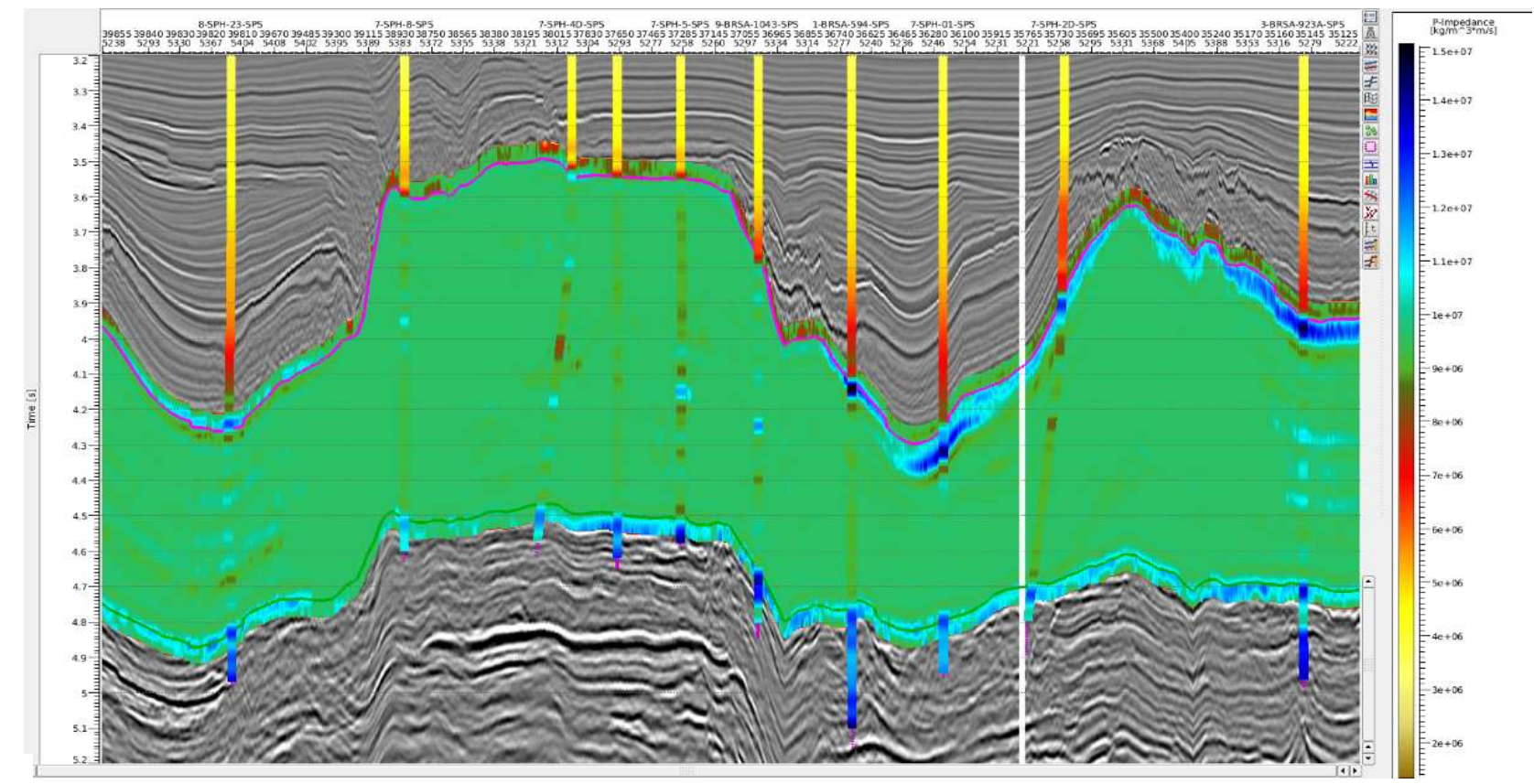

Figura 3.42: Modelo a Priori de Impedância -P na Seção Salífera para segunda passada da inversão sísmica.

O modelo a priori de Impedância acústica (IP) do Pré-Sal do PPSBS exibido na Figura 3.43 foi obtido a partir de uma ferramenta geoestatística de interpolação baseada no inverso da distância aos poços tendo como insumos os horizontes sísmicos mapeados (Base do Sal e Topo de Fm. Piçarras) e os perfis de Impedância -P dos poços filtrados até $6 \mathrm{~Hz}$. 


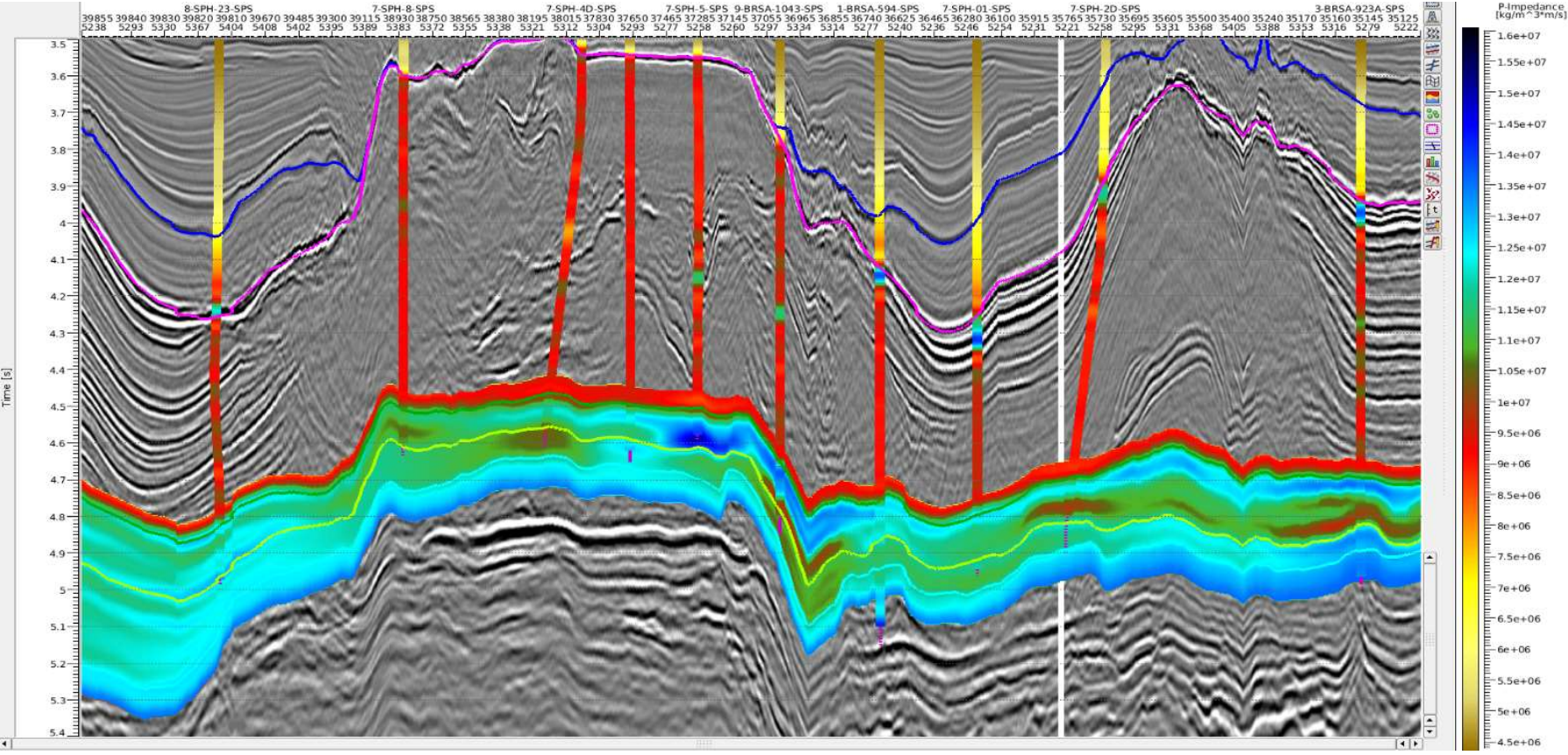

Figura 3.43: Modelo a Priori de Impedância - P no Pré-Sal do PPSBS

\subsection{2}

\section{Wavelets}

Conforme a Eq 2.28 do modelo convolucional para o traço sísmico, para estimar a refletividade (r) do meio a partir do traço sísmico $\mathbf{T}$, é necessário retirar o efeito da wavelet também conhecido como pulso sísmico residual (w). O pulso sísmico, ao se propagar em subsuperfície, sofre dispersão pelo meio e devem ser considerados os fenômenos de dispersão: mudança de forma / conteúdo de frequência do pulso e atenuação: mudança na amplitude do pulso, ao longo do soterramento. Nos pacotes de rochas delimitados pelos horizontes mapeados na sísmica exibida na Figura 3.44 


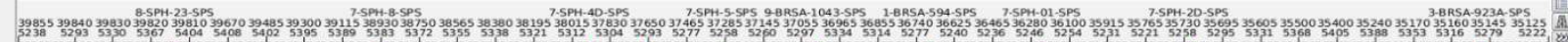

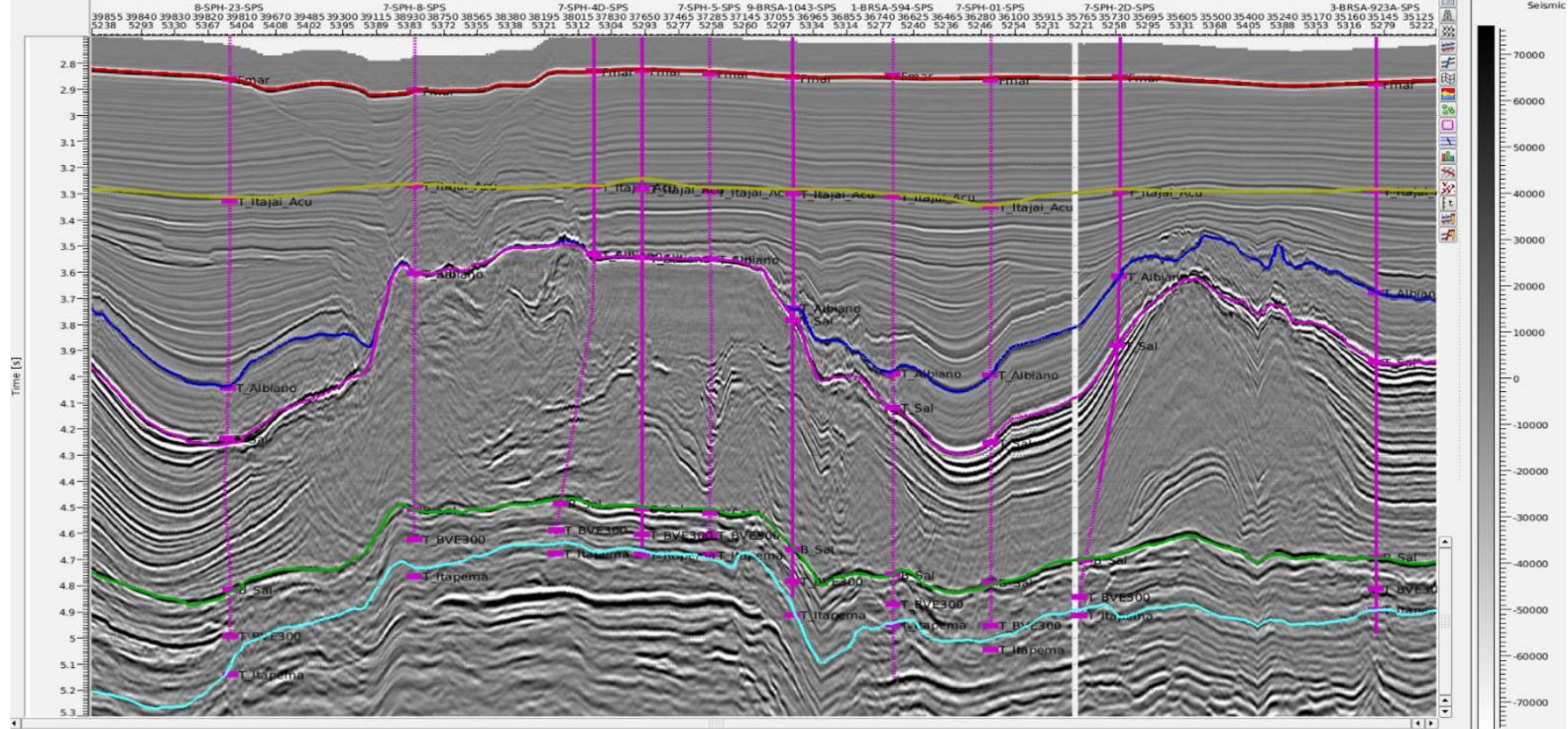

Figura 3.44: Sessão Sísmica com Horizontes Mapeados e Trajetória de

Poços no domínio do tempo (s)

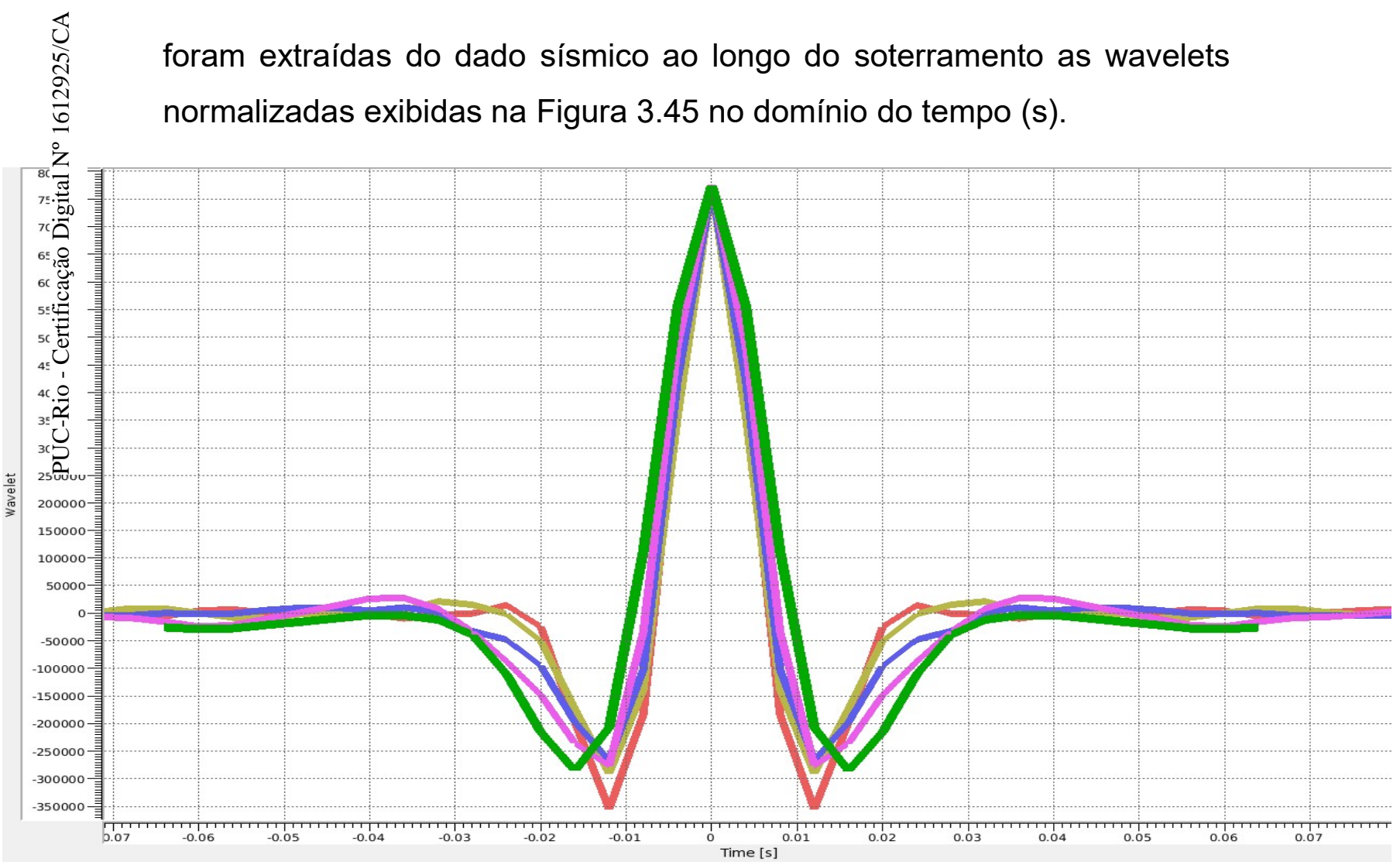

Figura 3.45: Wavelets Normalizadas ao Longo do Soterramento

(x-Tempo, y- Amplitude da Wavelet) 
Na Figura 3.46 são exibidos os espectros de frequência normalizados das wavelets ao longo do soterramento ilustradas na Figura 3.45

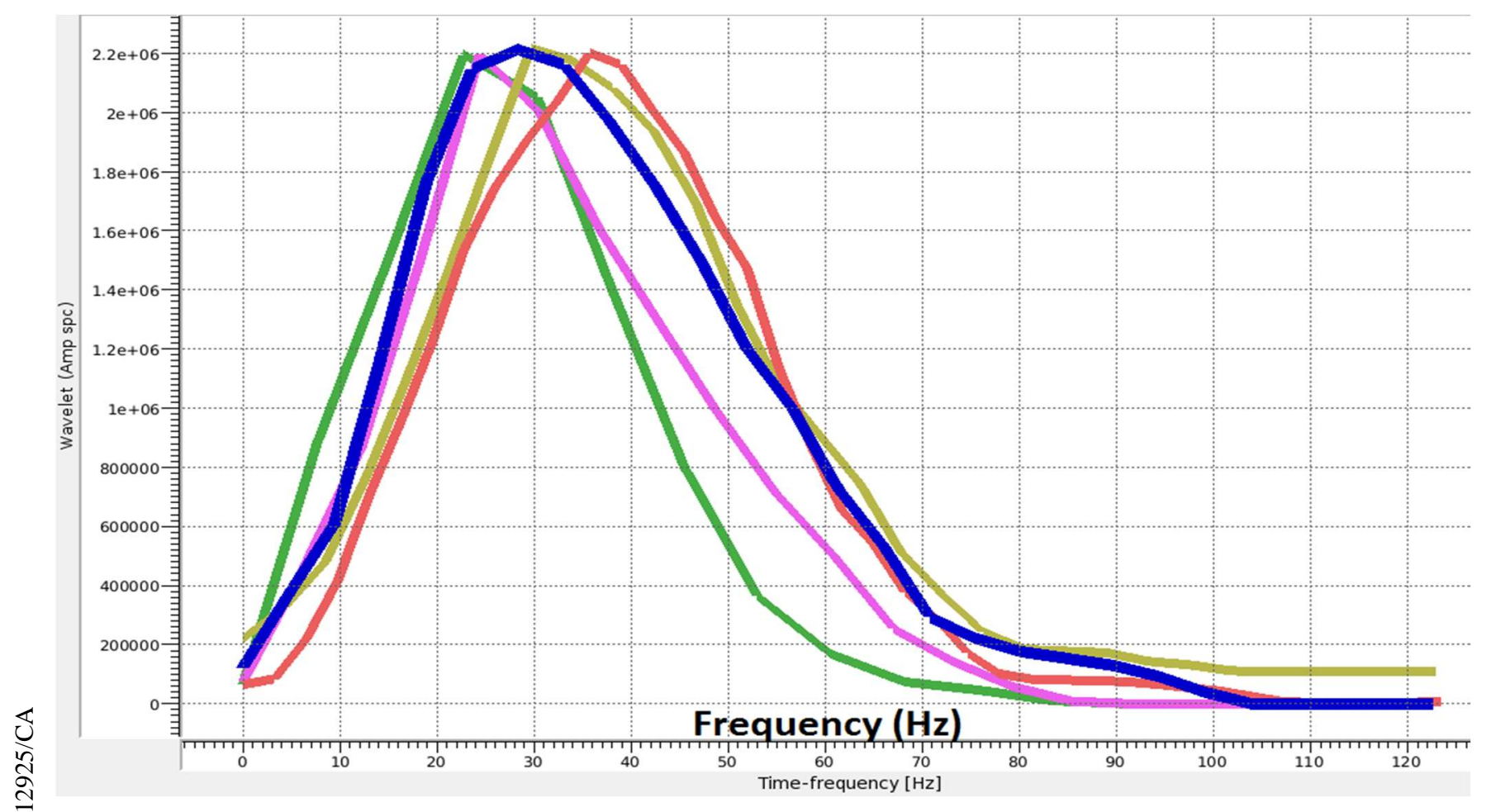

Figura 3.46: Espectro de Frequência Normalizado das Wavelets ao longo do soterramento

Nota-se da Figura 3.46 que tanto quanto maior o soterramento da camada, i.e, mais extenso o trajeto percorrido pelo pulso sísmico, menor serão as contribuições das altas frequências perante as baixas frequências as quais tendem a dispersar-se menos no meio. Este é um importante controle de qualidade que pode ser empregado para avaliar as wavelets passíveis de serem usadas no processo de inversão sísmica e também uma limitação inerente ao método sísmico: nosso alvo será sempre atingido por um pulso sísmico de conteúdo de frequência inferior ao das camadas sobrepostas. De modo que nas aquisições sísmicas, a fonte ou arranjo de fontes têm espectro muito mais amplo que o recuperado na profundidade objetivo.

Um descritivo de cada das wavelets empregadas na inversão sísmica segue na Tabela 3.2 


\begin{tabular}{|c|c|c|c|c|c|}
\hline Wavelet & $\begin{array}{l}\text { Horizonte } \\
\text { Topo }\end{array}$ & $\begin{array}{c}\text { Horizonte } \\
\text { Base }\end{array}$ & $\begin{array}{l}\text { Formação } \\
\text { Geológica }\end{array}$ & $\begin{array}{c}\text { Comprimento } \\
\text { (ms) }\end{array}$ & Fase \\
\hline Wav1 & $\begin{array}{c}\text { Topo } \\
\text { Marambaia }\end{array}$ & $\begin{array}{c}\text { Topo } \\
\text { Itajaí-Açu }\end{array}$ & Fm. Marambaia & $300 \mathrm{~ms}$ & 0 \\
\hline Wav2 & $\begin{array}{c}\text { Topo } \\
\text { Itajaí-Açú }\end{array}$ & $\begin{array}{c}\text { Topo } \\
\text { Itanhaém }\end{array}$ & Fm. Itajaí-Açú & $230 \mathrm{~ms}$ & 0 \\
\hline Wav3 & $\begin{array}{c}\text { Topo } \\
\text { Itanhaém }\end{array}$ & Topo Ariri & $\begin{array}{c}\text { Fm. } \\
\text { Itanhaém/Guarujá }\end{array}$ & $200 \mathrm{~ms}$ & 0 \\
\hline Wav4 & Topo Ariri & $\begin{array}{l}\text { Topo } \\
\text { Barra } \\
\text { Velha }\end{array}$ & Fm. Ariri & $160 \mathrm{~ms}$ & 0 \\
\hline 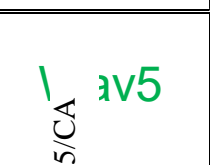 & $\begin{array}{c}\text { Topo Barra } \\
\text { Velha }\end{array}$ & $\begin{array}{c}\text { Topo } \\
\text { Piçarras }\end{array}$ & $\begin{array}{c}\text { Fm. Barra } \\
\text { Velha/Itapema }\end{array}$ & $128 \mathrm{~ms}$ & 0 \\
\hline
\end{tabular}

Tabela 3.2: Descritivo das Wavelets Empregadas para Inversão Sísmica

\section{5}

Equivalência entre Propriedades Mecânicas Drenadas e NãoDrenadas

As propriedades mecânicas de deformabilidade estimadas do dado sísmico são não-drenadas ou seja, o tempo de duração dos ciclos de carregamento e descarregamento das ondas sísmicas é pequeno demais para permitir uma dissipação dos excessos/decréscimos de poropressão induzidos na rocha e que são responsáveis por equilibrar o estado de tensões quando da passagem da onda sísmica. Já os ensaios mecânicos simultâneos de laboratório que fornecem as relações dinâmico vs. estático para as propriedades de deformabilidade são muitas vezes obtidos em rochas seca ou seja, que apresentam comportamento drenado uma vez que os ciclos de carregamento e descarregamento são compensados unicamente pela deformação do arcabouço sólido (grão, matriz e cimento) sem contribuição de excesso/decréscimo de poropressão de fluído. 
Por isso torna-se necessário um mecanismo que permita converter as propriedades de deformabilidade advindas da sísmica para a condição drenada na qual são realizados os ensaios mecânicos simultâneos e válidas as relações de equivalência dinâmico vs. estático.

O método mais comumente usado, teoricamente conhecido e que se presta a baixas frequências, como as do dado sísmico (menores que $100 \mathrm{~Hz}$ ) e de ensaios mecânicos estáticos, é baseado no trabalho de (Gassmann 1951).

$$
\begin{gathered}
K_{b}^{\text {ño dren }}=K_{b}^{d r e n}+\frac{\left(1-\frac{K_{b}^{d r e n}}{K_{S}}\right)^{2}}{\frac{\emptyset_{e f f}}{K_{f}}+\frac{1-\emptyset_{e f f}}{K_{\min }}-\frac{K_{b}^{d r e n}}{K_{\text {min }}^{2}}} \\
G^{\text {não dren }}=G^{d r e n} \quad(\text { Eq 3.5) }
\end{gathered}
$$

As Equações de Gassmann exibida na Eq 3.4 relaciona o módulo de compressibilidade volumétrica não-drenado da rocha $\left(K_{b}^{\text {não } d r e n}\right)$, o módulo de compressibilidade volumétrica drenado da rocha $\left(K_{b}^{d r e n}\right)$, a porosidade conectada da rocha $\left(\emptyset_{e f f}\right)$, o módulo bulk do fluido $\left(K_{f}\right)$, o módulo de compressibilidade volumétrica do mineral $\left(K_{\min }\right)$ e também os módulos de cisalhamento não-drenado $G^{\text {não dren }}$ e drenado $G^{d r e n}$ da rocha.

O modelo de Gassmann assume que a rocha é homogênea, isotrópica e que o espaço poroso é completamente conectado. Logo essas premissas são violadas se o arcabouço sólido da rocha é composto de múltiplos minerais com grande variação de parâmetros elásticos (Berge 1998) ou se é composto de minerais anisotrópicos preferencialmente orientados (Brown 1975). Quanto ao esqueleto poroso, as premissas são que os poros devem ser conectados e os fluídos devem ter mobilidade, porém recomenda-se que quando múltiplos tipos de poros estejam presentes na rocha, usar modelos mais complexos (Berryman 2000).

Muitas das premissas envolvendo conectividade e tipo de poros são provavelmente violadas em rochas de baixa porosidade. Rochas 
carbonáticas, em particular, podem ser problemáticas devido à variabilidade dos tipos de poros e a baixa conectividade frequentemente observadas já em lâminas delgadas.

O modelo de Gassmann aplica-se tanto melhor quanto suficientemente baixa a frequência do sinal, no sentido de que a variação de poropressão quando da passagem do sinal é equalizada ao longo de distâncias muito maiores que a dimensão do poro e muito menores do que o comprimento do sinal seja de pulso sísmico ou perfil de poço.

As frequências de perfis de poços são consideradas um limiar em que o modelo de Gassmann pode ser ou não aplicável (Berryman 1999).

Embora tenham sido relatados resultados confiáveis em águas profundas no Golfo do México para areias limpas com altas porosidades efetivas, os resultados não são confiáveis quando tipicamente as Equações de Gassmann (Eq 3.4 e Eq 3.5) são usadas para areias de baixa porosidade ou argilosas ou também para rochas carbonáticas. Neste sentido para as altas frequências (incluindo aqui já as frequências de perfis de poço) recomenda-se usar a formulação original de (Biot 1956,1962) que necessitará de uma maior quantidade de parâmetros para ser usada.

No âmbito da pesquisa que o texto se propõe, foram usadas as Equações de Gassmann (Eq 3.4 e Eq 3.5) uma vez que os corpos de prova de travertino romano (CPTR) possuem boas condições permoporosas assim como acredita-se que sejam os carbonatos reservatórios do Sub-Sal do PPSBS, estamos no domínio das baixas frequências e o resultados obtidos para as propriedades mecânicas estáticas de deformabilidade devem ser encarados como não mais que um cenário dentre muitos que deverão alimentar um simulador geomecânico.

Será introduzido o algoritmo ilustrado na Figura 3.47 que permite estimar as propriedades estáticas de deformabilidade (mais adequadas a simulação geomecânica que foca num horizonte produtivo de algumas décadas para o reservatório) a partir das propriedades dinâmicas de deformabilidade estimadas do dado sísmico (não-drenadas) e para tanto fazendo uso de relações de equivalência dinâmico vs. estático entre propriedades mecânicas de deformabilidade obtidas a partir de ensaios mecânicos simultâneos com rocha seca (drenada). 


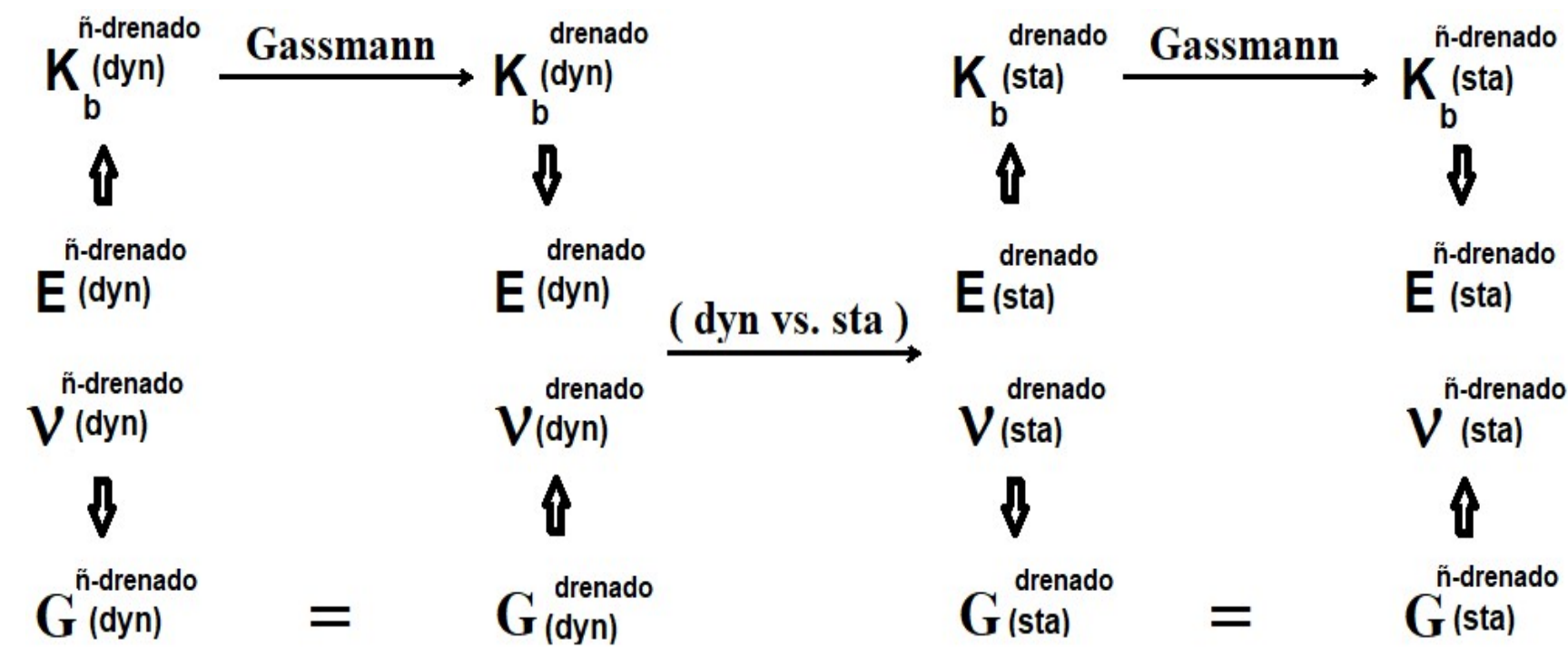

Figura 3.47: Algoritmo para conversão dinâmica vs. estática entre propriedades mecânicas de deformabilidade seguindo o MFR (Modelo de Física de Rochas) de Gassmann

No algoritmo exibido na Figura 3.47 são também empregadas as Equações 3.6 e 3.7 sempre que necessário:

$$
\begin{array}{cc}
\mathrm{G}=\frac{E}{2 \cdot(1+v)} & K_{b}=\frac{E}{3 \cdot(1-2 v)} \\
E=\frac{9 K_{b} \cdot G}{3 \cdot K_{b}+G} & v=\frac{3 \cdot K_{b}-2 \cdot G}{2 \cdot\left(3 K_{b}+G\right)}
\end{array}
$$

Assim como a inversa da Eq 3.4 de Gassmann, Equação 3.8 :

$$
K_{b}^{d r e n}=\frac{\left(\frac{\emptyset_{e f f}}{K_{f}}+\frac{1-\emptyset_{e f f}}{K_{\min }}\right) K_{b}^{\text {ño dren }}-1}{\frac{\emptyset_{e f f}}{K_{f}}+\frac{1-\emptyset_{e f f}}{K_{\min }}+\frac{K_{b}^{n a ̃ o d r e n}}{K_{\min }^{2}}-\frac{2}{K_{\min }}}
$$


Na primeira coluna à esquerda da Figura 3.47 o módulo de elasticidade e o coeficiente de poisson dinâmicos não-drenados são obtidos a partir de um modelo de física de rochas (MFR), que será exibido na seção 4 de Resultados, aplicado à impedância -P advinda de inversão sísmica.

Ainda na primeira coluna à esquerda são calculados o módulo de compressibilidade volumétrica e o módulo de cisalhamento dinâmico não drenado com uso das Eq 3.6 e aplicadas as Equações de Gassmann (Eq 3.4 e Eq 3.5) para o cálculo do módulo de compressibilidade volumétrica e do módulo de cisalhamento dinâmicos drenados presentes na segunda coluna da Figura 3.47.

Na segunda coluna da Figura 3.47 a partir do módulo de compressibilidade volumétrica e do módulo de cisalhamento dinâmicos drenados são calculados o módulo de elasticidade e o coeficiente de Poisson dinâmicos drenados com uso das Eq 3.7 e aplicadas as relações de equivalência dinâmico vs. estático para o cálculo do módulo de elasticidade e do coeficiente de Poisson estáticos drenados presentes na terceira coluna da Figura 3.47.

Na terceira coluna da Figura 3.47 a partir do módulo de elasticidade e do coeficiente de Poisson estáticos drenados são calculados o módulo de compressibilidade volumétrica e o módulo de cisalhamento estáticos drenados com o uso das Eqs 3.6 bem como o coeficiente de Biot-Willis dado pela Equação 3.9

$$
\alpha_{B}=1-\frac{K_{b}^{d r e n}(s t a)}{K_{\min }}
$$

Ainda na terceira coluna da Figura 3.47 com o uso da Eq 3.8 e Eq 3.5 são calculados o módulo de compressibilidade volumétrica e do módulo de cisalhamento estáticos não-drenados presentes na quarta coluna da Figura 3.47 . 
Por fim na quarta coluna da Figura 3.47 a partir do módulo de compressibilidade volumétrica e do módulo de cisalhamento estáticos nãodrenados são calculados o módulo de elasticidade e o coeficiente de poisson estático não-drenados com uso das Eq 3.7.

A questão da obtenção das propriedades mecânicas estáticas de deformabilidade a partir das propriedades mecânicas dinâmicas de deformabilidade advindas do dado sísmico fica então encerrada com o emprego do algoritmo descrito na Figura 3.47 para as litologias em que se aplicam o MFR (Modelo de Física de Rochas) de Gassmann a saber: carbonatos reservatórios do Pré-Sal, carbonatos do Pós-Sal e areias limpas do Pós-Sal. Para as demais litologias encontradas no PPSBS: siltitos, argilitos, folhelhos e argilominerais não será empregado o MFR de Gassmann aplicado no algoritmo descrito na Figura 3.47. No caso destas litologias e na falta de um MFR adequado as propriedades mecânicas estáticas não-drenadas de deformabilidade serão obtidas aplicando diretamente as relações de equivalência dinâmico vs. estático às propriedades mecânicas dinâmicas não-drenadas de deformabilidade advindas do dado sísmico. 


\section{Resultados}

Os principais resultados desta dissertação são a construção de três cenários de propriedades mecânicas estáticas de deformabilidade integradas ao dado sísmico, aos perfis de poços fornecidos pela ANP do bloco BM-S-0282 no Pólo Pré-Sal da Bacia de Santos ( PPSBS ) e às relações de equivalência estático vs. dinâmico obtidas de ensaios mecânicos simultâneos realizados com corpos de prova secos de travertino romano análogo mecânico do reservatório carbonático Fm. BVE 100 do Pré-Sal ( 1 relação ) e também relações de equivalência obtidas de trabalhos publicados em jornais científicos ( 2 relações).

Um importante resultado também obtido a partir dos perfis de poços e furos de avaliação de risco geotécnico (geohazards) será um modelo de física de rochas (MFR) para as seções: Pós-Sal, Sal e Sub-Sal que conectem a observável geofísica empregada neste texto: Impedância-P às propriedades físicas das rochas: Velocidade $-P$, Velocidade-S e Densidade.

\section{1}

\section{Estimativa de Propriedades Mecânicas Integradas ao Dado Sísmico}

A integração do dado sísmico à modelagem geomecânica, no sentido da construção de propriedades mecânicas de deformabilidade, passa pelas seguintes importantes etapas ilustradas na Figura 4.1: condicionamento do dado sísmico e de poço, mapeamento estratigráfico e estrutural, uso de atributos sísmicos para identificação de corpos, construção de modelo de física de rochas (MFR) e estimativa de propriedades mecânicas de deformabilidade do meio.

Para o caso de reservatórios siliciclásticos de campos de gás de idade Jurássica e Triássica localizados na Bacia de Carnarvon em águas profundas no Noroeste Australiano recomenda-se a leitura do Capítulo 6 de Seismic Geomechanics (Herwanger 2011). Nesta referência, para estes 
tipos de reservatórios, são tratados temas de grande valor para integração sísmica à modelagem geomecânica tais como: aquisição e processamento de dado sísmico, estimativa de wavelets no reservatório, inversão sísmica AVO e cálculo de propriedades mecânicas estáticas de deformabilidade e de resistência a compressão e tração.

No fluxograma da Figura 4.1 são apresentadas de forma encadeada, as operações básicas seguidas neste texto para integração do dado sísmico à modelagem geomecânica no contexto de toda a seção estratigráfica em águas ultra profundas do Pólo Pré-Sal da Bacia de Santos, Brasil.

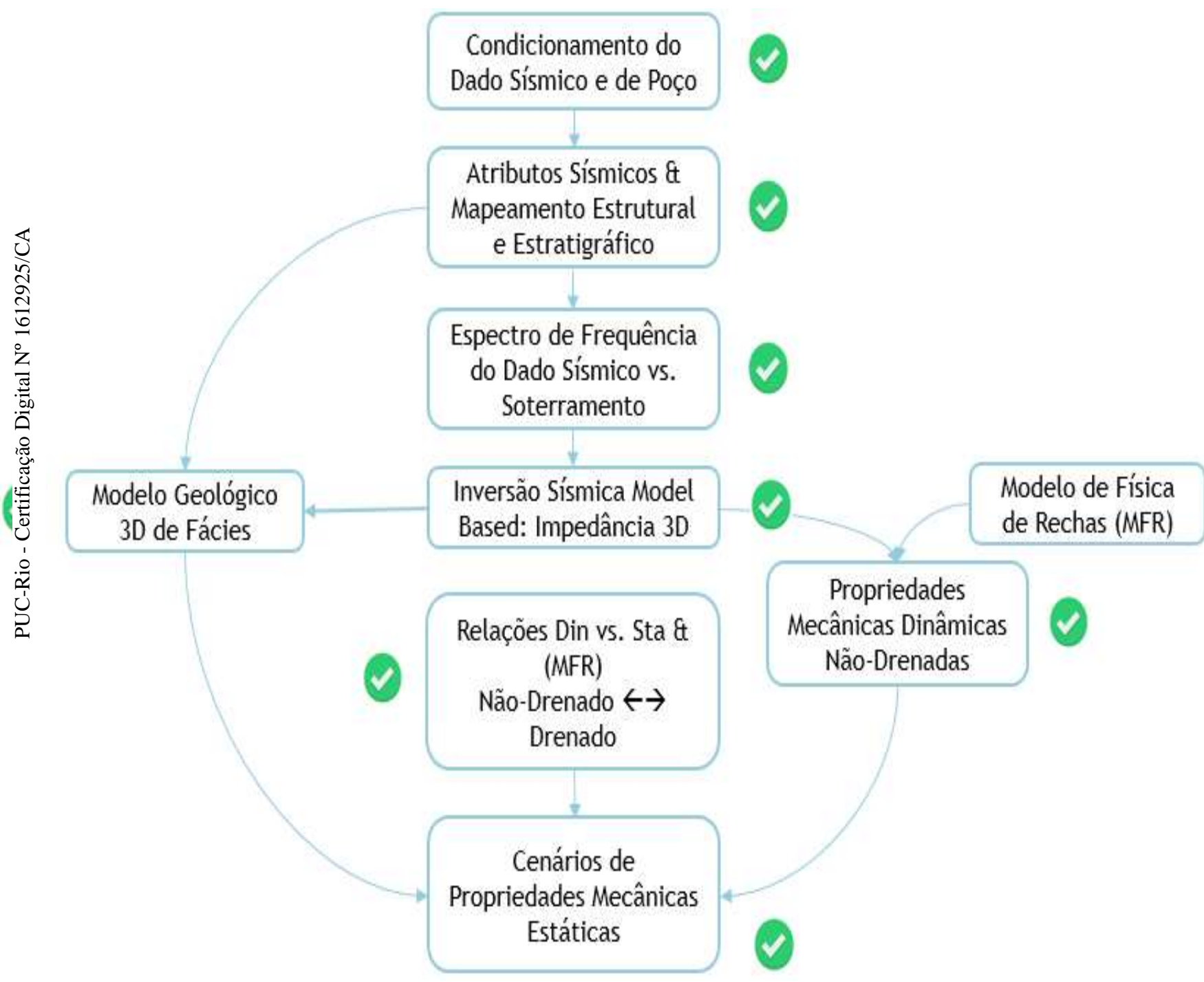

Figura 4.1: Fluxograma Básico de Integração Geomecânica - Sísmica para Construção de Propriedades Mecânicas de Deformabilidade. 
O conteúdo das etapas de execução são:

- Condicionamento do Dado Sísmico e de Poço

Melhores resultados são obtidos quando o dado sísmico e de poço são condicionados. O condicionamento constitui-se de um conjunto de algoritmos matemáticos parametrizáveis e aplicados ao dado de amplitude sísmica e de perfis de poço visando basicamente: eliminação de ruído e outliers, balanceamento do conteúdo de frequência e alinhamento do dado de amplitude sísmico.

Os resultados obtidos são os dados de amplitude sísmica (valores positivos e negativos) e perfis de poços com maior relação sinal/ruído na região de interesse e que podem ser empregados para auxiliar nas etapas seguintes.

- Extração de Atributos Sísmicos e Mapeamento Estrutural e Estratigráfico

Os dados sísmicos e de poços condicionados são utilizados para a extração de Atributos Sísmicos e Mapeamento Estrutural e Estratigráfico. Esta etapa consiste em interpretar ao longo do dado sísmico - dentro da resolução sísmica - superfícies correspondentes aos limites de sequência e que separam meios com propriedades mecânicas distintas, bem como, os planos das descontinuidades existentes através de mapeamento no dado sísmico. Faz-se também a extração de atributos sísmicos que auxiliem no mapeamento.

- Estimar Dependência do Espectro de Frequência do Dado Sísmico com o Soterramento

Etapa em que se considera os efeitos de atenuação e dispersão do pulso sísmico com o soterramento. Antecede a inversão do dado sísmico e presta-se a considerar o pulso sísmico mais adequado em cada das camadas de interesse.

\section{- Inversão Sísmica 3D baseada em Modelo a Priori}

A partir dos horizontes, cubo de amplitude sísmica e modelo a priori advindo dos perfis de poços e/ou modelo de velocidades sísmicas 
intervalares processado para a área, realizar o processo de inversão sísmica e estimar as Impedâncias $\mathrm{P}$ e S (caso tenha sido feita inversão elástica).

\section{- Modelo de Física de Rochas (MFR)}

A partir dos perfis de poços e furos de avaliação de risco geotécnico (geohazards) são construídos modelos de física de rochas (MFR) para as seções: Pós-Sal, Sal e Sub-Sal que permitem conectar a observável geofísica obtida na Inversão Sísmica 3D da etapa anterior: Impedância-P às propriedades físicas das rochas: Velocidade $-P$, Velocidade-S e Densidade.

\section{- Obtenção de Propriedades Mecânicas Dinâmicas Não-Drenadas}

Com a Impedância-P advinda da inversão sísmica e o MFR construído nas etapas anteriores são calculadas a densidade e usando as Eq 4.1 as propriedades mecânicas de deformabilidade: módulo de elasticidade $(E)$ e coeficiente de poisson $(v)$, porém dinâmicas e não-drenadas porque são provenientes do dado de amplitude sísmica e de perfis de poços: inversão sísmica e MFR.

$$
\mathrm{E}=\frac{\rho \cdot V_{S}^{2} \cdot\left(3 V_{P}^{2}-4 \cdot V_{S}^{2}\right)}{V_{P}^{2}-V_{S}^{2}} \quad v=\frac{\left(V_{P}^{2}-2 \cdot V_{S}^{2}\right)}{2 \cdot\left(V_{P}^{2}-V_{S}^{2}\right)}
$$

\section{- Modelo Geológico 3D de Fácies}

A partir dos horizontes mapeados, atributos sísmicos como amplitude, coerência, similaridade, mergulho e impedância-P invertida e do perfil de amostra de calha ou litologia interpretada dos poços é criado um modelo geológico 3D de fácies o qual condicionará a aplicação das relações de equivalência estático vs. dinâmico uma vez que estas se dão por fácies.

- Relações Dinâmico vs. Estático \& MFR Não Drenado $\leftrightarrow \rightarrow$ Drenado 
Para a aplicação das relações de equivalência dinâmico vs. estático, medidas com rocha seca (drenada), nas rochas porosas do PPSBS: arenitos e carbonatos do Pós-Sal e carbonatos do Sub-Sal será usado o MFR proposto por Gassmann (seção 3.5) que transforma as propriedades dinâmicas não-drenadas obtidas do dado sísmico em propriedades dinâmicas drenadas para então aplicação das relações de equivalência dinâmico vs. estático. Para as demais litologias encontradas no PPSBS: siltitos, argilitos, folhelhos e argilominerais não será empregado o MFR de Gassmann (seção 3.5). No caso destas litologias e na falta de um MFR adequado, as relações de equivalência dinâmico vs. estático são aplicadas diretamente às propriedades mecânicas dinâmicas não-drenadas de deformabilidade advindas do dado sísmico.

\section{- Cenários de Propriedades Mecânicas Estáticas}

A partir dos insumos obtidos nas etapas anteriores: propriedades mecânicas dinâmicas de deformabilidade integradas ao dado sísmico, cenários de relações de equivalência estático vs. dinâmica, modelo de fácies e o MFR descrito na etapa anterior, são computados cenários 3D de propriedades mecânicas estáticas de deformabilidade integradas ao dado sísmico.

O fluxograma de integração geomecânica sísmica deve ser revisado sempre que novos poços e novos dados sísmicos sejam por novas aquisições sísmicas ou novos reprocessamentos sísmicos forem incorporados à base de dados. 


\subsection{1}

\section{Seção Sub-Sal}

Uma sessão da Impedância - P obtida na inversão sísmica do Sub-Sal baseada em modelo a priori e confrontada com o perfil de Impedância -P de todos os 10 poços da área é exibida na Figura 4.2.

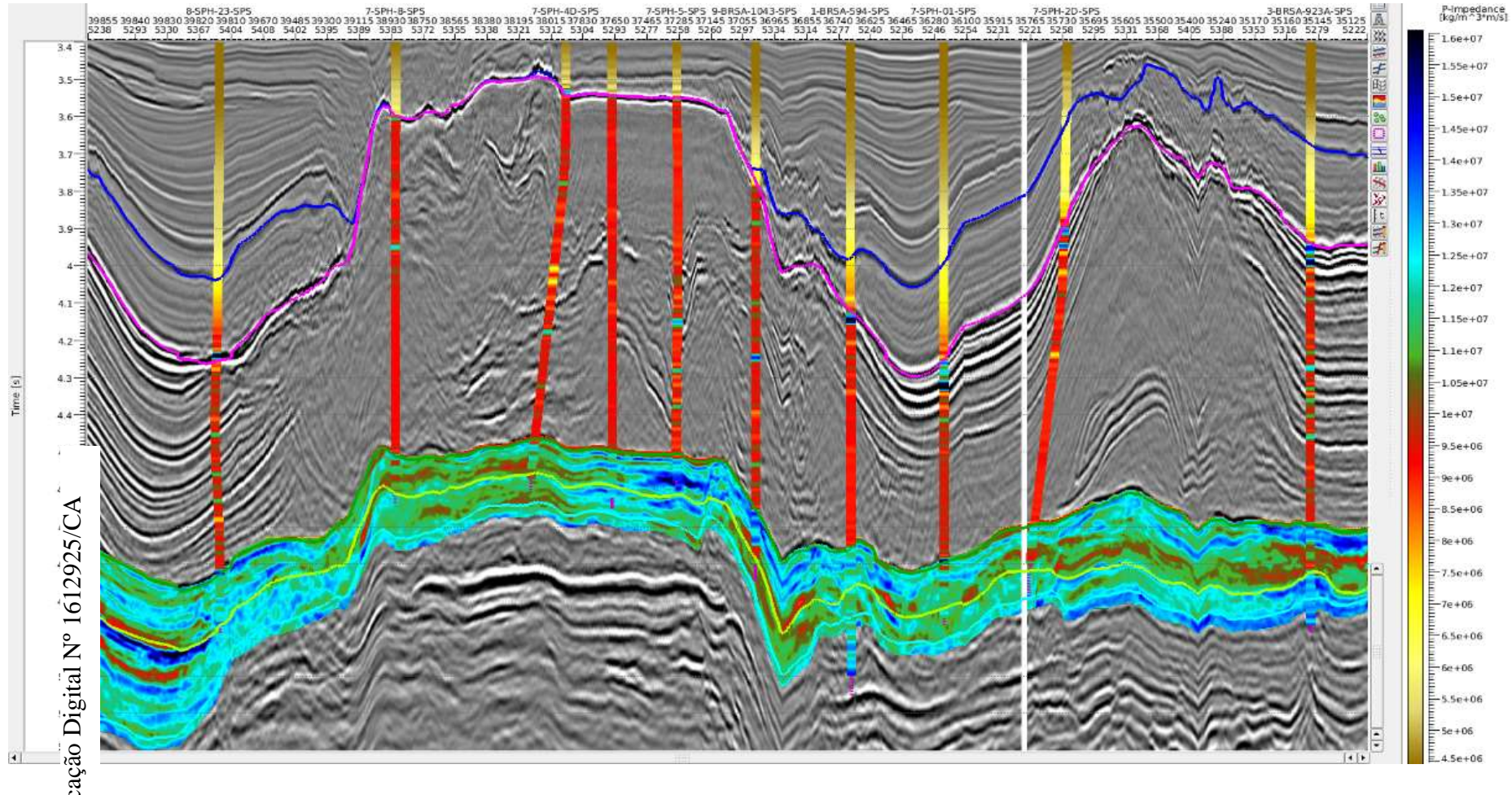

Figura 4.2: Impedância -P invertida do dado sísmico no Sub-Sal, em tempo

Consta-se da Figura 4.2 que a Impedância-P invertida além de incorporar os principais eventos presentes na sísmica concorda bem com a Impedância $-\mathrm{P}$ dos poços filtrada até $35 \mathrm{~Hz}$.

Através dos perfis de poços disponíveis na área, pode-se construir um Modelo de Física de Rochas (MFR) envolvendo as propriedades físicas das rochas: velocidade-P (VP), velocidade-S (VS) e densidade (RHO) como função da Impedância-P (IP) conforme ilustrado nas Figuras 4.3, 4.4 e 4.5 coloridas pelos poços. 


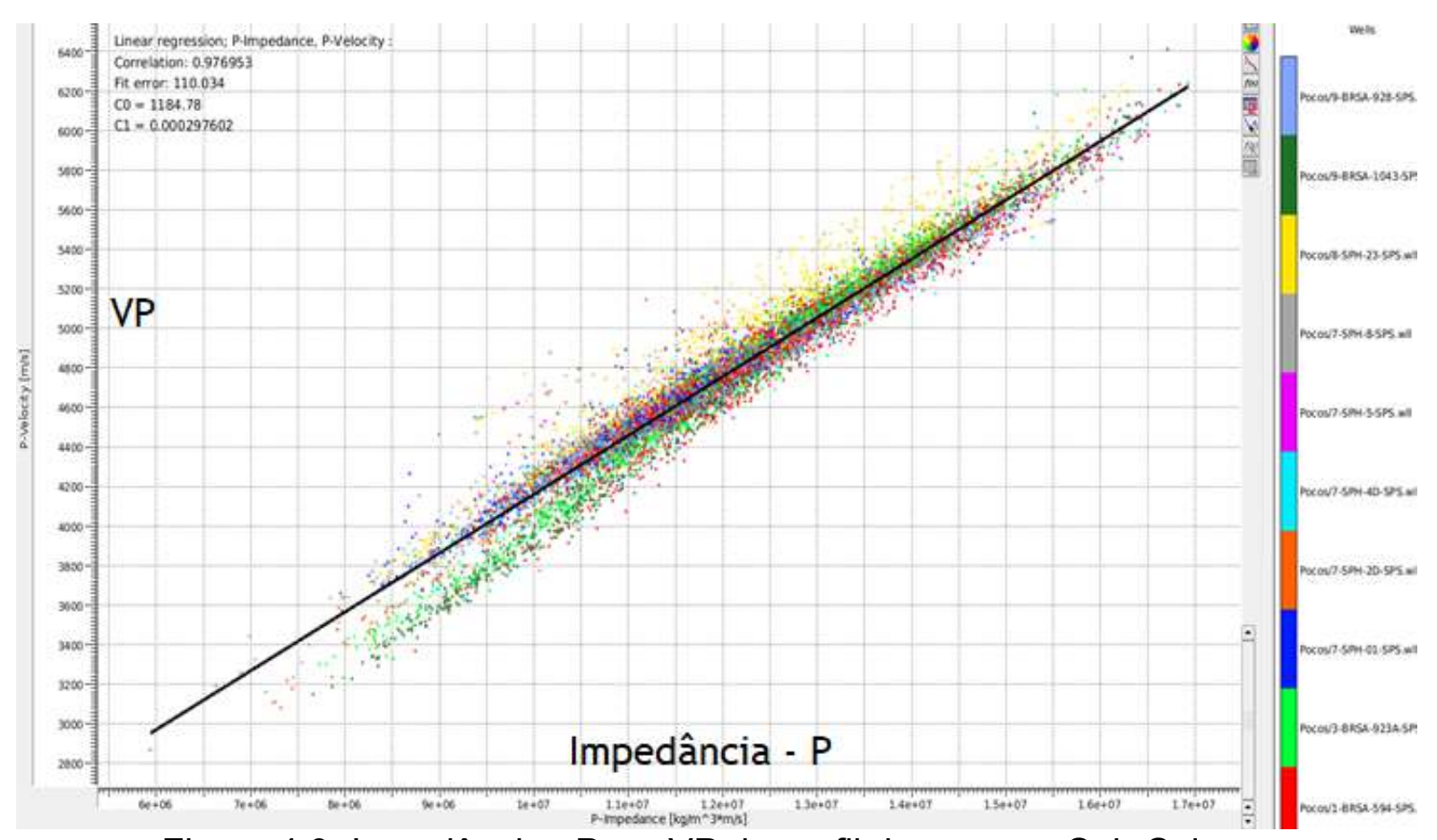

Figura 4.3: Impedância -P vs. VP de perfil de poço no Sub-Sal

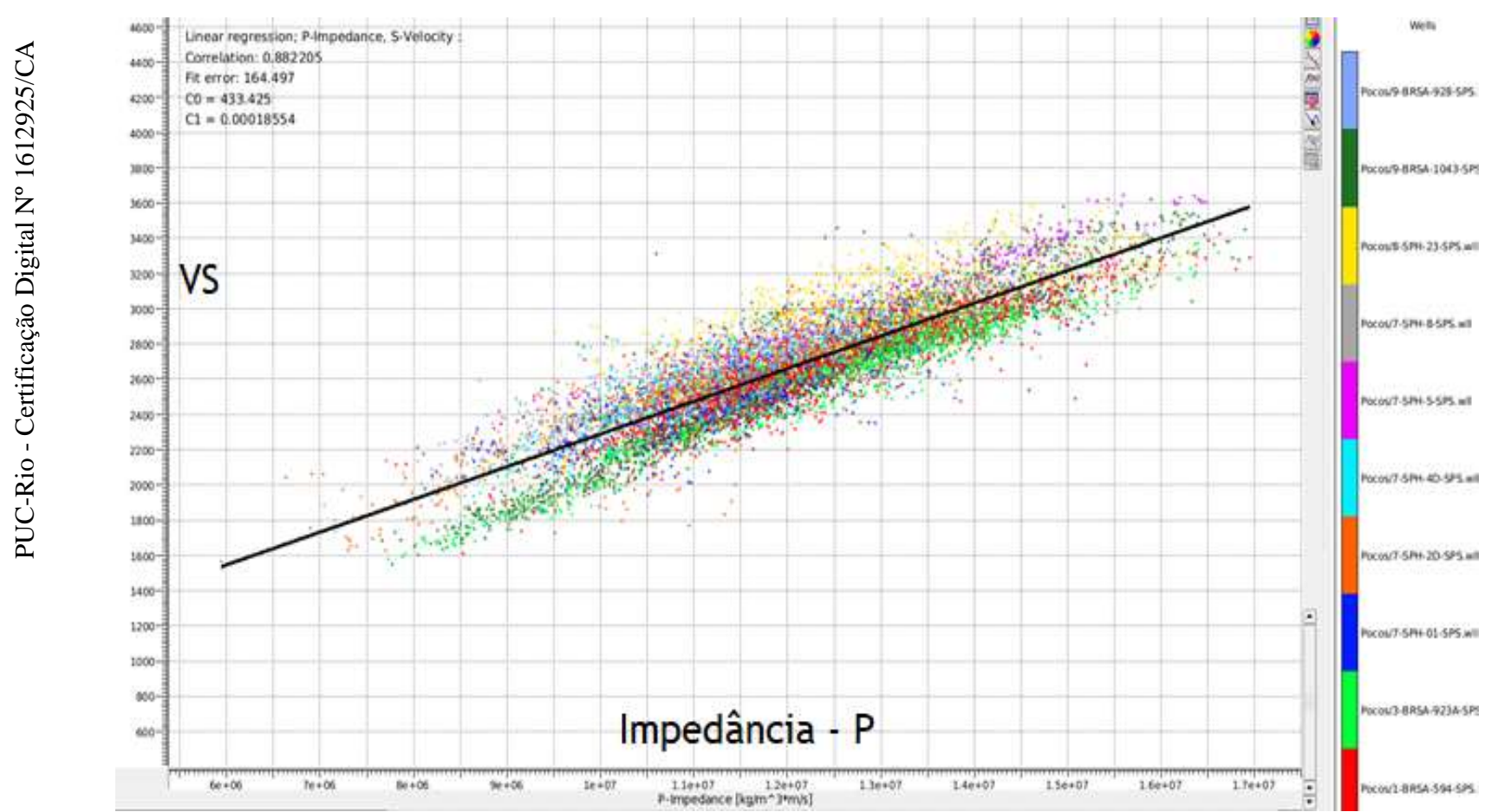

Figura 4.4: Impedância -P vs. VS de perfil de poço no Sub-Sal 


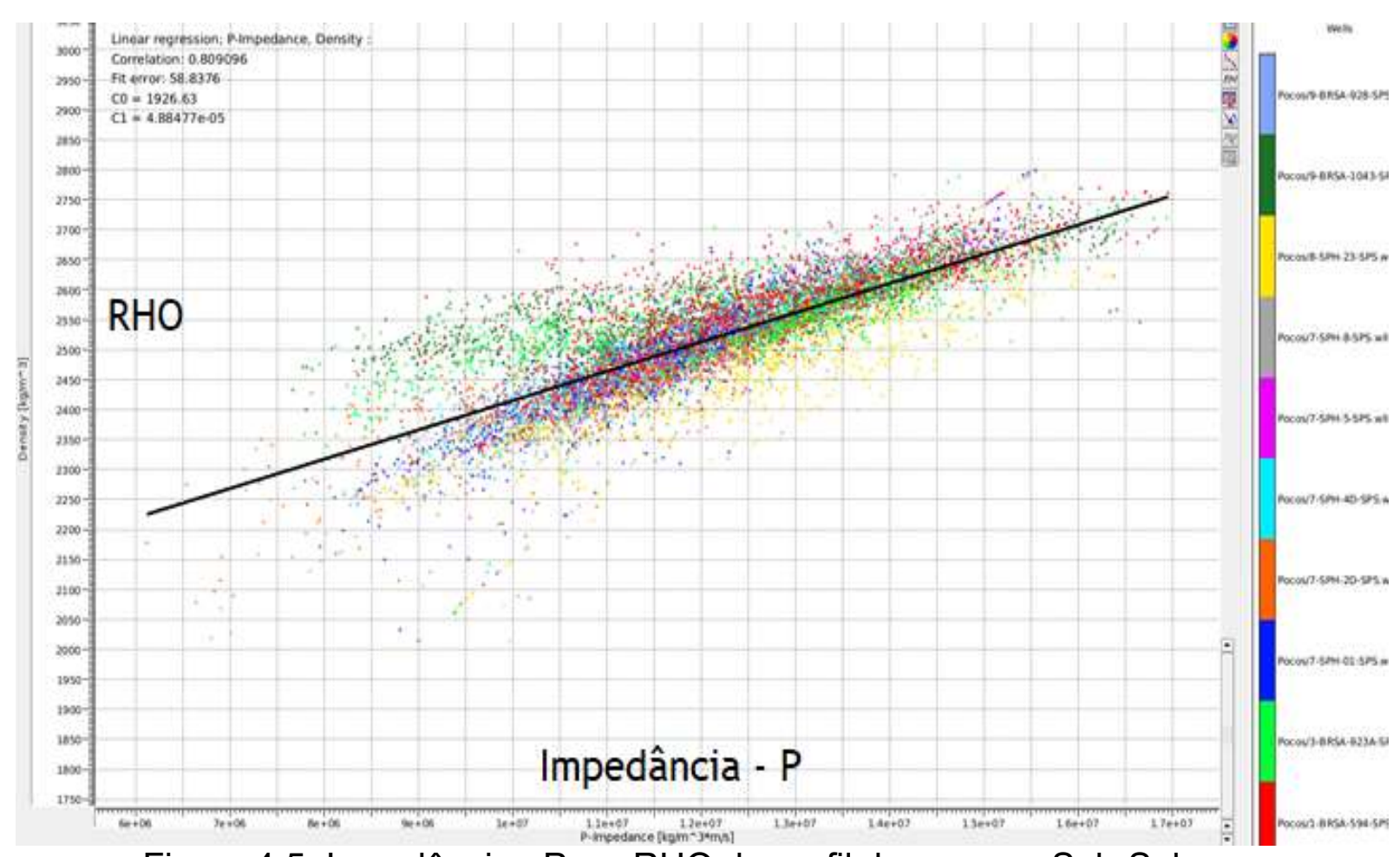

Figura 4.5: Impedância -P vs. RHO de perfil de poço no Sub-Sal

O MFR no Sub-Sal obtido a partir dos dados de poços e ilustrados pelas curvas pretas com bom ajuste nas Figuras 4.3, 4.4 e 4.5 são dados pelas Equações 4.2, 4.3 e 4.4 .

$$
\begin{aligned}
& \mathrm{VP}=1184,8+29,8 \mathrm{E}-05 . \mathrm{IP}(\mathrm{SI}) \\
& \mathrm{VS}=433,4+18,6 \mathrm{E}-05 . \mathrm{IP}(\mathrm{SI}) \\
& \mathrm{RHO}=1926,6+4,9 \mathrm{E}-05 . \mathrm{IP}(\mathrm{SI})
\end{aligned}
$$

A partir de VP, VS e RHO deste modo estimados a partir da Impedância $\mathrm{P}$ invertida do dado sísmico, são estimados $\mathrm{E}, v, K_{b}$ e $\mathrm{G}$ pelas equações da teoria da elasticidade (Eq 4.1 e 4.5):

$$
\begin{array}{cc}
\mathrm{E}=\frac{\rho \cdot V_{S}^{2} \cdot\left(3 V_{P}^{2}-4 \cdot V_{S}^{2}\right)}{V_{P}^{2}-V_{S}^{2}} & v=\frac{\rho \cdot V_{S}^{2} \cdot\left(3 V_{P}^{2}-4 \cdot V_{S}^{2}\right)}{V_{P}^{2}-V_{S}^{2}} \\
K_{b}=\frac{\rho \cdot\left(3 V_{P}^{2}-4 \cdot V_{S}^{2}\right)}{3} & G=\rho \cdot V_{S}^{2}
\end{array}
$$




\subsection{2}

\section{Seção Salífera}

$\mathrm{Na}$ seção salífera, a halita apresenta porosidade negligenciável e permeabilidade inferior a $1 \mu \mathrm{D}$ tornando a velocidade de propagação da onda compressional e a impedância acústica, indicadores independentes da profundidade, precisos e bem comportados da composição mineralógica halita $(\mathrm{NaCl}), \quad$ taquidrita $\left(\mathrm{CaCl}_{2} \cdot 2 \mathrm{MgCl}_{2} \cdot 12 \mathrm{H}_{2} \mathrm{O}\right)$, carnalita $\left(\mathrm{KCl} . \mathrm{MgCl} l_{2} \cdot 6 \mathrm{H}_{2} \mathrm{O}\right.$ ) e anidrita $\left(\mathrm{CaSO}_{4}\right)$, o que pode ser observado nos perfis (Sônico-P) de poços que atravessam a seção salífera.

$\mathrm{Na}$ Figura 4.6, pode-se observar a sessão de Impedância-P invertida do dado sísmico na seção salífera confrontada com os perfis de Impedância $P$ dos poços filtrados até $40 \mathrm{~Hz}$.

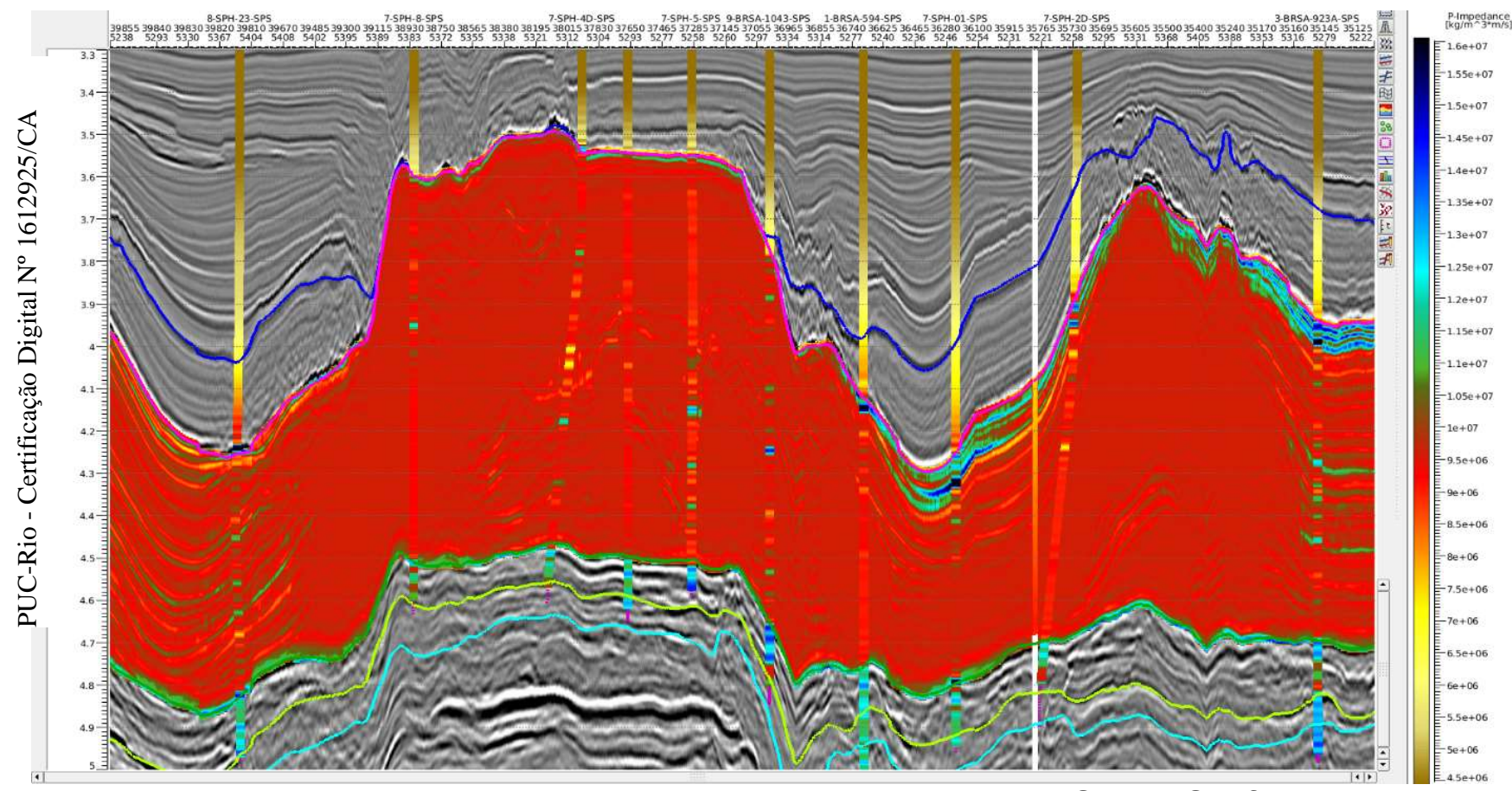

Figura 4.6: Impedância -P Invertida do dado sísmico na Seção Salífera

em tempo

Constata-se da Figura 4.6 que a Impedância-P invertida incorpora muitos dos principais sais observados nos perfis de Impedância dos poços ( filtrados até $40 \mathrm{~Hz}$ ) não sendo melhores os resultados da Impedância-P invertida em virtude de problemas de iluminação e ruído que atenua refletores sísmicos na Seção Salífera. 
Através dos perfis de poços disponíveis na área, pode-se construir um Modelo de Física de Rochas (MFR) envolvendo as propriedades físicas dos sais: velocidade-P (VP), velocidade-S (VS) e densidade (RHO) como função da Impedância-P (IP) conforme ilustrado nas Figuras 4.7, 4.8 e 4.9 coloridas pelos sais.

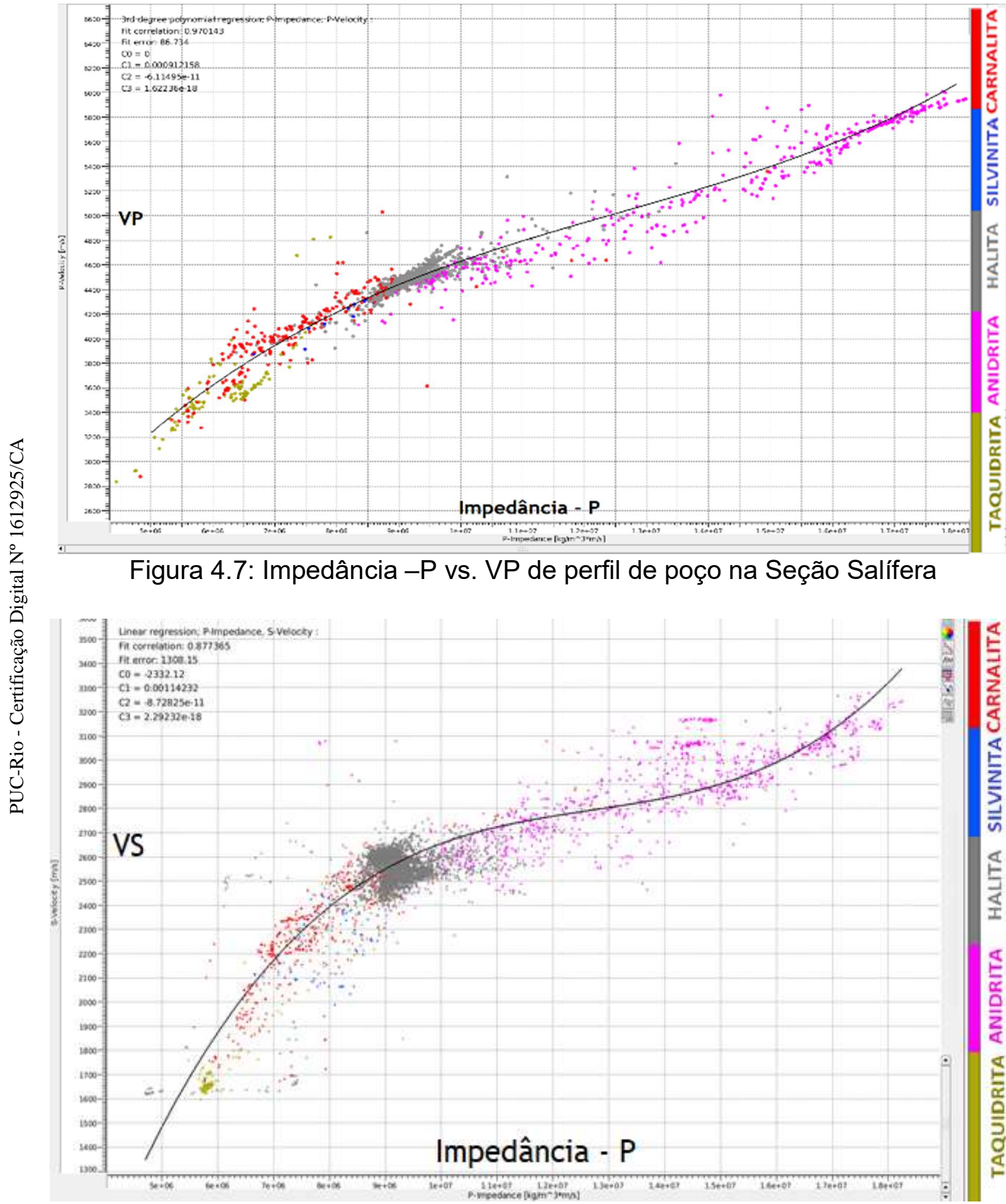

Figura 4.8: Impedância -P vs. VS de perfil de poço na Seção Salífera 


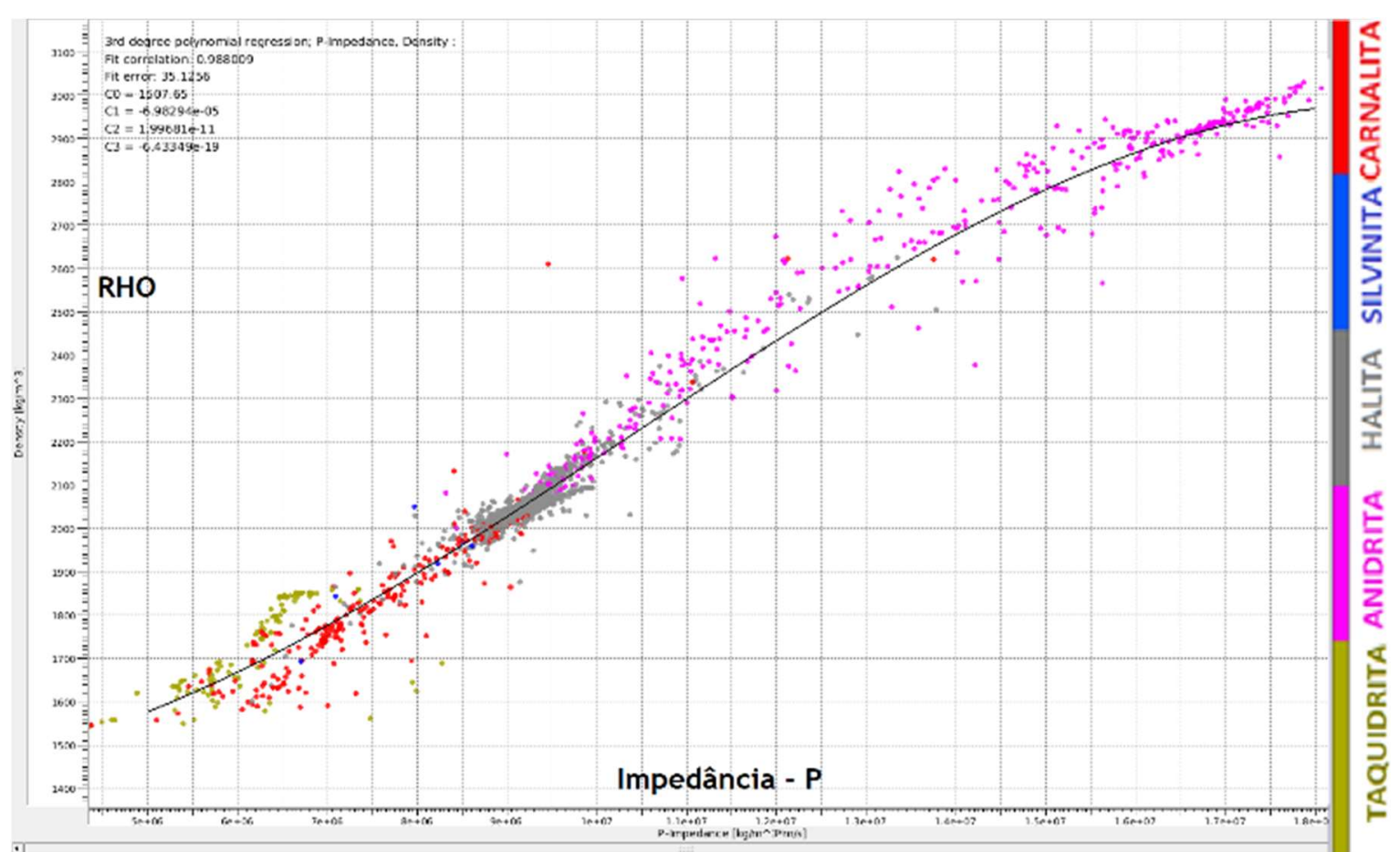

Figura 4.9: Impedância -P vs. RHO de perfil de poço na Seção Salífera

O MFR na Seção Salífera obtido a partir dos perfis de poços e ilustrados pelas curvas pretas com bom ajuste nas Figuras 4.7, 4.8 e 4.9 são dados pelas Equações 4.6, 4.7 e 4.8:

$$
\begin{aligned}
& V P=9,1 E-04 . I P-6,1 E-11 . I P^{2}+1,6 E-18 . I P^{3}(S I) \\
& V S=-2332,1+1,1 E-03 . I P-8,7 E-11 . I P^{2}+2,3 E-18 . I P^{3}(S I) \\
& R H O=1507,6-7,0 E-05 . I P+2,0 E-11 . I P^{2}-6,4 E-19 . I P^{3}(S I)
\end{aligned}
$$

A partir de VP, VS e RHO deste modo estimados, foram calculados E, $v$, $K_{b}$ e G com base nas equações da teoria da elasticidade (Eq 4.1 e 4.5). 


\subsection{3}

\section{Seção Pós-Sal}

Na Figura 4.10, pode-se observar a sessão de Impedância-P invertida do dado sísmico na seção pós-sal.

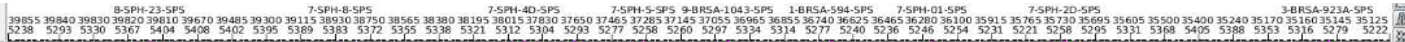

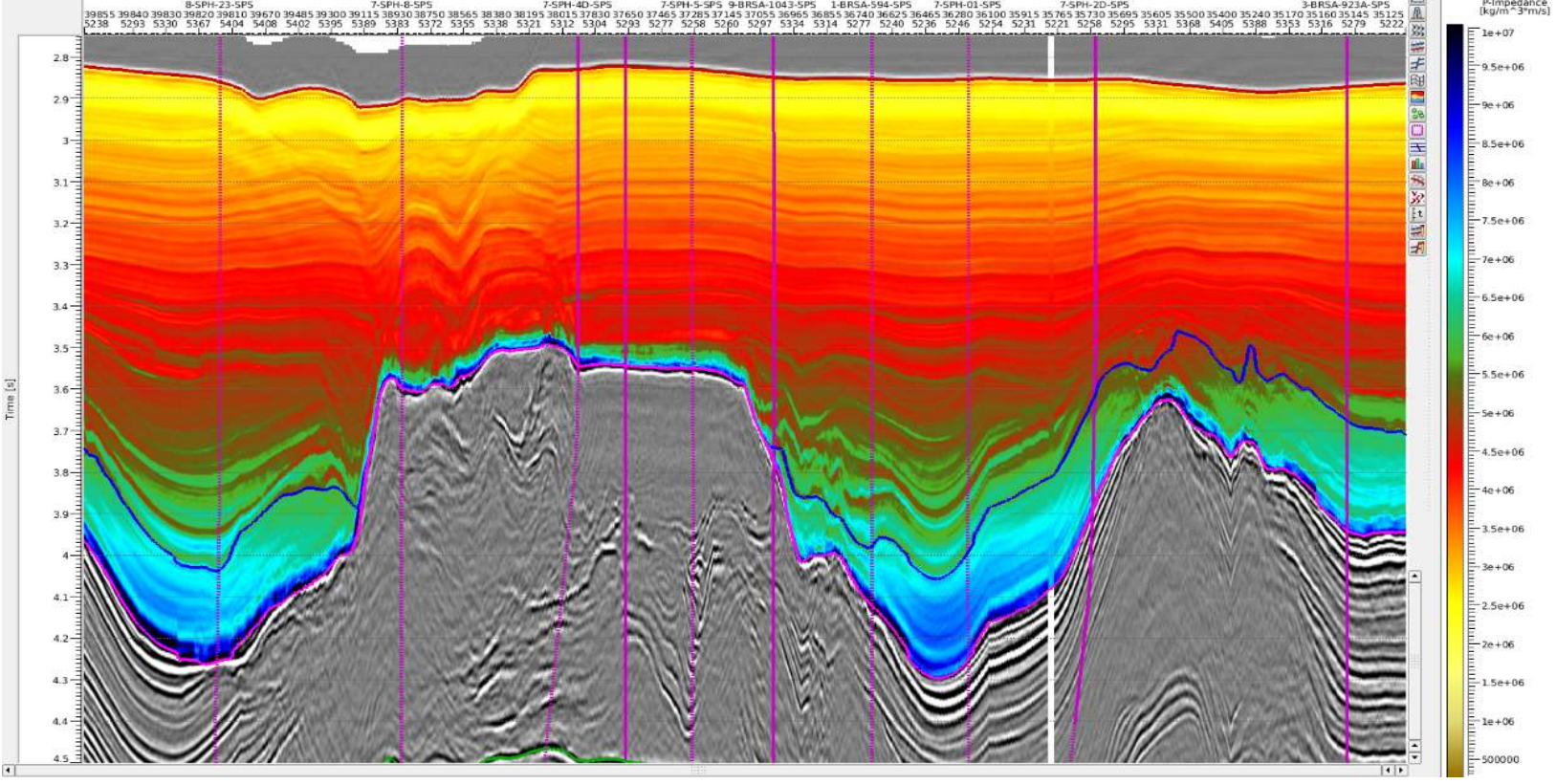

Figura 4.10: Impedância -P invertida do Dado Sísmico na Seção Pós-Sal, em tempo

Constata-se da Figura 4.10 que a Impedância-P invertida incorpora os principais eventos presentes na estratigrafia sísmica do Pós-Sal com maior continuidade lateral e frequência (aproximadamente $50 \mathrm{~Hz}$ em algumas camadas) que nas Seções Sub-Sal e Sal. Isto decorre da melhor qualidade do dado sísmico em termos de iluminação e dispersão na Seção Pós-Sal. 
Através dos perfis de poços disponíveis na área e furos de riscos geotécnicos (geohazards) do fundo marinho pode-se construir um Modelo de Física de Rochas (MFR) envolvendo as propriedades físicas das rochas: velocidade-P (VP), velocidade-S (VS) e densidade (RHO) como função da Impedância-P (IP) conforme ilustrado nas Figuras 4.11, 4.12 e 4.13 coloridas pelos sais.

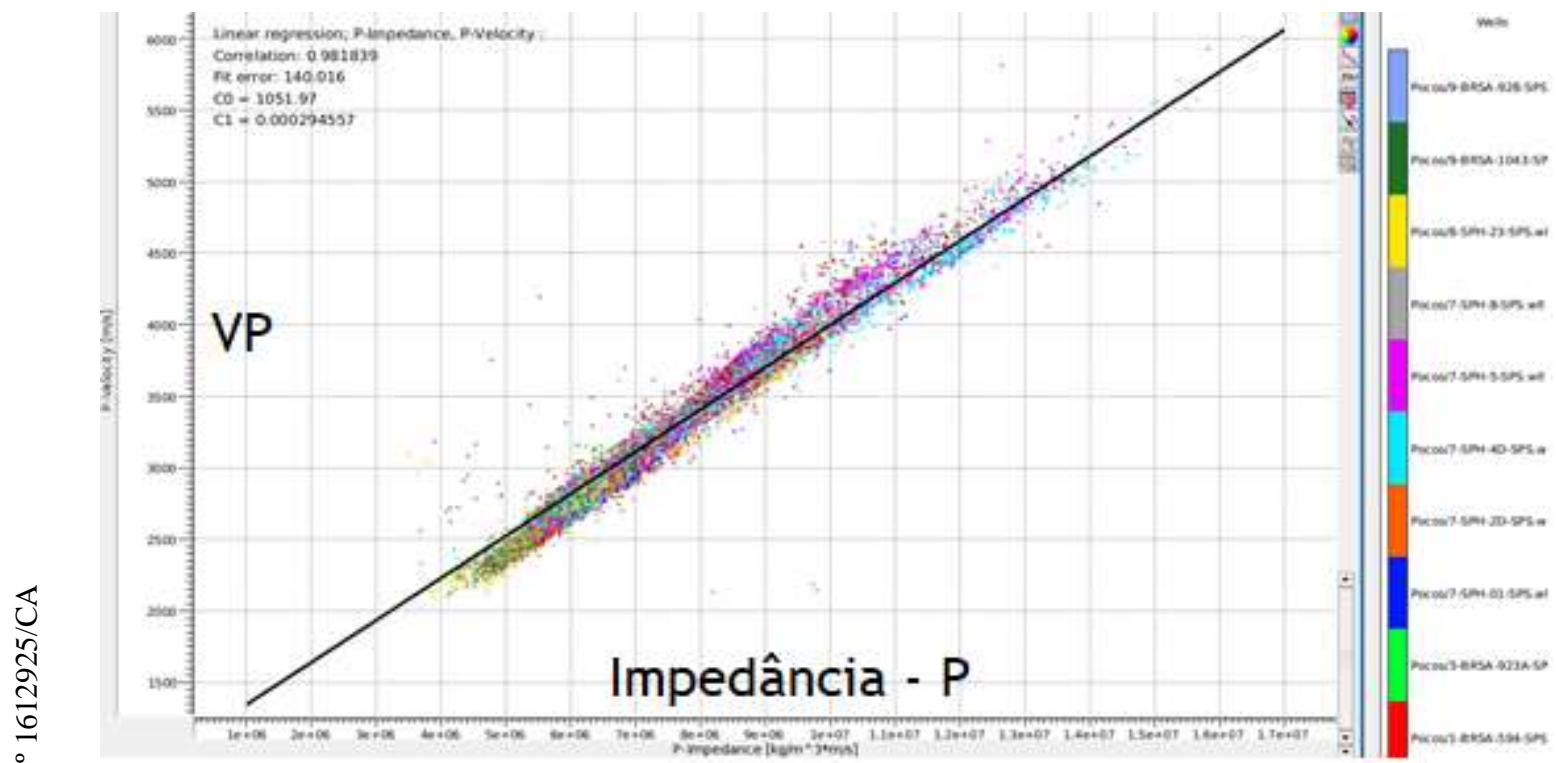

Figura 4.11: Impedância -P vs. VP de perfis de poços na Seção Pós-Sal

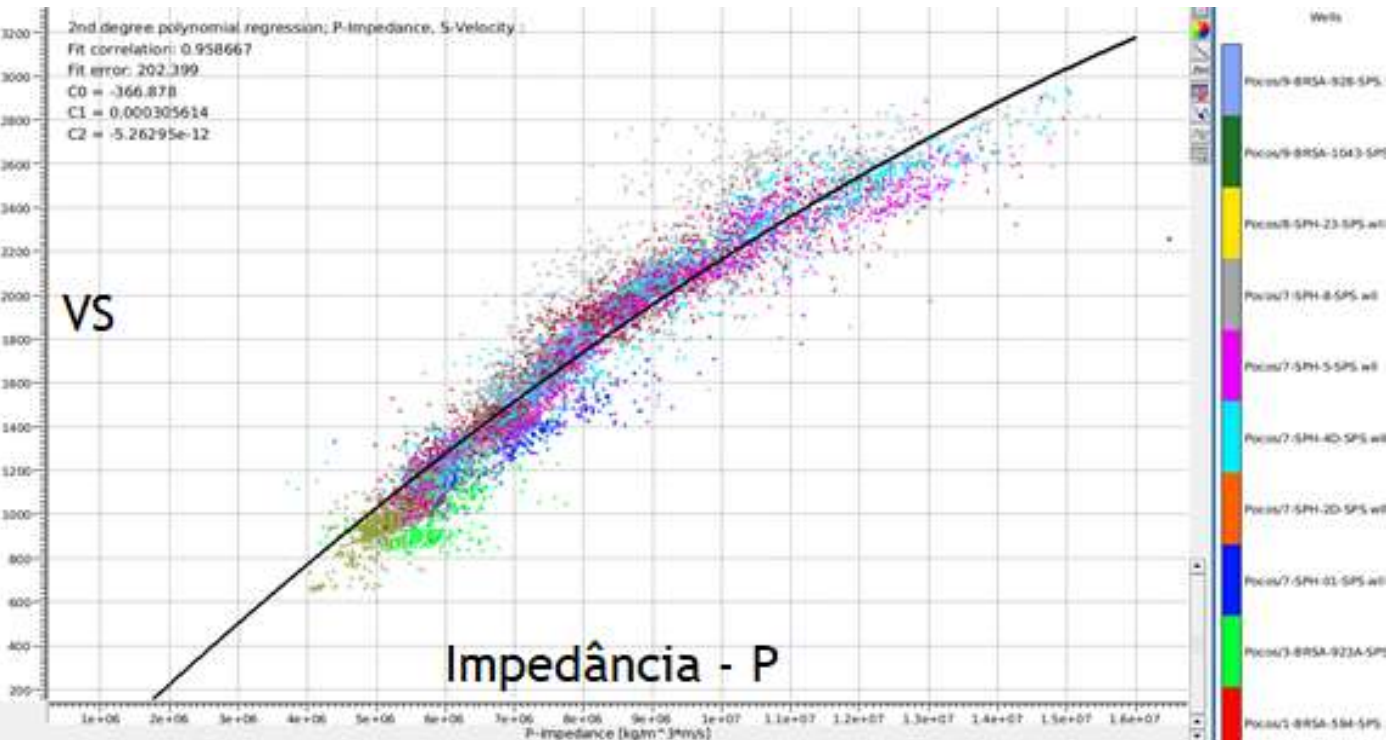

Figura 4.12: Impedância -P vs. VS de perfis de poços na Seção Pós-Sal 


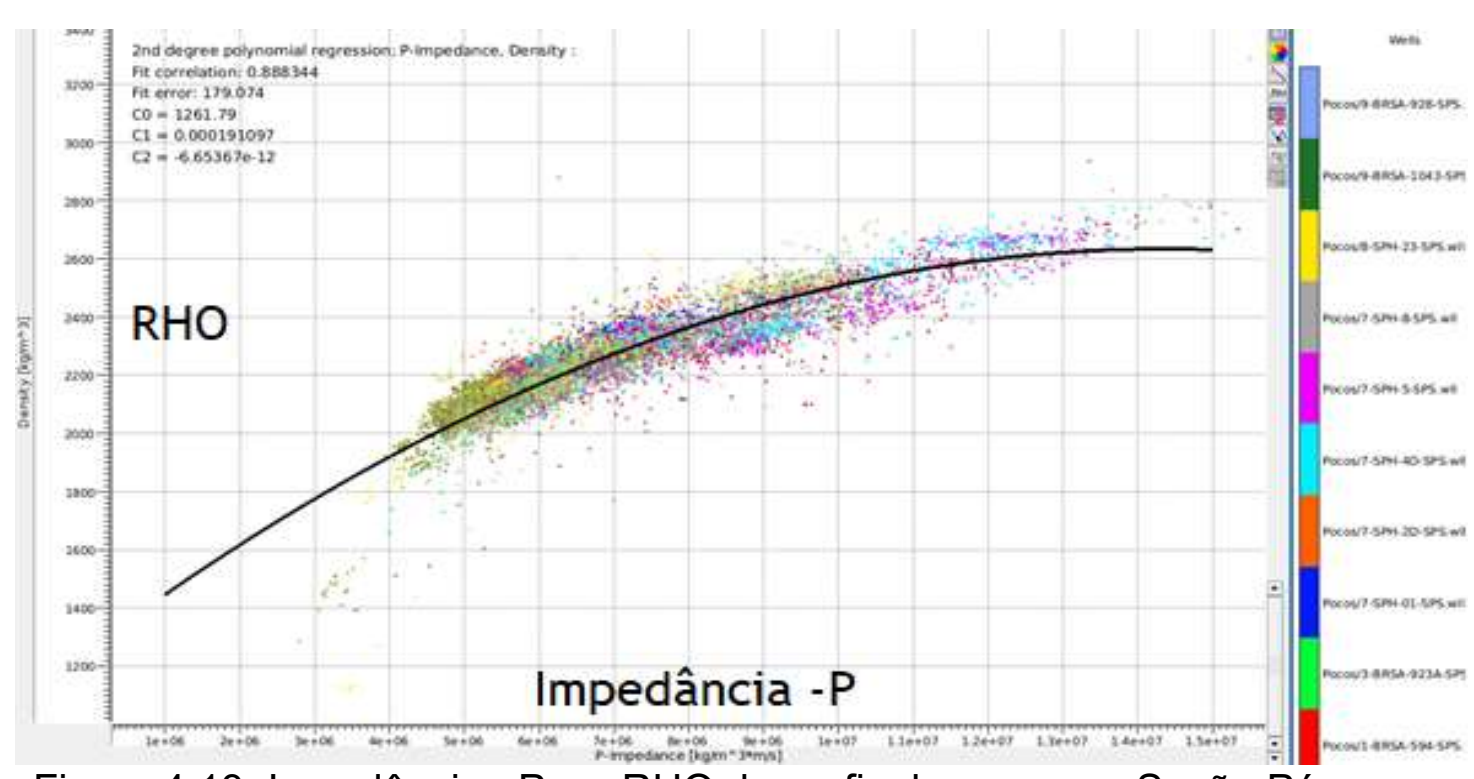

Figura 4.13: Impedância -P vs. RHO de perfis de poços na Seção Pós-

Sal

O MFR no Pós-Sal foi obtido a partir de perfis que se estendem do topo da

Seção Salífera até no máximo a Fm. Itajaí-Açú (em decorrência do diâmetro da fase dos poços não permitir perfilagem a cabo de densidade e Sônico$P$ nas camadas mais rasas) e furos de riscos geotécnicos (geohazards) com perfilagem de densidade, velocidades compressional e cisalhante nos primeiros $50 \mathrm{~m}$ do fundo marinho. O MFR ilustrado pelas curvas pretas com bom ajuste nas Figuras 4.11, 4.12 e 4.13 é dado pelas Equações 4.9, 4.10 e 4.11:

$$
\begin{gathered}
\mathrm{VP}=1052,0+29,5 \mathrm{E}-06 . \mathrm{IP}(\mathrm{SI}) \\
\mathrm{VS}=-367,0+30,6 \mathrm{E}-06 . \mathrm{IP}-5,3 \mathrm{E}-12 . \mathrm{IP}^{2}(\mathrm{SI}) \\
\mathrm{RHO}=1261,8+19,1 \mathrm{E}-06 . \mathrm{IP}-6,7 \mathrm{E}-12 . \mathrm{IP}^{2} \quad(\mathrm{SI})
\end{gathered}
$$

A partir de VP, VS e RHO deste modo estimados, foram calculados $\mathrm{E}, v$, $K_{b}$ e $\mathrm{G}$ com base nas equações da teoria da elasticidade (Eq 4.1 e 4.5). 


\subsection{4}

\section{Modelo Litológico}

Em termos de modelagem 3D de propriedades mecânicas estáticas de deformabilidade integradas ao dado sísmico faz-se necessário a construção de um modelo litológico 3D uma vez que as relações de equivalência dinâmico vs. estático medidas e também as disponíveis em trabalhos científicos para as propriedades de deformabilidade são dadas a depender da litologia desejada. As litologias de amostra de calha ou interpretadas a partir de perfis dos poços para oito dos dez poços disponíveis são ilustradas na Figura 4.13.

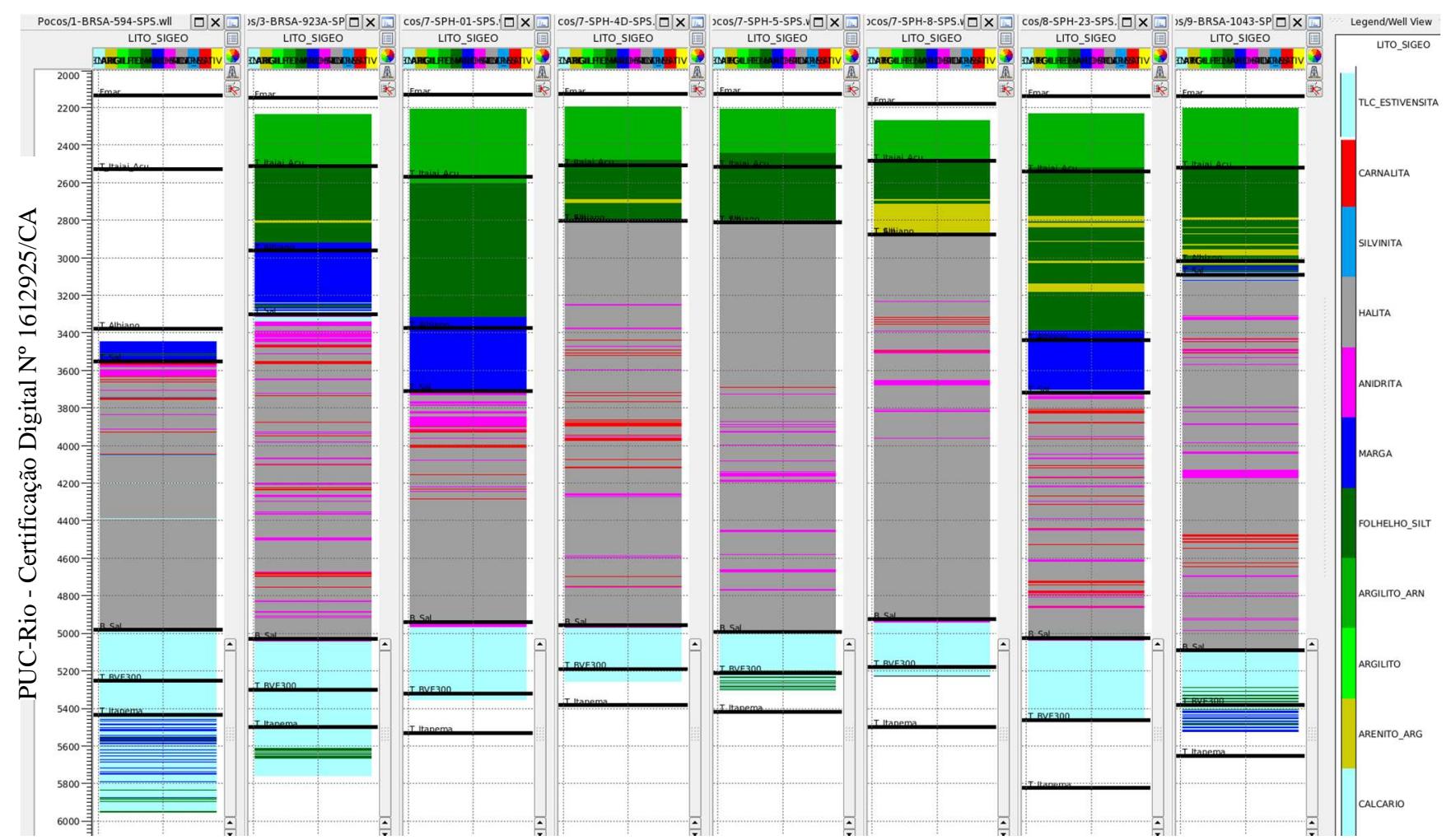

Figura 4.14: Litologias de Amostra de Calha ou Interpretada a partir de

Perfis de Poços

As litologias argilosas com presença de argilo-minerais como: argilitos e siltitos estão em verde claro e folhelhos estão em verde escuro. As areias e carbonato do Pós-Sal estão em amarelo e azul escuro respectivamente. Na seção salífera os sais halita em cinza, anidrita em roxo e sais solúveis em vermelho. Na seção pré-sal o carbonato está em azul claro. 
A partir da Impedância-P invertida do dado sísmico e demais atributos sísmicos como similaridade, mergulho e amplitude foi construído um modelo litológico 3D exibido na Figura 4.15 baseado em atributos sísmicos e com controle de qualidade baseado na litologia dos poços (Figura 4.14).

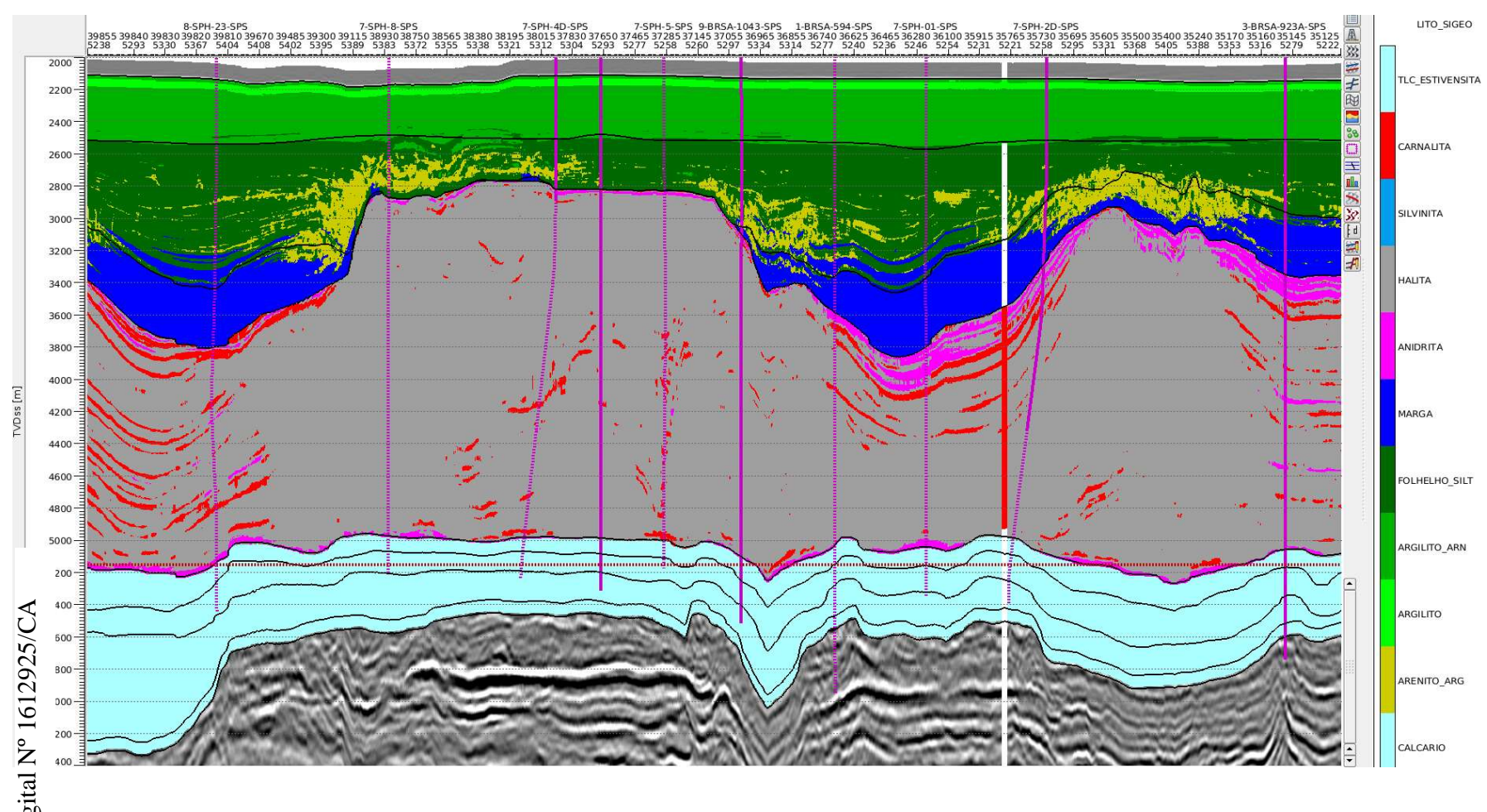

Figura 4.15: Sessão em profundidade do modelo litológico 3D

\section{2 \\ Incertezas}

Até aqui, dispomos das propriedades mecânicas elásticas: $\mathrm{E}, v, K_{b}$ e G dinâmicas e não-drenadas uma vez que foram estimadas com base na impedância $\mathrm{P}$ invertida do dado sísmico e no MFR construído com base nos perfis de poços. Para alimentar os simuladores Geomecânicos, insumos necessários em termos de propriedades mecânicas são a matriz de rigidez elástica estática não-drenada e o termo de acoplamento fluídomecânico (coeficiente de Biot). Diversos autores (Al-Shayea 2004), (Ide 1936), (Kolesnikov 2009) e (Vanheerdeen 1987) atribuem as diferenças entre os módulos dinâmicos e estáticos a fatores petrográficos texturais e petrofísicos como presença, tamanho e orientação espacial de: fraturas, 
fissuras, veios, estilolitos, cavidades, planos de fraqueza e foliação bem como composição mineralógica do arcabouço sólido, porosidade e distribuição do tamanho e formato dos poros (porosimetria) e diferença no tamanho dos grãos e cristais. O método estático necessário para quantificar a deformabilidade da rocha é mais sensível a presença de descontinuidades na rocha e , em geral, quanto mais descontinuidades na rocha menor será o módulo de elasticidade estático e maior a divergência entre os módulos estático e dinâmico. É exibida na Figura 4.16 uma compilação de relações de equivalência dinâmico vs. estático entre propriedades de deformabilidade para diversas litologias (Brotons 2016) que apresentam módulo dinâmico entre 5 e 80 GPa.

\begin{tabular}{|c|c|c|c|c|c|}
\hline Eq. & Reference & Relationship & $\mathrm{R}^{2}$ & $\begin{array}{l}E_{d y p} \\
(\mathrm{GPa})\end{array}$ & Rock type \\
\hline (3) & (King 1983) & $E_{\mathrm{gt}}=1.26 E_{\text {dyn }}-29.5$ & 0.82 & $40-120$ & $\begin{array}{l}\text { Igneous- } \\
\text { metamorphic }\end{array}$ \\
\hline (4) & (Vanheerden 1987) & $E_{s t}=a E_{d y n}^{b} \quad a[0.097-0.152]$ & - & $20-135$ & $\begin{array}{l}\text { Sandstone- } \\
\text { granite }\end{array}$ \\
\hline (5) & (Eissa and Kazi 1988) & $E_{s t}=0.74 E_{d y n}-0.82$ & 0.70 & $5-130$ & All types \\
\hline (6) & (Eissa and Kazi 1988) & $\log _{10} E_{\text {st }}=0.77 \log _{10}\left(\rho_{\text {bulk }} E_{\text {dyn }}\right)+0.02$ & 0.92 & $5-130$ & All types \\
\hline (7) & $\begin{array}{l}\text { (Christaras et al. } \\
\text { 1994) }\end{array}$ & $E_{s t}=1.05 E_{d y n}-3.16$ & 0.99 & $25-110$ & All types \\
\hline (8) & (Lacy 1997) & $E_{g t}=0.018 E_{d y n^{2}}{ }^{2}+0.422 E_{d y n}$ & - & - & Sedimentary \\
\hline (9) & $\begin{array}{l}\text { (Nur and Wang } \\
\text { 1999) }\end{array}$ & $E_{\mathrm{gt}}=1.153 E_{d y n}-15.2$ & - & - & $E_{s t}>15 \mathrm{GPa}$ \\
\hline (10) & (Horsrud 2001) & $E_{\mathrm{st}}=0.076 V_{p}{ }^{3.23}$ & - & - & Shale \\
\hline (11) & $\begin{array}{l}\text { (Martinez-Martinez } \\
\text { et al. 2012) }\end{array}$ & $E_{s t}=\frac{E_{\text {dyn }}}{3.8 \alpha_{s}^{-0.68}}$ & - & $5-50$ & $\begin{array}{l}\text { Limestone- } \\
\text { marble }\end{array}$ \\
\hline (12) & (Brotons et al. 2014) & $E_{s t}=0.867 E_{d y n}-2.085$ & 0.96 & $5-30$ & Calcarenite \\
\hline (13) & (Brotons et al. 2014) & $\log _{10} E_{a t}=1.28 \log _{10}\left(\rho_{\text {bulk }} E_{\text {dyn }}\right)-4.71$ & 0.97 & 5-30 & Calcarenite \\
\hline (14) & (Najibi et al. 2015) & $E_{a t}=0.014 E_{d y n}{ }^{1.96}$ & 0.87 & $13-74$ & Limestone \\
\hline (15) & (Najibi et al. 2015) & $E_{a t}=0.169 V_{p}^{2.224}$ & 0.90 & $13-74$ & Limestone \\
\hline
\end{tabular}

Figura 4.16: relações de equivalência entre módulos estáticos e dinâmicos (Brotons 2016). 
Com base no trabalho de (Brotons 2016) é exibido na Figura 4.17 um agrupamento em 6 classes de funcionais das relações de equivalência entre módulos estáticos e dinâmicos exibidos na Figura 4.16.

\begin{tabular}{|c|c|c|c|c|}
\hline Eq. type & Relationship & Eqs. & Vars. & Fig \\
\hline $\mathbf{I}$ & $E_{\mathrm{st}}=a E_{\mathrm{dyn}}+b$ & (3) (5) (7) (9) (12) & \multirow{3}{*}{$E_{\text {dyn }}$} & \multirow{4}{*}{1} \\
\hline II & $E_{g t}=a E_{d y n^{2}}+b E_{d y n}$ & (8) & & \\
\hline III & $E_{s t}=a E_{d y n^{b}}^{b}$ & (4) (14) & & \\
\hline IV & $\log _{10} E_{a t}=a \log _{10}\left(\rho_{\text {bulk }} E_{\text {dyn }}\right)+b$ & (6) (13) & $\rho_{\text {bulk }}: E_{\text {dyn }}$ & \\
\hline v & $E_{s t}=a V_{p}^{D}$ & $(10)(15)$ & $V_{p}$ & 9 \\
\hline VI & $E_{s t}=\frac{E_{\mathrm{dyn}}}{3.8 \alpha_{s}^{-0.68}}$ & (11) & $\alpha_{g i} E_{\text {dyn }}$ & - \\
\hline
\end{tabular}

Figura 4.17: Diferentes funcionais para equivalência entre módulos estáticos e dinâmicos (Brotons 2016)

Finalmente na Figura 4.18 é ilustrado o comportamento gráfico de cada uma das relações de equivalência entre módulos estáticos e dinâmicos exibidos na Figura 4.16. 


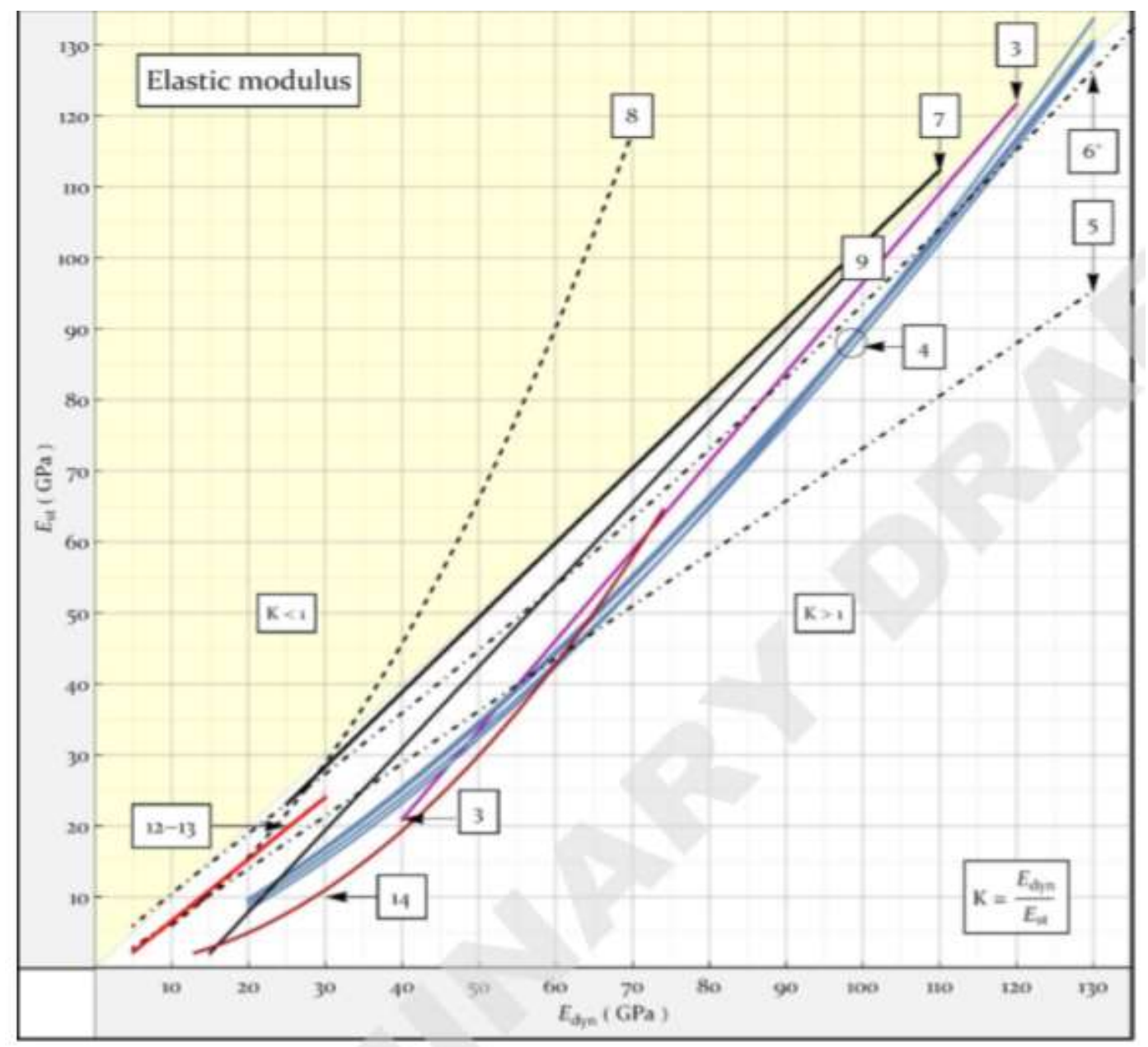

Figura 4.18: Comportamento Gráfico das diferentes relações de equivalência entre módulos estáticos e dinâmicos (Brotons 2016) (xMódulo de Elasticidade Dinâmico, y-Módulo de Elasticidade Estático)

\subsection{1}

\section{Relações de Equivalência entre Propriedades Mecânicas Dinâmicas e Estáticas}

Para tratar a enorme variedade de funcionais a serem empregados nas relações de equivalência estático vs. dinâmico entre propriedades de deformabilidade, foram empregados 3 cenários: 2 cenários baseados em relações de equivalência estático vs. dinâmico de trabalhos científicos e 1 cenário baseado na relação de equivalência estático vs. dinâmico obtida no ensaio simultâneo para o corpo de prova de travertino romano de número 2 (CPTR-2). 
Em todos os cenários usou-se para as litologias salíferas a correspondência de 1 para 1 entre propriedades de deformabilidade dinâmicas e estáticas e também correspondência de 1 para 1 entre coeficiente de Poisson dinâmico e estático para os carbonatos e areias do Pós -Sal e carbonatos do Pré-Sal quando secos (drenados).

O primeiro cenário é baseado na relação de equivalência estático vs. dinâmico entre módulos de elasticidade de (Pandula 2002) empregada para todas as litologias secas conforme a Tabela 4.1.

\begin{tabular}{||c||c||}
\hline Litologia & Relação (Pa) \\
\hline \hline Siltito ( Pós-Sal) & Es $=0,77^{*} \mathrm{Ed}+5854,12$ (Pandula) \\
\hline \hline Argilito ( Pós-Sal) & Es $=0,77^{*} \mathrm{Ed}+5854,12$ (Pandula) \\
\hline \hline Folhelho (Pós-Sal) & Es $=0,77^{*} \mathrm{Ed}+5854,12$ (Pandula) \\
\hline \hline Arenito (Pós-Sal) & Es $=0,77^{*} \mathrm{Ed}+5854,12$ (Pandula) \\
\hline \hline Carbonato (Pós-Sal) & Es $=0,77^{*} \mathrm{Ed}+5854,12$ (Pandula) \\
\hline \hline Carbonato (Pré-Sal) & Es $=0,77^{*} \mathrm{Ed}+5854,12$ (Pandula) \\
\hline \hline Talco_Estivensita ( Pré-Sal) & Es $=0,77^{*} \mathrm{Ed}+5854,12$ (Pandula) \\
\hline \hline
\end{tabular}

Tabela 4.1: Cenário 1 - Relações de equivalência Dinâmico vs. Estático Pandula (2002)

O segundo cenário é baseado nas relações de equivalência estático vs. dinâmico entre módulos de elasticidade de (Lacy 1996) empregada para todas as litologias secas conforme a Tabela 4.2 . 


\begin{tabular}{|c|c|}
\hline Litologia & Relação (GPa) \\
\hline \hline Siltito (Pós-Sal) & $\mathrm{Es}=2,61 \mathrm{E}-3 \cdot E d^{2}+4,22 \mathrm{E}-1 . \mathrm{Ed}$ (Lacy) \\
\hline \hline Argilito (Pós-Sal) & $\mathrm{Es}=2,61 \mathrm{E}-3 \cdot E d^{2}+4,22 \mathrm{E}-1$.Ed (Lacy) \\
\hline \hline Folhelho (Pós-Sal) & $\mathrm{Es}=6,21 \mathrm{E}-3 \cdot E d^{2}+2,33 \mathrm{E}-1 . \mathrm{Ed}$ (Lacy) \\
\hline \hline Arenito (Pós-Sal) & $\mathrm{Es}=4,25 \mathrm{E}-3 \cdot E d^{2}+4,53 \mathrm{E}-1 . \mathrm{Ed}$ (Lacy) \\
\hline \hline Carbonato (Pós-Sal) & $\mathrm{Es}=4,78 \mathrm{E}-1 . E d^{1,029}($ Lacy) \\
\hline \hline Carbonato (Pré-Sal) & $\mathrm{Es}=4,78 \mathrm{E}-1 . E d^{1,029}$ (Lacy) \\
\hline Talco_Estivensita (Pré-Sal) & $\mathrm{Es}=2,61 \mathrm{E}-3 \cdot E d^{2}+4,22 \mathrm{E}-1 . \mathrm{Ed}$ (Lacy) \\
\hline \hline
\end{tabular}

Tabela 4.2: Cenário 2 - Relações de equivalência Dinâmico vs Estático (Lacy 1996)

O terceiro cenário é baseado nas relações de equivalência estático vs. dinâmico entre módulos de elasticidade de (Lacy 1996), (Morales 1993), (Borges 2010) e do ensaio simultâneo realizado no (CPTR-2) conforme a Tabela 4.3 para as litologias secas.

\begin{tabular}{|c|c|}
\hline Litologia & Relação (GPa) \\
\hline Siltito ( Pós-Sal) & $\mathrm{Es}=2,61 \mathrm{E}-3 \cdot E d^{2}+4,22 \mathrm{E}-1 . \mathrm{Ed}(\mathrm{Lacy})$ \\
\hline Argilito ( Pós-Sal) & $\overline{E s}=2,61 \mathrm{E}-3 \cdot E d^{2}+4,22 \mathrm{E}-1 . \mathrm{Ed}$ (Lacy) \\
\hline Folhelho (Pós-Sal) & $\mathrm{Es}=6,21 \mathrm{E}-3 \cdot E d^{2}+2,33 \mathrm{E}-1 . \mathrm{Ed}(\mathrm{Lacy})$ \\
\hline Arenito ( Pós-Sal) & $\begin{array}{c}\ln (\mathrm{Es})=2,3 \cdot \mathrm{A}+(1-\mathrm{B}) \cdot 1,93+\mathrm{B} \cdot \ln (\mathrm{Ed}) \\
\mathrm{A}=-0,4575 ; \mathrm{B}=0,9402 ; \phi_{\text {ef }}>0,25 \\
\text { Morales \& Marcinew }\end{array}$ \\
\hline Carbonato (Pós-Sal) & $E s=0,72 . E d-4,693$ (Borges) \\
\hline Carbonato (Pré-Sal) & $E s=1,09 . E d-22,31$ (CPTR-2) \\
\hline Talco-Estivensita (Pré-Sal) & $\mathrm{Es}=2,61 \mathrm{E}-3 \cdot E d^{2}+4,22 \mathrm{E}-1 . \mathrm{Ed}(\mathrm{Lacy})$ \\
\hline
\end{tabular}

Tabela 4.3: Cenário 3 - Relações de equivalência Dinâmico vs Estático (Lacy 1996), (Morales 1993) e (Borges 2010) 


\subsection{2}

\section{Parâmetros Petrofísicos Empregados na Equação de Gassmann}

O uso da equação de Gassmann (seção 3.5) nas litologias: carbonatos e arenitos do Pós-Sal e carbonato do Pré-Sal visando passar para o domínio drenado as propriedades de deformabilidade dinâmicas (não-drenadas) advindas do dado sísmico para então aplicação dos 3 cenários de relações de equivalência expostos nas Tabelas 4.1, 4.2 e 4.3 faz necessário a caracterização dos parâmetros petrofísicos de fluído, mineral e porosidade conectada destas litologias.

Na tabela 4.4 o módulo de compressibilidade volumétrica do fluído Kf é determinado a partir da Temperatura, confinamento, salinidade, módulo de compressibilidade volumétrica da salmoura, grau API e RGO do óleo, módulo de compressibilidade volumétrica do óleo e saturação de água

\begin{tabular}{|c|c|c|c|c|c|c|c|c|c|}
\hline ปั & $\begin{array}{c}\mathrm{T} \\
\left({ }^{\circ} \mathrm{C}\right)\end{array}$ & $\begin{array}{c}\sigma_{m} \\
(\mathrm{Mpa})\end{array}$ & $\begin{array}{l}\text { Salinidade } \\
\qquad \mathrm{NaCl} \\
\text { (ppm) }\end{array}$ & $\begin{array}{c}\mathrm{Kw} \\
(\mathrm{GPa})\end{array}$ & API & RGO & $\begin{array}{c}\text { Ko } \\
(\mathrm{GPa})\end{array}$ & Sw & $\begin{array}{c}\mathrm{Kf} \\
(\mathrm{GPa})\end{array}$ \\
\hline 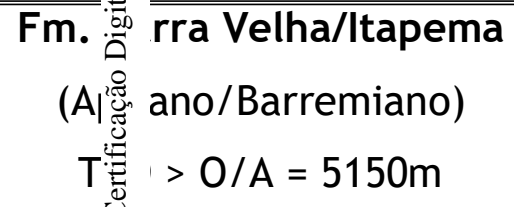 & 90 & 85 & 250.000 & 4,53 & & & & 1 & 4,53 \\
\hline 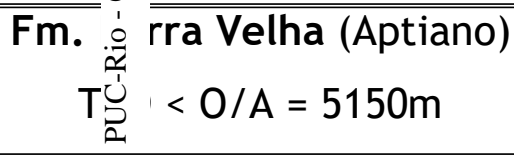 & 80 & 80 & 250.000 & 4,53 & 28 & 250 & 1,39 & 0,2 & 4,53 \\
\hline $\begin{array}{c}\text { Fm. Guarujá/Itanhaém } \\
\text { (Albi-Cenomaniano) }\end{array}$ & 35 & 32 & 190.000 & 2,61 & & & & 1 & 2,61 \\
\hline Fm. Itajaí-Açu (Cretáceo) & 28 & 27 & 160.000 & 2,61 & & & & 1 & 2,61 \\
\hline $\begin{array}{c}\text { Fm. Marambaia } \\
\text { (Mioceno/Eoceno) }\end{array}$ & 20 & 20 & 100.000 & 2,61 & & & & 1 & 2,61 \\
\hline
\end{tabular}

Tabela 4.4: Parâmetros Petrofísicos de Fluídos 
Para os carbonatos porosos do Pré-Sal (Fm. Barra Velha e Itapema) foi empregado o módulo de compressibilidade volumétrica mineral (Kmin) da Tabela 4.5.

\begin{tabular}{|lc||}
\hline \multicolumn{2}{|c|}{ Fm. Barra Velha / Itapema (Aptiano/Barremiano) } \\
\hline Minerais & Calcita \\
\hline Proporção & $100 \%$ \\
\hline \multicolumn{3}{|c|}{ Kmin $=70 \mathrm{GPa}$} \\
\hline
\end{tabular}

Tabela 4.5: Módulo de compressibilidade volumétrica Minerais no Pré-Sal

A porosidade conectada $\phi_{e f}$ foi estimada da Impedância $-\mathrm{P}$ invertida do dado sísmico através da Equação 4.12 proveniente do MFR obtido a partir de perfis de poços Figura 4.19 que relaciona a porosidade conectada e a Impedância-P nos carbonatos do Pré-Sal.

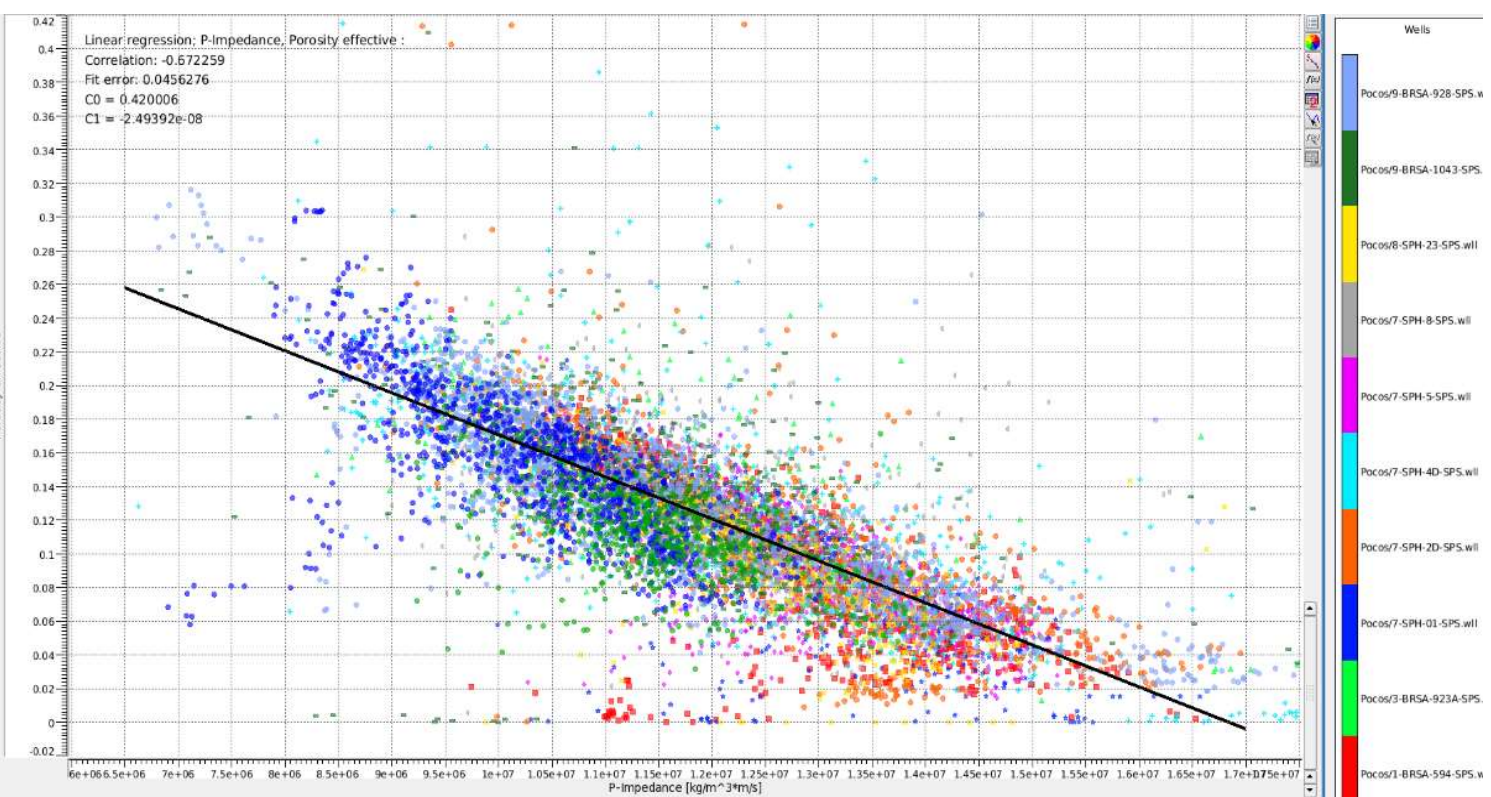

Figura 4.19: Porosidade Efetiva vs. Impedância-P dos poços para os carbonatos do Pré-Sal.

$\phi_{e f}($ Carbonato Pré-Sal $)=0,42-2,494 \mathrm{E}-8^{*} \mathrm{IP}(\mathrm{SI}) \quad(\mathrm{Eq} 4.12)$ 
Para os carbonatos porosos do Pós-Sal (Fm. Guarujá e Itanhaém) foi empregado o módulo de compressibilidade volumétrica mineral (Kmin) da Tabela 4.6.

\begin{tabular}{|c|c|c|c|c|c|}
\hline \multicolumn{6}{|c|}{ Fm. Guarujá / Itanhaém (Albi-Cenomaniano) } \\
\hline \multicolumn{2}{|c|}{ Constituintes } & Calcita & \multicolumn{3}{|c|}{ Folhelho } \\
\hline \multicolumn{2}{|l|}{ Proporção } & $65 \%$ & \multicolumn{3}{|l|}{$35 \%$} \\
\hline \multicolumn{2}{|l|}{$\overline{\mathrm{Kmin}(\mathrm{GPa})}$} & 70 & \multicolumn{3}{|l|}{27} \\
\hline \multicolumn{2}{|l|}{ Kmin Voigt $=55 \mathrm{GPa}$} & \multicolumn{2}{|c|}{ Kmin Reuss $=45 \mathrm{GPa}$} & \multicolumn{2}{|c|}{ Kmin VRH $=50 \mathrm{GPa}$} \\
\hline \multicolumn{6}{|c|}{ Folhelho } \\
\hline Minerais Quartzo & Biotita & Feldspato & Caolinita & Calcita & Hematita \\
\hline Prop & $24 \%$ & $18 \%$ & $10 \%$ & $8 \%$ & $5 \%$ \\
\hline Kmin(GPa) 38 & 50 & 38 & 1,5 & 70 & 100 \\
\hline \multicolumn{2}{|l|}{ Kmin Voigt $=43 \mathrm{GPa}$} & Kmin Reuss & $=11 \mathrm{GPa}$ & Kmin VR & $\mathrm{d}=27 \mathrm{GPa}$ \\
\hline
\end{tabular}

Tabela 4.6: Módulo de Compressibilidade Volumétrica Mineral para os carbonatos do Pós-Sal.

A porosidade conectada $\phi_{e f}$ foi estimada da Impedância $-\mathrm{P}$ invertida do dado sísmico através da Equação 4.13 proveniente de MFR obtido a partir de perfis de poços e que relaciona a porosidade conectada e a Impedância$\mathrm{P}$ nos carbonatos do Pós-Sal.

$$
\phi_{e f}(\text { Carbonato Pós-Sal })=0,41-3 \mathrm{E}-8^{*} \mathrm{IP}(\mathrm{SI}) \quad(\mathrm{Eq} 4.13)
$$

Para os arenitos porosos do Pós-Sal (Fm. Itajai-Açú e Juréia) foi empregado o módulo de compressibilidade volumétrica mineral (Kmin) da Tabela 4.7. 


\begin{tabular}{|c|c|c|c|}
\hline \multicolumn{4}{|c|}{ Arenitos Fm. Itajaí-Açú (Cretáceo/Eoceno/Mioceno) } \\
\hline Constituintes & Quartzo & Feldspato & Gulf Clay \\
\hline Proporção & $70 \%$ & $25 \%$ & $5 \%$ \\
\hline Kmin (GPa) & 38 & 37,5 & 25 \\
\hline \multicolumn{4}{|c|}{ Kmin Voigt $=37,2 \mathrm{GPa}$} \\
\hline
\end{tabular}

Tabela 4.7: Módulo de compressibilidade Volumétrica Mineral das Areias do Pós-Sal

A porosidade conectada destes arenitos limpos e porosos do Pós-Sal $\phi_{e f}$ foi usada como constante segundo a Equação 4.14 tendo em base areias limpas e porosas de outras áreas do Pós-Sal do PPSBS.

$$
\phi_{e f}(\text { Arenito Pós-Sal })=0,27
$$

\begin{abstract}
Os parâmetros petrofísicos a serem empregados no modelo de Gassmann estão portanto bem determinados e regrados a fim de satisfazer as premissas de Gassmann (seção 3.5).
\end{abstract}

\title{
4.2.3
}

\section{Cenários de Propriedades Mecânicas Estáticas de Deformabilidade}

A análise dos 3 cenários de propriedades mecânicas estáticas modeladas integrados ao dado sísmico mostrou que o cenário 1 o qual emprega as relações de equivalência dinâmico vs estático descritas na Tabela 4.1 (Pandula 2002) é o que apresenta menor rigidez (maior módulo de elasticidade) nos carbonatos reservatórios do Pré-Sal, seguido do cenário 2 descrito na Tabela 4.2 (Lacy 1996) o qual apresenta rigidez intermediária nos carbonatos reservatórios do Pré-Sal e por fim o cenário 3 descrito na Tabela 4.3 o qual emprega a relação de equivalência dinâmico vs. estático obtida do ensaio simultâneo realizado com o corpo de prova de travertino romano (CPTR-2) é o mais rígido dos cenários (menor módulo de 
elasticidade) nos carbonatos reservatórios do Pré-Sal. Na Figura 4.20 é exibida uma sessão em profundidade do módulo de elasticidade estático não-drenado referente ao cenário 2 (Tabela 4.2) com escala de cor que privilegia a caracterização da Seção Pré-Sal.

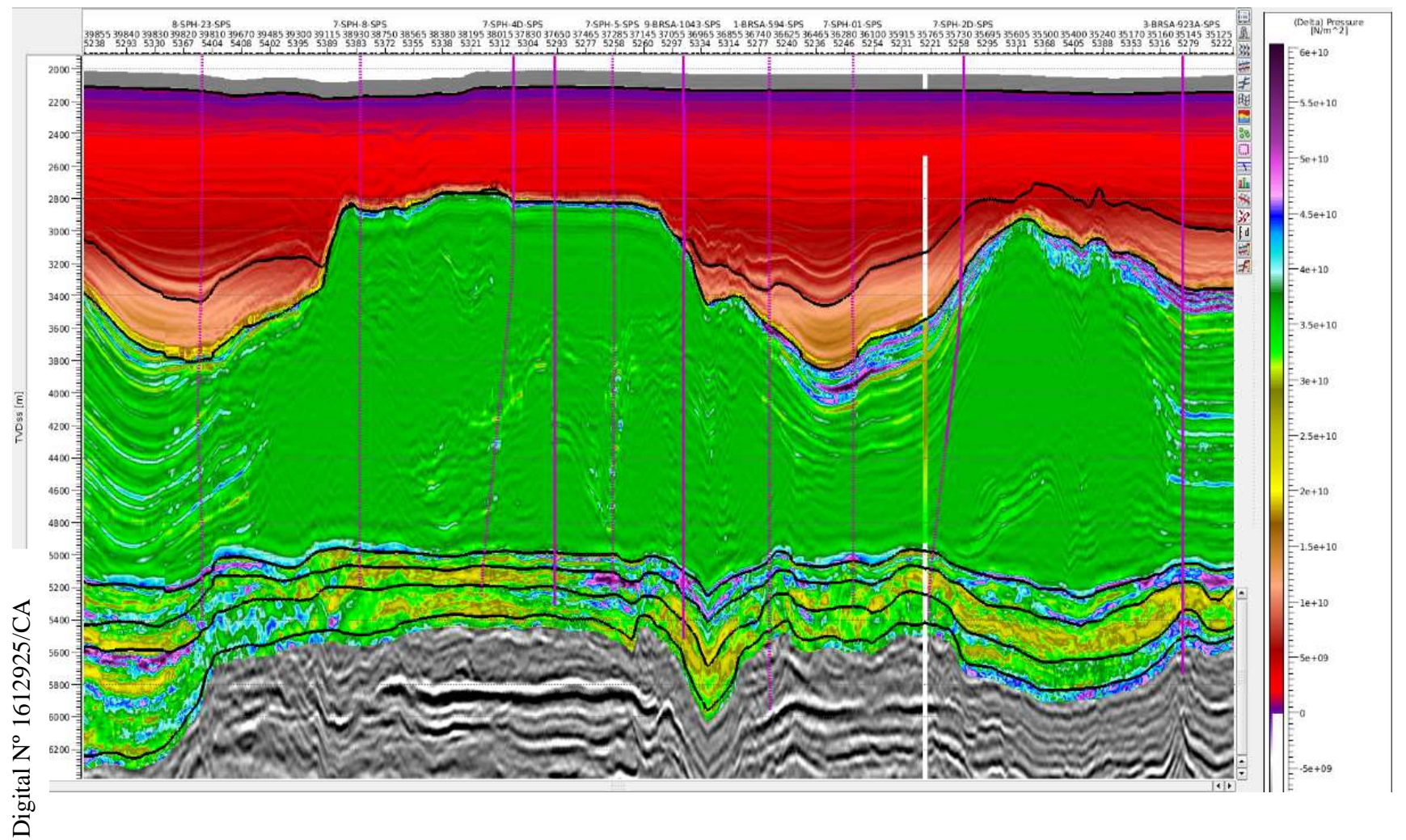

Figura 4.20: Módulo de Elasticidade Estático Não-Drenado em profundidade - cenário 2 (Tabela 4.2).

Pode-se notar na Figura 4.20 que os principais eventos sísmicos sensibilizam o módulo de elasticidade estático integrado ao dado sísmico o qual terá resolução sutilmente superior a dado sísmico e, portanto, que diminui com o soterramento. 
Na Figura 4.21 é exibida uma sessão em profundidade do Coeficiente de Poisson estático não-drenado referente ao cenário 2 (Tabela 4.2).

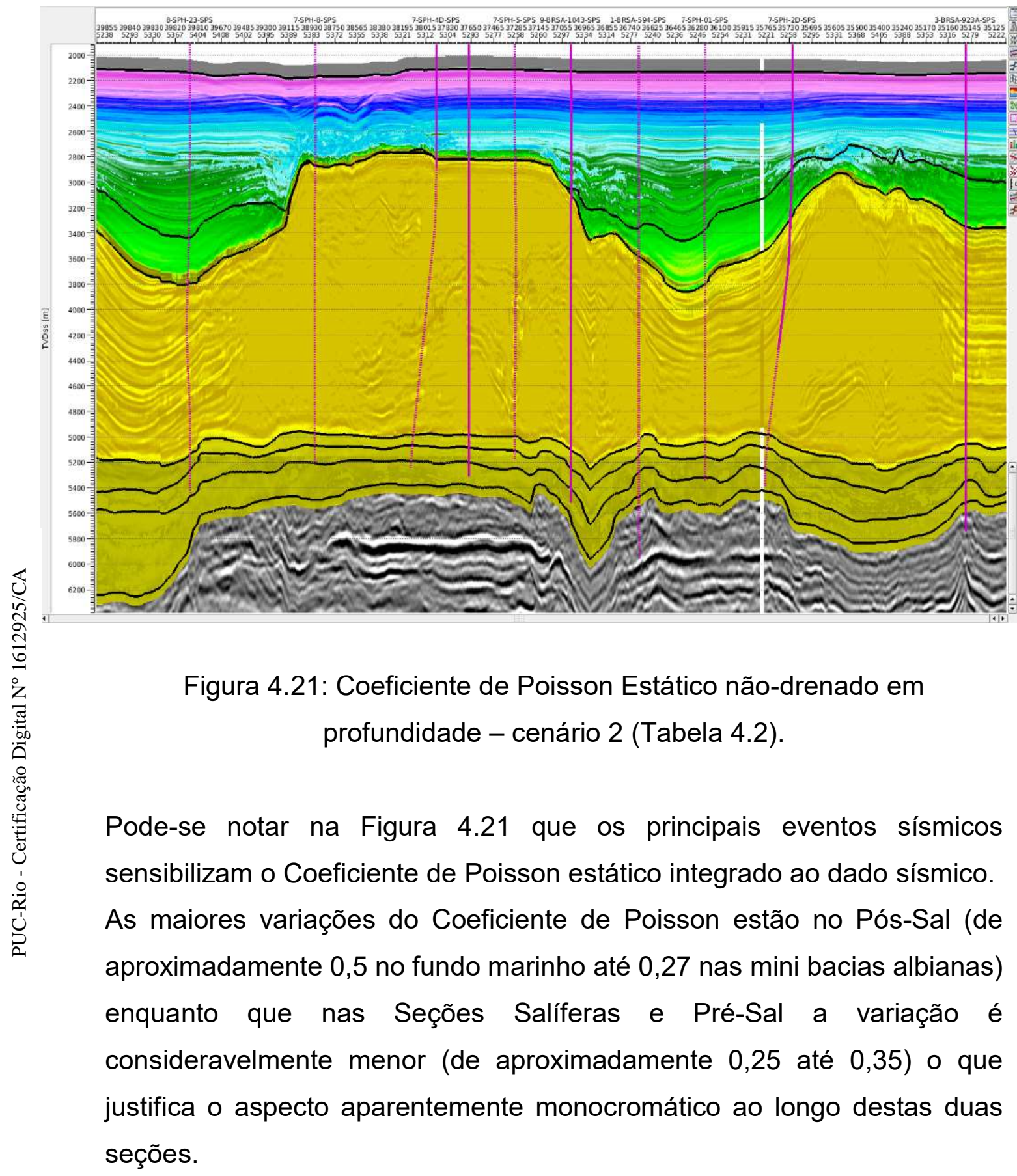


Para o poço 8-SPH23-SPS cuja trajetória e eventos sísmicos são apresentados na Figura 4.22 serão extraídos as curvas dos cenários 3D modelados de propriedades mecânicas estáticas de deformabilidade Figuras 4.23 e 4.24 .

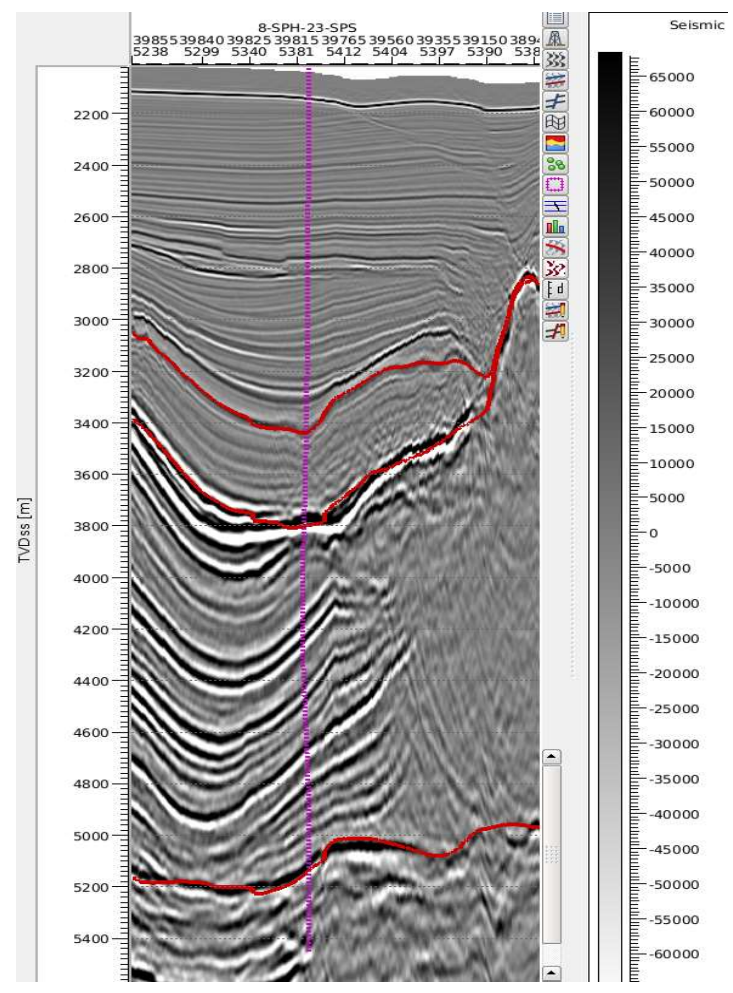

Figura 4.22: Sessão sísmica em profundidade passando pelo poço 8-SPH23-SPS

Na Figura 4.23 são exibidas, ao longo da trajetória do poço 8 - SPH23SPS, as curvas de litologia e de módulo de elasticidade não - drenado extraídas dos modelos $3 D$ de litologia e de propriedades de deformabilidade integradas ao dado sísmico. A curva em preto se refere ao módulo de elasticidade dinâmico, a curva em azul ao módulo de elasticidade estático do cenário 1, a curva em verde ao módulo de elasticidade estático do cenário 2 e a curva em vermelho ao módulo de elasticidade estático do cenário 3. 


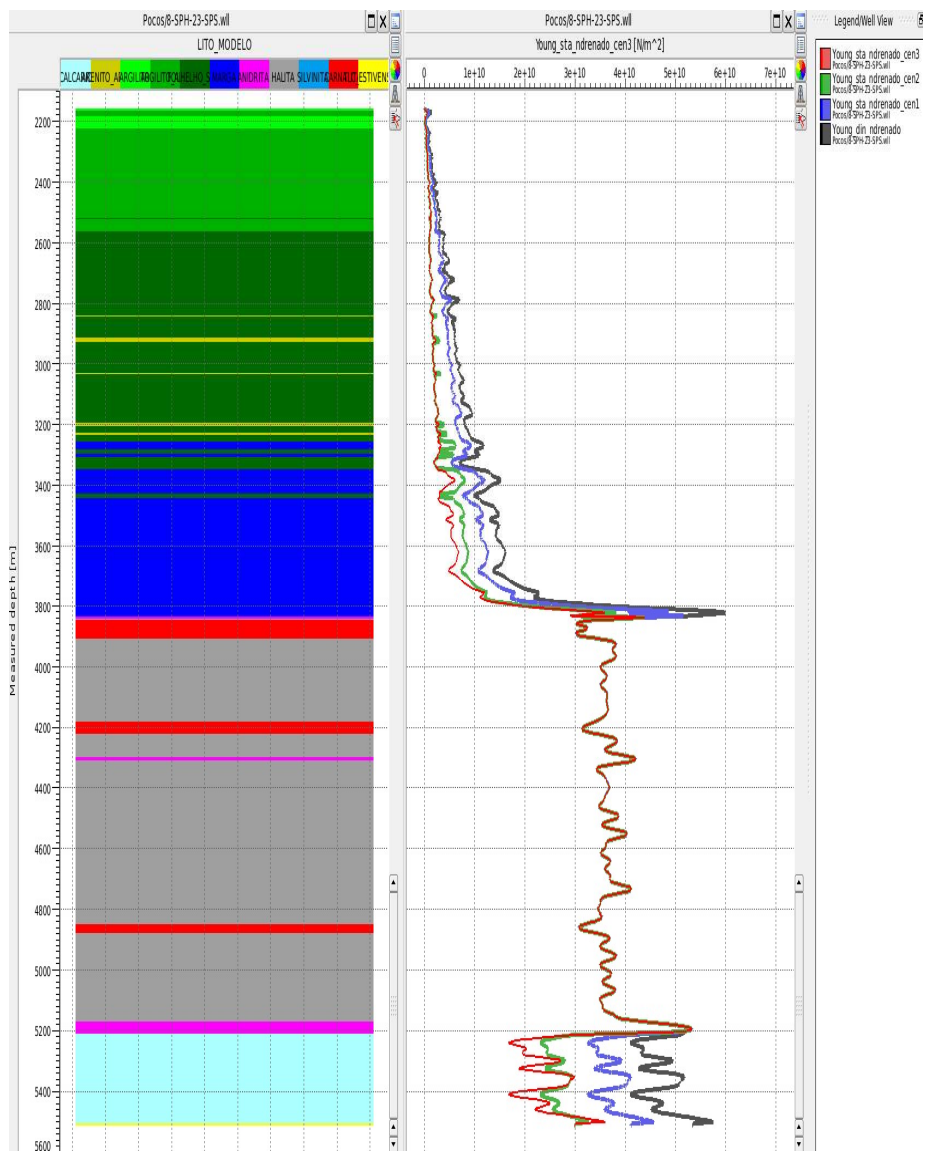

Figura 4.23: Módulo de Elasticidade Estático Não-Drenado.

Preto (Dinâmico-Sísmica), Azul (Estático-Cenário 1), Verde (Estático-Cenário 2) e Vermelho (Estático-Cenário 3)

Da Figura 4.23 observa-se que a variação entre os 3 cenários do módulo de elasticidade estático chegou a $35 \%$. Sendo as maiores divergências entre os três cenários nos carbonatos reservatórios do Pré-Sal e nos carbonatos e areias do Pós-Sal. Na seção salífera será considerado que o módulo de elasticidade dinâmico é igual ao estático com base no trabalho de (Justen 2014). 
Na Figura 4.24 são exibidas, ao longo da trajetória do poço 8 - SPH23SPS, as curvas de litologia e do coeficiente de poisson não - drenado extraídas dos modelos 3D de litologia e de propriedades de deformabilidade integradas ao dado sísmico. A curva em preto se refere ao coeficiente de poisson dinâmico, a curva em azul ao coeficiente de poisson estático do cenário 1, a curva em verde ao coeficiente de poisson estático do cenário 2 e a curva em vermelho ao coeficiente de poisson estático do cenário 3 .

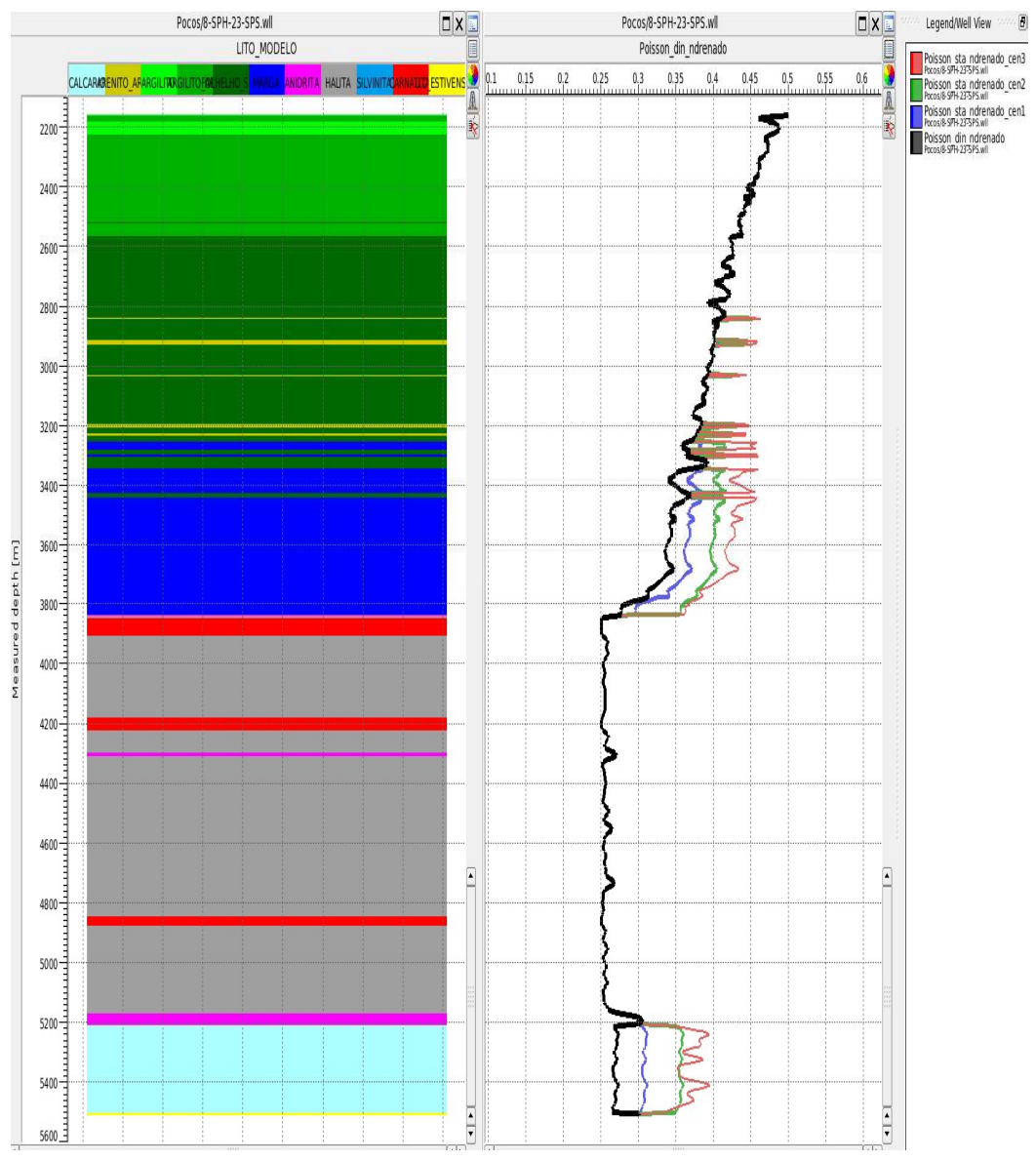

Figura 4.24: Coeficiente de Poisson Estático Não-Drenado.

Preto (Dinâmico-Sísmica), Azul (Estático-Cenário 1), Verde (EstáticoCenário 2) e Vermelho (Estático-Cenário 3) 
Da Figura 4.24 observa-se que a variação entre os 3 cenários do coeficiente de poisson estático chegou a $22 \%$. Sendo as maiores divergências entre os três cenários nos carbonatos reservatórios do PréSal e nos carbonatos e areias do Pós-Sal. Na seção salífera será considerado que o coeficiente de poisson dinâmico é igual ao estático devido ao trabalho de (Justen 2014).

Na Figura 4.25 são exibidas, ao longo da trajetória do poço 8 - SPH23SPS, as curvas de litologia e do módulo de compressibilidade volumétrica não - drenado extraídas dos modelos 3D de litologia e de propriedades mecânicas integradas ao dado sísmico. A curva em preto se refere ao módulo de compressibilidade volumétrica dinâmico, a curva em azul ao módulo de compressibilidade volumétrica estático do cenário 1 , a curva em verde ao módulo de compressibilidade volumétrica estático do cenário $2 \mathrm{e}$ a curva em vermelho ao módulo de compressibilidade volumétrica estático do cenário 3 . 


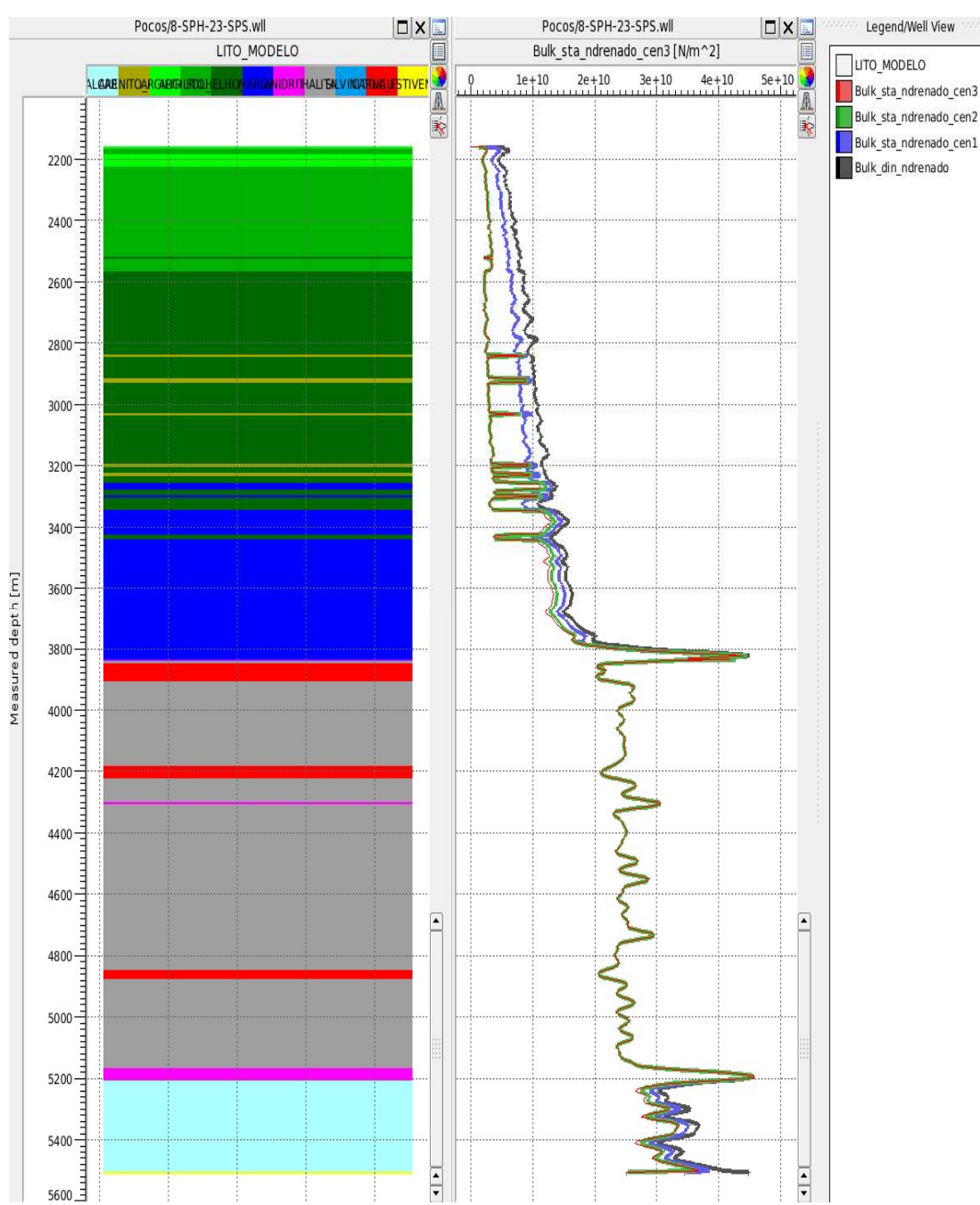

Figura 4.25: Módulo de Compressibilidade Volumétrica Estático Não-Drenado. Preto (Dinâmico-Sísmica), Azul (Estático-Cenário 1), Verde (Estático-Cenário 2) e Vermelho (Estático-Cenário 3)

Da Figura 4.25 observa-se que a variação entre os 3 cenários do módulo de compressibilidade volumétrico estático chegou a $35 \%$. Sendo as maiores divergências entre os três cenários nos carbonatos reservatórios do Pré-Sal, nos carbonatos e areias do Pós-Sal de aproximadamente $27 \%$ e nos folhelhos e argilitos do Pós-Sal de aproximadamente 35\%. 
Na Figura 4.26 são exibidas, ao longo da trajetória do poço 8 - SPH23SPS, as curvas de litologia e do módulo de cisalhamento não - drenado extraídas dos modelos 3D de litologia e de propriedades mecânicas integradas ao dado sísmico. A curva em preto se refere ao módulo de cisalhamento dinâmico, a curva em azul ao módulo de cisalhamento estático do cenário 1 , a curva em verde ao módulo de cisalhamento estático do cenário 2 e a curva em vermelho ao módulo de cisalhamento estático do cenário 3 .

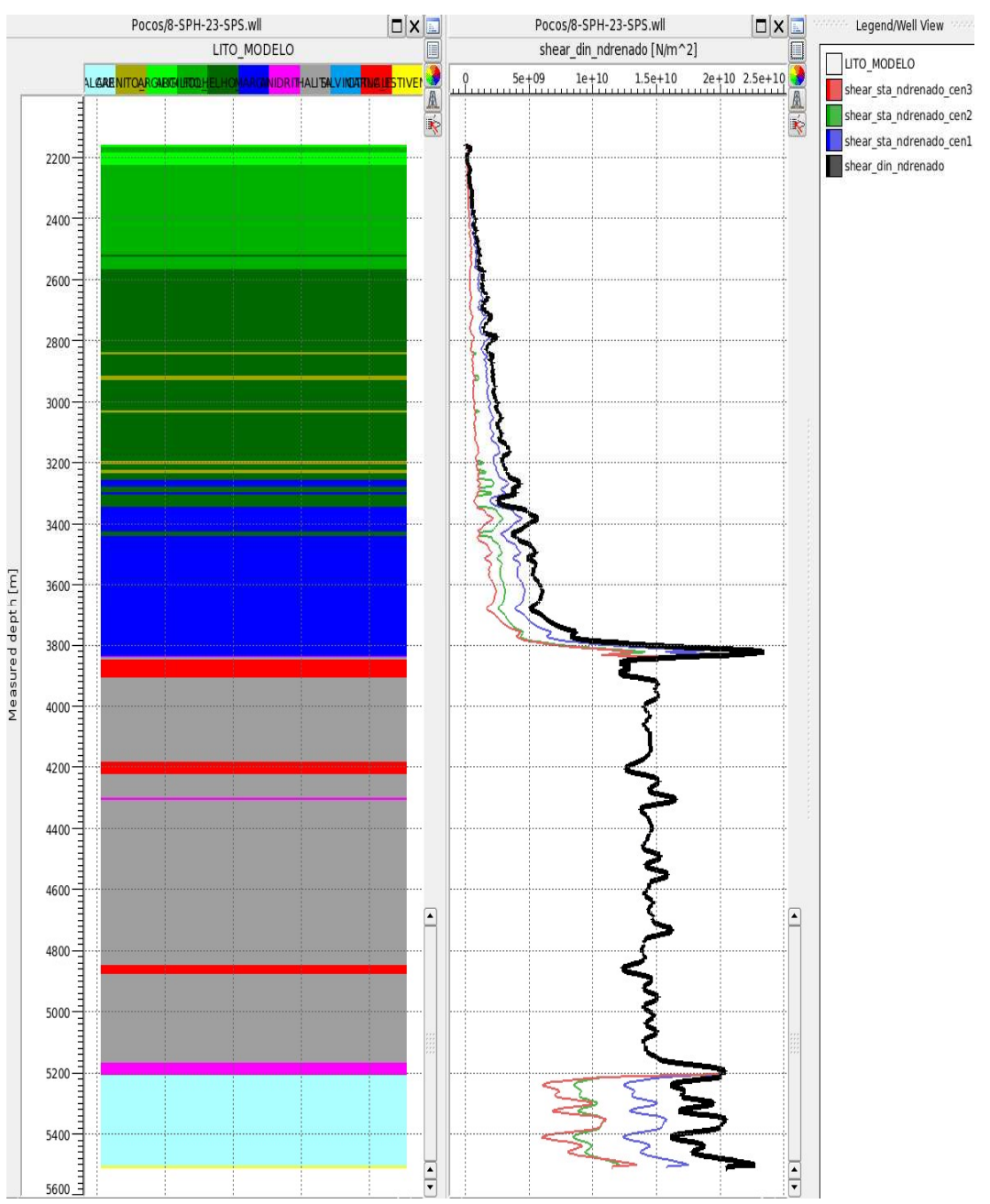

Figura 4.26: Módulo de Cisalhamento Estático Não-Drenado.

Preto (Dinâmico-Sísmica), Azul (Estático-Cenário 1), Verde (EstáticoCenário 2) e Vermelho (Estático-Cenário 3). 
Da Figura 4.26 observa-se que a variação entre os 3 cenários do módulo de compressibilidade volumétrico estático chegou a $52 \%$. Sendo as maiores divergências entre os três cenários nos carbonatos reservatórios do Pré-Sal de aproximadamente $41 \%$ e nos carbonatos, areias, folhelhos e argilitos do Pós-Sal de aproximadamente $52 \%$.

Na Figura 4.27 são exibidas, ao longo da trajetória do poço 8 - SPH23SPS, as curvas de litologia e do coeficiente de acoplamento fluídomecânico extraídos dos modelos 3D de litologia e de propriedades mecânicas integradas ao dado sísmico. A curva em azul corresponde ao coeficiente de Biot-Willis do cenário 1, a curva em verde ao coeficiente de Biot-Willis do cenário 2 e a curva em vermelho ao coeficiente de Biot-Willis do cenário 3 .

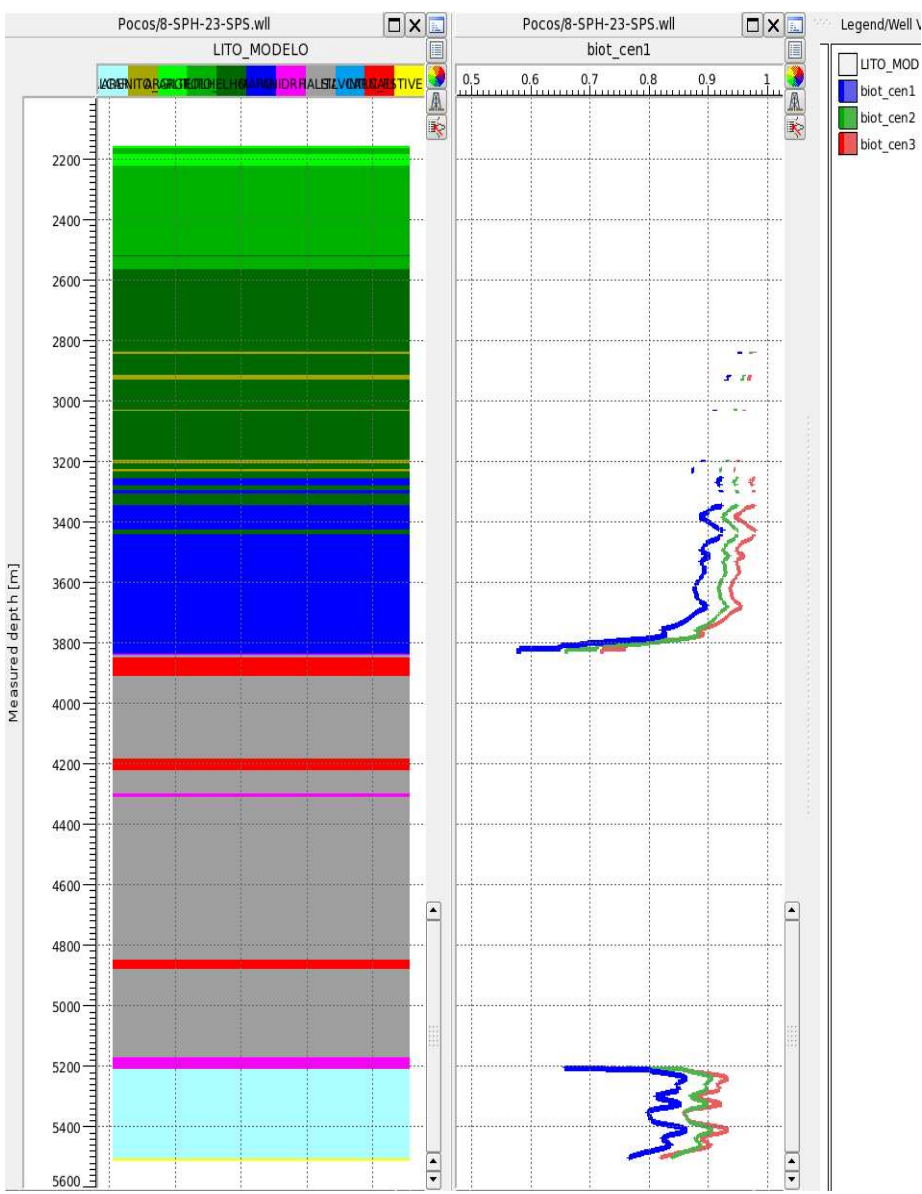

Figura 4.27: Coeficiente de Biot.

Azul (Cenário 1), Verde (Cenário 2) e Vermelho (Cenário 3) 
Na Figura 4.27 o coeficiente de Biot-Willis é dado por:

$$
\alpha_{B}=1-\frac{K_{B}^{\text {drenado }}(\text { sta })}{K_{\min }}
$$

Da Figura 4.27 observa-se que a variação entre os 3 cenários do coeficiente de acoplamento fluido-mecânico chegou a 8 \%. Sendo as maiores divergências entre os três cenários nos carbonatos reservatórios do Pré-Sal de aproximadamente $8 \%$ e nos carbonatos e areias do Pós-Sal de aproximadamente $5,5 \%$. Os sais que compõem a seção salífera apresentam porosidade negligenciável, portanto, não há acoplamento fluído-mecânico para estas litologias e os folhelhos e argilitos do Pós-Sal apresentam coeficiente de acoplamento fluido-mecânico igual a 1.

São também comparados os 3 cenários modelados de propriedades de deformabilidade integradas ao dado sísmico através de análise gráfica confrontando os cubos $3 \mathrm{D}$ dos 3 cenários de módulo de elasticidade estático.

Na Figura 4.28 são comparados os módulos de elasticidade estático provenientes dos cenários 1 e 2 . A reta cheia em preto possui inclinação de $45^{\circ}$. 


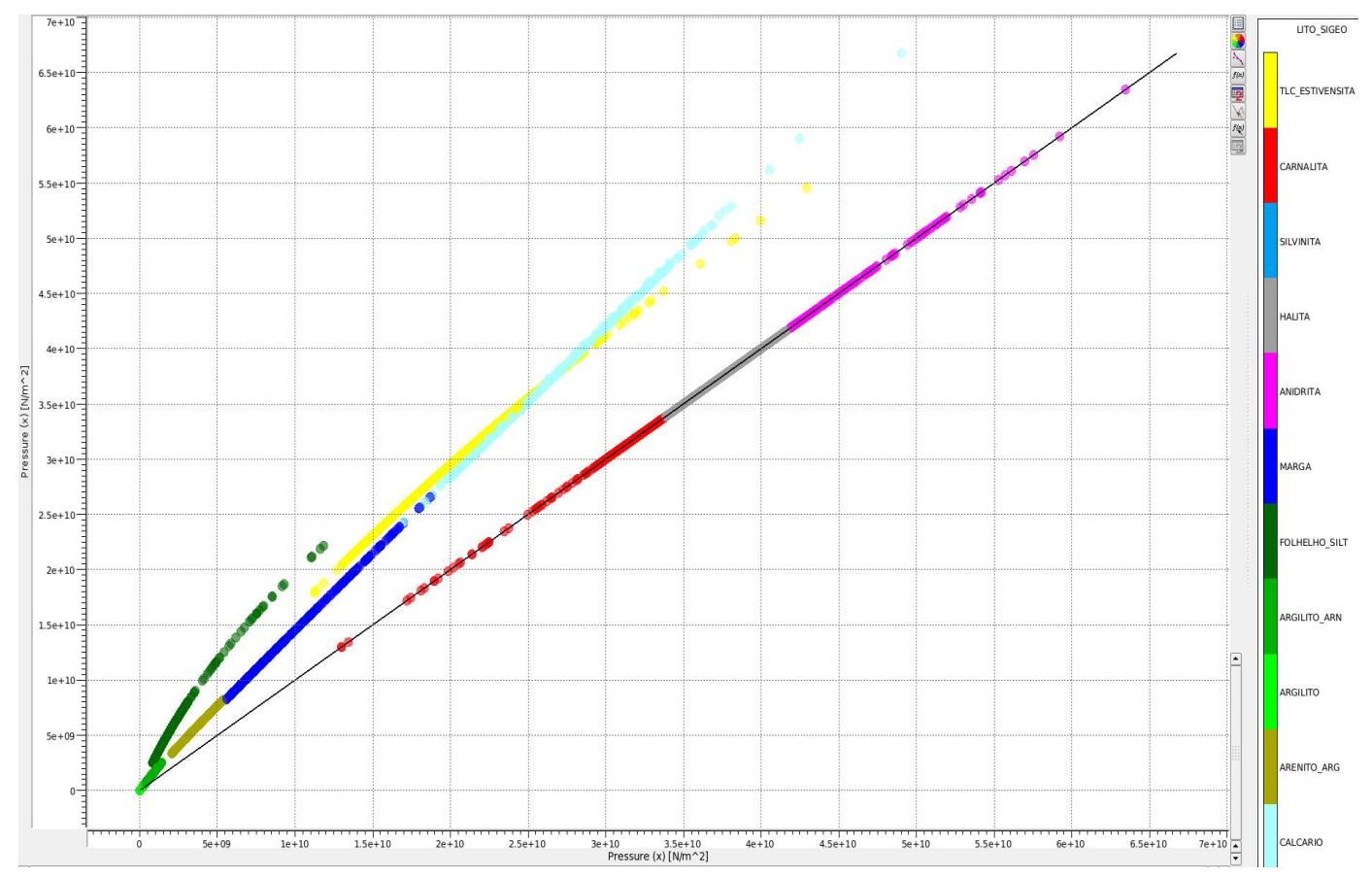

Figura 4.28: Módulo de Elasticidade Estático Não-Drenado ( x-Cenário 2 vs. y- Cenário 1 )

Da Figura 4.28 observa-se que os cenários 1 e 2 conduziram a valores do módulo de elasticidade estático iguais nos sais e que o cenário 1 conduz a valores do módulo de elasticidade estático maiores que o cenário 2 nas demais litologias : carbonatos do Pré-Sal e carbonatos, areias, folhelhos e argilitos do Pós-Sal.

Na Figura 4.29 são comparados os módulos de elasticidade estático provenientes dos cenários 1 e 3 . A reta cheia em preto possui inclinação de $45^{\circ}$. 


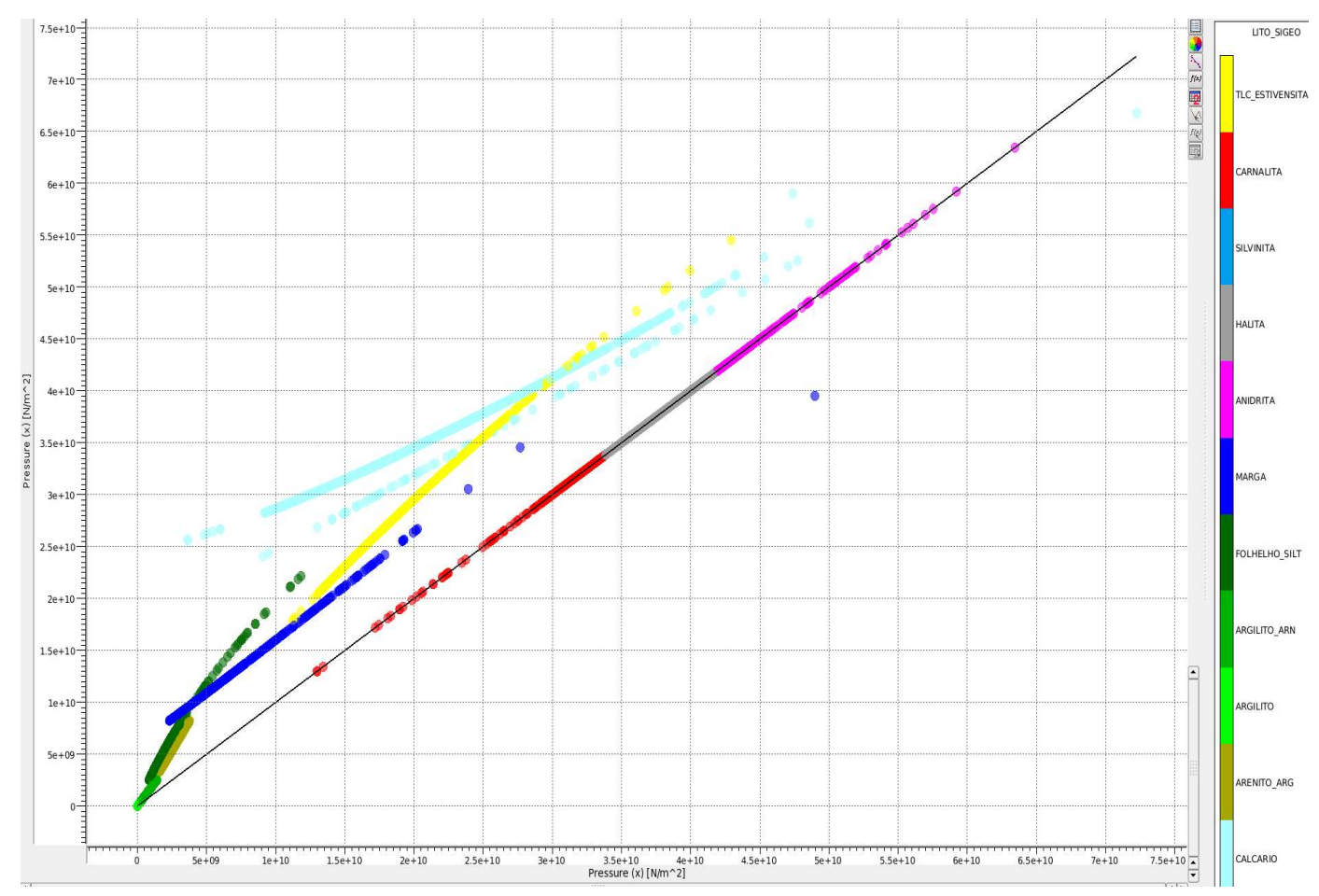

Figura 4.29: Módulo de Elasticidade Estático Não-Drenado (x-Cenário 3 vs. y-Cenário 1)

Da Figura 4.29 observa-se que os cenários 1 e 3 conduziram a valores do módulo de elasticidade estático iguais nos sais e que o cenário 1 conduz a valores do módulo de elasticidade estático maiores que o cenário 3 nas demais litologias: carbonatos do Pré-Sal e carbonatos, areias, folhelhos e argilitos do Pós-Sal.

$\mathrm{Na}$ Figura 4.30 são comparados os módulos de elasticidade estático provenientes dos cenários 3 e 2. A reta cheia em preto possui inclinação de $45^{\circ}$. 


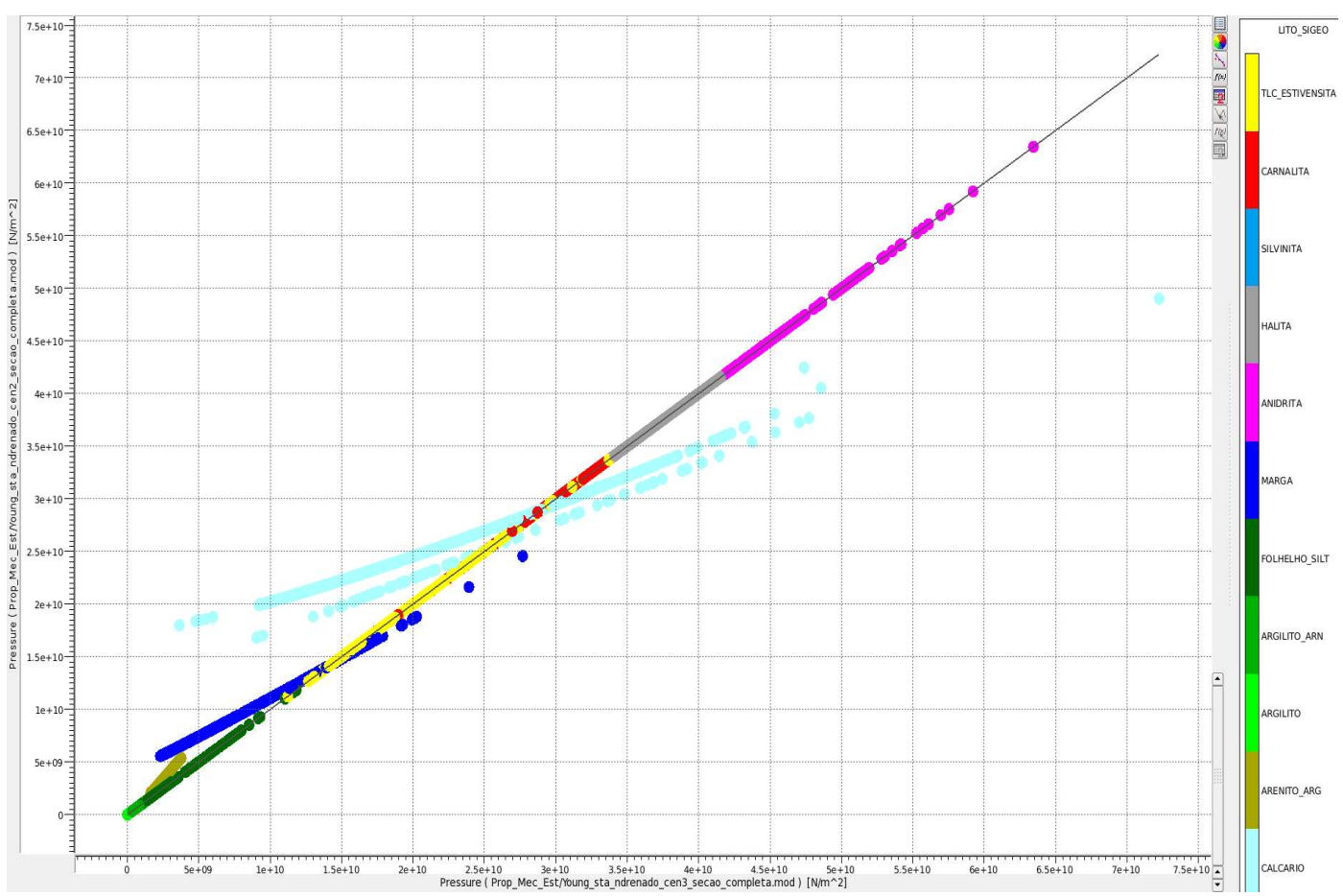

Figura 4.30: Módulo de Elasticidade Estático não-drenado.

(x-Cen3 vs. $y$-Cen2)

Da Figura 4.30 observa-se que os cenários 3 e 2 conduziram a valores do módulo de elasticidade estático iguais nos sais, folhelhos e argilitos do PósSal e que o cenário 2 conduz a valores do módulo de elasticidade estático maiores que o cenário 3 nos carbonatos albianos do Pós-Sal e nos melhores carbonatos reservatórios do Pré-Sal. 


\section{Conclusões}

O pioneirismo do presente estudo encontra-se em integrar o dado sísmico à modelagem de cenários de propriedades elásticas estáticas de deformabilidade no contexto do Pólo Pré-Sal da Bacia de Santos, e passando pelas seguintes etapas:

I. Realização de inversão sísmica determinística CSSI (constrained sparse spike) baseada em modelo inicial de Impedância-P ao longo de toda a sequência estratigráfica da Bacia de Santos: Pós-Sal, Sal e Pré-Sal considerando o efeito do soterramento em dado sísmico 0-offset cedido pela ANP (Agência Nacional do Petróleo).

II. Desenvolvimento de Modelo de Física de Rochas (MFR) para toda a sessão estratigráfica da Bacia de Santos, com base em perfis de poços cedidos pela ANP e furos geotécnicos, para estimativa das propriedades mecânicas elásticas dinâmicas a partir da ImpedânciaP obtida na inversão sísmica.

III. Realização de ensaios mecânicos simultâneos em análogo mecânico (bloco de travertino romano) da camada Pré-Sal da Bacia de Santos para determinação de relação de equivalência estático vs. dinâmico, como também emprego de duas relações de equivalência estático vs. dinâmico advindas de trabalhos científicos totalizando três cenários de propriedades mecânicas de deformabilidade estáticas e de coeficiente de Biot-Willis.

Pode-se pontuar algumas das principais conclusões deste trabalho: 
- A base para integração do dado sísmico à modelagem geomecânica são dados sísmicos (amplitude sísmica e velocidade da onda-P processada), de perfis de poços (densidade, velocidade das ondas compressional e cisalhante e Litologia), Geomecânicos (Furos Geotécnicos, Testes de Absorção e Fraturamento e medida da poropressão da Formação) e Modelo de Física de Rochas para associar as observáveis sísmicas às propriedades físicas das rochas;

- A inversão sísmica baseada em modelo inicial que leva em conta o soterramento, permite obter as propriedades elásticas estáticas de deformabilidade com resolução sísmica e passíveis de alimentar simulador mecânico;

- Diferentes relações de equivalência dinâmico vs. estático entre propriedades de deformabilidade estáticas possibilitam o desenvolvimento de cenários destas propriedades que diferem entre si até $35 \%$ no caso do módulo de elasticidade, até $22 \%$ no caso do coeficiente de poisson e até $8 \%$ no caso do coeficiente de acoplamento fluído-mecânico de Biot-Willis o que contribuem para minimizar incertezas;

e pode-se pontuar também alguns pontos de melhoria :

- Melhor mapeamento de horizontes sísmicos, sobretudo: Topo do Sal e Topo do Reservatório Pré-Sal;

- Testemunhos para confecção de corpos de prova, de modo, a atingir as condições típicas de confinamento do reservatório;

- Munido de simulador mecânico, avaliar subsidência e pressão limite de injeção para os diferentes cenários construídos de 
propriedades elásticas estáticas de deformabilidade;

- Construção de cenários empregando outros (MFR) além de Gassmann. 
Referências bibliográficas

AMERICAN SOCIETY FOR TESTING AND MATERIALS. D7012-14. Standard Test Methods for Compressive Strength and Elastic Moduli of Intact Rock Core Specimens under Varying States of Stress and Temperatures. United States, West Conshohocken, Pennsylvania. 2013

AMERICAN SOCIETY FOR TESTING AND MATERIALS. D2845-08 Standard Test Method for Laboratory Determination of Pulse Velocities and Ultrasonic Elastic Constants of Rock. United States, West Conshohocken, Pennsylvania. 2008

AMERICAN SOCIETY FOR TESTING AND MATERIALS. D4543-08. 2008. Standard Practices Preparing Rock Core as Cylindrical Test Specimens and Verifying Conformance to Dimensional and Shape Tolerances. United States, West Conshohocken, Pennsylvania.

BERGE, P.A., Pore Compressibility in Rocks, in Thimus,

J.F.,Abousleiman, Y., Cheng, A.H.D., Coussy, O., and Detournay, E.,Eds., Biot Conference on Poromechanics: Université Catholique de Louvain, 351-356.1998

BERRYMAN, J. G., Origin of Gassmann's equations: Geophysics, 46, 1627-1629. 1999

BERRYMAN, J.G., WANG, H.F., Elastic wave propagation and attenuation in a double-porosity dual permeability médium: Internat. J. Rock Mech. and Min.Sci., 37, 63-78. 2000

BIOT, M.A., General theory of three-dimensional consolidation. Journal of Applied Physics, 12:155_164, February 1941. 
BIOT, M.A., Theory of propagation of elastic waves in a fluid satured porous solid. I. Low frequency range and II. Higher-frequency range: Acoust. Soc. Am., 28, 168-191-----1962, Mechanisms of Deformation and Acoustic Propagation in Porous Media: J.Appl. Phys., 33, 1482-1498. 1956

BLUM, P., Physical properties handbook: a guide to the shipboard measurement of physical properties of deep-sea cores. ODP Tech. Note, 26. 1997

BOTAO Lin., YAN Jin., HUIWEN Pang., Amy B. Cerato., Experimental Investigation on Dilation Mechanisms of Land-Facies Karamay Oil Sand Reservoirs under Water Injection. Rock Mechanics and Rock Engineering. Volume 49, Issue 4, pp 1425-1439.April 2016

BROTONS, V., TOMAS, R., IVORRA, S., GREDIAYA, A., MARTINEZ, J., BENARVENTE, D., GOMEZ, M., Improved Correlation Between the Static and Dynamic Elastic Modulus of Different Types of Rocks, Materials and Structures, 49(8) : 3021-3037.doi:10.1617/s11527-0150702-7. 2016

BROWN, R., KORINGA, J., On the dependence of the elastic properties of a porous rock on the compressibility of the pore fluid: Geophysics, 40, 608-616. 1975

DAS, B. M. Fundamentos de engenharia geotécnica. Tradução de All Tasks; Revisão Técnica de P. L. A. Barros. São Paulo, Thomson Learning. 2007.

DE SOUZA, A. L. S., FERNANDES, P. D., MENDES, R., ROSA, A. J. \& FURTADO, C. J. A. 2005. The Impact of Fracture Propagation on Sweep Efficiency During a Waterflooding Process. SPE Latin American and Caribbean Petroleum Engineering Conference held in Rio de Janeiro, Brazil, Rio de Janeiro: Society of Petroleum Engineers. DEAN, 20 - 23 June 2005 
DOSSAL. C., MALLAT. S., Sparse Spike Deconvolution with minimum Scale, CMAP École Polytechnique

Eissa, E.A.Kazi, A. Relation Between Static and Dynamic Young's Moduli of Rocks. Int. J. Rock Mech. Min. Sci. \& Geomech. Abstr. Vol 25, No6, pp 479-482. 1988

FALCÃO, L., O Sal Estratificado e sua Importância na Modelagem de Velocidades para Fins de Migração Sísmica. Dissertação de Mestrado. UFF. Dinâmica Oceânica e Costeira. 2017

FJAER, E., HOLT, R. M., HORSRUD, P., RAAEN, A. M., RISNES, R. Petroleum Related Rock Mechanics, Elsevier Science., 2nd Ed. 2008.

FUCHS. J.J., On sparse representations in arbitrary redundant bases. IEEE-I-IT. 2002.

FUCHS. J.J., Recovery of exact sparse representations in the presence of bounded noise. Publication interne de I'IRISA, (1618). 2005.

GASSMANN, F., Über die Elastizität Poröser Medien: Vier. der Natur. Gesellschaft in Zürich, 96,1-23.1951

GOODMAN, R. E. Introduction to Rock Mechanics, 2nd Edition,1989

HANSEN, K., S., Modeling of Reservoir Compaction and Surface Subsidence at South Belridge , SPE Journal, SPE 26074. 1993.

HERWANGER, J., KOUTSABELOULIS, N., Seismic Geomechanics How to Build and Calibrate Geomechanical Models using 3D an 4D Seismic Data., EAGE Publications. 2011.

HOLM, L. W., JOSENDAL, V. A. Mechanisms of oil displacement by carbon dioxide. Journal of Petroleum Technology, v. 26, n.12, p. 14271438. 1974. 
HUBBERT., WILLIS., Mechanics of hydraulic fracturing, Dez 1972

IDE, J.M., Comparison of statically and dynamically determined young's modulus of rocks Proceedings of the National Academy of Sciences of the United States of America 22:81-92 doi:10.1073/pnas.22.2.81. 1936

ISRM Suggested Method for Uniaxial-Strain Compressibility Testing for Reservoir Geomechanics, Rock Mech Rock Eng 49:4153-4178.

DOI 10.1007/s00603-016-1055-4. 2016

ISRM. Suggested Methods for Determining Water Content, Porosity, Density, Absorption and Related Properties and Swelling and SlakeDurability Index Properties.1977

JUSTEN, R.C.J. Análise das Propriedades Elásticas de Rochas e Minerais Evaporiticos. Dissertação de Mestrado Puc-Rio. 2014

KOLESNIKOV, Y.I., Dispersion effect of velocities on the evaluation of material elasticity J Min 645 Sci 45:347-354. 2009

LACY, L.L., Dynamic Rock Mechanics Testing for Optimized Fracture Designs. SPE paper 38716 presented at the 1997 SPE Ann. Tech. Conf \& Exhib. held in San Antonio, Texas, 5-8 October. 1996

MAUL, A., CETALE, M.A., SILVA, C.G., Few Considerations, Warnings and Benefits for the E\&P Industry when Incorporating Stratifications Inside Salt Sections. Revista Brasileira de Geofísica. 2018

MENEGUIM, T.B., MENDES, S.C., MAUL, A.R., FERNANDES, L.F., FARIAS, M.G., GONZÁLEZ G., Combining seismic facies analysis and well Information to guide new interval velocity models for a Pre-Salt study, Santos Basin, Brazil.14th International Congress of the Brazilian Geophysical Society, p.1365-1368. DOI 10.1190/sbgf2015-271. 2015 
MINSSIEUX., DUQUERROIX WAG Flow Mechanisms in Presence of Residual Oil, Sept 1994

MORALES, R.H., MARCINEW, R.P. Fracturing of High-Permeability Formations: Mechanical Properties Correlations. SPE paper 26561 presented at the 68th Ann. Tech. Exhib. \& Conf. Held in Houston, Tx. 6-8 October. 1993

MORSCHBACHER, M.J., VASQUEZ, G.F., JUSTEN, J.C.R., Metodologias de estimativa das velocidades sísmicas em ensaios de laboratório. 4o Simpósio Brasileiro da Sociedade Brasileira de Geofísica, Brasília. 2010

NAGEL, N. B., Compaction and Subsidence Issues within the Petroleum Industry: From Wilmington to Ekofisk and Beyond, Physis. Chem. Earth, v. 26, pp. 3 -14, Dez 2001.

NORDBOTTEN, J., CELIA, M. \& BACHU, S. Injection and Storage of $\mathrm{CO} 2$ in Deep Saline Aquifers: Analytical Solution for $\mathrm{CO} 2$ Plume Evolution During Injection. Transport in Porous Media, 58, 339-360. 2005.

PANDULA, B., MOCKOVČIAKOVÁ, A., Study of the Relation Between the Static and Dynamic Moduli of Rocks . 2002

PEGORARO, T.R,. Escoamento Trifásico em Meios Porosos: Permeabilidade Relativa Óleo-Gás-Água, UFRJ, Escola de Química. 2012

PERKINS, T. K. \& GONZALEZ, J. A. The Effect of Thermoelastic Stresses on Injection Well Fracturing. OLD SPE Journal. 1985 
PINTO, Mecânica dos Solos Avançada e Introdução as Obras da Terra. 2006

POIATE Jr., E.; Costa, A.M. e Falcão, J.L. 2006. Well design for drilling through thick evaporite layers in Santos Basin - Brazil. IADC/SPE Drilling Conference, Miami. 2006

ROSCOE, K.H., SCHOFIELD, A.N., Mechanical Behaviour of an Idealised Wet-Clay. Proc. $2^{\text {nd }}$ European Conf. Soil Mech, Wiesbaden, I, 4754. 1963

ROSCOE, K.H., SCHOFIELD, A.N., WROTH. C.P., On the Yielding of the Soils. Géotechnique, 9, 71-83. 1958

ROSCOE. K.H., BURLAND. J.B., On the Generalised Stress-Strain Behaviour of Wet-Clay. 1968

SANTOS, E.S.R.F, FRANCISCO, H., Mechanical Behaviour of a Brazilian Off-Shore Carbonate Reservoir. Artigo ARMA 10-199, $44^{\text {th }}$ US Rock Mechanics Symposium, Salt Lake City, UT June 27-30. 2010

SCHOFIELD, A.N., WROTH. C.P., Critical State Soil Mechanics, Mc Graw-Hill. 1968

SElVADURAI, A.P.S., DAVIS, R.O Plasticity and Geomechanics, Cambridge University Press. 2002

SHAYEA, N.A., Effects of testing methods and conditions on the elastic properties of limestone rock Engineering Geology 74:139-156 doi:10.1016/j.enggeo.2004.03.007. 2004 
SOLTANZADEH, H., HAWKES, C. D. Semi-analytical models for stress change and fault reactivation induced by reservoir production and injection. Journal of Petroleum Science and Engineering, 60, 71-85. 2008

SOUZA NETO, E.A., OWEN, D.R.J., PÉRIC, D., Computational Methods for Plasticity , United Kingdom, John Wiley \& Sons Ltd. 2008

SYLTE, J. E., THOMAS, L.K., RHETT, D.W., BRUNING, D.D., NAGEL, N. B., Water Induced compaction in Ekofisck Field, SPE Journal, SPE 56426, pp.1-11, Out.1999.

TEATINI, P., CASTELLETTO, N. \& GAMBOLATI, G. 3D Geomechanical Modeling for $\mathrm{CO} 2$ Geological Storage in Faulted Formations. A Case Study in an Offshore Northern Adriatic Reservoir, Italy. International Journal of Greenhouse Gas Control, 22, 63-76. 2014.

TEIXEIRA, L., GOBATTO, F., MAUL, A., CRUZ, N.M., LAQUINI, J., Rock Physics and Seismic Inversion to identify stratification within salt section supporting velocity, facies modeling and geomechanical analysis. In: 15th International Congress of the Brazilian Geophysical Society, p. 5-10. BrazilianGeophysicalSociety.Doi:10.1190/sbgf2017-002. 2017

TORÍBIO, T., QUEIROZ, L.E., TEIXEIRA, L., YAMAMOTO,T., MENEGUIM, T, LEONARDO, L.M., CORTEZ, M., RELVAS, M.T., MOLITERNO, A.M., TARTARINI, A., Characterizing Evaporitic Section and Geomechanical Properties Using Seismic Inversion, a Case Study for Santos Basin. In: 15th International Congress of the Brazilian Geophysical Society, Brazilian Geophysical Society.Doi:10.1190/sbgf2017-226. 2017

VANHEERDEN, W.L., General relations between static and dynamic moduli of rocks Int J Rock Mech Min Sci 24:381-38. 1987 
WANG, H.F. Theory of Linear Poroelasticity with Applications to Geomechanics and Hydrogeology. Princeton Series in Geophysics. Princeton University Press, Princeton, New Jersey. 2000.

YAMAMOTO, T., MAUL, A., BORN, E., GOBATTO, F., CAMPOS, M.T., GONZÁLES, M., Incorporação de Estratificações Salíferas na Modelagem de Velocidade de uma Jazida da Bacia de Santos. VII Simpósio Brasileiro de Geofísica, OuroPreto - MG. 2016 